\title{
Designing Graphic Messages to Promote Mental Health
}

\author{
by
}

Alanna Bamber

A thesis submitted to the Faculty of Graduate and Postdoctoral Affairs in partial fulfillment of the requirements for the degree of

Master of Design

in

Industrial Design

Carleton University

Ottawa, Ontario

(C) 2020, Alanna Bamber 


\section{Abstract}

Post-secondary students are experiencing elevated and increasing levels of mental illness. Colleges and universities have developed programs and services to help address this problem, however many institutions are overwhelmed by the high demand for counselling services and students must wait long periods for an appointment. This study explores the development and design of a persuasive mental health campaign that may help to increase the resilience and mental health of post-secondary students. The study consisted of four phases: exploratory interviews, a survey on the student experience and mental health, and two rounds of evaluative feedback on prototypes from different populations. The results of these research phases led to insights on factors affecting mental health, the importance of collaboration between designers, experts, and the target audience, and design guidelines for persuasive graphic messages. 


\section{Acknowledgments}

\section{To my co-supervisors:}

Lois Frankel, my deepest appreciation and thanks. I would not have made it this far without your encouragement, generosity, and guidance. I can’t express how much your support has meant to me.

James Miller, thank you for your patience, support, and valuable insight. I so appreciate the perspective and thoughtfulness you brought to this project.

\section{To my family:}

Thank you for your constant help and encouragement. The love and care you have all shown me throughout my academic career is incredible. Thank you mom for always being my cheerleader, dad for your advice, encouragement, and editing help, Bryn for your constant inspiration, and Renee for being my stress therapist and source of laughter.

\section{Special thanks:}

To Sam Astles and to all my friends, and to all the participants who were so generous with their time and insight. 


\section{Table of Contents}

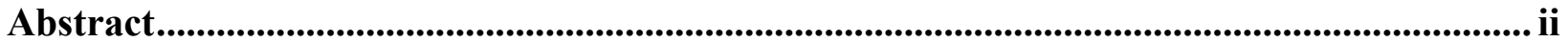

Acknowledgments ............................................................................................................................

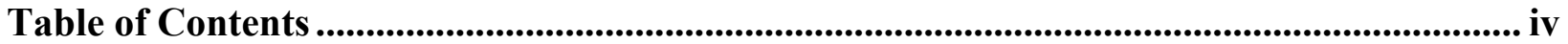

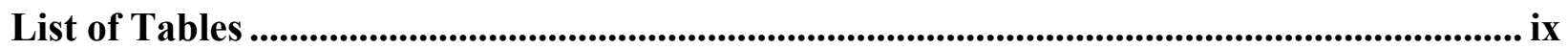

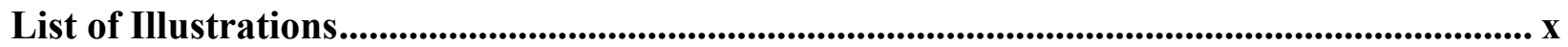

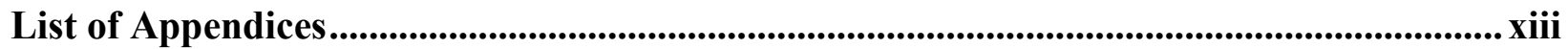

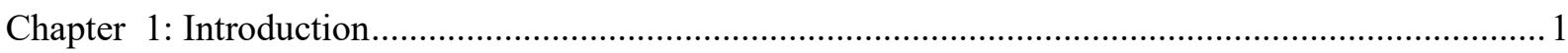

$1.1 \quad$ Statement of the problem ………………………………………………………….

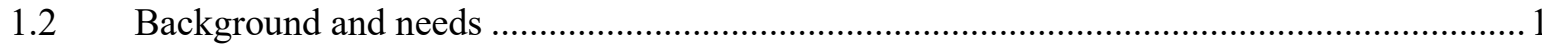

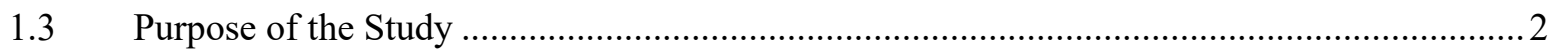

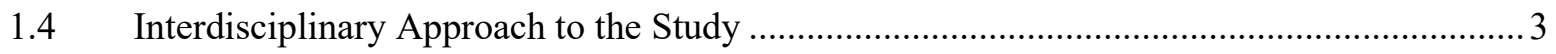

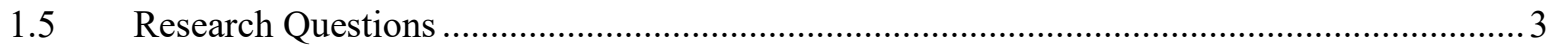

1.6 Scope

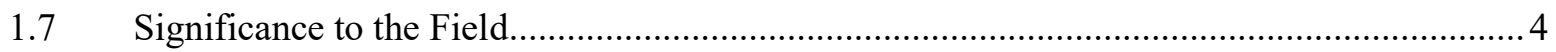

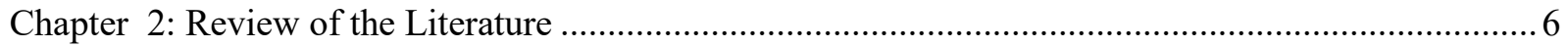

$2.1 \quad$ Post-Secondary Student Mental Health.............................................................................

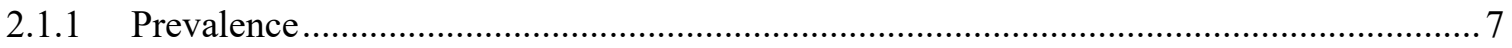

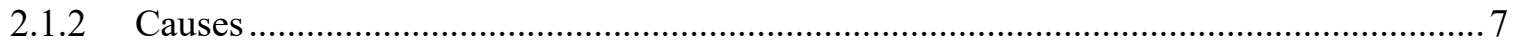

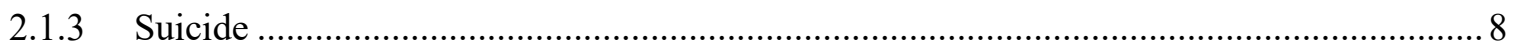

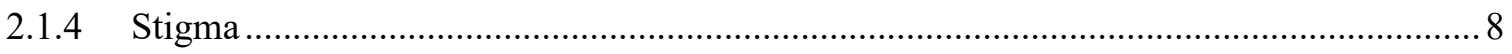

2.2 Technology Use and Student Mental Health..................................................................... 9 


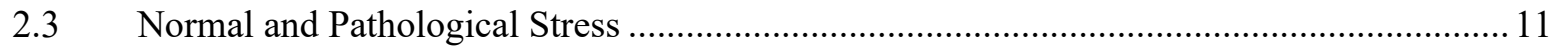

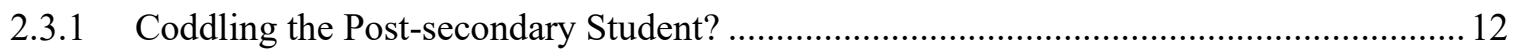

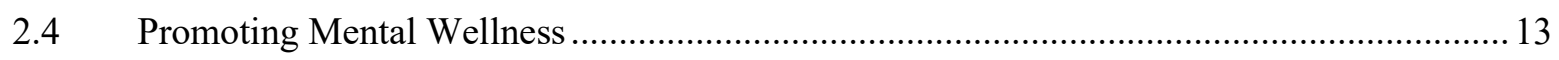

2.4.1 Health Behaviours................................................................................................ 13

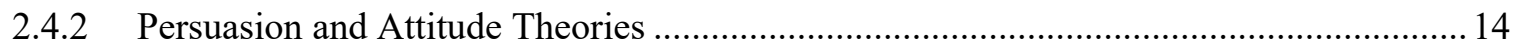

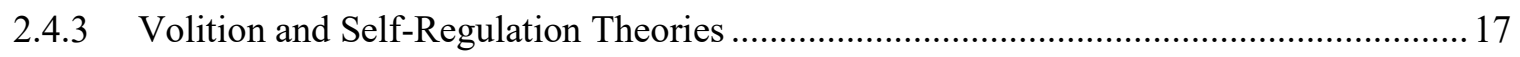

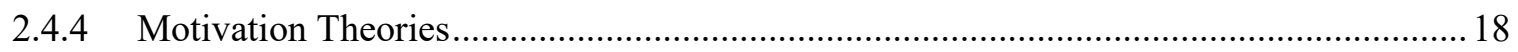

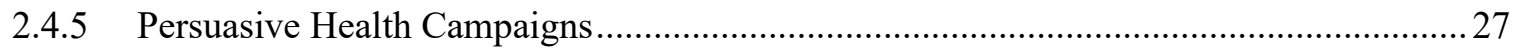

2.4.6 Human-Centered Design for Persuasive Health Campaigns ......................................... 30

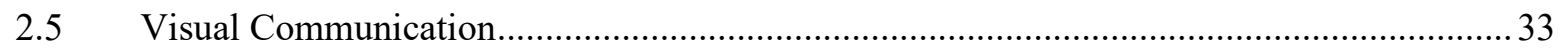

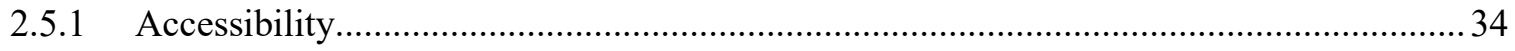

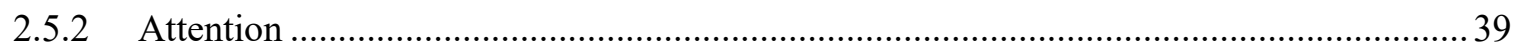

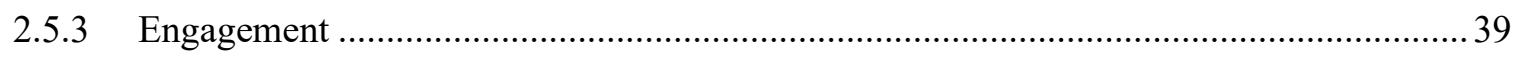

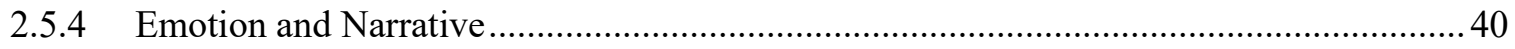

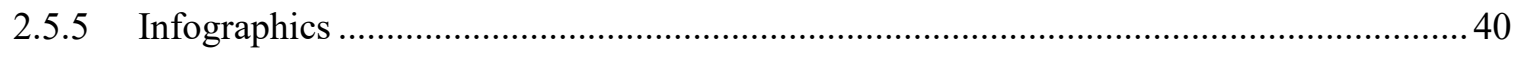

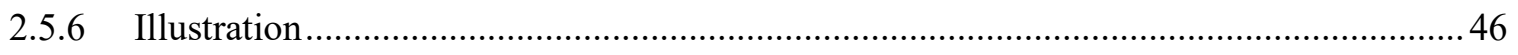

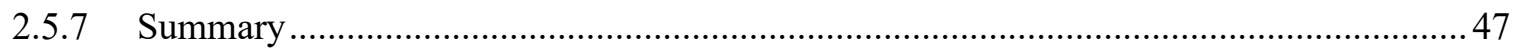

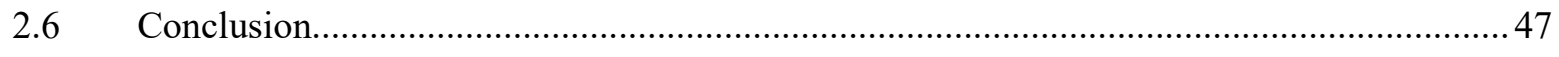

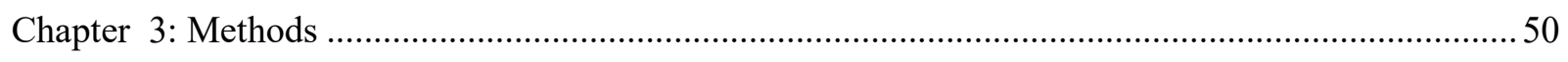

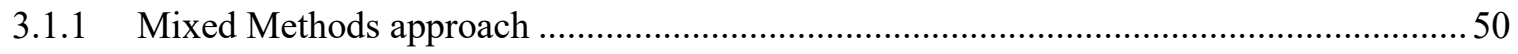

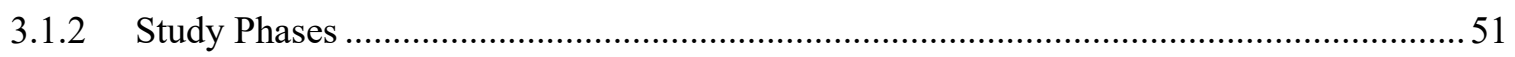

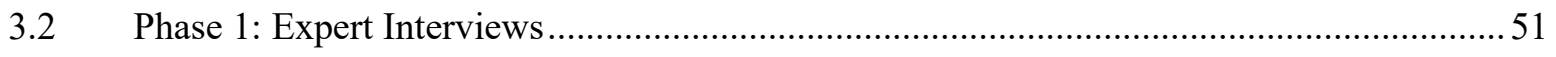

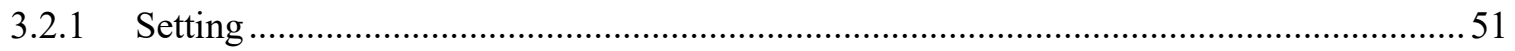




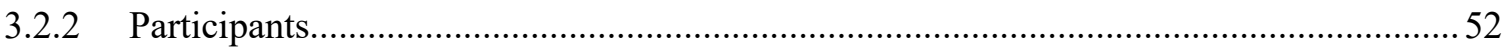

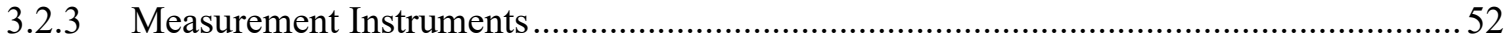

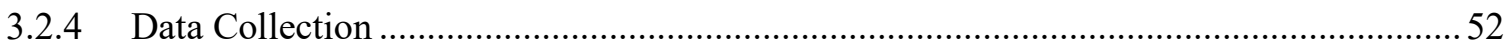

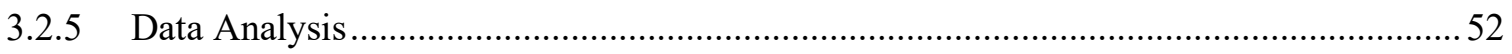

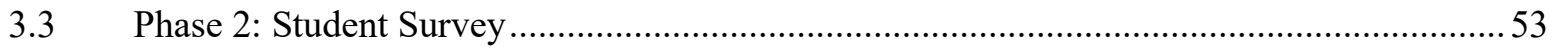

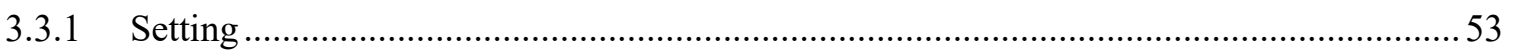

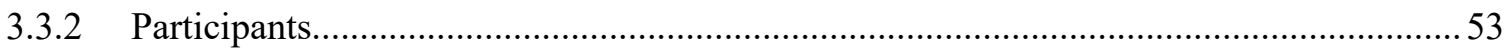

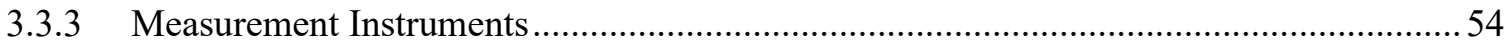

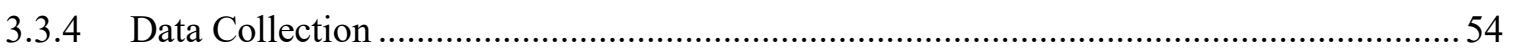

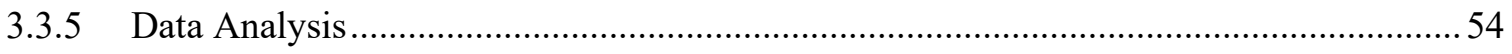

3.4 The Intervention: A Persuasive Health Campaign of Graphic Messages ........................... 55

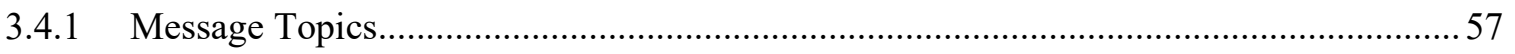

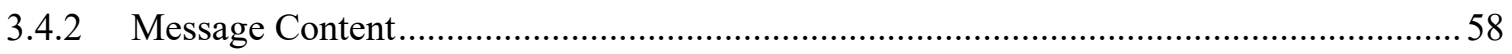

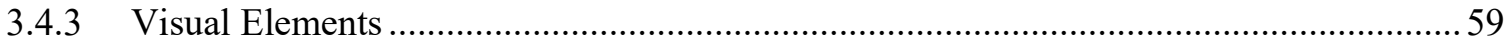

3.5 Phase 3: Graphic Message Feedback Form - Professionals .............................................. 62

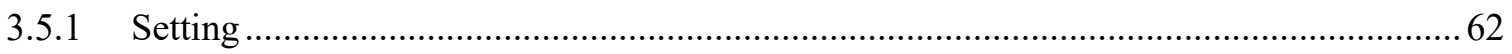

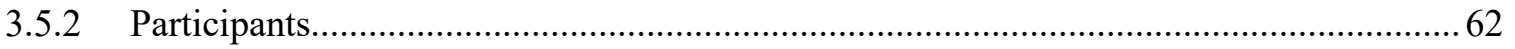

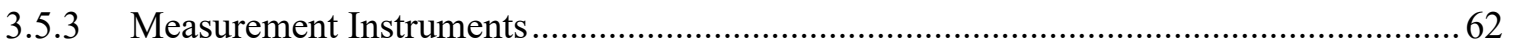

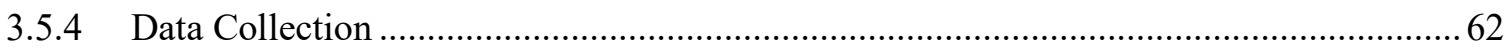

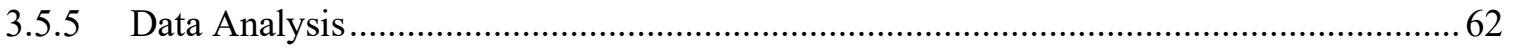

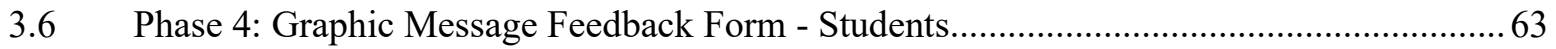

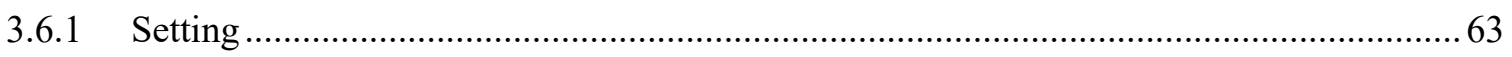

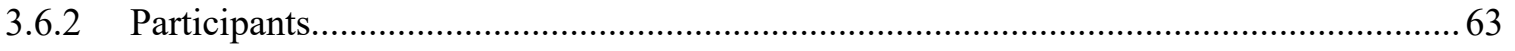




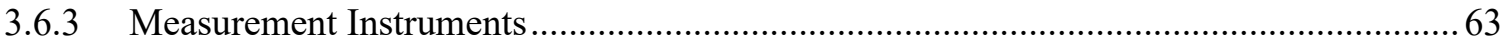

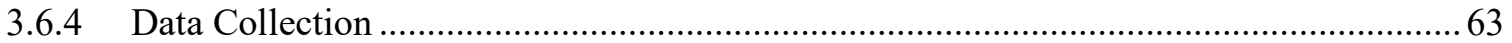

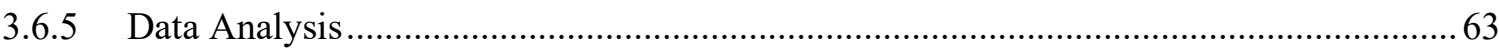

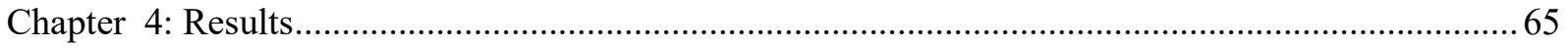

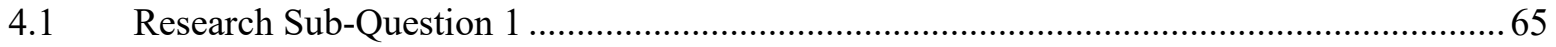

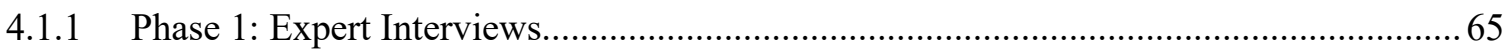

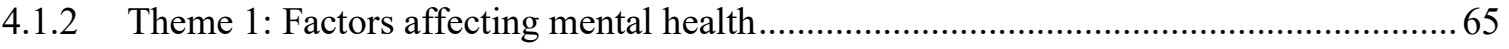

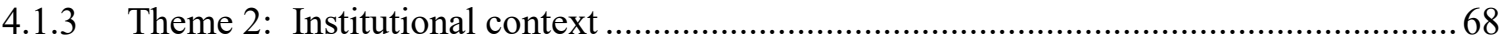

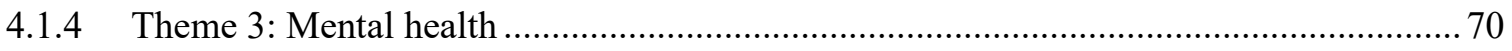

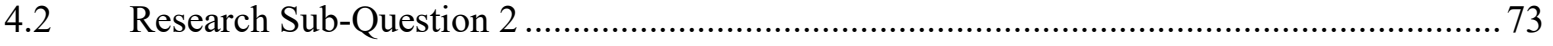

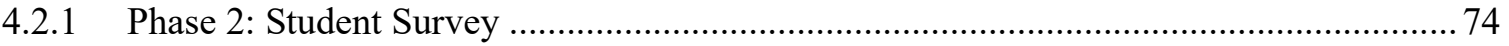

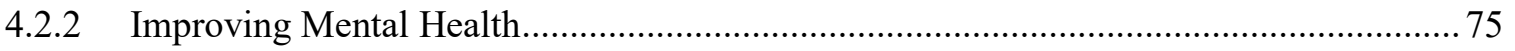

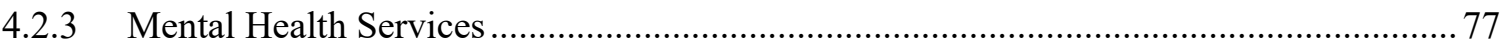

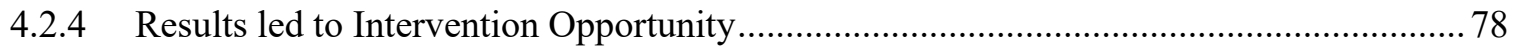

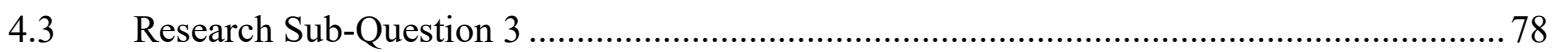

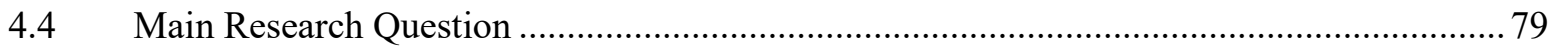

4.4.1 Phase 3 and 4: Graphic Message Feedback Form............................................................ 79

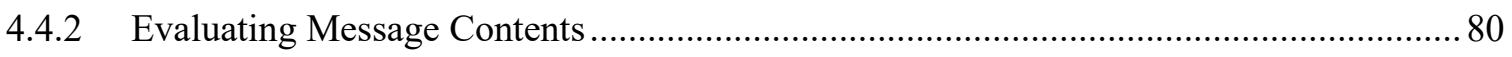

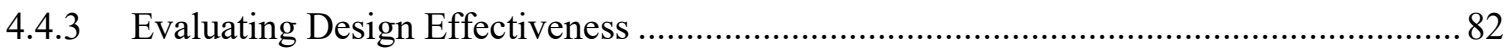

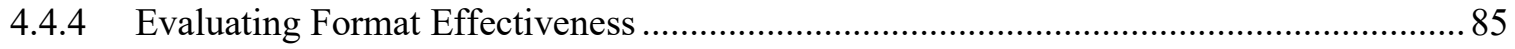

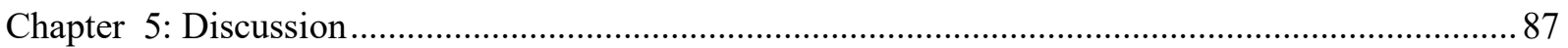

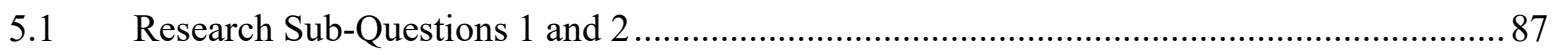

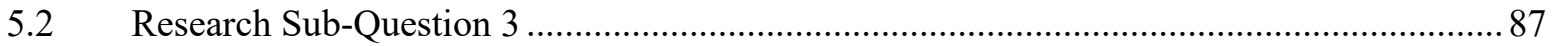

vii 
5.2.1 Effectiveness of the Graphic Messages in Informing Post-Secondary Students

5.2.2 Effectiveness of the Graphic Messages in Changing Behaviour..... 88

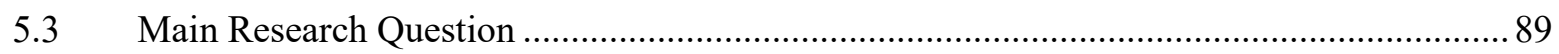

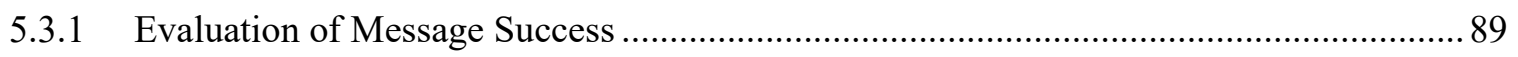

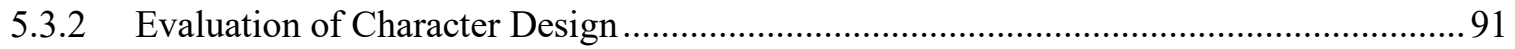

5.3.3 Evaluation of Backgrounds and Contrast ................................................................ 92

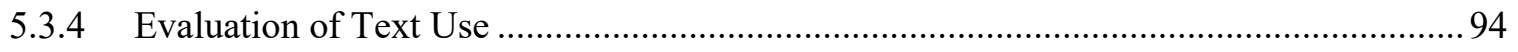

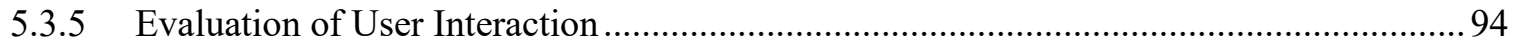

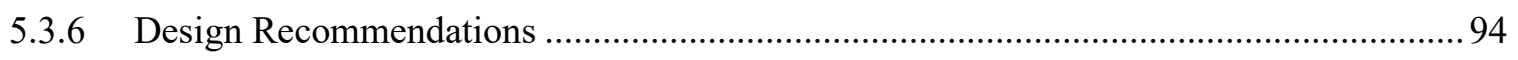

5.4 A Human-Centered Design Process …........................................................................ 97

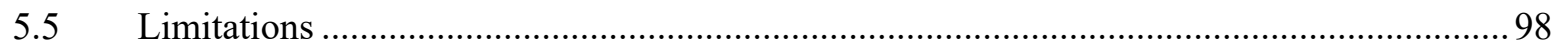

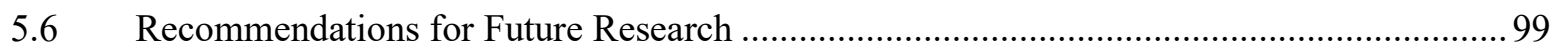

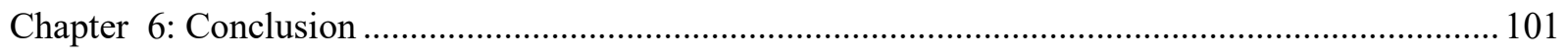

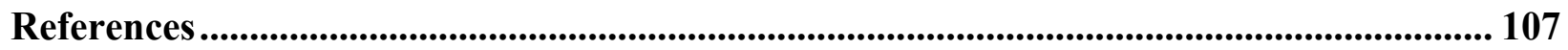

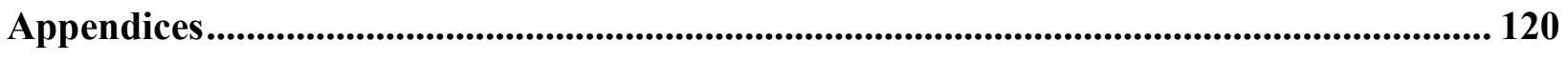




\section{List of Tables}

Table 1: Qualities of volitional actions and coerced action. Adapted from Moller et al., 2006... 19

Table 2: Factors for evaluating a health promoting message.

Table 3: Types of Infographics. Adapted from Siricharoen \& Siricharoen, 2015.

Table 4: Criteria for effective infographics. From Siricharoen \& Siricharoen, 2015. 45

Table 5: Specifications for effective infographics. Adopted from Okanagan College Library, 2020 .

Table 6: Phase one participants and their places of work 52

Table 7: Scores for the four statements related to the individual graphic messages. 80

Table 8: Scores for the statements evaluating the usefulness, legibility, design, and aesthetics of the graphic messages 82

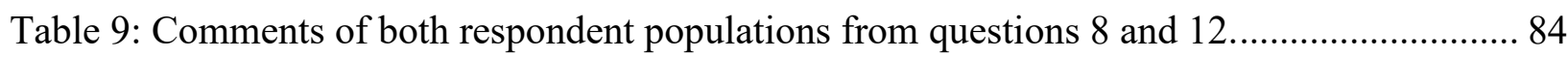

Table 10: Scores for the different potential formats for transmitting the graphic messages ........ 86

Table 11: Summary of design recommendations for graphic messages with reasoning. 95 


\section{List of Illustrations}

Illustration 1: Elaboration likelihood model diagram. Adapted from Petty \& Cacioppo, 1986; Jensen et al., 2012; Cyr et al., 2018.

Illustration 2: Shannon-Weaver model of communication. Adapted from Corman et al., 2007. 16 Illustration 3: Model of persuasive communication. Adapted from op den Akker et al., 2016; Petty, 2018. 17

Illustration 4: Self-Determination Theory. Adapted from Legault, 2017 19

Illustration 5: Example creative concepts for Rethink Vape that were favored by the adults but rejected by teens. From England et al., 2020.

Illustration 6: : Selected still images of final Rethink Vape campaign assets, including microsite

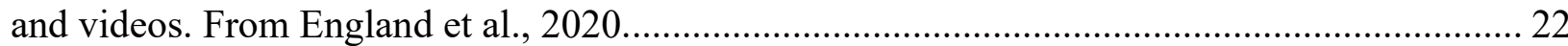

Illustration 7: Transtheoretical Model of Behaviour. Adapted from Al Rawahi et al., 2020....... 23

Illustration 8: Information-motivation-behavioural skills model. Adapted from Fisher et al., 2003.

Illustration 9: Fogg Behaviour Model. From Fogg, 2009. 25

Illustration 10: Human-centered design framework. Adapted from IDEO, 2015; Biroscak, 2018.

Illustration 11: Human-centered design framework for behavioural interventions. Adapted from

Wallen \& Daut, 2018. 31

Illustration 12: Campaign poster for "Will's Story", the media campaign developed by Borg et al., 2019 .

Illustration 13: Example of how to use chunking, hierarchy, emphasis, and loose line spacing to decrease the cognitive load navigate through text. 35

Illustration 14: Simplicity model. Adapted from Davidson, 2017. 36 
Illustration 15: Examples of text fonts (left) and display fonts (right) ...... 37

Illustration 16: Example of text with no kerning applied vs kerning applied................................ 37

Illustration 17: Examples of text with normal tracking, tight tracking, and loose tracking ......... 38

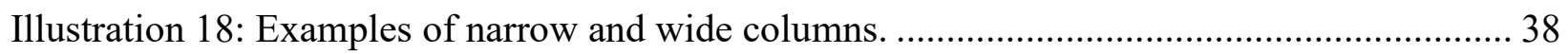

Illustration 19: Examples of center aligned and justified columns............................................... 38

Illustration 20: Infographic priorities by application. From Lankow et al., 2012 ....................... 44

Illustration 21: The iterative design cycle method used in this study ....................................... 50

Illustration 22: : Pie chart showing survey respondent age groups. ............................................ 54

Illustration 23: Design thinking model overlayed with study phases. Adapted from Balcaitis,

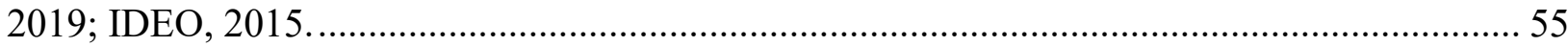

Illustration 24: Current examples of graphic design used to communicate messages from

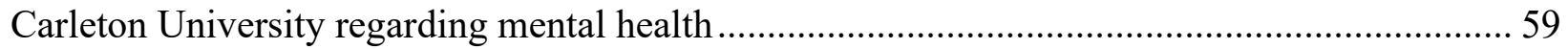

Illustration 25: Construction of a human character with simple geometric shapes ...................... 60

Illustration 26: A human character with colour and shading ..................................................... 60

Illustration 27: Graphic layout of a health-promoting graphic message......................................... 61

Illustration 28: Factors affecting mental health coding diagram. .................................................. 66

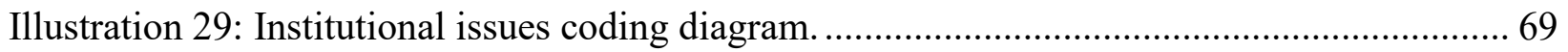

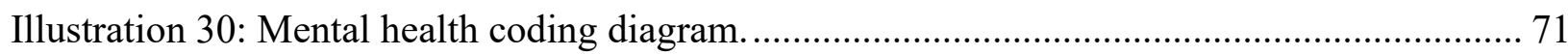

Illustration 31: Pie chart showing levels of stress/mental distress during the post-secondary

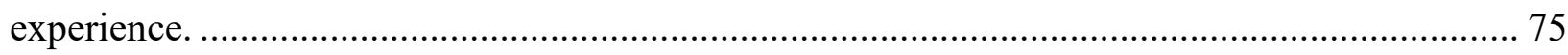

Illustration 32: Steps taken to improve mental health during the post-secondary experience and their impact rating. . 
Illustration 33: Factors cited as having the greatest impeding impact on the desire or ability to take steps to improve mental health......

Illustration 34: Reasons cited for not using a post-secondary institution's mental health services.

Illustration 35: Graphic message on scrolling.

Illustration 36: The health eating graphic message altered based on the design recommendations generated from the feedback form data. 


\section{List of Appendices}

Appendix A Expert Interview Protocol ................................................................................ 120

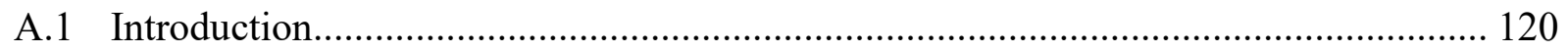

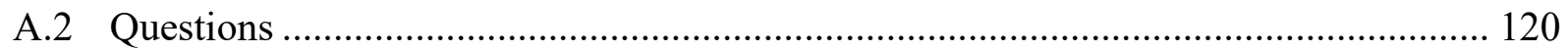

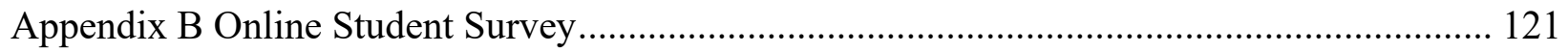

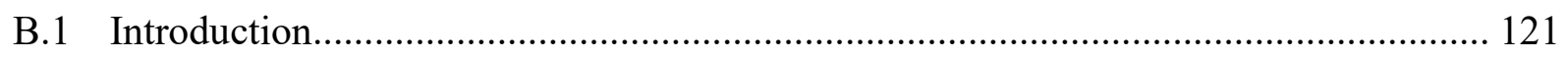

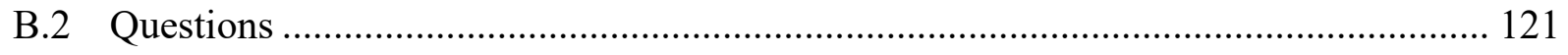

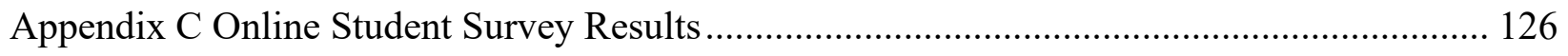

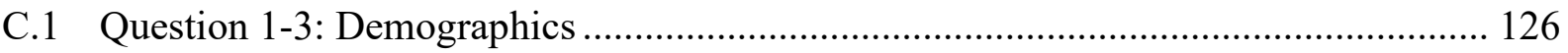

C.2 Question 4: Level of stress or mental distress during the post-secondary experience . 126

C.3 Questions 5-6: Factors detrimental to mental health during the post-secondary

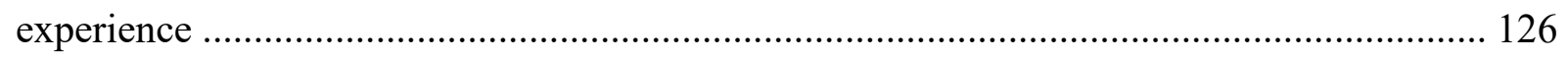

C.4 Question 7: Factors affected by mental health during the post-secondary experience. 128

C.5 Questions 8-10: Steps taken to improve mental health during the post-secondary

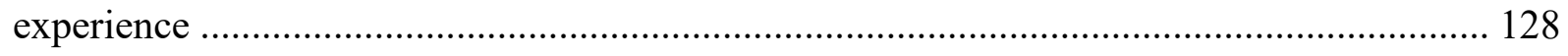

C.6 Question 11: Factors that impeded taking steps to improve mental health .................. 129

C.7 Question 12-13: Awareness of institutional mental health services ............................ 130

C.8 Questions 14-15: Use of institute's mental health services......................................... 131

C.9 Question 16: Reasons for a lack of use of institute's mental health services................ 132

C.10 Question 17-18: Reasons for neutral or improved levels of stress or mental distress during the post-secondary experience .............................................................................. 133

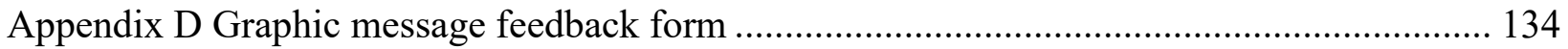

xiii 
D.1 Introduction

D.2 Questions

Appendix E Graphic message feedback form Results from Expert Interviewees

E.1 Question 1-6: Evaluation of individual graphic messages ...

E.2 Question 7: Evaluation of the graphic messages as a whole

E.3 Questions 8: Changes to the graphics to enhance their usefulness, legibility, design, and/or aesthetics

E.4 Question 9: Effectiveness of formats.

E.5 Questions 10-11: Alternative formats and ways the information can be conveyed ..... 152

E.6 Questions 12: Additional comments

F.1 Question 1-6: Evaluation of individual graphic messages

F.2 Question 7: Evaluation of the graphic messages as a whole

F.3 Questions 8: Changes to the graphics to enhance their usefulness, legibility, design, and/or aesthetics 156

F.4 Question 9: Effectiveness of formats. 160

F.5 Questions 10-11: Alternative formats and ways the information can be conveyed ..... 160

F.6 Questions 12: Additional comments. 162

Appendix G Graphic Message Prototypes 164

G.1 Healthy Eating 164

G.2 Confiding. 165

G.3 Exercising 166 


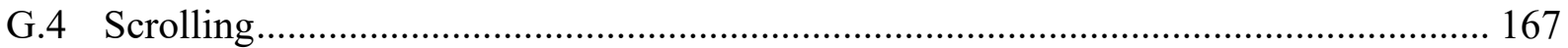

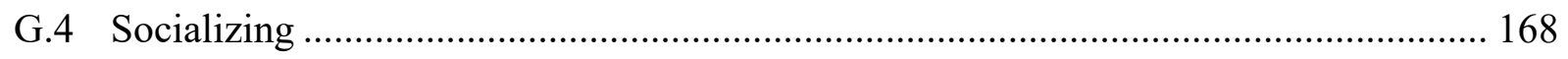

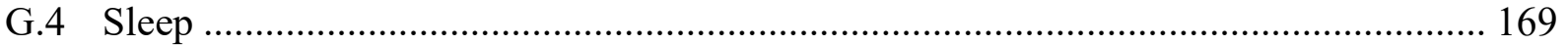





\section{Chapter 1: Introduction}

\subsection{Statement of the problem}

Young Canadians are currently facing a mental health crisis (CBC, 2019). Post-secondary student mental illness rates are higher than those in the general adult population and are increasing rapidly (Lipson \& Eisenberg 2018; Pedrelli et al., 2015; Brown, 2020; Robinson et al., 2016). Along with the prevalence of mental illness, incidences of suicide in post-secondary students are also on the rise (Stallman, 2010; Sivertsen et al., 2019). The state of this issue is both extremely serious and complex. Post-secondary education institutions are attempting to address this issue by offering counselling services, but are overwhelmed with demand (Brown, 2020; Coordinating Committee of Vice Presidents Students, 2015). Because of the high volume, post-secondary institutions' mental health centres are unable to cope and must "triage" students, who may have to wait weeks and sometimes months to get an appointment (Brown, 2020). Additionally, young people who are most in need of psychological help are the least likely to seek it out (Velasco, et al., 2020; Gulliver et al., 2010). Many post-secondary students who experience mental health issues find it difficult to connect with available mental health services (Brown, 2020; Velasco et al., 2020).

One factor that is theorized to be affecting student mental health is resilience, a person's positive adaptation to the experience of adversity (Davydov et al., 2010). There is increasing opinion that current post-secondary students are more emotionally fragile and less resilient than students in the past (Gray, 2020; CIGNA, 2020). High levels of resilience can protect again mental illness, whereas lowered levels of resilience are correlated with lower ability to weather stress and take on challenges (Davydov et al., 2010), both of which are typical of student life.

\subsection{Background and needs}

There is evidence that post-secondary student mental health is in crisis and is worsening (Lipson \& Eisenberg 2018; Pedrelli et al., 2015; Brown, 2020; Robinson et al., 2016). Researchers have proposed a number of factors that may be contributing to this state, such as adolescence (Pedrelli et al. 2015; Lipson \& Eisenberg, 2018), post-secondary education as a time of major transition and stress (Brown, 2020), increased technology use among post-secondary students and the 
proliferation of smart phones (Demirci et al., 2015; Roberts et al., 2014; Elhai et al., 2017), academic and financial pressure (Pedrelli et al., 2015; Brown, 2020 Maldonado, 2018), as well as diminished resilience (Ecclestone \& Hayes, 2019; Lipson \& Eisenberg, 2018; Gray, 2020; CIGNA, 2020). Universities and colleges have employed online therapy and peer support programs to help lighten the load on counselling centers and have been training faculty and staff to identify students in distress (Brown, 2020). However, the number of post-secondary students meeting the criteria for clinical levels of mental illness is extremely high, and colleges and universities are not capable of treating the mental state of all those who need it (Binkley \& Fenn, 2020; Hensley, 2020; Brown, 2020).

Persuasive health campaigns have been shown to have positive effects on large populations (Wakefield et al., 2010). Additionally, using behavioural theory has been shown to positively impact the efficacy of these campaigns (Webb et al., 2010; Luca \& Suggs, 2013), as has developing and testing the campaign materials with the target audience (England et al., 2020; Borg et al., 2019). Additionally, the design details of visual messages can affect their efficacy (SanJosé-Cabezudo et al., 2009; Smiciklas, 2012). This presents an opportunity; to develop a persuasive health campaign with post-secondary students that can reach individuals that are not willing to seek help, to direct students to resources besides health and counselling that they may not have been aware of, and to increase the coping skills, self-efficacy, and resilience of postsecondary students that may not feel like they are in control of their own mental health.

\subsection{Purpose of the Study}

The purpose of this study is to explore the design of a persuasive mental health campaign that may help to increase the variety of coping mechanisms and therefore the resilience of postsecondary students with mental health issues. The research investigates the kind of mental health issues post-secondary students are facing, the current solutions that universities may be offering, and the factors that are contributing to poor mental health. The study then presents the possibility of an approach to providing students with information that may support self-efficacy and resilience and increase their range of coping skills. A potential format of graphic messages for a persuasive health campaign is presented and evaluated by experts and professionals to develop a list of specific recommendations for future researchers in this topic. 


\subsection{Interdisciplinary Approach to the Study}

The issue of post-secondary student mental health is a "wicked problem": a problem that is complex, difficult, and does not have a single "correct" solution (Bishop \& Dzidic, 2014). The effects of proposed solutions to wicked problems are difficult to evaluate due to their complexity (Bishop \& Dzidic, 2014), but it is critical that interventions that attempt to address the issue of mental health have a tangible, positive impact on their target audience. To accomplish this task many different facets must be addressed. This includes understanding post-secondary student mental health, its antecedents, and its impacts, understanding health behaviour, designing an intervention that can change behaviour, and evaluating its effectiveness. Given its complexity, this task cannot be tackled by a single discipline. According to Bishop and Dzidic, "an interdisciplinary approach often arises because of the grounded nature of problems and also because a single discipline does not have the range of expertise to deal with all aspects of the issues" (2014, p. 13). In fact, interdisciplinarity may be unavoidable in design; "design is by necessity interdisciplinary because it has to consider so many issues" (Boradkar, 2016, p. 457). For these reasons, this study draws from multiple fields: mental health, behavioural theory, persuasive communication, design theory, and graphic design.

\subsection{Research Questions}

To investigate how an intervention could be designed to best support the self-efficacy, resilience, coping skills repertoire, and ultimately mental health of post-secondary students, the following questions were addressed in this study.

The three sub-questions addressed in this study are:

1. How can the student mental health crisis be addressed through design in a way that strengthens student mental health self-efficacy and resilience?

2. What factors affecting mental health can be targeted through a design intervention to create the greatest positive impact on student mental health?

3. How will experts and the target audience perceive the effectiveness of the proposed design intervention in informing students about their mental health and changing their mental health behaviours? 
The main research question addressed in this study is:

How can graphic messages promoting positive mental health behaviours be designed to maximize their effectiveness?

\subsection{Scope}

Due to the time and resource limitations related to this study, the scope of what this study investigates is limited. Within the scope of the study is:

1. An exploration of the issues and context related to student mental health.

2. An exploration of how a design intervention could be used to improve student mental health.

3. The proposal of an intervention designed to improve student mental health by supporting the self-efficacy and resilience of students and increasing their coping skills repertoire.

4. The collection of evaluative feedback from experts and the target audience on the proposed intervention.

5. An extrapolation of the feedback on how the design intervention could be modified to be more effective.

Outside of the scope of the study is:

1. An assertion that the proposed intervention will have an actual impact on student mental health behaviours.

2. A measurement of the effectiveness of the proposed intervention in changing knowledge, attitudes, behavioural intentions, or behaviours.

\subsection{Significance to the Field}

This study presents an overview of the kind of mental health issues that post-secondary students are experiencing, the factors and behaviours that lead to these issues and the steps that could be taken to improve their mental health. A possible approach is then proposed that can provide information to students to improve their self-efficacy, coping skills, and resilience and is separate 
from the services colleges and universities are currently offering. Feedback from professionals and students on this approach is given. The study discusses the importance of collaboration between designer, professionals and subject matter experts, and the target audience to develop and evaluate the messages and to identify the factors that make specific messages helpful or not helpful. Additionally, a list of recommendations on an approach to the design of these graphics in terms of their specific elements (message, layout, character design, etc.) is provided. 


\section{Chapter 2: Review of the Literature}

This literature review explores five main subsections. The first three subsections deal with mental health issues experienced by those pursuing higher education. Student mental health rates appear to be rising rapidly, and mental health services of colleges and universities in Canada and the United States are becoming overwhelmed by demand for treatment (Brown, 2020; Coordinating Committee of Vice Presidents Students, 2015). This begs the question: why are some students enrolled in higher education experiencing such high levels of distress and mental illness?

The first subsection includes a general discussion on post-secondary student mental health. The current state of students' mental health and how prevalent this issue is, with possible antecedents, causes, and consequences of mental illness experienced by students during college or university will be covered. The influence that technology use has on mental health is then discussed. The impact that the widespread adoption of smartphones and social media has on the mental health of adolescents and university students is then covered. Third, distinctions between normal and pathological stress are explored, as are critical appraisals of "therapeutic education".

The last two subsections deal with issues surrounding creating effective persuasive health campaigns. These sections of the literature review will look at how the issue of post-secondary student mental health can be improved through a media campaign. The fourth subsection deals with health behaviours and designing persuasive health campaigns. Models of behaviour that can help increase an understanding of how health behaviours may be changed will be discussed. Additionally, health promoting messages will be discussed, as well as the issues that can affect a health message's efficacy. The model of persuasive communication will be presented in this section. The last subsection deals with visual communication; how visuals can impact attention, engagement, and persuasion are discussed, as well as the impact of graphic design choices on how messages are processed. 


\subsection{Post-Secondary Student Mental Health}

\subsubsection{Prevalence}

Many sources assert that student mental health problems are both highly prevalent and increasing (Lipson \& Eisenberg 2018; Pedrelli et al., 2015; Brown, 2020; Robinson et al., 2016). According to the American College Health Association, two thirds of students have experienced overwhelming anxiety (Brown, 2020). Evidence suggests that psychological distress in college and university students is significantly elevated; a 2016 study asserts that the prevalence rate of psychologically distressed students is "markedly higher" than in the general population and that students experience greater distress throughout their degree than at pre-enrolment levels (Robinson et al.). Additionally, an Australian study found that 19.2\% of students had very high levels of distress as compared to $3 \%$ of the general adult population (Stallman, 2010). However, Mortier et al. (2018) state that it is unclear whether university students are at an increased risk of suicidal thoughts and behaviours as compared to non-enrolled peers of the same age, and that being enrolled in college may have a protective effect on the onset of suicidal thoughts and behaviours.

\subsubsection{Causes}

The causes of mental illness in college and university students have been attributed to many different factors over time. The age at which many students enter higher education may be a factor, as most mental disorders begin during late adolescence and early adulthood (Pedrelli et al. 2015; Lipson \& Eisenberg, 2018). Brown (2020) points out that college is a time of transition and the introduction of new demands, and therefore has the inherent potential to be a time of increased stress, and Pedrelli et al. (2015) state that academic pressures and the stressors of college life have the potential to trigger the onset of mental health problems. Another factor is that the cost of university education has shifted dramatically over time; between 1989 and 2016 the cost to attend a university increased eight times faster than wages did (Maldonado, 2018). This has resulted in a huge increase in the average student loans and increased financial pressure on students. 
Another factor that may be exacerbating stress and loneliness in students is the increased use of mobile devices: this factor will be discussed further below. Additionally, psychopathology can often be chronic because of a failure to seek treatment or low treatment adherence (Pedrelli et al., 2015). Robinson et al. (2016) report that only a small proportion of students meeting the criteria for clinical psychological distress ever access counselling services and Brown (2020) states that many students that commit suicide are unknown to school counsellors.

\subsubsection{Suicide}

The second leading cause of death for people aged 15-29 years worldwide is suicide, and deaths by suicide among post-secondary students are reportedly higher than in the general adult population and rising (Stallman, 2010; Sivertsen et al., 2019). In a study in Norway on suicide ideation, $21 \%$ of university students reported having had suicidal thoughts, $4.2 \%$ reported a suicide attempt, 19.6\% reported non-suicidal self-harm behaviours, and 23.6\% reported thoughts of non-suicidal self-harm (Sivertsen et al., 2019). Mortier et al. (2018) report that worldwide, approximately one in four college students has experienced suicide ideation, with $65 \%$ of those experiencing it within the last year. These statistics are revealing as suicidal thoughts and behaviours are significant not only for the dangers they signify, but also because they are markers for extreme psychological distress.

\subsubsection{Stigma}

Stereotypes of mental illness and "crazy" behaviour may be learned early in childhood and reinforced by social interactions and mass media that stigmatize those with mental illness (Markowitz, 2005). Although some anti-stigma campaigns have seen success in changing attitudes and reducing discrimination, stigma still has a great negative impact on people with mental illness (Collins et al., 2015; Markowitz, 2005; Brown, 2020). Mental illness can call one's character into question and may be linked to negative stereotypes, like dangerousness and criminality (Markowitz, 2005; Rueve \& Welton, 2008).

Stigma is damaging in several ways. It may contribute to lowered rates of treatment seeking for students with mental illness; in an online survey of college mental health, only $36 \%$ of students who screened positive for mental health issues sought and received treatment (Pedrelli et al., 
2015). Markowitz (2005), citing a 1982 study by Link, suggests that the label of "mentally ill" has twice as large an effect on income and employment than symptoms of psychiatric illness. Furthermore, stigmatization may increase the likelihood of chronic mental illness by affecting the self-concept of mentally ill people.

\subsection{Technology Use and Student Mental Health}

Smartphone ownership has become increasingly pervasive; from the introduction of the iPhone in 2007, American smartphone ownership reached $50 \%$ in 2012 and $81 \%$ in 2019 , with $96 \%$ of those in the 18-29-year-old range owning smartphones (Brown, 2020; Pew Research Center, 2019). In 2014, Roberts et al. found that college students spent on average almost nine hours daily on their smartphones. Because mobile computing is a relatively new technology, the impacts on the users' mental health are still being investigated; this is concerning as smartphones have already become so widely adopted. Smartphones are ubiquitous due to their utility, becoming an indispensable part of daily life, but they have the capacity to be both a helpful tool and a dependence-forming device (Roberts et al., 2014).

Smartphone addiction or "problematic smartphone use" is a type of behavioural addiction like Internet addiction, defined as habitual use of a smartphone in a way that interferes with wellbeing and daily function (Demirci et al., 2015; Roberts et al., 2014). Additionally, people may use their smartphones in a compensatory capacity, to escape real-world responsibilities and avoid negative emotions (Elhai et al., 2017). A growing amount of research suggests that people are increasingly becoming addicted to their smartphones (Elhai et al., 2017; Roberts et al., 2014).

The desire for social connection commonly underlies smartphone overuse (Roberts et al., 2014). However, young people are lonelier than ever despite the ability to connect to people at any time through their phones; Pittman and Reich (2016) characterize the current generation of young adults (18-34) as maybe "the loneliest ever" despite the increased interconnectivity of people through social media.

Social media usage has been shown to relate to greater degrees of loneliness, mental illness, and overwhelm (Brown, 2020; Hunt et al., 2018). According to Hunt et al. (2018), Facebook and Instagram usage are both correlated with symptoms of depression; higher use of Facebook is 
associated with lower self-esteem and greater loneliness, and higher use of Instagram is correlated with body image issues. Their study had undergraduate university students limit their social media use of Instagram, Facebook, and Snapchat to 10 minutes a day, which in each case showed a significant reduction in loneliness and depression over three weeks as compared to the control group. Some of their participants who started the study with moderately severe depression symptoms found that those symptoms declined to the mild range just by limiting social media usage for three weeks (Hunt et al., 2018).

Overuse of smartphones and social media seems to be taking a toll on the mental health and well-being of the current generation of young adults; comparison through social media can decrease confidence, constant consumption of negative news can decrease optimism, and interacting more online and less in person can increase feelings of isolation (Brown, 2020). Rosen et al. (2013) report an extensive amount of evidence linking depression and excessive texting, video watching, gaming, chatting, emailing, and other media uses. Furthermore, a Turkish study indicates that smartphone overuse is associated with depression, anxiety, and a decrease in sleep quality (Demirci et al., 2015). Elhai et al. (2017) report a consistent significant link between problematic smartphone use and depression severity, and to a lesser extent, with anxiety, stress, and lowered self-esteem. Additionally, Rosen et al. (2013) report that emotional negativity may be transmittable online through "emotional contagion"; they state that not only can depressing media consumption lead to a negative mood, but that negative mood can also be transmitted through online interactions. However, the link between smartphone and social media use and mental illness may not be unidirectional. There is some evidence that psychopathology can cause smartphone overuse when it is used in a compensatory way to avoid stress and negative emotion (Elhai et al., 2017).

In addition to interfering with mental wellness, smartphone overuse can cause maladaptive behaviour, reduce face-to-face social interaction, lead to relationship disorders, and cause academic and work problems (Demirci et al., 2015). Smartphone addiction can also undermine academic performance by distracting students during classes and disrupting their studies (Roberts et al., 2014). 
Sleep is a significant factor in mood regulation, and technology may be disrupting the sleep patterns of university students, leading to markers of depression such as loss of energy and concentration problems. Some of the factors linking poor sleep quality and smartphone use are: use of the smartphone during normal sleeping hours; use causing cognitive, emotional, or physiological arousal; light emissions from screens disrupting circadian rhythm; and notifications waking users up while asleep (Demirci et al., 2015).

Considering the rapid increase in the rate of anxiety, depression, and suicide ideation reported by Brown (2020) and Sivertsen et al. (2019) in the last 10 or so years, the fact that American smartphone ownership reached 50\% in 2012 (Brown, 2020), and also the findings that college students in 2014 spent on average almost nine hours per day on their phones (Roberts et al., 2014), it seems that the overuse of smartphones and social media may be a critical factor in the sudden rapid spike in severe mental distress in post-secondary students.

\subsection{Normal and Pathological Stress}

Stress is a normal part of everyday life, and in manageable amounts can increase drive and motivation. However, too much stress can cause feelings of overwhelm due to an inability to meet the demands of the situation. Some authors assert that there is a current societal trend of pathologizing everyday stress by turning normal traits into psychiatric disorders (Ecclestone \& Hayes, 2019). Brown (2020) attributes this to a decrease in stigma; "With less stigma comes more liberal use of clinical terms to describe everyday problems. Many students no longer say they're worried; they say they're anxious. They're not sad; they're depressed." (p. 7).

However, a more negative interpretation of this trend is that drug companies have driven the relabelling of daily stress into psychopathology for their own benefit and have influenced psychiatrists to create new mental illnesses so that new classes of drugs can be marketed (Ecclestone \& Hayes, 2019; Scull, 2011). Scull (2011) discusses how the Diagnostic and Statistical Manual from 1968 to 1994 evolved to increase inter-rater reliability through a checklist of symptomology and to transform "all sorts of daily distress and the ordinary vicissitudes of human existence into new 'diseases' allegedly caused by 'chemical imbalances', all resting on the apparent authority of science, but in reality on purely circular reasoning." (p. 
111). With increased inter-rater reliability, diagnoses could be more concretely linked to treatment with new classes of drugs; Scull also asserts that the creation of new classes of drugs has driven the creation of new psychopathologies to match (2011). Indeed, there have been huge increases in the numbers of American college students using psychiatric medication; a five-fold increase between 1992 and 2002 (Kraft, 2011; Schwartz, 2006), and an increase from about one in six or seven students to one in four between 2009 and 2020 (Brown, 2020).

\subsubsection{Coddling the Post-secondary Student?}

Some authors argue that an educational system that puts a focus on mental well-being decreases resilience and self-efficacy, leading to an actual decrease in mental well-being. By suggesting that students may need help, educators may weaken self-efficacy, which, as Lipson and Eisenberg (2018) state, is the quality that determines perseverance, confidence in their capacity to face a challenge and resilience in the face of adversity. Self-efficacy mediates the connection between external stressors and internal distress, so students who have more confidence in their ability to succeed will experience less stress over their academic careers (Lipson \& Eisenberg, 2018). This also has an impact on what they can accomplish academically, as there is a significant correlation between academic self-efficacy and academic achievement (Lipson \& Eisenberg, 2018).

Ecclestone and Hayes (2019) assert that educational institutes at the primary, secondary, and post-secondary levels that combine the goal of emotional well-being with educational and academic goals have a negative impact on students' mental states. They state that 'therapeutic education" increases anxiety and self-preoccupation while reducing optimism, resiliency, and the willingness to learn in students, and socially engineers feeble and passive students and promotes a life that is focused on the self, whereas confidence and self-esteem result from active engagement in the world (Ecclestone \& Hayes, 2019).

The authors give explanations for this; in addition to the motivation stemming from psychiatric drug revenue to pathologize everyday stress, they state that therapeutic ideas from popular culture offer a diminished view of human potential influence policy and social thought (Ecclestone \& Hayes, 2019). This influence has caused schools to implement programs to 
increase emotional literacy and well-being, but they foster dependence by compelling students to participate in therapeutic activities. Ecclestone and Hayes (2019) attribute the unprecedented numbers of children reporting anxiety in school which encourages feelings of vulnerability and anxiety, and state that this ultimately results in students who come to university already thinking of themselves as in need of help.

Whether the issue of rising levels of anxiety can be attributed mostly or even partially to an increased focus on emotional literacy and well-being in education is a question that would require serious critical examination. However, it does seem prudent to ensure that these initiatives are not weakening the self-efficacy of students, but instead encouraging the belief that students are up to the challenge and able to meet the demands of a post-secondary education.

\subsection{Promoting Mental Wellness}

This section of the literature review will discuss behavioural interventions, and more specifically persuasive health campaigns.

\subsubsection{Health Behaviours}

Behaviour is a critical component of health, both mental and physical; behavioural factors are integral in illness prevention and healthy behaviours help promote a long and healthy life (Spring, B., Moller, A. C., \& Coons, 2012). However, creating healthy habits is not an easy task. Behaviour is a complex issue, and there are many elements that influence it. These factors can be cognitive, social, and/or contextual in nature. One way of influencing behaviour is through persuasive design, an area of design that uses social and psychological principles to attempt to influence human behaviour through the use of a product or service (Fogg, 2002). However, attempts at changing behaviour through persuasive design often fail because the factors that lead to behavioural change are not well understood (Fogg, 2009). It is therefore critical when developing persuasive health campaign messages to understand the factors that impact health behaviour. This understanding can help when determining what content to deliver to an audience and how this content should be delivered to optimally affect the targeted behaviours. Persuasive health campaign messages will be discussed further below. 
There are many theories that attempt to analyze or describe human behaviour. Research suggests that both more extensive use of behavioural theory is associated with larger effects on behaviour in internet-based approaches to behaviour change (Webb et al., 2010) and in healthcare campaigns theory can provide a valuable framework to design and evaluate interventions (Luca \& Suggs, 2013). A cursory understanding of a variety of behavioural theories and models is beneficial to understand how an intervention campaign can be most effective in changing behaviour.

\subsubsection{Persuasion and Attitude Theories}

Theories of persuasion and attitude change offer guidance on the use of tailoring strategies, as tailored messages enhance attitude change and result in more durable behaviour change (Morrison, 2015).

Elaboration Likelihood Model: This is a dual process theory describing two ways a persuasive message can be processed: through a central route based on the strength of the arguments presented through a peripheral route based on cues such as attractiveness of the message source (Cyr et al., 2018). This model of persuasion dictates that tailoring a message increases perceived relevance and reduces irrelevant "noise" and cognitive load (Jensen et al., 2012). If messages are tailored to the receiver, they are more likely to adopt a high-involvement processing style, taking the "central" route of processing. In this processing style, the receiver uses a great amount of cognitive processing, pays close attention to the arguments within the message, and resultant attitude change will be relevantly enduring, resistant, and predictive of behaviour (Jensen et al., 2012; Petty \& Cacioppo, 1986). If the message is perceived as personally irrelevant, the peripheral route of processing is more likely to be used, and decisions are likely to be made on surface level details (a low-involvement processing style) (Jensen et al., 2012; Petty \& Cacioppo, 1986). 


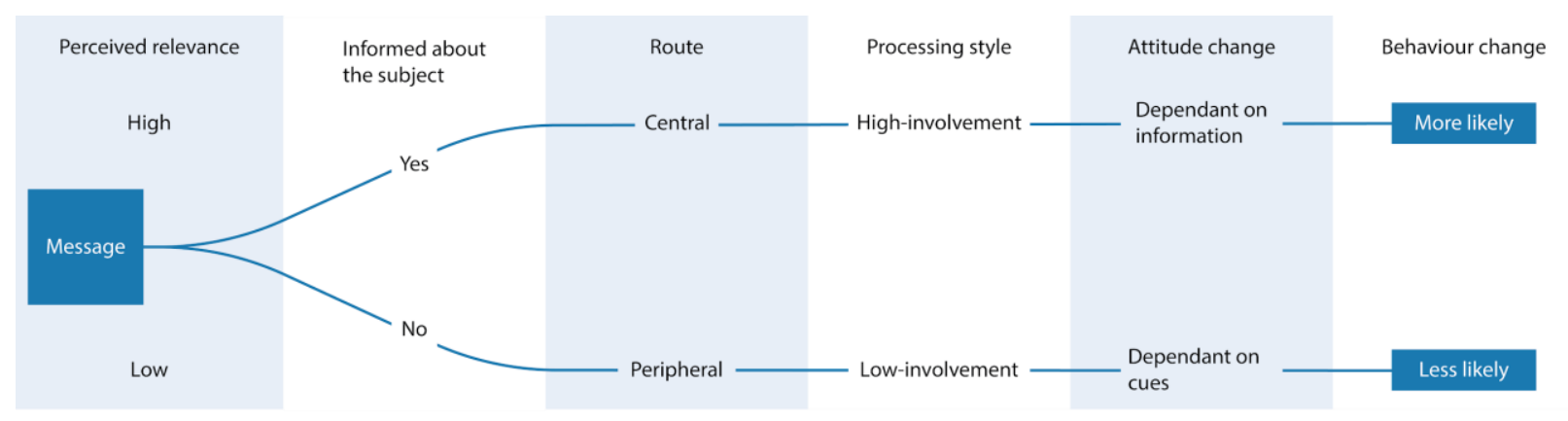

Illustration 1: Elaboration likelihood model diagram. Adapted from Petty \& Cacioppo, 1986; Jensen et al., 2012; Cyr et al., 2018.

However, there is evidence that the peripheral cues will affect the persuasiveness of a message even if the audience uses a high-involvement processing style. The elaboration likelihood model (ELM) was explored in a study on whether peripheral cues will affect the persuasiveness of the argument strength in online advertising (SanJosé-Cabezudo et al., 2009) in which researchers suggested that a website's format constitutes a set of peripheral cues and the information the website provides is the central argument. The researchers presented an airline travel website with the same informational content in two different formats, serious (featuring Times New Roman font, still images, and very little colour) and amusing (featuring Comic Sans font, animation, and many colours). Their hypothesis that the serious format would be more effective (because it emphasizes the informative nature of the website) was supported by their findings.

Additionally, a study that used the ELM to examine the impact of central and peripheral prevention messages on alcohol consumption and disordered eating on post-secondary students suggested that the central route may not always lead to increased behaviour change. In a study called "Using the Elaboration Likelihood Model to Address Drunkorexia among College Students", Glassman et al. (2018) created two types of messages aiming to dissuade postsecondary students from "drunkorexia" behaviour (dangerous behaviour characterized by skipping meals and/or exercising excessively in attempt to compensate for calories associated with high volume drinking). The peripheral route messages used a brief but direct message along with an image, whereas the central route messages contained more detailed information and an image. Over a 30-day period, students who received the peripheral route messages reduced their 
overall alcohol consumption and disordered eating and excessive exercising behaviours while the students who received the central route messages did not (Glassman et al., 2018).

Self-Referencing Encoding Model: The self-referencing encoding model (SREM) refers to the way people organize information in terms of how it pertains to themselves to help facilitate recall. Self-referencing (relating a message to one's personal experiences) is a type of elaborative processing, like the central route in the ELM (Chang, 2011). Message recall improves when the message receiver relates the message to themselves (Rogers et al. 1977; Chang, 2011). Additionally, when a message is made more personally relevant, relating to some aspect of a person's past or personality, they are more likely to be persuaded by it (Burnkrant \& Unnava, 1995; Chang, 2011).

Model of Persuasive Communication: One way to analyze a message is through the model of persuasive communication. Persuasive communication has been defined as any message that is intended to shape, reinforce, or change the responses of another, or others (Roloff \& Miller, 1980).

This model of communication borrows from the Shannon-Weaver model of communication. This model, sometimes referred to as "the mother of all models" (Hollnagel \& Woods, 2005), was developed in the late 1940s and conceptualizes messages as a vehicle for carrying information from a source to a receiver (Corman et al., 2007).

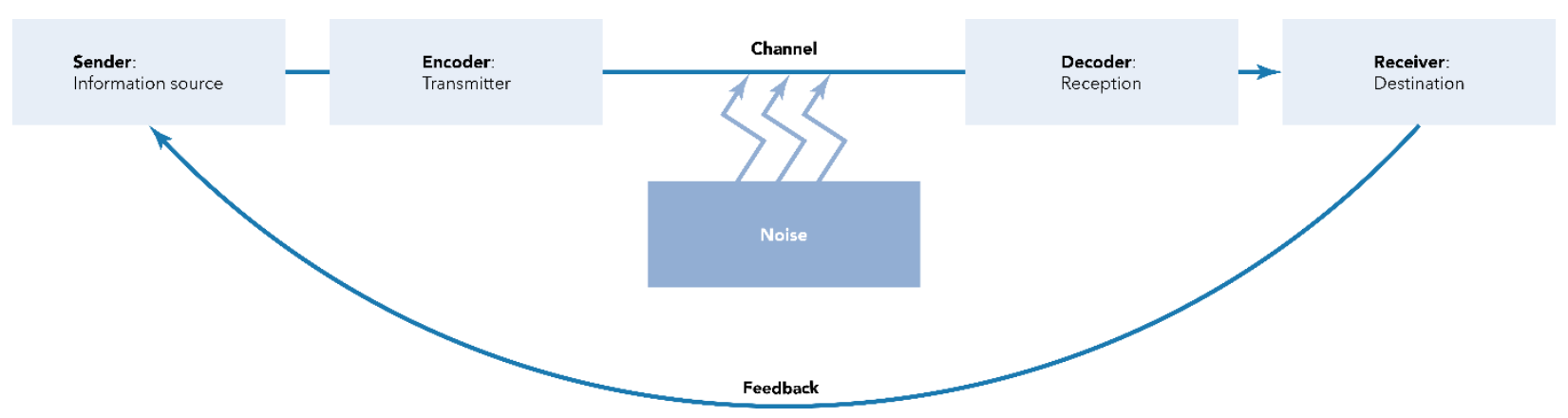

Illustration 2: Shannon-Weaver model of communication. Adapted from Corman et al., 2007.

Although this model has been widely adopted in the social sciences, it has been subject to much criticism due to its simplicity and inability to consider context (Garcia, 1996). This model assumes that failures in communication are due to issues in transmission, that the message will 
be successful unless there is some interference, and that to improve communication, it is best to improve transmission fidelity (Corman et al., 2007). The model of persuasive communication, however, introduces the element of the internal processes of the recipient as a mediating factor of communication.

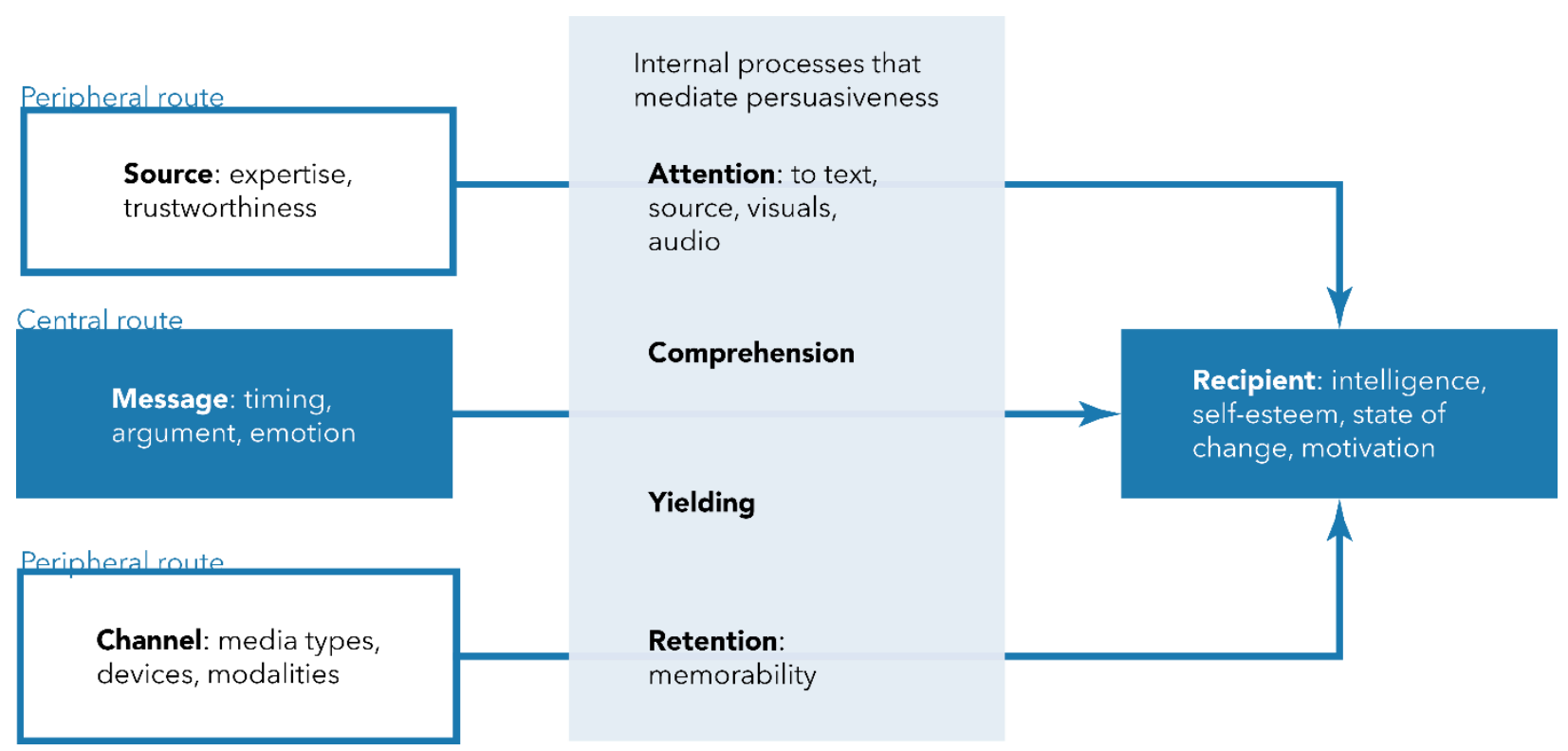

Illustration 3: Model of persuasive communication. Adapted from op den Akker et al., 2016; Petty, 2018.

This model suggests that the process of persuasive communication has four elements: message, source, channel, and recipients (op den Akker et al., 2016; Petty, 2018). This model borrows from the ELM, in that it includes the concepts of the central route and peripheral route of persuasion (Jensen et al., 2012; Petty \& Cacioppo, 1986).

Like the ELM, when one elaborates on the content of the message, they are taking the central route to persuasion. Conversely, one takes a peripheral route when they respond to peripheral cues, such as source credibility and attractiveness, qualities of the channel, and social consensus. (op den Akker et al., 2016).

\subsubsection{Volition and Self-Regulation Theories}

Theories of volition and self-regulation can provide guidance on the types of goals and progress feedback that will better support users to change health-related behaviours (Morrison, 2015). 
Reasoned Action/Planned Behaviour Theory: This theory states that behavioural intentions are formed guided by one's attitude toward the behaviour, subjective norm, and perceived behavioural control. If both attitude and subjective norm are positive, and the perceived control is high, intentions are more likely to be carried out (Ajzen, 2002). In studies, the use of the theory of reasoned action/planned behaviour led to the largest effect sizes across all interventions (Webb et al., 2010).

Self-Efficacy Theory: As stated in section 2.3.1, self-efficacy is the quality that determines perseverance, confidence in one's capacity to face a challenge, and resilience in the face of adversity (Lipson \& Eisenberg, 2018; op den Akker et al., 2016). Self-efficacy theory puts the concept of self-efficacy as a main driver of behaviour; if an individual feels capable and able to obtain a goal, they will act (Sweet et al., 2012; Bandura et al., 1999).

\subsubsection{Motivation Theories}

Theories of motivation can be used to guide the implementation of a persuasive health campaign to enhance the audience's motivation to change their behaviour (Morrison, 2015).

Self-Determination Theory: Like the self-efficacy theory discussed above, this theory conceptualizes people as active agents who regulate their own behaviour (Sweet et al., 2012; Ryan \& Deci, 2000). However, as opposed to putting the construct of self-efficacy at the forefront of behaviour enactment, self-determination theorists believe autonomy plays a bigger role; "if one feels autonomous in their actions, the likelihood of behaviour enactment and sustainability is greater, making self-determined motivation the main element of the agent" (Sweet et al., 2012, p. 320). 


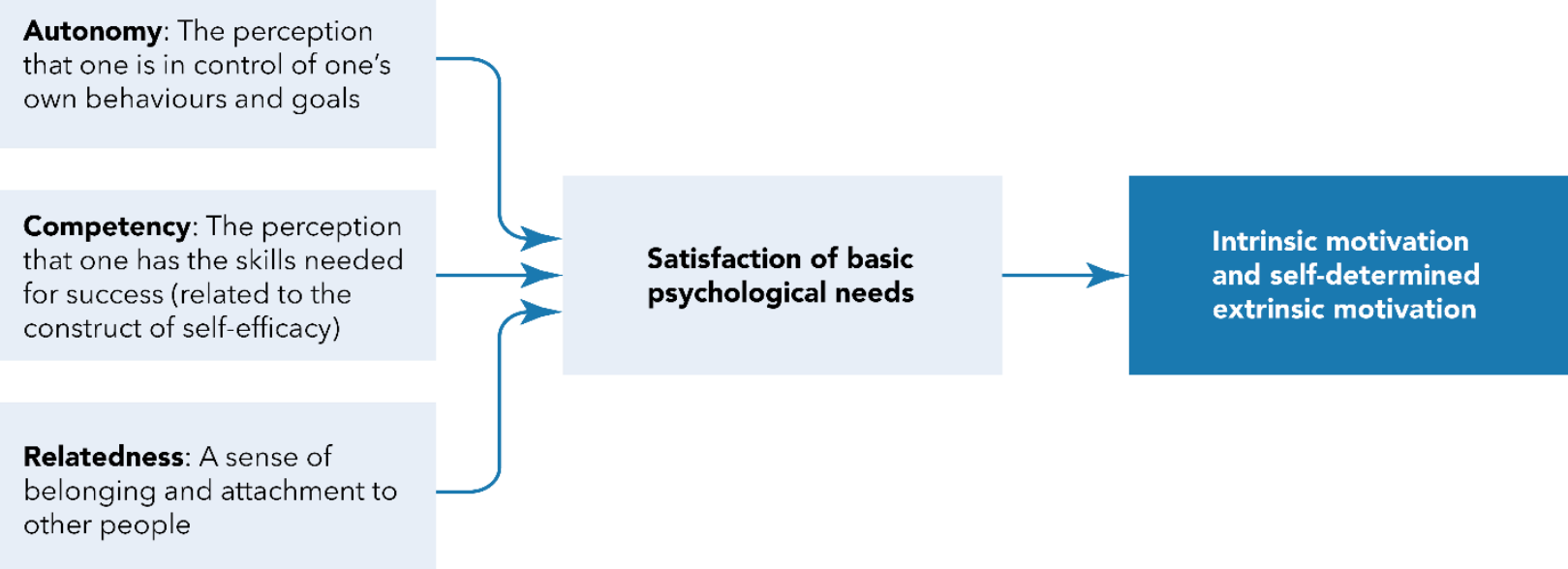

Illustration 4: Self-Determination Theory. Adapted from Legault, 2017.

Self-determination is defined as the ability of a person to make choices and manage their own life (Ryan \& Deci, 2000). The first key aspect of self-determination theory (SDT) is that autonomous motivation is critical to self-determination; the psychological need for autonomy is a central feature for understanding effective self-regulation and well-being (Moller et al., 2006). The second key aspect of SDT is that the need for growth drives behaviour; to achieve psychological growth, people need to feel a sense of competency, relatedness, and autonomy (Morrison, 2015; Sweet et al., 2012).

Table 1: Qualities of volitional actions and coerced action. Adapted from Moller et al., 2006.

\section{Volitional action}

- Feeling a sense of choice or volition

- Fully endorsing one's own actions

- Action is interesting or personally important

- Enjoying the action and/or valuing the outcome

- Related to intrinsic motivation: doing something because it is interesting, enjoyable, and satisfying
Coerced action

- Acting based on external pressures

- Perceived external locus of causality (actions caused by external forces)

- Associated with poorer psychological wellbeing

- Related to extrinsic motivation: doing something because it is instrumental to an outside consequence 
The self-determination approach to motivation differentiates between volitional and coerced action (see table 1); although one may be highly motivated to perform a coerced action, it does not enhance motivation or self-determination (Morrison, 2015; Moller et al., 2006). When one is motivated by tangible extrinsic rewards (i.e., money), his or her autonomous motivation is often undermined; likewise, a sense of autonomy is diminished when one experiences threats of punishment, deadlines, or goal imposition (Moller et al., 2006; Ryan \& Deci, 2000). Controlling communication styles (those that pressure one into behaviour and dictate how that behaviour should be performed) also undermine autonomous motivation (Moller et al., 2006).

In general, meaningful choice and a lack of controlling rewards/punishments enhance a sense of autonomy; likewise, persuasive messages that provide a meaningful rationale for behaviour and offer opportunities for choice also enhance a sense of autonomy (Moller et al., 2006). Moller et al. (2006) endorse using SDT to help create public messages that are not coercive to enhance the autonomous motivation of the audience, increase the chances of maintained behaviour change, and increase psychological well-being. Autonomy-supportive communications allow the audience to engage in mindful consideration of their choices and behaviours, the quality of the autonomous choices is a direct function of the quality of the information, and resultant changes are more likely to be maintained over time because this approach facilitates autonomous selfregulation (Moller et al., 2006; Sweet et al., 2012).

Self-determination theory may help explain the design development and reported efficacy of a persuasive health campaign. In a study called "Rethink Vape: Development and evaluation of a risk communication campaign to prevent youth E-cigarette use" England et al. (2020) detail the development of a media campaign designed to reduce vaping initiation and promote vaping cessation in teens. The research team used a community-engaged research process to gather input, develop, and evaluate the media campaign using a combination of workgroup, survey, and focus group methods, that included groups of adults, adolescents, and a production company. Interestingly, the preferences for campaign content differed greatly between the adult and teen participants. In fact, "the two favorite campaign concepts among adults - both considered to be edgy visuals warning teens not to be tobacco companies' test dummy or guinea pig - were 
rejected outright by teens in both the TAC [Teen Advisory Council] and focus groups" (England et al., 2020, p. 3).

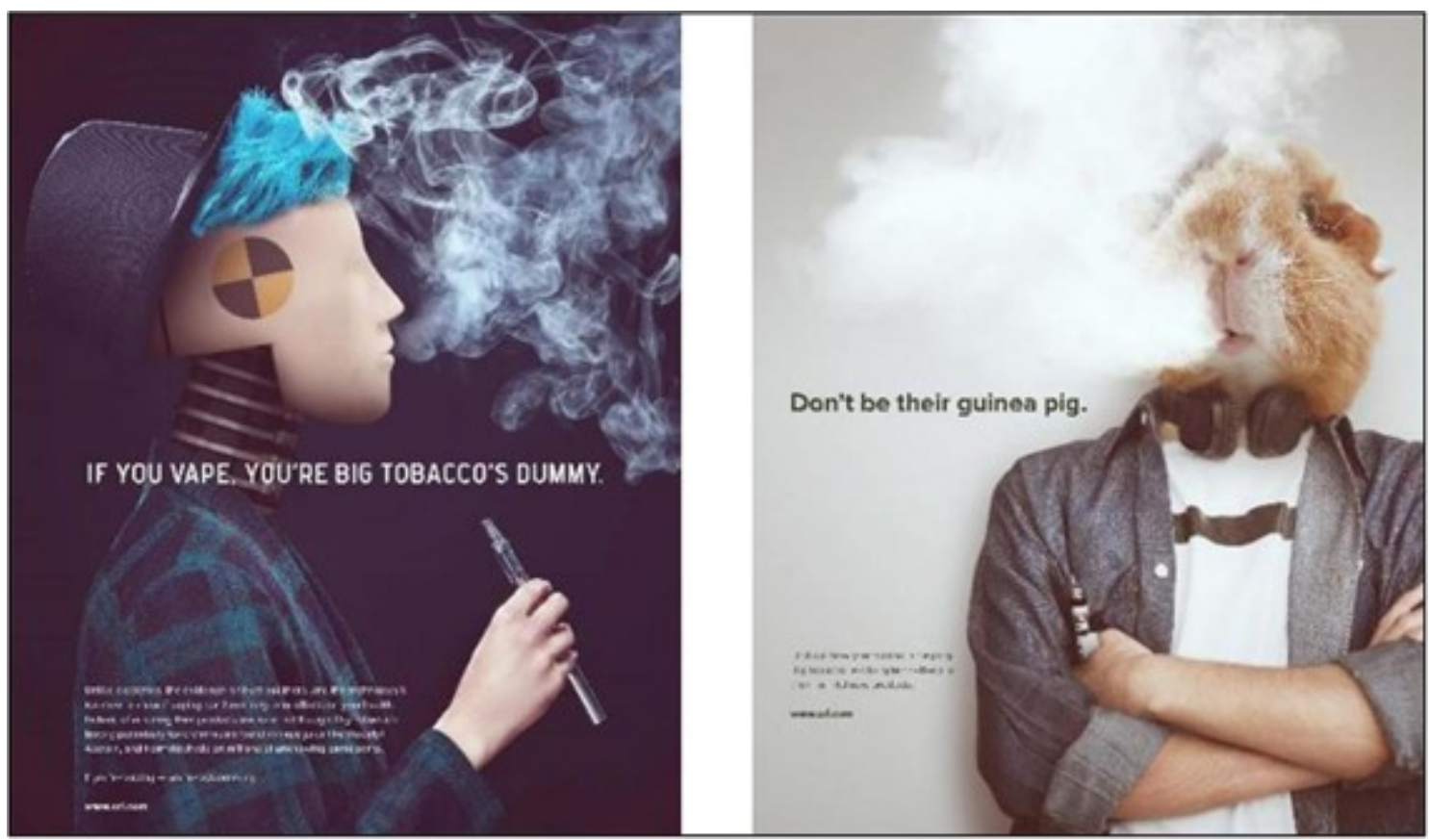

Illustration 5: Example creative concepts for Rethink Vape that were favored by the adults but rejected by teens. From England et al., 2020.

The difference in preference between the adult participants and adolescent participants may be due to the principles in self-determination theory; the concepts preferred by the adult participants seem to use a form of controlling/coercive communication. Moller et al. said this about the use of coercive communication in public health campaigns about substance use aimed at adolescents (2006, p. 109):

Policies that are aimed at preventing the use of cigarettes, alcohol, or illegal drugs among adolescents frequently present information that is explicitly intended to shock and scare. The underlying assumption behind this approach is that youths would not make thoughtful and healthy decisions if they were not manipulated to do so. However, self-determination theory maintains that, indeed, people (including teens) have the capacity to make quality choices for 
themselves and are likely to do so if they are provided with information that is evidence based and relevant.

The concepts that were preferred by the adolescent participants had a larger emphasis on communicating information, including descriptions of scientific findings regarding the chemical content of vape juice, the dangers of vaping, and parallels between marketing strategies of vape manufacturers and Big Tobacco companies.

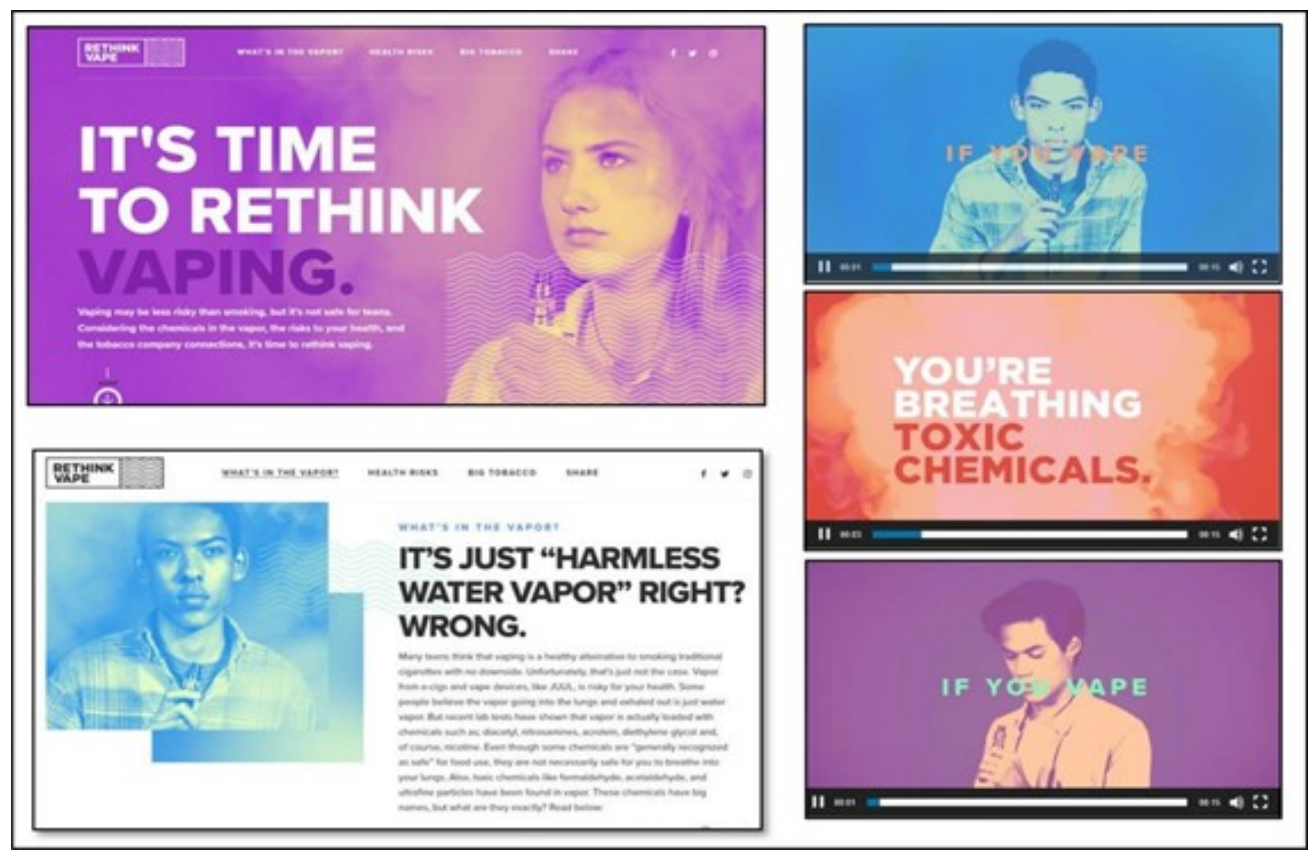

Illustration 6: : Selected still images of final Rethink Vape campaign assets, including microsite and videos. From England et al., 2020.

A controlled study showed that the Rethink Vape advertisements showed significant effects in increasing knowledge, perceptions of risk, susceptibility, and anti-vape intentions in teen audiences. The campaign was then launched locally and exceeded the industry standards for click through rates on social media placements (England et al., 2020). Long term results are not yet reported, but because the advertisements support autonomous choice and allow the audience to engage in mindful consideration of their choices, any resultant attitude and behaviour changes (such as vaping cessation and anti-vape intentions) may be more likely to be maintained over time (Moller et al., 2006; Sweet et al., 2012). 
Transtheoretical Model/State of Change Model: This model of behaviour suggests that changing health behaviour is a process that involves different stages: pre-contemplation (not intending to take action), contemplation (beginning to realize their behaviour is problematic), preparation/determination (getting ready to take action), action (making overt positive changes to health behaviour), maintenance (sustaining action and preventing relapse), and termination (having no temptations to return to old unhealthy behaviours).

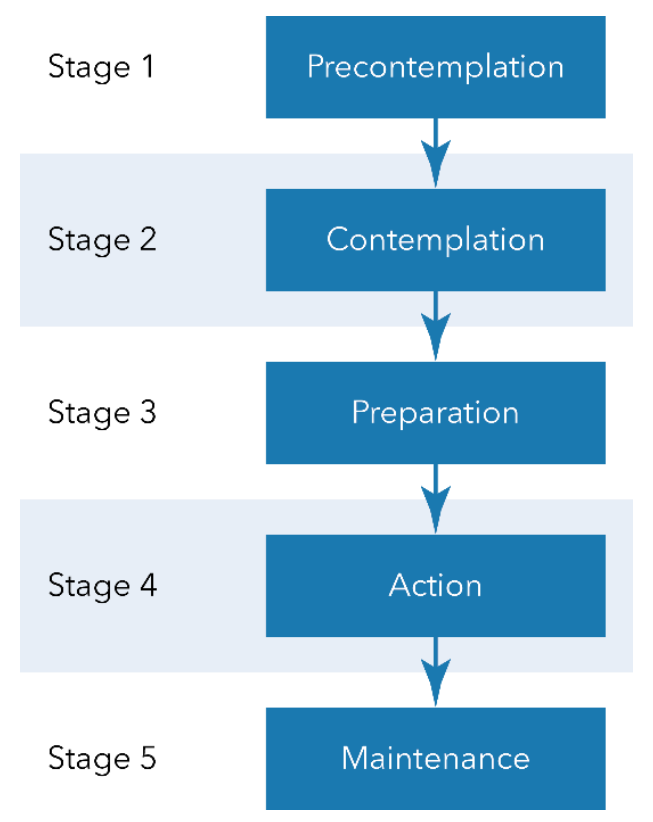

Illustration 7: Transtheoretical Model of Behaviour. Adapted from Al Rawahi et al., 2020.

To implement this model, the persuader should adapt an intervention strategy to the persuadee's state of change (Prochaska \& Velicer, 1997; op den Akker et al., 2016). In a review of the use of models and theories in social marketing health interventions, the transtheoretical model was used most often (Luca \& Suggs, 2012). This model has been used to develop public health campaigns to target groups in specific states of change, to tailor the information in the message to an audience in a specific state of change (i.e., give information of the benefits of smoking cessation to those in the contemplation and preparation stages, or give information on services that can help facilitate behaviours in the actions stages) (Luca \& Suggs, 2012; De Gruchy \& Coppel, 2008). 
Information-Motivation-Behavioural Skills Model: The IMB model was developed to describe the psychological determinants of behaviours that either impair or improve health (Fisher et al., 2003). According to this model, health-promoting behaviour is supported by being well informed about the behaviour, highly motivated to perform the behaviour (practically or socially), and sufficiently skilled to perform the behaviour. For this model, health behaviour information encompasses facts or relevant heuristics about health; motivation constitutes personal attitudes as well as social motivation, and behavioural skills encompasses both abilities and sense of self-efficacy (Fisher et al., 2003). Health promoting messages can target any or all these three aspects (Klonoff, 2019). The effects of health promoting information and health behaviour motivation are the application of behavioural skills, enacted to initiate and maintain health behaviour (see Illustration 8). This model can also be used to identify patient-specific barriers to treatment adherence (Klonoff, 2019).

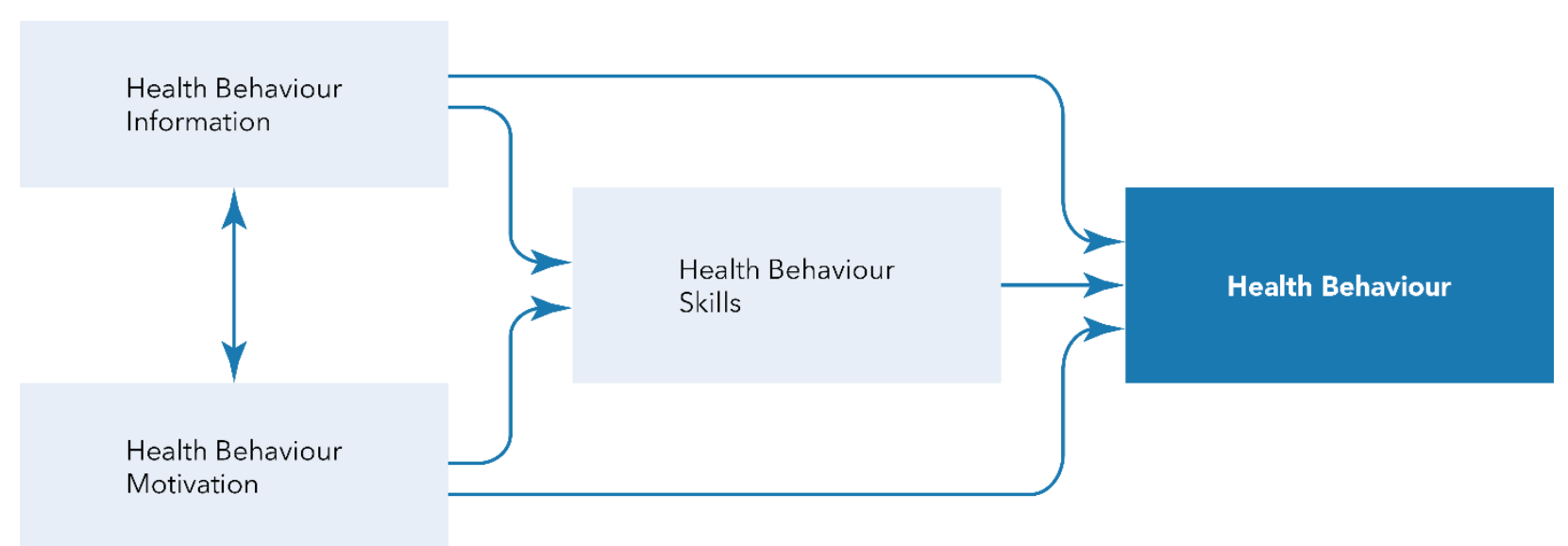

Illustration 8: Information-motivation-behavioural skills model. Adapted from Fisher et al., 2003.

The IMB model was used to help develop a social marketing program designed to reduce the rate of chlamydia infections in Yukon youth (Luca \& Suggs, 2012; Wackett, 1998). The researchers used the IMB model to determine the goals, design, and execution of the campaign to increase awareness about chlamydia. The campaign emphasized a few short (1-2 sentences long), focused, clear messages and gave guidance on action. The information given was designed to be understandable and pertinent to the target audience (teens and young adults). For the motivation aspect, the messages were designed to foster positive attitudes towards STD testing and safer sex. In terms of the behaviour skills aspect, the health information was intended to be readily 
translatable into behaviours that could reduce the probability of infection. The campaign materials were evaluated with focus groups consisting of members of the target audience. The effectiveness of the campaign was evaluated with pre- and post-campaign surveys; there was a significant increase in post-campaign responses indicating knowledge and awareness about chlamydia (Wackett, 1998).

Fogg Behavioural Model: This is a persuasive design model; there is a large overlap between behavioural models and persuasive design models; both are concerned with behaviour, but the topics are approached in different ways by different disciplines. This model includes two elements of the IMB model: motivation and behavioural skills/ability. Instead of the third element of the IMB model, information, this model includes the element of a trigger or prompt (Fogg, 2009). According to the FBM, these three factors combined (motivation, ability, and a timely prompt) will result in a behavioural response. For the behaviour to occur, people must have some level of both motivation and ability; therefore, a successful intervention will boost either motivation or ability (Fogg, 2009).

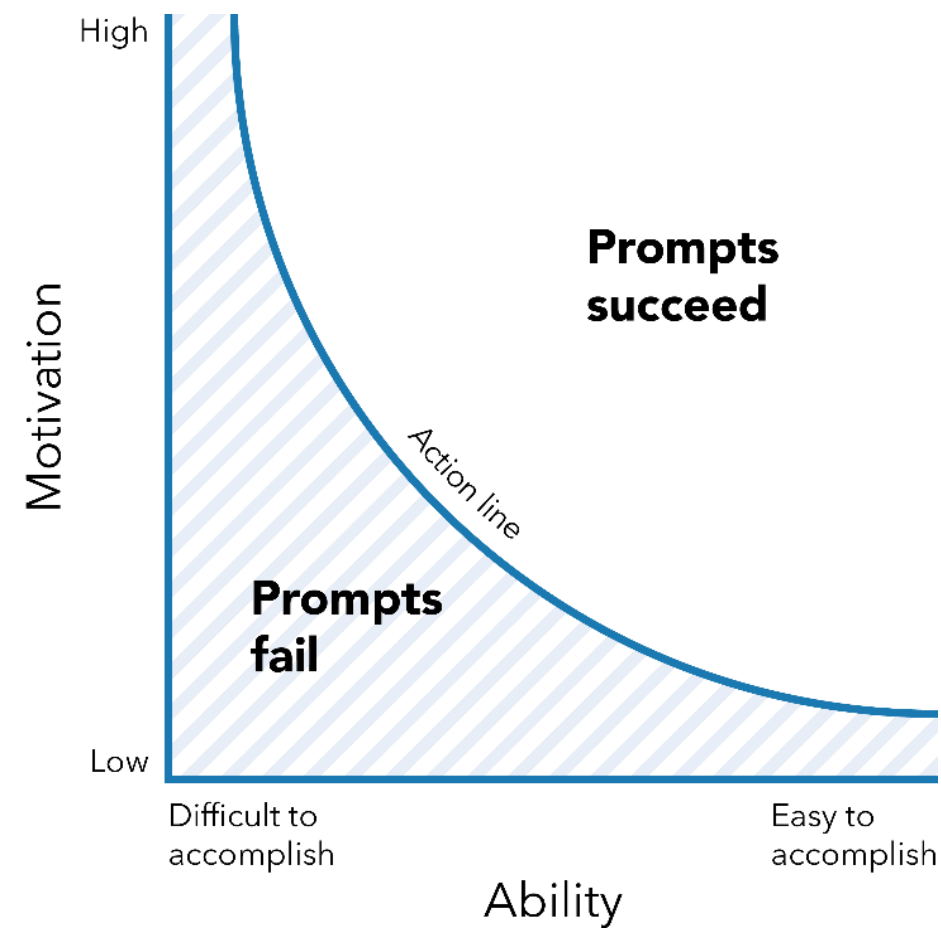

Illustration 9: Fogg Behaviour Model. From Fogg, 2009. 
This model identifies three main elements of motivation: pleasure/pain, hope/fear, and social acceptance/social rejection. Appropriate application of which core motivator is used must be determined through consideration by the designer (there is no one motivator that fits all scenarios) (Fogg, 2009).

In terms of ability, this model assumes that people are fundamentally lazy, and therefore will resist learning new skills because it requires effort. Therefore, to increase the likelihood of behaviour enactment, the motivation of the audience must be high, or the behaviour must be made simpler to perform. Major elements of simplicity include time, money, physical effort, cognitive load, social deviance, and non-routine. Additionally, what is simple for one person is not always simple for another; each person has a different simplicity "profile", which is a function of that person's scarcest resource at the moment a behaviour is triggered (Fogg, 2009).

Additionally, this model posits that successful triggers have three characteristics; they are noticeable, associated with the target behaviour, and timed appropriately. The model also defines three types of triggers: sparks (motivate behaviour), facilitators (make the behaviour easier to perform), and signals (reminders). Fogg suggests that users will be most tolerant of signals and facilitators; sparks may be annoying because they will seek to motivate the user to do something they did not intend to do (2009).

In summary, the following recommendations for creating a health promotion campaign can be derived from these models and principles. The campaign messages should:

1. Be as relevant as possible to their target audience

2. Inform the audience about the behaviours in question and rationales for behaviour

3. Give the audience concrete steps they can take towards modifying their behaviours

4. Encourage the audience to perform wanted behaviours

5. Use communication styles that support autonomy

6. Assure the audience that they can modify their own behaviours

7. Prompt the audience to increase their capacity to perform the behaviours through practice or by referring them to services that can facilitate their behaviour change. 


\subsubsection{Persuasive Health Campaigns}

Persuasive health promotion campaigns, such as the Rethink Vape campaign discussed in section 2.4.4 can be considered a form of social marketing, an enterprise that uses commercial marketing techniques to achieve social good (French et al., 2010). Social marketing has been widely used to promote public health initiatives, and has also been used to promote disaster preparedness, conservation, financial literacy, and more (Lefebvre, 2013; Wallen \& Daut, 2018). This approach combines social science and social policy with commercial and public sector marketing approaches and aims to influence the wider culture as well as individual behaviour (French et al., 2010).

According to Jansen (2017), most health behaviours that people perform are automatic and unconscious, driven by habit, attitudes, and situational limitations. Convincing people to change their health behaviours is difficult, and messages aimed at changing one's behaviour can be rejected due to being difficult to understand, irrelevant, boring, annoying, or unconvincing. Another issue is that individuals tend to resist pressure for change, as this may be perceived as a threat to personal freedom and therefore conjure high levels of skepticism and rejection (Jansen, 2017). However, health promotion campaigns may be able to positively impact large numbers of people. According to Wakefield et al., "Mass media campaigns can directly and indirectly produce positive changes or prevent negative changes in health-related behaviours across large populations" (2010).

There are many aspects that affect a health promotion campaign's rate of success. Besides the complex nature of health behaviour, how a health promoting message is conveyed is important to its success. There are also external factors that may affect the impact of health promoting messages. For example, a crucial element in persuading those motivated by health promotion messages to act is the availability of key services that can facilitate these behaviours (Wakefield et al., 2010). Another aspect is the landscape of modern media, which will be discussed below.

In the 1970 s, the average person in the United States reportedly saw around 500 advertisements per day; that figure grew to approximately 5000 in 2019 (Holmes \& Follow, 2019). The average person is also bombarded daily by information, funneled to them through computers, mobile 
devices, radio, television, and print media. In fact, on average one is exposed to the equivalent of 174 newspapers worth of information per day (Clark, 2020; Smiciklas, 2012). Because people are exposed to so many daily messages, achieving adequate exposure to an individual message is made more difficult due to the low signal to noise ratio, and fierce competition for the audience's attention (Wakefield et al., 2010; Lidwell et al., 2010; McCoy, 2000; Smiciklas, 2012).

This information overload can distract a person from his or her tasks, interfere with thought processes, inhibit logic, and create action paralysis (Clark, 2020). This presents two problems in terms of persuading a user to change their behaviour. Firstly, it makes decisions more difficult (Clark, 2020), which may influence the user to default to automatic behaviours rather than using executive function to make healthier choices. Secondly, it may drown out the message in a sea of information (Murchie \& Diomede, 2020; Chang, 2011).

Also, health promoting messages are often contradicted by advertising messages, such as those for unhealthy food and alcohol. These messages may be much more attractive in the eyes of the recipient, and this, coupled with the power of social norms and the drive of addiction hinder the positive outcomes of public health interventions (Jansen, 2017; Wakefield et al., 2010).

Another aspect to consider is how to frame a message, whether to discuss the positive consequences of the wanted behaviours or the negative consequences of the unwanted behaviours. According to Block and Keller (1995), a message that has lower perceived efficacy, meaning that the audience is not convinced that it will be effective, will typically be processed with a high-involvement style (i.e., taking the central route in the ELM). For these types of messages, negative framing of the issue is more effective in motivating audiences to act. The examples given for behaviours that are perceived as highly efficacious are immunizations for disease preventions and nicotine patches for smoking cessation; the examples for less efficacious behaviours are stress reduction techniques and diet modifications (Block \& Keller, 1995).

Additionally, how explicit and forceful the message is may affect its reception. Subtle or hidden messages may not be noticed, while messages that preach or lecture may be experienced as annoying and resisted (Jansen, 2017). It is therefore crucial to plan and test campaign content and format (Wakefield et al., 2010). 
From the issues discussed above, several factors can be derived to evaluate the potential success in communicating a health promoting message.

Table 2: Factors for evaluating a health promoting message.

\begin{tabular}{|c|c|}
\hline Element & Evaluating factors \\
\hline Message & $\begin{array}{l}\text { - How sound is the message's argument? } \\
\text { - Does the message evoke a persuasive emotional response? } \\
\text { - How forceful is the message? Will it be noticed by the recipient? Will } \\
\text { it be rejected as a threat to personal freedom? } \\
\text { - Will the message be presented at a time during which the message } \\
\text { recipient is receptive? }\end{array}$ \\
\hline Source & $\begin{array}{l}\text { - Does the message come from an expert, trustworthy, credible source? } \\
\text { - Does the message come from a source that is likeable or similar to the } \\
\text { recipient? } \\
\text { - Does the message come from a powerful source? A role model? }\end{array}$ \\
\hline Channel & $\begin{array}{l}\text { - Through what channel will the message be best received? } \\
\text { - How can the message be presented to be noticed amid a barrage of } \\
\text { messages? } \\
\text { - Through which modalities will the message be best received? }\end{array}$ \\
\hline Recipient & $\begin{array}{l}\text { - What are the recipient's beliefs and social norms? } \\
\text { intelligence? Self-esteem? } \\
\text { - What state of change is the recipient likely to be at? How can the } \\
\text { message be tailored to their state of change? } \\
\text { - How can the message be tailored to maximize the recipient's } \\
\text { motivation to change? } \\
\text { How can the message be tailored to the recipient's needs? Their } \\
\text { personality? }\end{array}$ \\
\hline $\begin{array}{l}\text { External } \\
\text { factors }\end{array}$ & $\begin{array}{l}\text { - Can the message connect the recipient to services that can help them } \\
\text { in modifying their health behaviours? } \\
\text { - Are the recipients receiving messages that promote unhealthy } \\
\text { behaviours? How can these messages be contradicted? }\end{array}$ \\
\hline
\end{tabular}




\subsubsection{Human-Centered Design for Persuasive Health Campaigns}

Human-centered design (HCD) is an approach that puts people at the center of the design process, with the assumption that the people facing a problem day after day are the people who hold the insights to solve that problem (IDEO, 2015; Biroscak, 2018). The HCD approach is suited to address problems that are highly complex, grounded in context, and involve many different systems and stakeholders (Biroscak, 2018; Wallen \& Daut, 2018). The process involves three phases: inspiration, ideation, and implementation (IDEO, 2015; Biroscak, 2018).

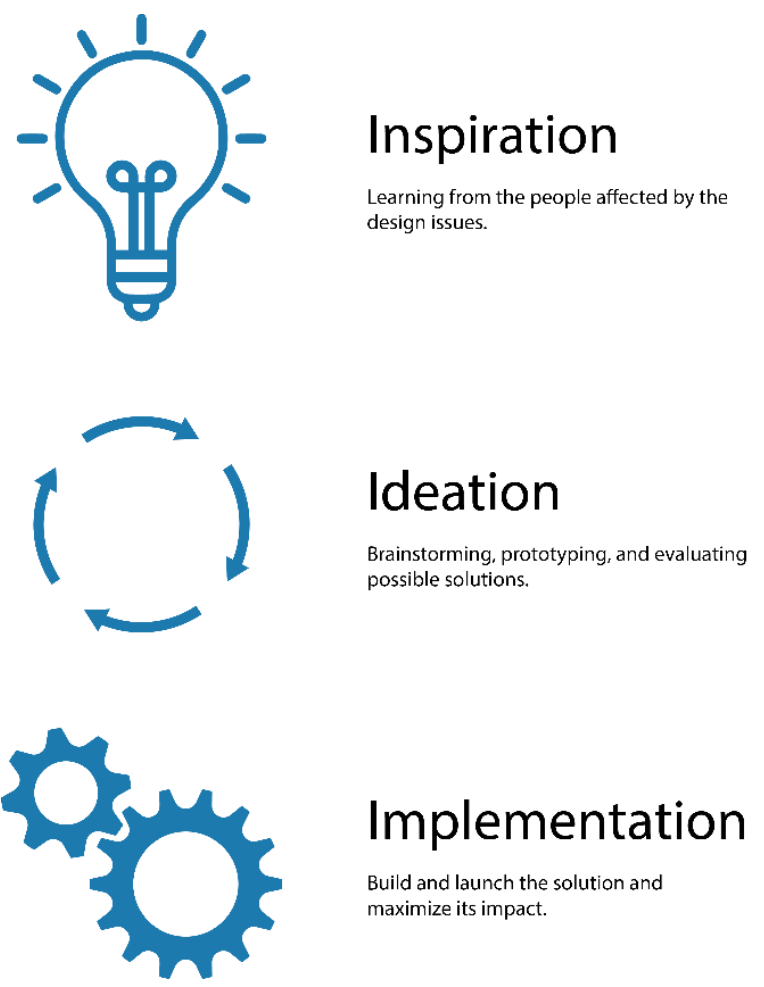

Illustration 10: Human-centered design framework. Adapted from IDEO, 2015; Biroscak, 2018.

When applied in a social marketing context, the aim of the HCD framework is to work with those affected by an issue to develop and implement a context-specific behaviour change strategy (IDEO 2015; Wallen \& Daut, 2018). Human centered design is an appropriate approach for developing behaviour change strategies because according to Wallen and Daut (2018), HCD has an "explicit focus on behaviour, viewing issues through a behavioural lens" (2018, p. 67). HCD can help those in social marketing transform information into action (Biroscak, 2018). 
Wallen and Daut (2018) propose a framework for applying human-centered design principles to the development of a behaviour change strategy (see Illustration 11).

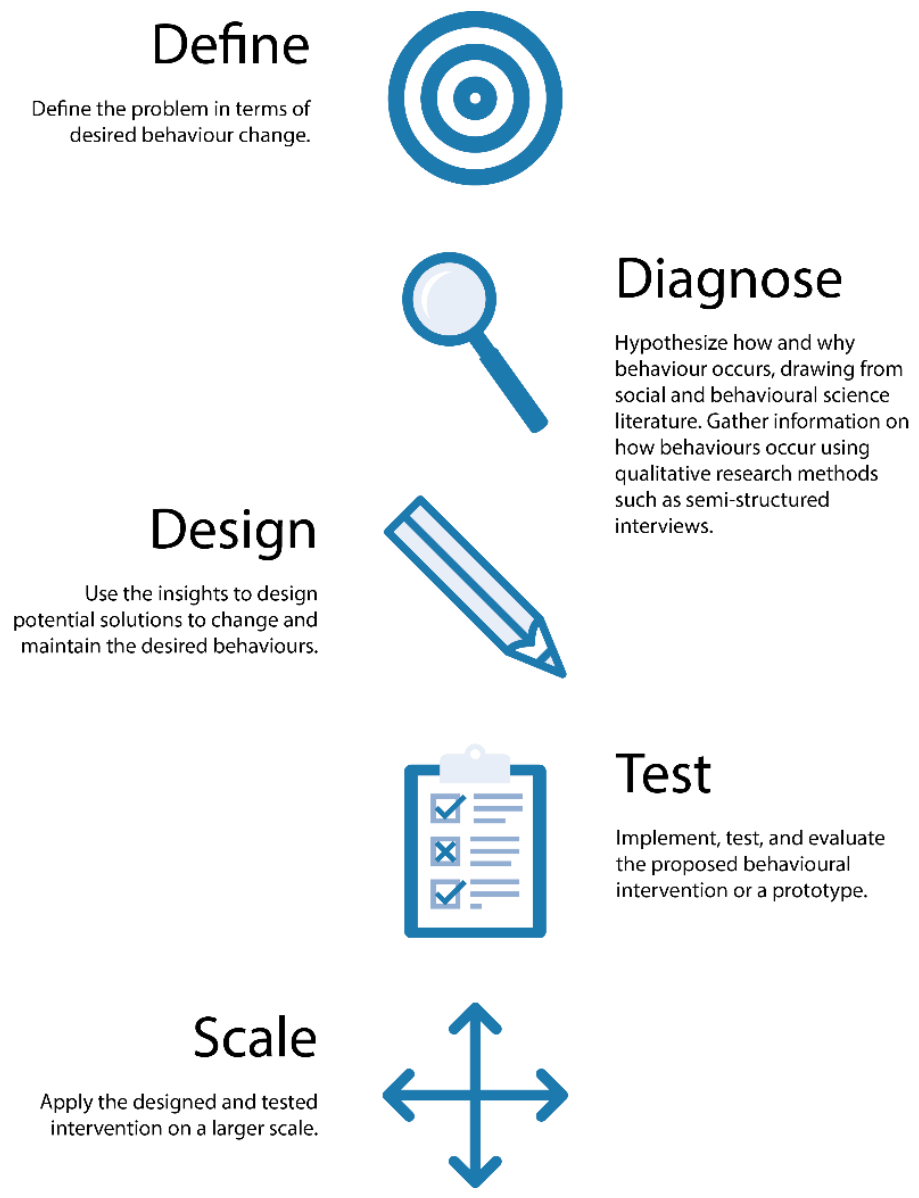

Illustration 11: Human-centered design framework for behavioural interventions. Adapted from Wallen \& Daut, 2018.

An example of a successful persuasive media campaign that uses a human-centered design process is a study called "Ambulances are for emergencies: shifting attitudes through a researchinformed behaviour change campaign”. In this study, Borg et al. (2019) developed a media campaign to influence the public to reduce the use of ambulances for non-emergencies (to increase the chances that an ambulance is available in the case of a life-threatening emergency). Although not explicitly stated by the researchers, this campaign follows the stages of define, diagnose, design, and test; the solution that the researchers developed has not yet been implemented in any different contexts. 
Define: The targeted behaviour was non-emergency calls to emergency services.

Diagnose: Along with a literature review they conducted semi-structured interviews with members of the public, targeting misusers of emergency services, and people working in ambulance services or dispatch. According to the researchers, the use of a semi-structured interview "adds a critical dimension to the academic literature review" as the literature review is concerned with evidence and interviews can address issues in practice and implementation (Borg et al., 2019, p. 2). The researchers used a semi-structured interview format to explore both salient issues as well as emergent themes. The researchers also conducted a "stakeholder dialogue" focus group to expand on the findings.

Develop: Using the formative research as well as behavioural theories, the researchers developed a campaign message called "Will's Story", about the real-life story of a boy whose life was saved due to the availability of emergency services.

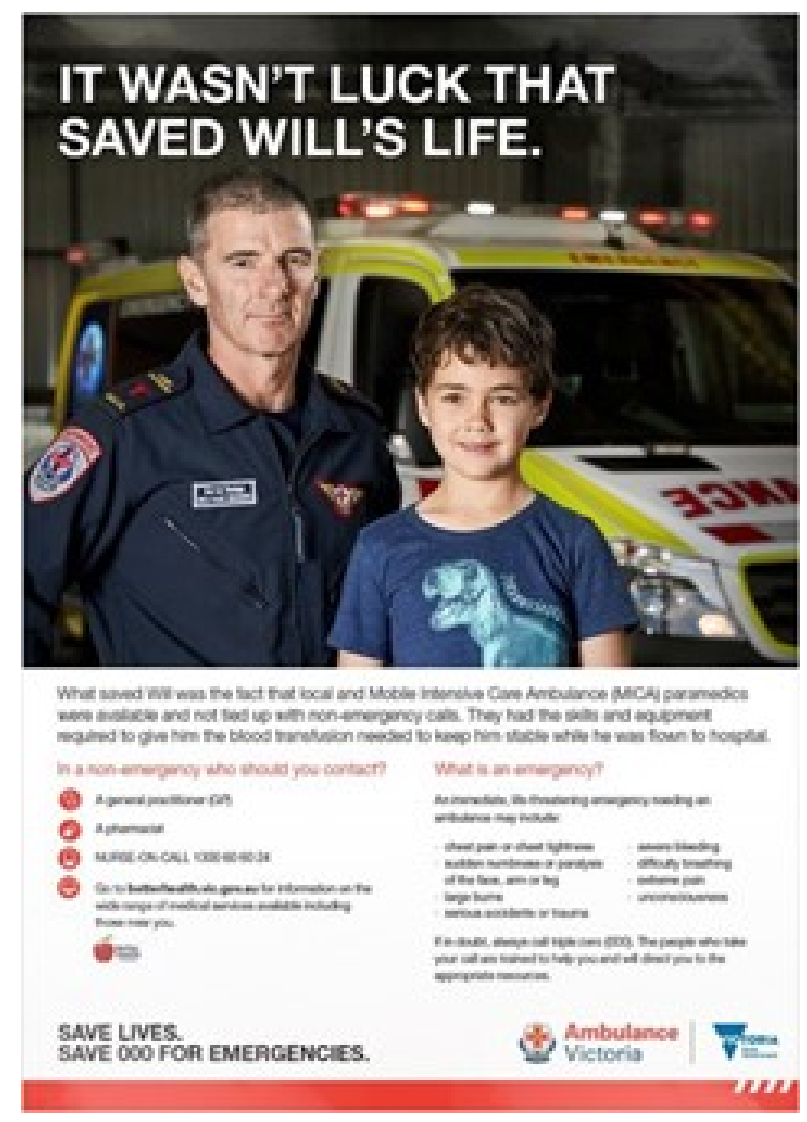

Illustration 12: Campaign poster for "Will's Story", the media campaign developed by Borg et al., 2019. 
Test: The campaign message was deployed as a television advertisement. After deployment, the researchers developed a framework to evaluate the campaigns effectiveness in capturing attention/awareness, changing attitudes, and increasing knowledge. There was a significant increase in campaign awareness, service knowledge, and the attitude that "ambulances are for emergencies" between the pre- and post-intervention conditions.

By collaborating with people in the target demographic, Borg et al. (2019) were able to create a campaign that was compelling for their audience. Similarly, because England et al. (2020) included their target demographic in the development process of their Rethink Vape campaign, they avoided using messaging that seemed confusing and mean-spirited to their audience.

\subsection{Visual Communication}

Besides the written content, health promoting messages may also use visual elements to help convey the message. As stated above according to the ELM, if an audience member pays attention to the information in a message, they are taking the central route of persuasion. The visual presentation of the message is a set of peripheral cues and becomes relevant if the viewer takes the peripheral route of persuasion. However, as seen in the 2009 study on the effect of visual presentation in online advertising, peripheral cues can influence persuasion even if the central route of persuasion is used (SanJosé-Cabezudo et al.). And in fact, messages that are designed to be evaluated on peripheral cues (by not presenting an informed argument) can be more persuasive than those that rely on elaborative processing in some cases (Glassman et al., 2018). Therefore, the presentation of the visual elements of graphic messages is important to their overall persuasiveness.

Vision is a huge part of the human brain, with $50 \%$ dedicated directly or indirectly to visual functions, so using visuals to communicate makes it easier to relate and connect to the message (Smiciklas, 2012). However, it is not enough to create visual content, it must be visually interesting to be effective in making an impact and communicating a message (Lankow et al., 2012). Visual interest is created with an optimum level of visual complexity (Kocaoğlu \& Olguntürk, 2018). Some dimensions of complexity are intelligibility, contrast, organization, number of elements, variety of elements, symmetry, and variety of colors (Kocaoğlu \& 
Olguntürk, 2018; Madan et al., 2018). Visual compositions that are too simple (have a low level of visual complexity) can seem boring. However, visual compositions that are too complex can seem chaotic and "unreadable" (Kocaoğlu \& Olguntürk, 2018). Additionally, visually interesting compositions feature organized complexity; this is preferred to disorganized complexity or simplicity. Visual interest can be added to a message by adding visual elements that are organized and complex, representative iconography, and/or illustrative metaphor. (Kocaoğlu \& Olguntürk, 2018; Lankow et al., 2012). Visual interest can contribute by catching attention, increasing engagement, stimulating positive emotion, or creating a compelling narrative (Lankow et al., 2012).

Additionally, the graphic design (how text and visual elements are laid out and combined) is also crucially important, as this affects the overall look and feel of the message (peripheral cues) as well as the ease of comprehension. Graphic design can aid in communicating an idea and persuading a user to accept that idea, due to its influence on information processing, appeal, attention, and engagement, and emotion stimulation, which will be discussed below (Barnard, 2013; Murchie \& Diomede, 2020).

\subsubsection{Accessibility}

An important part of visual communication is ensuring that the message is accessible and understandable by as many people as possible. According to the Association of Registered Graphic Designers of Ontario, "all design by definition promotes accessibility" (2010, p. 1), as graphic design principles attempt to make messages more understandable. One of the ways that information can be made more understandable is to make it easier to process cognitively.

Information that is well laid-out requires less cognitive load for processing, making it easier to absorb (Cook, 2006; Murchie \& Diomede, 2020). Cognitive load refers to the amount of working memory needed to process information (Cooper, 2009). To reduce cognitive load, there are many strategies that can be applied. Chunking is a layout strategy that involves breaking up information into digestible chunks to minimize fatigue in processing the information (Lidwell et al., 2010; Murchie \& Diomede, 2020). Also important are the relationships between pieces of information and a hierarchical structure. Arranging related information together and creating a 
hierarchy in the information organization can assist the user in navigating information, guiding them through the "path of least resistance" (Murchie \& Diomede, 2020). Using a hierarchy that creates an explicit logical order can also benefit readers of varying ability (Association of Registered Graphic Designers of Ontario, 2010).
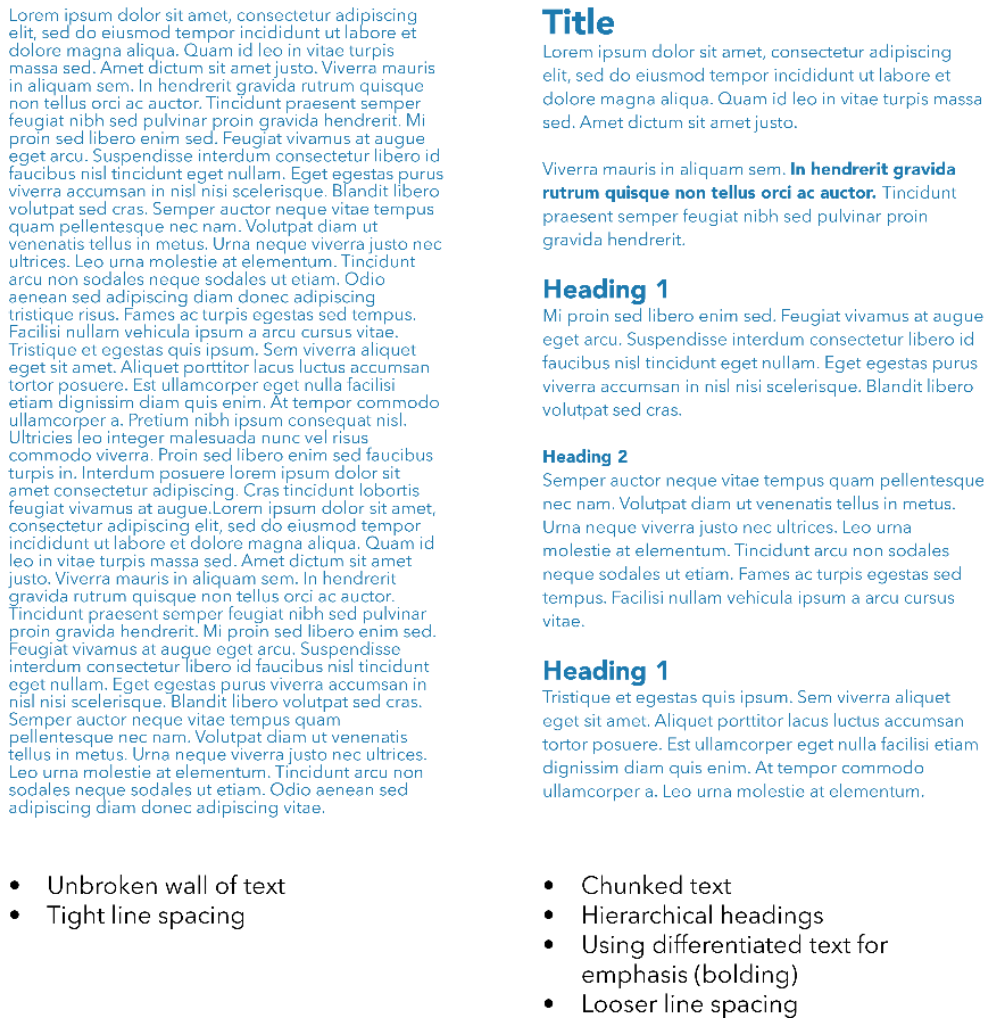

- Chunked text

- Hierarchical headings

- Using differentiated text for emphasis (bolding)

- Looser line spacing

Illustration 13: Example of how to use chunking, hierarchy, emphasis, and loose line spacing to decrease the cognitive load navigate through text.

Besides spatial organization, text font and spacing contributes to how the information is organized. Font weight and size contribute to information hierarchy, and key information presented in noticeably different text can be recalled more easily than common text (a phenomenon called the Von Restorff effect) (Lidwell et al., 2010; Murchie \& Diomede, 2020). Additionally, looser line spacing and generous amounts of white space allow for more room for the eye to read, reducing the cognitive load needed to process the information (Murchie \& Diomede, 2020). 
Another way to reduce cognitive load is through simplification. "Visual clutter", or elements of a graphic layout or message that are unnecessary should be stripped away (Davidson, 2017). This relates back to the concept of visual complexity and its relationship with visual interest; the complexity of a composition adds value up until a critical point, at which it begins to take away value (Davidson, 2017; Kocaoğlu \& Olguntürk, 2018).

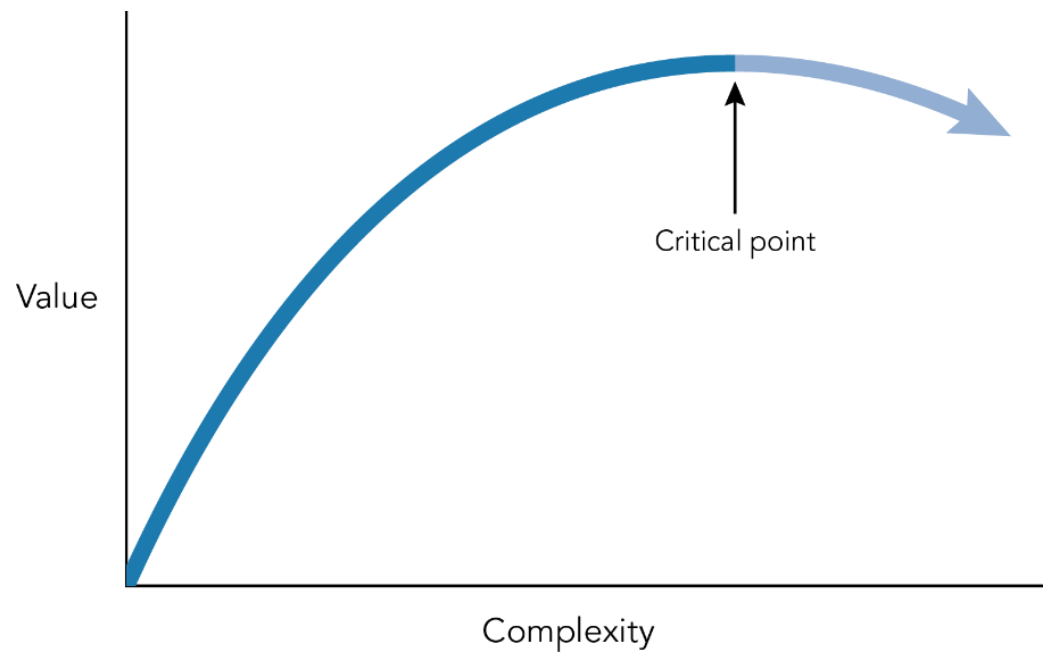

Illustration 14: Simplicity model. Adapted from Davidson, 2017.

Another way the accessibility of visual messages can be improved is by considering the effects of colour, contrast, and font size for those with visual impairments. Perception of colour can be affected by congenital vision problems or the effects of age, injury, or the environment (Association of Registered Graphic Designers of Ontario, 2010). Increased contrast between background and type improves legibility; at least $70 \%$ difference in colour value is desirable (Association of Registered Graphic Designers of Ontario, 2010).

Font choice also affects legibility; a medium font weight is preferable to extra bold or extra light, and a text font with easily identifiable typeforms is preferable to a stylized display font (Association of Registered Graphic Designers of Ontario, 2010). 


\section{Myriad Pro Bauhaus 93 \\ Avenir

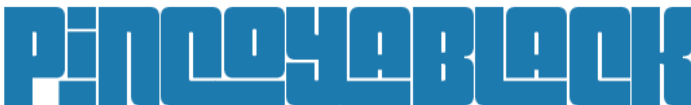 \\ Helvetica \\ Pacifico}

Illustration 15: Examples of text fonts (left) and display fonts (right)

Font should also be large enough to read; the Association of Registered Graphic Designers of Ontario does not specify a point size for font as a standard of accessibility because of the differences between typefaces but emphasizes the importance of keeping the factors that affect legibility in mind when making design decisions about text (2010). Improper kerning and tracking and that is too tight or too loose can also affect readability (Association of Registered Graphic Designers of Ontario, 2010).

\section{No kerning \\ With kerning}
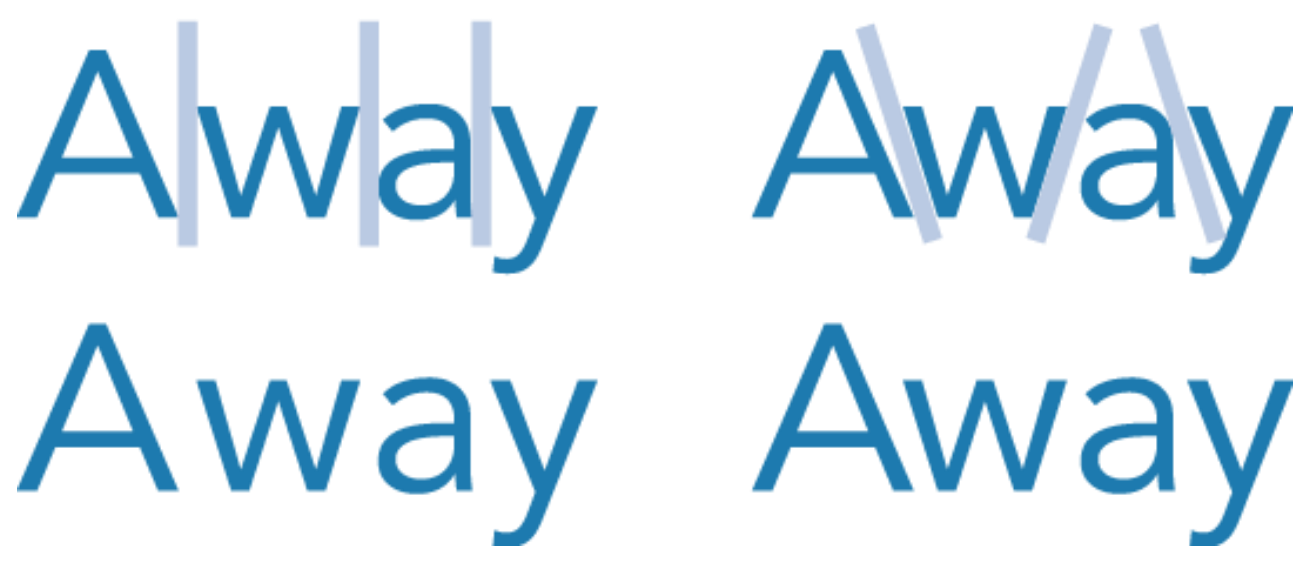

Illustration 16: Example of text with no kerning applied vs kerning applied 


\section{Normal tracking Tight tracking Loose tracking}

Illustration 17: Examples of text with normal tracking, tight tracking, and loose tracking

Columns of text should be neither too narrow (which causes awkward hyphenation) or too wide (which makes it difficult to find the start of the next line) and left justified for easiest reading (Association of Registered Graphic Designers of Ontario, 2010).

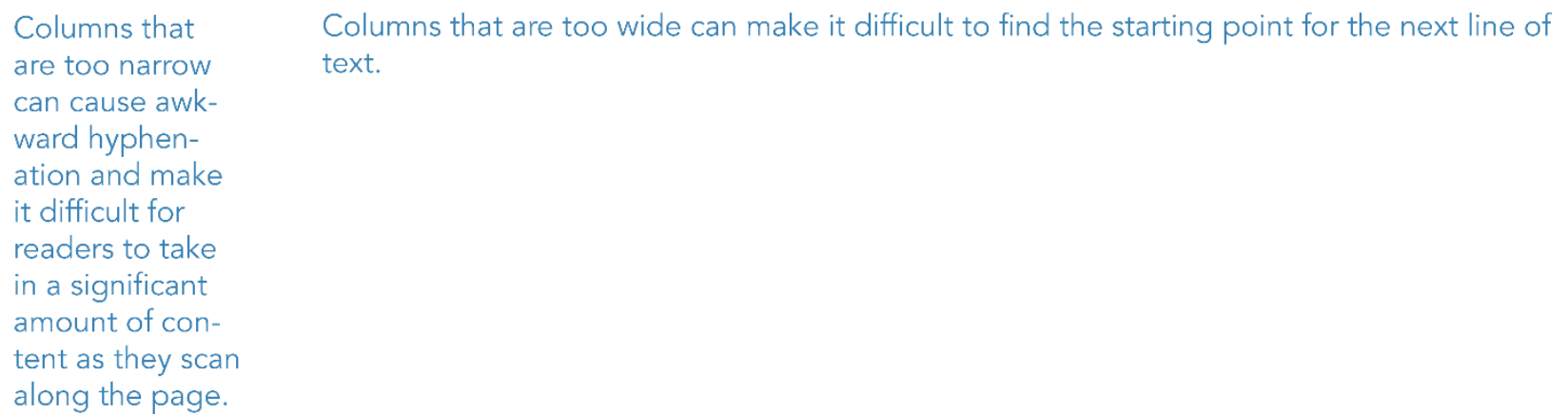

Illustration 18: Examples of narrow and wide columns.

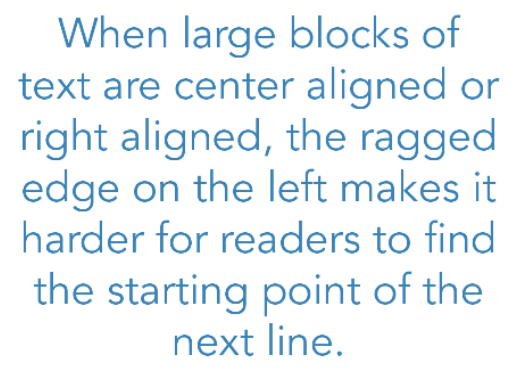

Columns that are justified provide a straight left line that makes it easier for readers to find the start of the next line. However, because both edges of the text are aligned, spacing becomes inconsistent, creating blank spots within the text and negatively affecting reada $b$ i l i $t y$.

Illustration 19: Examples of center aligned and justified columns. 
When visual messages are displayed online, there is another set of accessibility issues to consider. Some users with visual impairments may use screen readers to have the text on a page read out loud to the user or sent to a Braille display (for users who are both blind and deaf). Information that is only displayed in images cannot be read by a screen reader; therefore, any written content displayed in images should also be conveyed in "alt text" (text that is tagged to the image and describes the image content for people using screen readers) (Association of Registered Graphic Designers of Ontario, 2010).

\subsubsection{Attention}

As stated above, the average person today is bombarded by information; this has resulted in the "attention economy", the idea that a person's attention has become a form of currency (Smiciklas, 2012). The human brain is constantly filtering information and ends up discarding 99\% of all the sensory information almost immediately after perceiving it, but if incoming information is novel or unusual it is less likely to be immediately discarded (Smiciklas, 2012). Using visual communication provides the opportunity to present information in a unique and engaging manner.

Compelling visual materials are superior to written communication in drawing attention (Cook, 2006; Murchie \& Diomede, 2020; Seo, 2020). People tend to first see the visual part of the message, and attention to these visual images affect subsequent attitudes and recall (Male, 2019; Seo, 2020; Yan, 2019; Dunlap \& Lowenthal, 2016). This may be explained by the picture superiority effect, which indicates that a picture and appropriate text are easier to recall than words or a picture alone (Lidwell et al., 2010; Murchie \& Diomede, 2020; Seo 2020).

\subsubsection{Engagement}

Lankow et al. state that getting a recipient to commit to engaging with content is the first and potentially most challenging step in conveying a message, and that graphics should look appealing to encourage this engagement (2012). Additionally, McCoy (2000) describes graphic design as a tool that can "seduce" the audience to engage with the material. Engaging visuals can 
immediately attract the audience's attention and entice them to delve deeper into the content (Lankow et al., 2012). The seductive power of appealing graphic design "initiates the entry step in the communications process, promising a reward for the audience's attention." (McCoy, 2000).

\subsubsection{Emotion and Narrative}

Seo (2020) states that public messages that have both written and visual components are more effective at stimulating emotions. Additionally, messages that stimulate positive emotions lead to increased persuasion outcomes and behavioural intentions. According to Lankow et al., messages with emotional appeal can also increase information retention; "Appealing to someone not only aesthetically but also emotionally prompts a deeper connection with the information, which makes them more likely to remember it”(2012 p. 52).

In their book, "Stories that move mountains: Storytelling and visual design for persuasive presentations", Syke et al. (2012) describe visual stories as being a useful way to persuade a user. A visual story gives the user a selected set of information to create a single complete picture designed to draw an audience to a conclusion. The message is reduced "down to the minimum necessary to influence the audience to take an action".

\subsubsection{Infographics}

The popularity of using infographics to convey information has been recently rising (Dunlap \& Lowenthal, 2016). Infographic is short for information graphic, a type of image that combines information and design to concisely communicate messages to an audience. Infographics present information in a quickly digestible format (Smiciklas, 2012). This format succeeds when information needs to immediately engage and inform audiences and be noticed over the vast amount of information encountered day to day. The "graphic" aspect of infographic is critical in this respect. Part of the reason well-designed infographics are effective communication tools is aesthetic; people are attracted to and enjoy looking at interesting and well-designed visuals (Smiciklas, 2012). With good design, the appeal of engaging with data is increased. About the role of aesthetic design in infographic creation, Lankow et al. put it simply, stating, "Design is to data as cheese sauce is to broccoli." (2012, p. 40). 
Although there are several accepted types of infographics, an infographic is simply a message that uses visual cues to convey information; there are no formal requirements that define an infographic (Dunlap \& Lowenthal, 2016). However, there are guidelines that can help match a set of data with an appropriate infographic format.

Lankow et al., define two types of approaches to infographic design, narrative and explorative. They define narrative approaches as illustrative, design-focused, seeking to appeal to viewers with engaging visuals, and seeking to inform and entertain. Applications of narrative approaches to infographic design include publications, blogs, content marketing, sales, and marketing materials. Alternatively, explorative approaches to infographic design are minimalist, include only elements that represent data, and seek to communicate information in the most clear, concise manner. Applications of explorative approaches include academic research, science, business intelligence, data analysis (Lankow et al., 2012). Using a more specific approach, Siricharoen and Siricharoen (2015) define 10 individual types of infographics:

Table 3: Types of Infographics. Adapted from Siricharoen \& Siricharoen, 2015

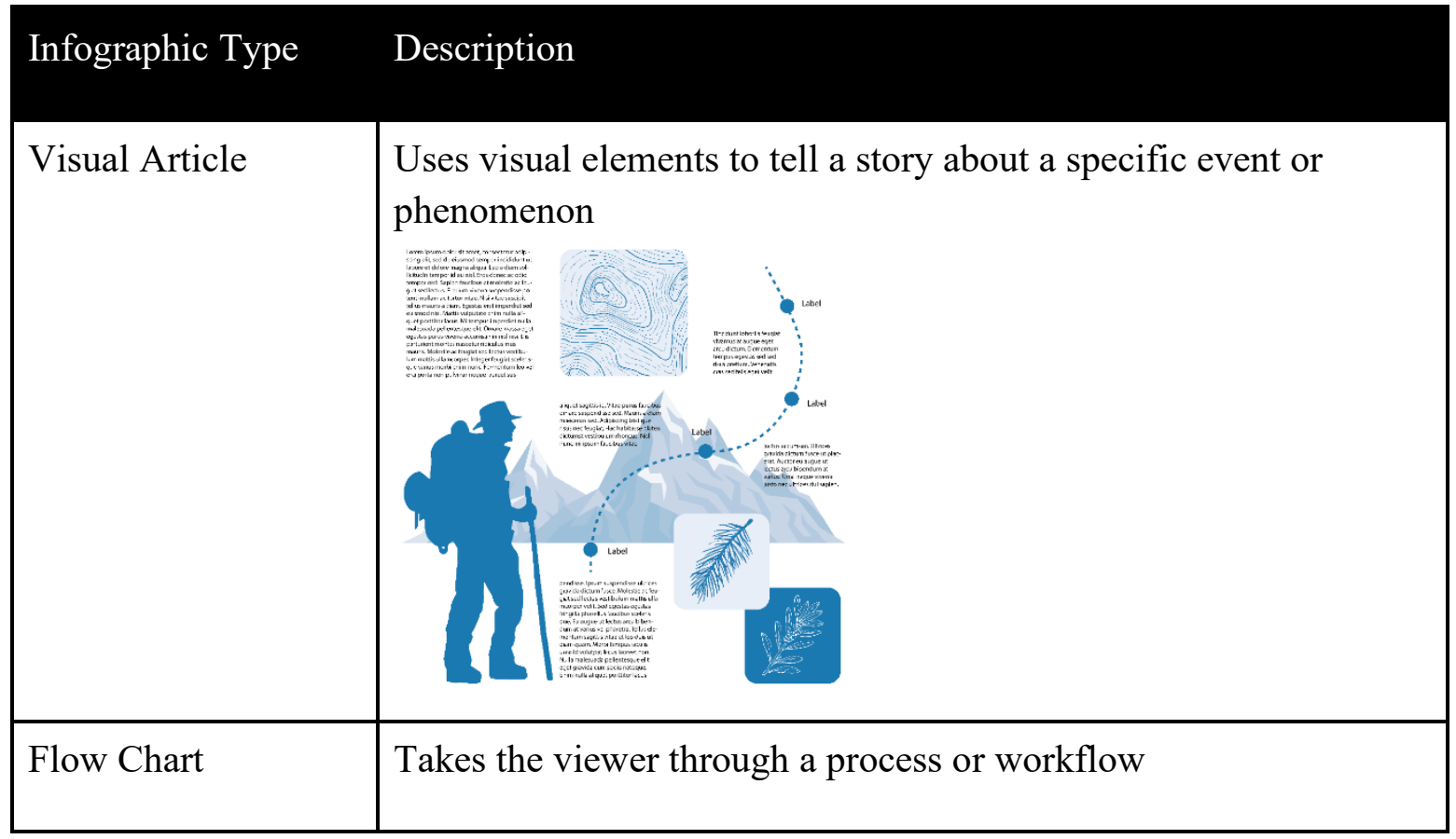




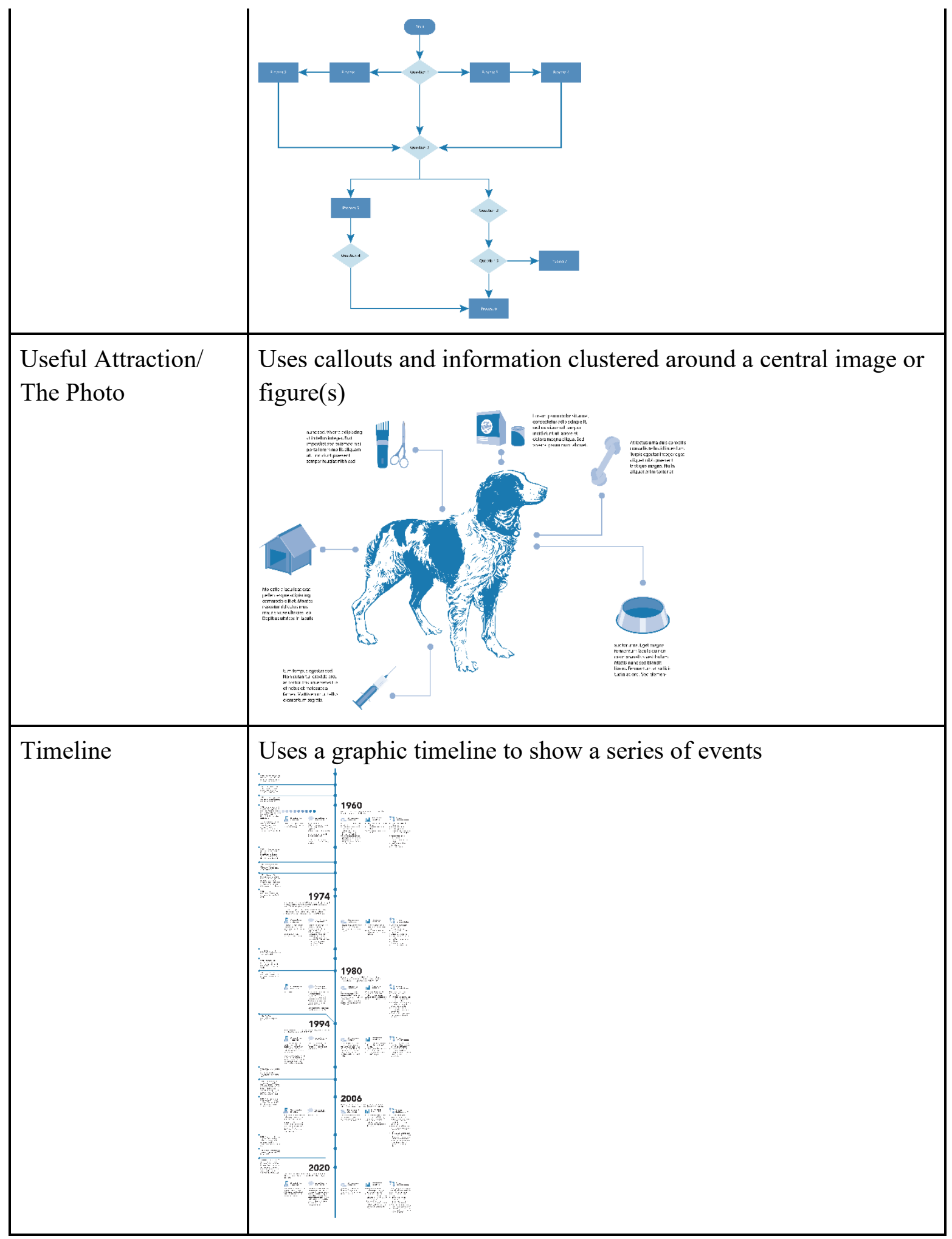




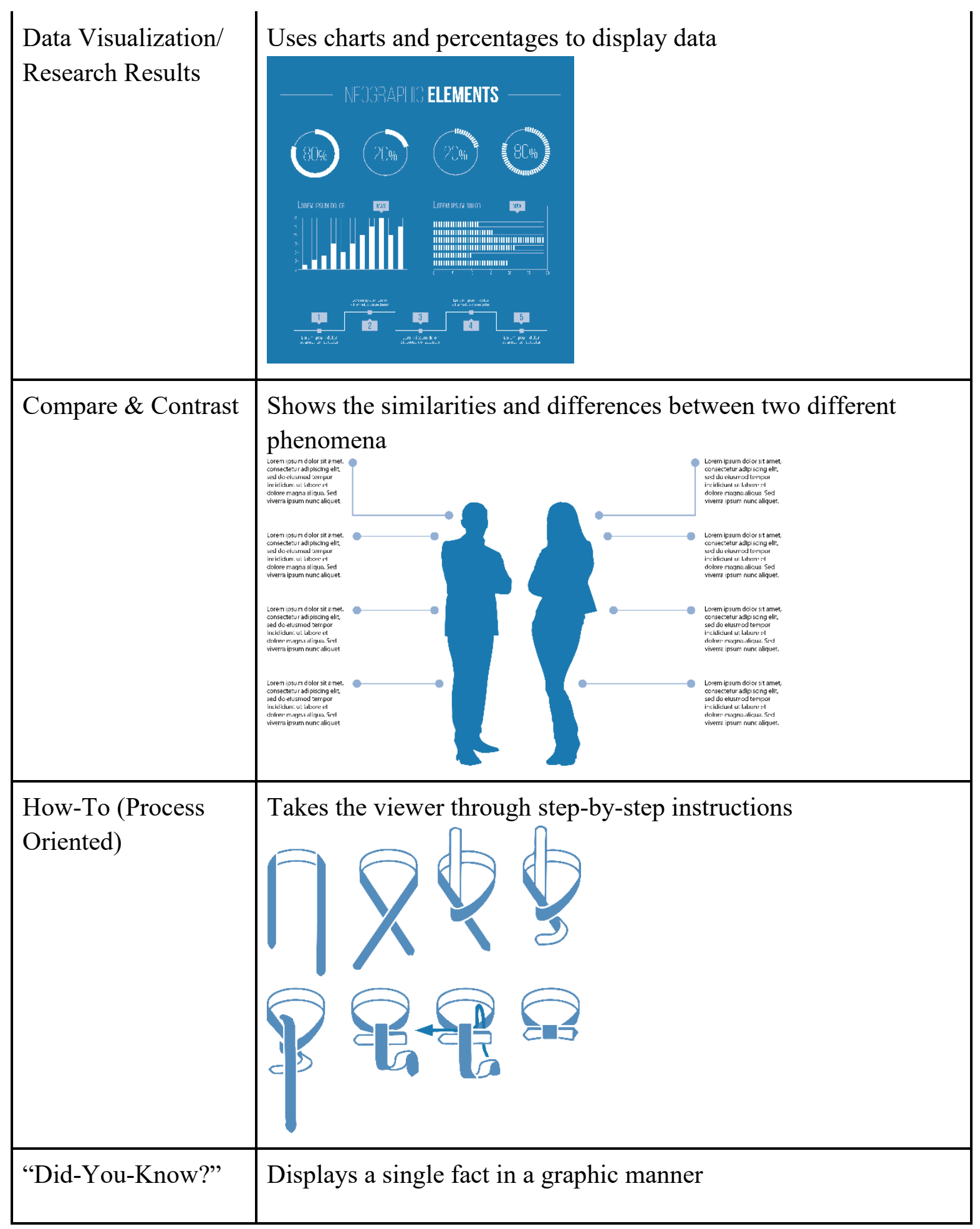




\section{Did you know?}

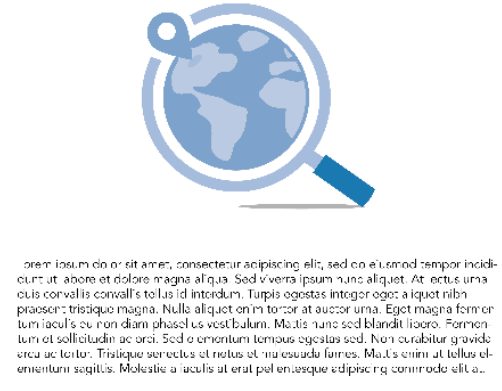

Lankow et al. (2012) talk about three elements of effective visual communication methods as appeal (voluntary engagement), comprehension (enabled understanding), and retention (memorability). Although any infographic should include these three elements, different applications will have different priorities in terms of the order of these elements.

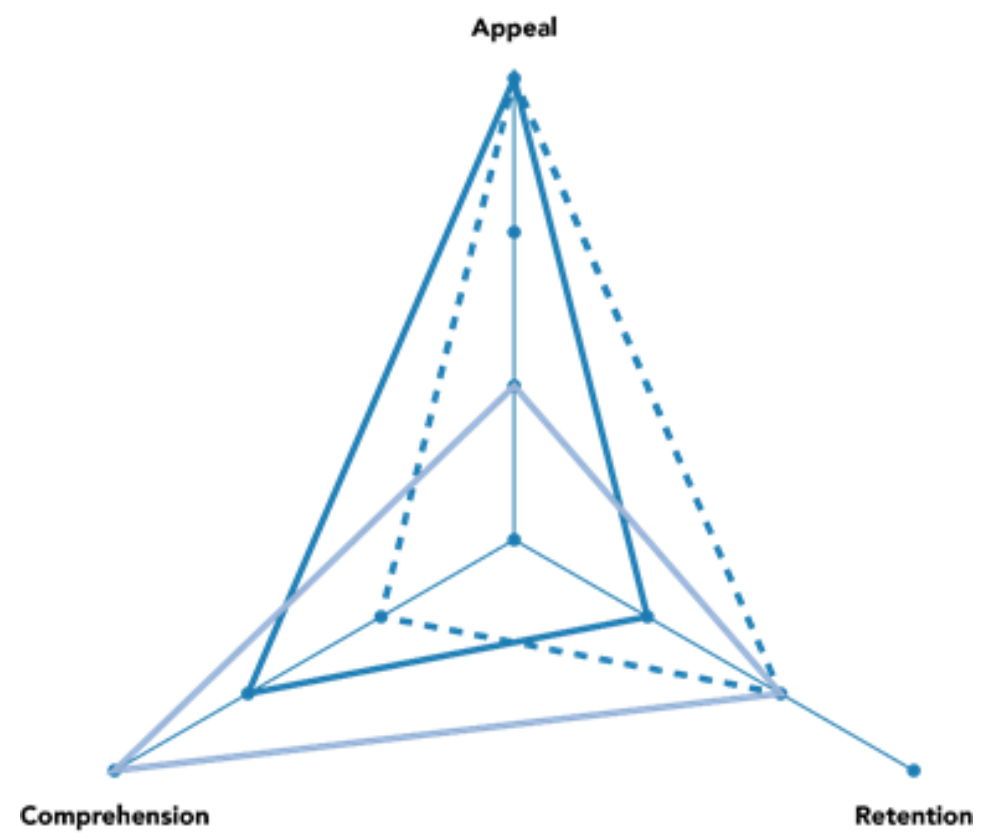

Academic/Scientific

Marketing

Editorial

Illustration 20: Infographic priorities by application. From Lankow et al., 2012. 
Siricharoen and Siricharoen (2015) present several sets of criteria for effective infographics, including contrast, hierarchy, accuracy, relevance, and truth, as well as usefulness, legibility, design, and aesthetics.

Table 4: Criteria for effective infographics. From Siricharoen \& Siricharoen, 2015.

\begin{tabular}{|c|c|}
\hline Criterion & scription \\
\hline Usefulness & $\begin{array}{l}\text { - } \text { Easy to understand } \\
\text { - } \text { Clear purpose } \\
\text { - Reliable data (sources cited) } \\
\text { - Informative - viewer learns something. }\end{array}$ \\
\hline Legibility & $\begin{array}{l}\text { - } \text { Easy to read } \\
\text { - Color scheme should not hinder ability to read } \\
\text { - Graphs/diagrams labeled appropriately } \\
\text { - } \text { Font choice, size and color used }\end{array}$ \\
\hline Design & $\begin{array}{l}\text { - Graphics should reflect purpose and audience } \\
\text { - Graphics are good quality, not distracting and consistent } \\
\text { - Space used effectively (no excess clutter) } \\
\text { - Appropriate use contrast and color. }\end{array}$ \\
\hline Aesthetics & $\begin{array}{l}\text { - Easy to follow, overall design facilitates understanding } \\
\text { - Hierarchy/organization of data. }\end{array}$ \\
\hline
\end{tabular}

The Okanagan College Library's guide to evaluating infographics (2020) has some overlap with the previous criteria, but is presented more granularly:

Table 5: Specifications for effective infographics. Adopted from Okanagan College Library, 2020

\begin{tabular}{|l|ll|} 
Element & \multicolumn{2}{l|}{ Specifications } \\
\hline Data & $\begin{array}{l}\text { The data presented makes the information easier for the viewer } \\
\text { to understand } \\
\text { The data is and/or supports the main argument directly }\end{array}$ \\
\hline Purpose & \begin{tabular}{l} 
- The reason the infographics is created is clear \\
\hline
\end{tabular}
\end{tabular}




\begin{tabular}{|c|c|}
\hline & - Information and data presented is meaningful and \\
\hline Sources & $\begin{array}{l}\text { - } \quad \text { Sources are from credible places } \\
\text { - } \quad \text { Easy to see where data and information comes from } \\
\text { - } \quad \text { Consistent citations }\end{array}$ \\
\hline $\begin{array}{l}\text { Organization } \\
\text { and flow }\end{array}$ & $\begin{array}{l}\text { - } \quad \text { Easy for the eye to move through the content } \\
\text { - Data and information are clearly organized and connected }\end{array}$ \\
\hline Colour & $\begin{array}{l}\text { - Colours are attractive and complement each other } \\
\text { - } \quad \text { Consistently used } \\
\text { - Enhances the flow and visual appeal of the infographic }\end{array}$ \\
\hline Text & $\begin{array}{l}\text { - } \quad \text { Consistent use of fonts throughout the infographic } \\
\text { - } \quad \text { Clearly describes data, graphs, charts, and images } \\
\text { - } \quad \text { No spelling or grammar errors }\end{array}$ \\
\hline $\begin{array}{l}\text { Diagrams and } \\
\text { charts }\end{array}$ & $\begin{array}{l}\text { - } \quad \text { Supports content and theme of the infographic } \\
\text { - } \quad \text { Appropriately chosen to represent data } \\
\text { - } \quad \text { Makes the data easy to understand }\end{array}$ \\
\hline $\begin{array}{l}\text { Overall } \\
\text { aesthetics }\end{array}$ & $\begin{array}{ll}\text { - } & \text { Engages the reader } \\
\text { - } & \text { Would work well on a social media platform } \\
\text { - } & \text { Overall pleasing look and feel }\end{array}$ \\
\hline
\end{tabular}

From these different sources, the following general guidelines can be assembled: infographics should be understandable, purposeful, memorable, credible, legible, organized, engaging, and aesthetically appealing.

\subsubsection{Illustration}

The use of illustration in graphic messages can contribute to the persuasiveness of those messages. In his book The Power and Influence of Illustration, Male states, "The power of persuasion cannot be underestimated, and illustration has throughout the years contributed enormously to this precept" (2019). Using illustration combined with a message provides the opportunity to create a connection between audience and message, combining information with 
appeal (Murchie \& Diomede, 2020; Chu, 2018). Using illustration can evoke emotions, and the uniqueness and interestingness of the illustration can enhance the user's affective response (Yan, 2019).

Using illustration and visual metaphor in the creation of infographics can enhance their appeal, and even aid in information retention (Lankow et al., 2012). Viewers prefer a greater use of illustration in visual representations, and graphics that contain illustrative embellishments may be not only more appealing to viewers but can help with understanding and memory retention (Lankow et al., 2012).

\subsubsection{Summary}

Visual materials draw the audience's attention and persuade them to engage with the message. The design of a visual message may increase its persuasiveness by stimulating positive emotions and creating a compelling visual narrative. Additionally, the graphic design of the message may aid its effectiveness by decreasing the cognitive load needed to navigate through the material. This is accomplished by presenting information in digestible chunks, presenting information in a hierarchical structure through spatial layout and use of font size and weight, and using loose line spacing and generous amounts of negative space.

\subsection{Conclusion}

In the last decade, anxiety, depression and suicide rates in post-secondary students have spiked, and these rates appear to be higher in students than in the general adult population. The number of severely distressed people attending post-secondary education indicates a need for intervention so that students can achieve their academic goals without sacrificing their mental wellness. However, any initiatives that are proposed must ensure that they are promoting and not weakening the self-efficacy of students by portraying them as fragile and unable to cope with campus life. This leads to the first research sub-question of this thesis: how can the student 
mental health crisis be addressed through design in a way that strengthens student mental health self-efficacy and resilience?

The increased rates of depression and anxiety in students have many possible factors, including adolescence, lower levels of self-efficacy and resilience, a decrease in stigma and an increase in willingness to seek help, technology overuse, and disrupted sleep patterns. However, part of the increase in rates of depression and anxiety may be due to the pathologizing of normal feelings and daily stress, and the increased focus that educational institutes put on emotional well-being which may weaken self-efficacy and increase self-preoccupation and anxiety. Because there are many different possible causes of poor mental health in post-secondary students, it is hard to distinguish which factors are the most detrimental, and which factors can be impacted by behaviour change. This leads to the second sub-question of the thesis: what factors affecting mental health can be targeted through an intervention to create the greatest positive impact on student mental health?

Much of mental health, like physical health, is influenced by one's behaviour. There are many antecedents that prompt the performance of health behaviours, and therefore influencing people to change their behaviour is complex. There has been some success in using health messages to change the behaviour of the public, but because of the large amount of information bombarding modern audiences it is difficult to get audiences to engage with a message. However, models of behaviour and persuasion can aid in understanding how to create effective, eye-catching messages that can influence behaviour. Additionally, there is evidence that using visuals, infographics, and illustration in health promoting messages can help engage and persuade an audience. This leads into the third sub-question of this thesis paper: how will experts and the target audience perceive the effectiveness of the proposed design intervention in informing students about their mental health and changing their mental health behaviours?

The design choices of graphics that include a mix of visuals and text influence their effectiveness and ultimately their persuasiveness. The literature indicates that a design layout that is organized, legible, and with a clear hierarchy can reduce the cognitive processing necessary to absorb the information and therefore aid a message's effectiveness. The level visual complexity and visual interest affect the appeal of a visual composition. What types of visual elements are used, and 48 
how information is conveyed in a graphic message can also impact its effectiveness. This relates to the main research question of this thesis: how can graphic messages promoting positive mental health behaviours be designed to maximize their effectiveness? 


\section{Chapter 3: Methods}

To reiterate, clinical levels of psychological distress in post-secondary students are high and rapidly increasing. However, post-secondary institutions may be unable to meet the high demand for counselling services and the most psychologically distressed students will often not seek counselling. Yet any implemented intervention must be carefully designed to avoid decreasing self-efficacy through a focus on emotional well-being. Persuasive health campaigns have been shown to positively influence behaviour when they are well designed, and the use of visual elements can help the process of communication. So, the methods used in this thesis are employed in service of answering the four research questions, focused on the development of a persuasive health campaign targeted at improving the resilience and mental wellness of postsecondary students.

\subsubsection{Mixed Methods approach}

Due to the complexity of the subject of post-secondary student mental health, this study followed an emergent mixed methods approach. The information that arose from the first method led to more questions, and therefore a second research method was used; this cycle was repeated until the research questions were sufficiently addressed.

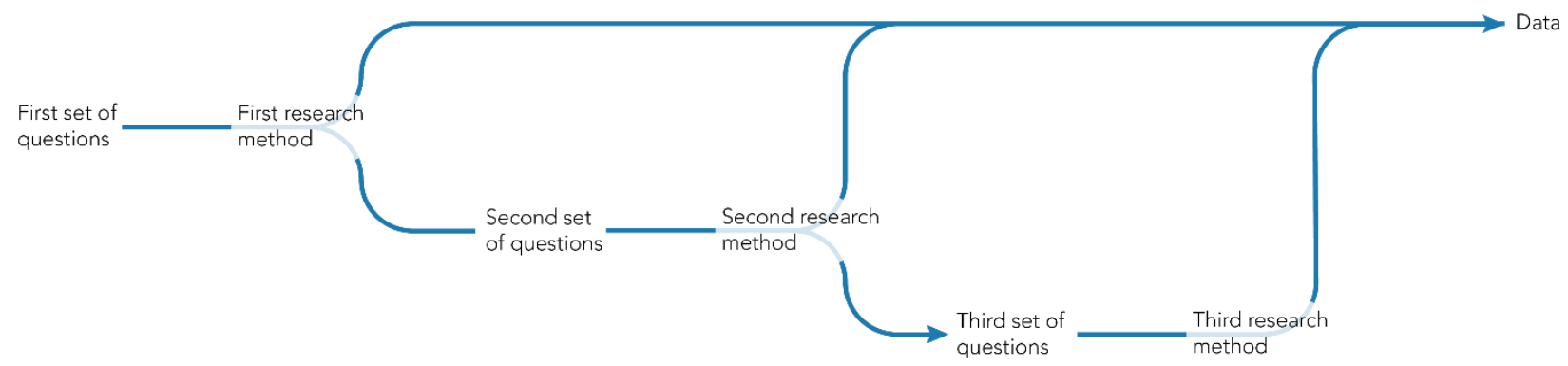

\section{Illustration 21: The iterative design cycle method used in this study}

Given the complex nature of the problem, a mixed methods approach was appropriate because there was a need to "first explore before administering instruments"; this is one of Cresswell and Clark's classifications of research problems that require a mixed methods approach (2017). The questions that needed to be asked and the variables that needed to be measured were unknown to the researcher at the beginning of the study, requiring a period of exploration to gain an 
understanding of the issue of student mental health and its context. The themes found from the initial exploration were then used to develop questions and measurement instruments used in subsequent phases of the study.

\subsubsection{Study Phases}

During Phase 1, interviews were conducted with professionals from Carleton University to gather attitudes and insights on student stress and mental distress from people working within the mental healthcare services and programs and faculty at Carleton University. The narrative data were transcribed, coded, and organized into themes related to different factors that affect student mental health.

During Phase 2, current and former post-secondary students were surveyed using an anonymous online questionnaire about their college or university experience and what factors contributed to and detracted from their mental well-being. The information that emerged from analysis of the student survey as well as the expert interviews was then synthesized to craft a potential design intervention in the form of a series of graphic messages.

During Phase 3, a feedback form was created for evaluation of the graphic messages. This feedback form was first completed by the professionals interviewed in Phase 1.

During Phase 4, minor changes were made to the graphic messages and feedback form wording, and the feedback form was sent to current and former post-secondary students.

\subsection{Phase 1: Expert Interviews}

\subsubsection{Setting}

The first three interviews were conducted in person on Carleton's campus. Due to the COVID-19 pandemic, the rest of this study was conducted entirely online through conferencing tools and by phone. 


\subsubsection{Participants}

The first phase of this study used the purposive sampling method: participants were selected based on their knowledge on mental health issues and their experience working at Carleton University. Expert interviewees were initially found on Carleton's staff website, and subsequent interviewees were found through the initial interviewees (snowballing). All eight participants were professionals working in fields related to mental health at Carleton University.

Table 6: Phase one participants and their places of work

\begin{tabular}{|l|l|l|l|}
$\begin{array}{l}\text { Participant } \\
\#\end{array}$ & Workplace & \multicolumn{2}{|l|}{$\begin{array}{l}\text { Participant } \\
\text { Workplace }\end{array}$} \\
\hline 1 & Office of the President & 5 & $\begin{array}{l}\text { Paul Menton Center for } \\
\text { Students with Disabilities }\end{array}$ \\
\hline 3 & Healthy Workplace Program & 6 & $\begin{array}{l}\text { Environmental Health and } \\
\text { Safety }\end{array}$ \\
\hline 4 & $\begin{array}{l}\text { From Intention to Action } \\
\text { Program }\end{array}$ & 7 & Student Care and Support \\
\hline & $\begin{array}{l}\text { Student Care \& Support, } \\
\text { Student Mental Health } \\
\text { Outreach }\end{array}$ & 8 & Department of Neuroscience \\
\hline
\end{tabular}

\subsubsection{Measurement Instruments}

The researcher used a semi-structured interview to collect data from professionals in Phase 1 (see Appendix A). The interviews were conducted over the phone or over Zoom. The interviews lasted approximately 45 minutes each. The interviews consisted of eight questions, but these questions were elaborated on using additional probes during the interviews. These interviews were audio recorded and transcribed by the researcher.

\subsubsection{Data Collection}

Each interview was tape recorded for accuracy. The interviews were then transcribed by the researcher.

\subsubsection{Data Analysis}


The expert interview transcripts were coded to find emergent themes and issues. Descriptive coding was used in the first cycle of coding, and pattern coding was used in the second cycle of coding (Saldaña, 2009). The first round of coding used descriptive coding to assign each chunk of text (sentence, multiple sentences, or paragraph) to a code. This process produced 121 codes. The next round of coding used pattern coding to group these codes into themes. This process produced three emergent themes: factors affecting mental health, institutional context, and mental illness. To better conceptualize the frequency of each response, three coding theme diagrams were created (see Illustrations 28 to 30). These diagrams map out each code within the three themes in mind map/bubble formation. The frequency of references per code are shown by bubble colour, and the number of respondents per code are shown through bubble size (i.e., the bubbles that are the darkest and largest have the most references from the highest number of participants).

\subsection{Phase 2: Student Survey}

\subsubsection{Setting}

The student survey was conducted entirely online.

\subsubsection{Participants}

The second phase of this study used the convenience sampling method: using a recruitment poster posted on the Carleton School of Industrial Design Facebook group page and the Carleton University public Facebook group page. Sixty-two anonymous respondents were recruited to complete an online survey (see Appendix B). Targeted participants were current or former postsecondary students.

Most of the survey respondents were former post-secondary students (75.8\%). The respondents were mostly female (66.7\%) with $31.7 \%$ reporting their gender as male and one respondent listing their gender as non-binary (1.7\%). The age range with the most respondents was 23-30 (40.3\%), followed by 51-60 (21.0\%). 


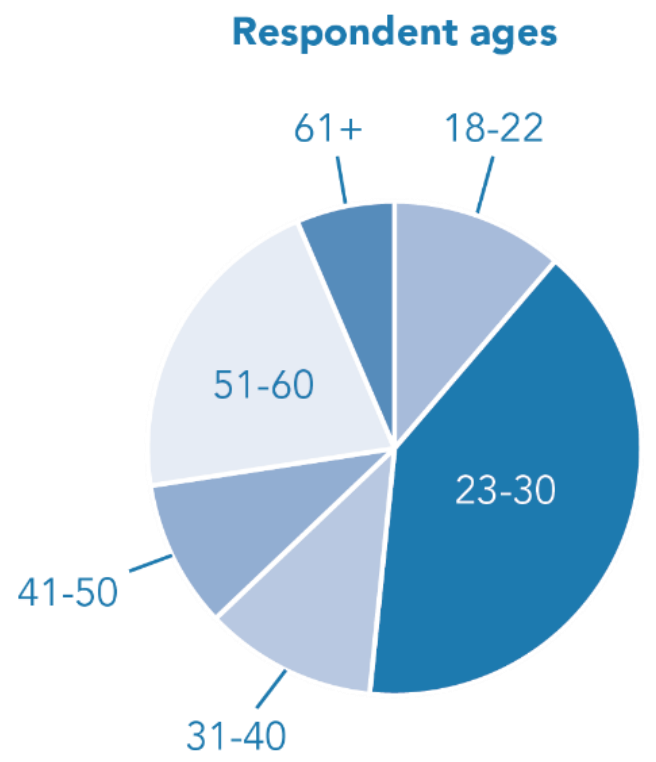

Illustration 22: : Pie chart showing survey respondent age groups.

\subsubsection{Measurement Instruments}

The researcher used an online survey to collect data from current and former post-secondary students (see Appendix B). The purpose of this survey was to collect data on the levels of stress and mental distress experienced during the participants' time at college and university, whether they took any action to improve their levels of stress or mental distress including using their institutes mental health services, what they did or why they didn't act, and what factors had the greatest impact on their levels of stress and mental distress. The survey consisted of 18 questions in total: eight multiple choice, seven yes/no, and three short-answer. This survey was administered online using Google Forms and participant responses were collected anonymously.

\subsubsection{Data Collection}

The survey answers were collected through Google Forms over a period of two weeks.

\subsubsection{Data Analysis}

Most items in the student survey were measured with a five-point Likert scale. This type of scale was chosen to be easily understandable and to allow respondents to choose the degree to which a factor may have impacted them. Because a Likert scale produces ordinal data, it may not be 
suitable to use an average of Likert scale items to draw a conclusion about a single survey item, as this assumes that there is an underlying continuous variable that characterizes respondents' opinions or attitudes (Allen \& Seaman, 2007). However, averages were used to rank the impact of different factors from most impactful to least impactful.

The analysis of the survey data was reported through charts and bar/pie graphs. Specific survey questions were matched to answer specific study research questions. Data from the survey was also compared to data from the interviews to see if there was a difference in the categorization of the factors affecting student mental health.

\subsection{The Intervention: A Persuasive Health Campaign of Graphic Messages}

This study was born from the desire to positively impact the state of student mental health. Because of the complexity of the problem, the form of the intervention was not known at the beginning of the study. The study was approached from a designer's perspective, and the creation of the intervention followed a design thinking framework, as seen in illustration 23.

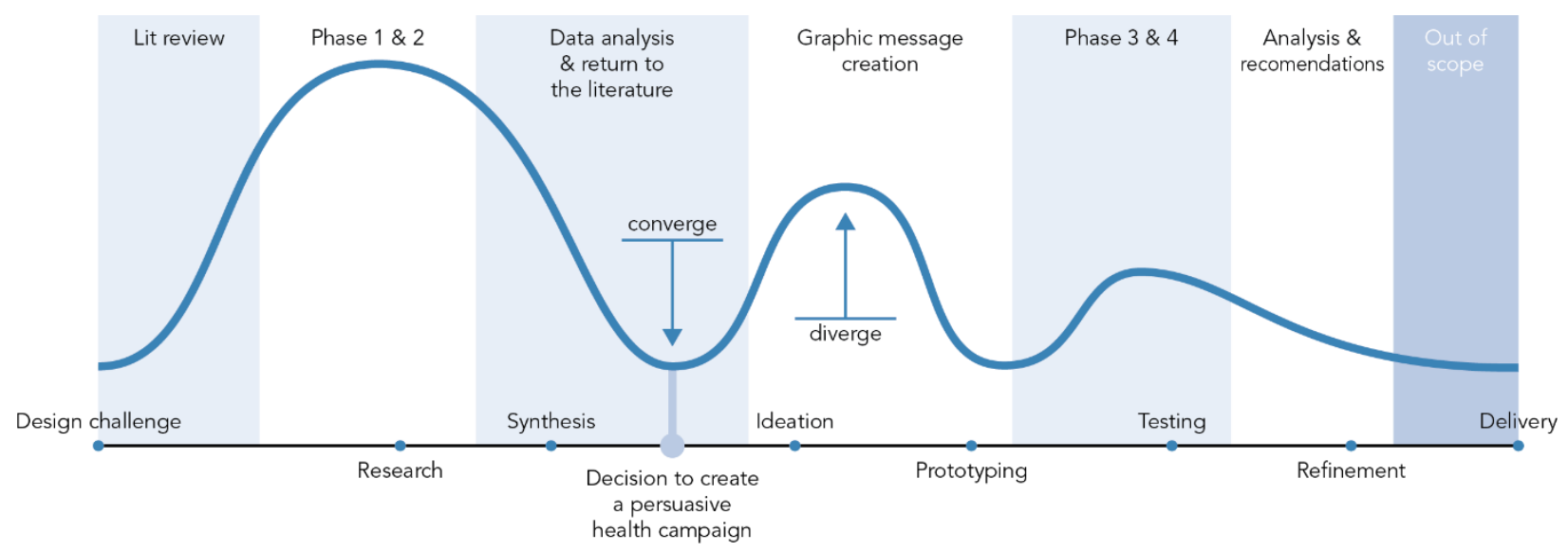

Illustration 23: Design thinking model overlayed with study phases. Adapted from Balcaitis, 2019; IDEO, 2015.

After phase 1 and 2 were completed and the data was analyzed, a potential intervention was created to attempt to improve the issues surrounding student mental health brought up by the interviewees and student survey respondents. A persuasive health campaign was chosen to help students take steps to improve their own mental health by increasing their repertoire of coping skills. This type of intervention was chosen for several reasons. The interviewees spoke at length 
about programs the university offers and yet in the student survey only a small percentage of students reported ever using the university's services. Moreover, most of the students who did use any of their institution's services only reported using the health and counseling services; 12 of the 14 services talked about by the interviewees were not reported as being used by respondents. Therefore, a solution other than a student service seemed appropriate. Also, a media campaign can reach students who do not want to seek help (as they may passively encounter the graphic messages). According to some interviewees and researchers, the students who are experiencing the highest levels of mental distress or who commit suicide are often unknown to the health and counselling services (Robinson et al., 2016; Brown, 2020); participant three stated:

But we do know that a lot of the people that ended up committing suicide, for example, are not the ones that usually are seen or get help from some of our systems that are in place.

Furthermore, this type of intervention does not put extra pressure on health and counselling services, which according to some interviewees and Brown (2020) are experiencing overload. According to one of the interviewees, health and counselling services are already overwhelmed with students to the point where they are no longer advertising their availability. Additionally, by giving information about the services the university provides, especially outside of the health and counseling services, the graphic messages could draw more attention to these services, and possibly increase the number of students using them.

Also, this type of persuasive health campaign targets the behaviour of individuals as well as the wider culture (French et al., 2010). Targeting individual action is beneficial not only because it does not put pressure on an institution's service center, but also due to the effects it can have on one's self-efficacy and coping skills repertoire. By informing students that they have (at least some) control of their mental health, the graphic messages may help increase the students' selfefficacy (Sweet et al., 2012; Bandura et al., 1999), which according to Lipson and Eisenburg (2018) can be weakened by suggesting that students need help with their mental health. Therefore, it was determined that the intervention should empower students to take steps to 
improve their own resilience, increase their own coping skills, and therefore improve their own mental health.

Using a digital health app as an intervention was considered but rejected due to the typically low engagement of these types of apps (Serrano et al., 2017; Becker et al., 2014; Laing et al., 2014). Likewise, the implementation of a student program or workshop was considered but rejected due to an expected low usage rate (as stated by Participant 7, "Students don't tend to come to workshops as much as we would like") and a high cost in terms of staff involvement and organization. A persuasive health campaign using graphic messages was ultimately selected due to its low cost of implementation, and its potential to reach and perhaps influence many students.

\subsubsection{Message Topics}

The survey data from Phase 2 was used to determine the message topics that would be most valuable to communicate to students. Because of the high impact rating physical health factors had on improving mental health, it became apparent that physical health should be promoted as a key factor in improving mental health. Similarly, because of the high ranking of confiding and socialization as effective in reducing mental distress, it was determined that these coping skills should be promoted as well. Although reducing technology was not highly rated as effective in the student survey, it was selected as a topic to address because of the breadth of literature linking technology overuse with mental ill-health in post-secondary students (Demirci et al., 2015; Roberts et al., 2014; Elhai et al., 2017; Pittman \& Reich, 2016; Brown, 2020; Hunt et al., 2018; Rosen et al., 2013).

Although academic pressure was listed as the factor that had the greatest impact on stress level, there are issues that make it an unsuitable target for messages. This is because neither improving academic performance nor reducing course load was rated particularly highly in terms of improving mental health. Additionally, as explained by the expert interviewees, academic pressure has many causes: financial (scholarships/competitive internships/competitive job market), from family and parents, from competition with other students, from how the institution's classes are structured, etc. Therefore, relieving academic pressure may be complex and involve different factors for different individuals. Also, because of the nature of education, 
some academic pressure is inevitable, and some of this pressure may be considered positive "eustress" needed to challenge oneself.

Additionally, because the highest impact factor in terms of preventing students from taking steps to improve their mental health was not being sure which service would be appropriate for them, it seems fitting that these graphic messages will have suggestions for specific Carleton services based on the ad content.

\subsubsection{Message Content}

When determining the message contents the following factors were considered. Firstly, the messages should inform users about the factors that can impact their mental health. According to the IMB model (Fisher et al., 2003; Klonoff, 2019), being well-informed about a behaviour is one element that supports health-promoting behaviors. Secondly, the messages should increase self-efficacy and perceived behavioural control; according to the reasoned action/planned behavior theory (Ajzen, 2002), if perceived control is high behaviors are more likely to be carried out. Thirdly the messages should be relevant to post-secondary students. According to the ELM (Cyr et al., 2018; Jensen et al., 2012; Petty \& Cacioppo, 1986), tailoring messages to the receiver increases the likelihood that they will pay attention to the message. The self-referencing encoding model (Burnkrant \& Unnava, 1995; Chang, 2011; Rogers et al. 1977) states that this will also increase the persuasiveness of the message. Fourth, the message should motivate students to examine and/or modify their behavior. Lastly, the messages should be short and easily digestible.

When creating the messages, the researcher therefore searched for information on the selected subjects that could be easily summarized into a few sentences and easily understood by postsecondary students. The messages also needed to be actionable/implementable by post-secondary students. The messages were worded in a way that was intended to increase the self-efficacy of the recipient by suggesting that they could improve their own mental health. The wording of the messages was also intended to be motivational. The information in the messages was taken from scholarly sources and studies, but the references were not included in the graphics to reduce the 
amount of text and because the resources would be available to the viewers through the "learn more" button.

\subsubsection{Visual Elements}

When developing the graphic messages, the visual element was another important consideration in their impact. The goals of the visual elements were catching attention, increasing engagement, and making the graphic messages relevant for post-secondary students.

To catch attention and increase engagement, a fun and playful feel seemed appropriate. It was also an aim to stand out from Carleton University's current Mental Health and Well Being branding to be more attention-getting.

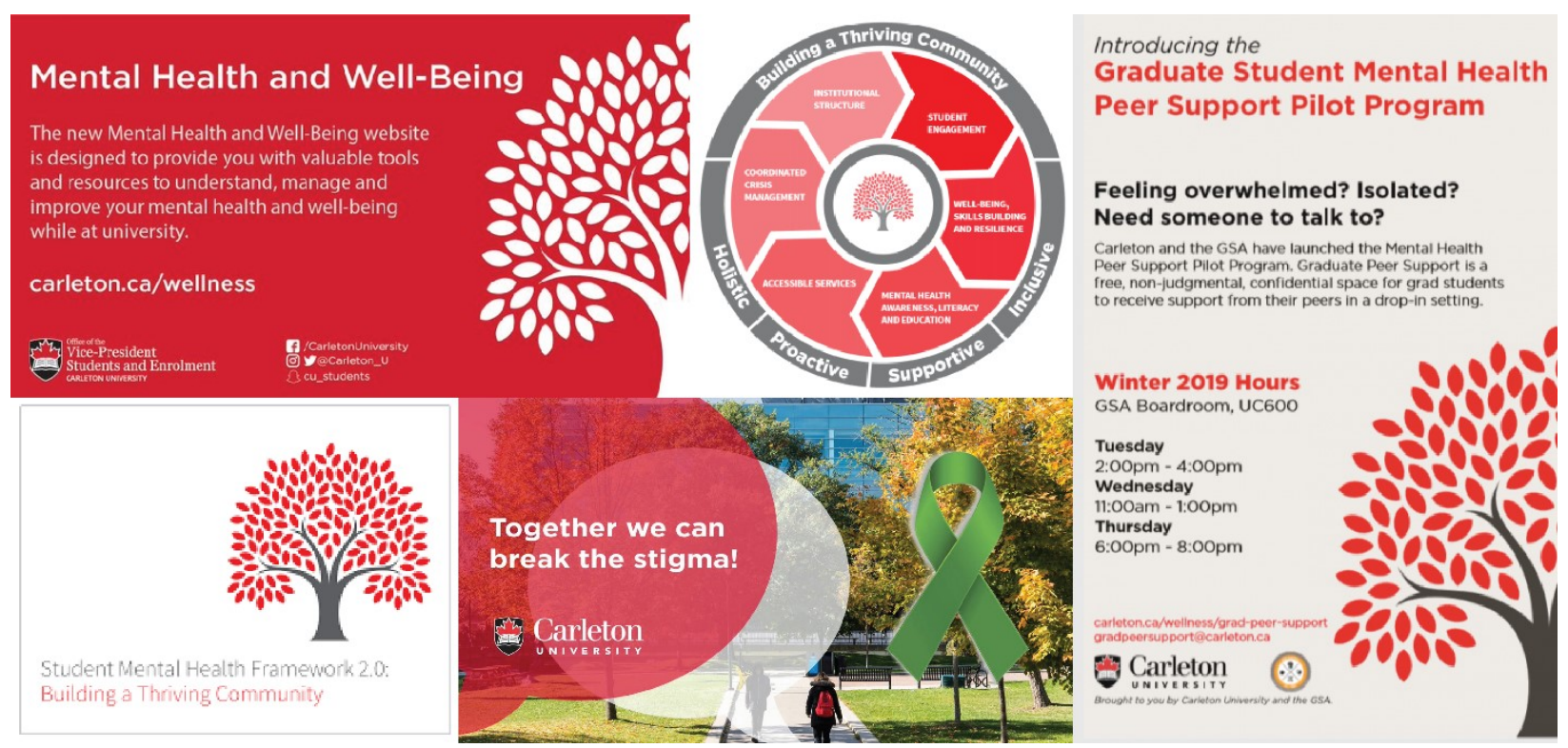

Illustration 24: Current examples of graphic design used to communicate messages from Carleton University regarding mental health

The existing Mental Health and Well Being branding features simple flat iconography or photography and a colour palette featuring red and black (Carleton's branding colours). To bring personality and interest to the graphic messages, illustrated characters and a bold, varied colour palette were used. The graphic messages were created by the researcher using a combination of illustration and graphic design. The human characters in the graphic messages were created using 
vector illustration. They were all composed using simple geometric shapes, mainly ellipses, to evoke a fun and playful feel and provide visual consistency across the graphics.

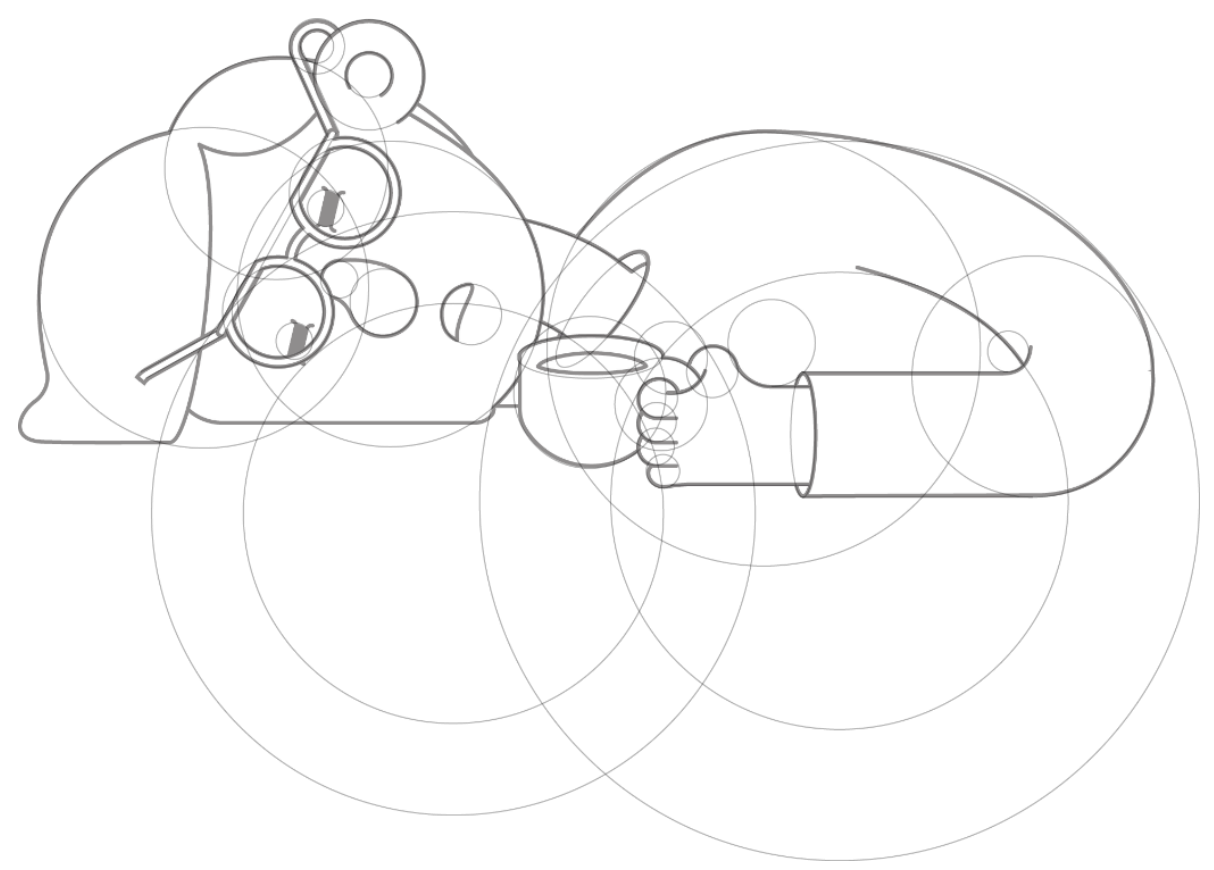

Illustration 25: Construction of a human character with simple geometric shapes

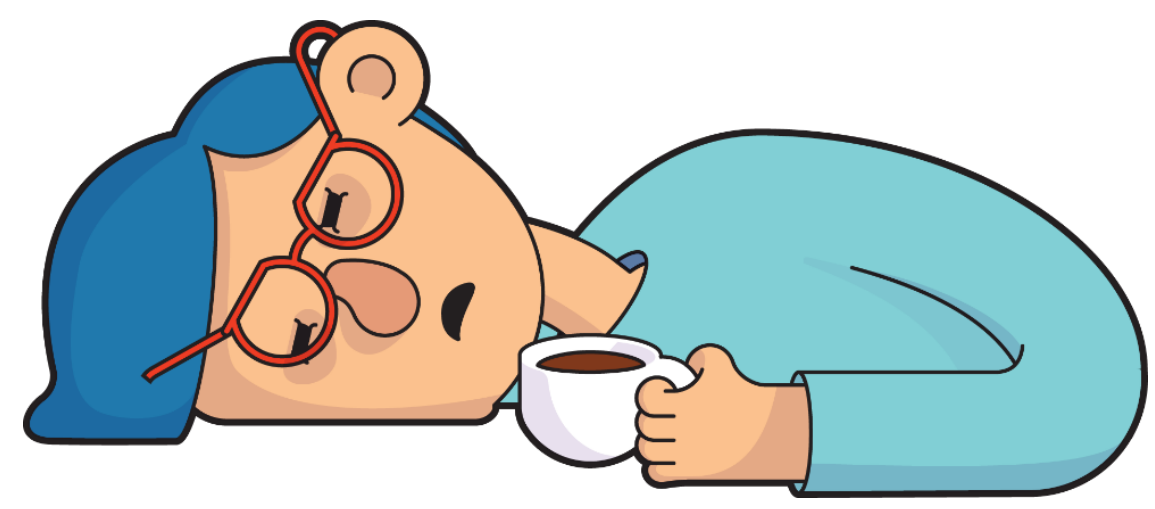

Illustration 26: A human character with colour and shading

The illustrations use shadow to add depth to the illustration, and a varied line weight to add visual interest. The characters all used the same palette of colours to again be visually consistent across all the graphic messages. 
The illustrated characters were placed in photo settings to give the graphic messages a realistic context (such as a lecture hall or a campus quadrangle). The photos were blurred and sometimes darkened to soften the contrast between realistic setting and illustrated character while allowing the character to stand out.

The text elements of the graphic messages were laid out using a grid for visual organization and neatness. The text is laid out in a hierarchical format, with a title, subtitle, and body text, all using the same typeface. The dominant text for each graphic message is the title, "Did you know?", in a large heavy font. The sub-dominant text is the subtitle that explains how the topic discussed in the graphic message can benefit or harm one's mental health, in a slightly smaller font. Other sub-dominant elements are the "Learn more" and "More tips" buttons located at the bottom of the composition. The subordinate text is the body text that gives further explanation on the topic, in a small light font.

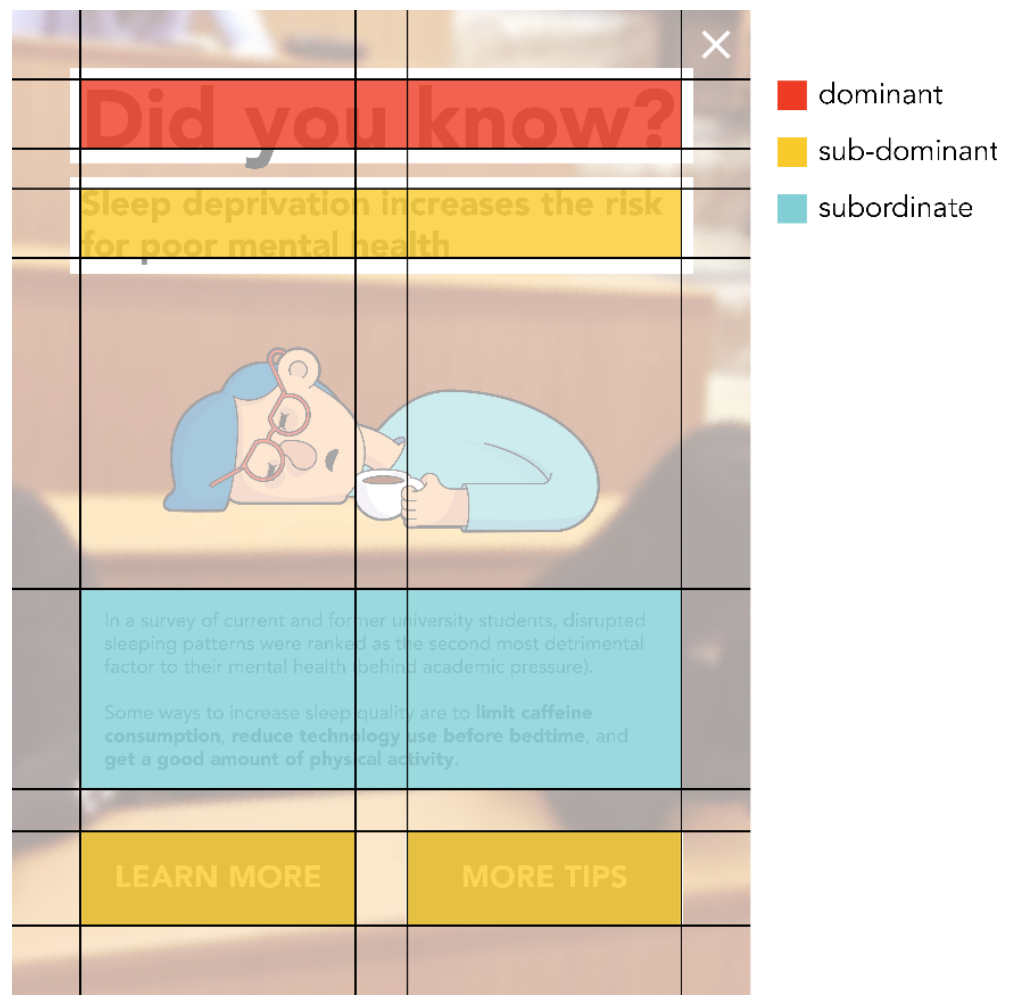

Illustration 27: Graphic layout of a health-promoting graphic message 


\subsection{Phase 3: Graphic Message Feedback Form - Professionals}

\subsubsection{Setting}

The feedback form was filled out entirely online.

\subsubsection{Participants}

The third phase of this study involved the same participant group from Phase 1. The feedback form was first completed by the professionals that were interviewed in Phase 1. Seven out of the eight initial interviewees filled out the form.

\subsubsection{Measurement Instruments}

The researcher used an online form to gather feedback from on a series of graphic messages (see Appendix D). The purpose of this feedback form was to evaluate the effectiveness, usefulness, legibility, design, and aesthetics of the graphic messages. Potential channels through which the graphic messages could be delivered were also evaluated by respondents. The survey consisted of three major sections. The feedback form consisted of 12 questions in total: eight multiple choice and four short-answer. This survey was administered online using Google Forms.

\subsubsection{Data Collection}

The survey answers were collected through Google Forms over a period of two weeks.

\subsubsection{Data Analysis}

The results of the feedback form were analyzed using descriptive statistics. As in phase 2, many of the items were measured with a five-point Likert scale to be easily understandable and to allow respondents to choose the degree to which they agreed or disagreed with a statement. The data was downloaded into an Excel spreadsheet and the software was used to find the mean and median scores for the items scored on the Likert scale of 0 to 4.

Because a Likert scale is an ordinal scale, the median was used as a measure of the "average" or "typical" response instead of the average (Allen \& Seaman, 2007). However, the average scores were also included to determine how certain items ranked against each other, i.e., if one graphic 
message has a higher overall average score than another, it is assumed that respondents rank that graphic message more favourably, even if the median scores of the two are the same.

If the median score is below a 2 , it is assumed that the respondents generally disagreed with that statement. If the median score is 2 , it is assumed to represent neutral or ambiguous opinion. If the median is above 2 , it is assumed that the respondents generally agreed with that statement.

The overall averages were calculated by taking the sum of all the scores from both populations and dividing by the number of participants from both populations. Similarly, the overall medians were found by locating the central number of all the scores from both populations.

\subsection{Phase 4: Graphic Message Feedback Form - Students}

\subsubsection{Setting}

The feedback form was filled out entirely online.

\subsubsection{Participants}

The fourth phase of this study used the same demographic of participants as Phase 2. A recruitment poster was again posted on the Carleton School of Industrial Design Facebook group page and the Carleton University public Facebook group page. Fifty-two respondents were recruited to complete the feedback form.

\subsubsection{Measurement Instruments}

The researcher again used the same online form to gather feedback from on a series of graphic messages (see Appendix D).

\subsubsection{Data Collection}

The survey answers were collected through Google Forms over a period of two weeks.

\subsubsection{Data Analysis}

The data from phase 4 was analyzed using the same methods as the data from phase 3 (see section 3.5.5). The data from both phases was reported together to show the differences and similarities between the opinions of the two populations. Recommendations on how the graphic 63 
messages could be improved were made using the combined scores from both populations. This was done firstly because both populations had similar opinions in terms of the graphic messages they preferred, and secondly to consider the perspectives of both populations. 


\section{Chapter 4: Results}

\subsection{Research Sub-Question 1}

The review of the literature on post-secondary student mental health lead to the first research sub-question: how can the student mental health crisis be addressed through design in a way that strengthens student mental health self-efficacy and resilience? Phase 1 was conducted to begin to explore this question.

\subsubsection{Phase 1: Expert Interviews}

The exploratory interviews with experts yielded a dense amount of information, which was organized into three major themes: factors affecting mental health, institutional context, and mental health.

\subsubsection{Theme 1: Factors affecting mental health}

This theme included 205 references from all eight participants. The content from this section is most related to question 3, 4, and 4a from the interview protocol (In your opinion, what are the major issues causing a lack of student mental wellness? Do you think Carleton has any issues that contribute to the negative mental health of the students? What are they?). The participants identified a wide range of factors affecting mental health; 35 different descriptive codes were generated by the researcher within this theme.

One issue of note was the wide range of factors discussed by participants as impacting student mental health. 


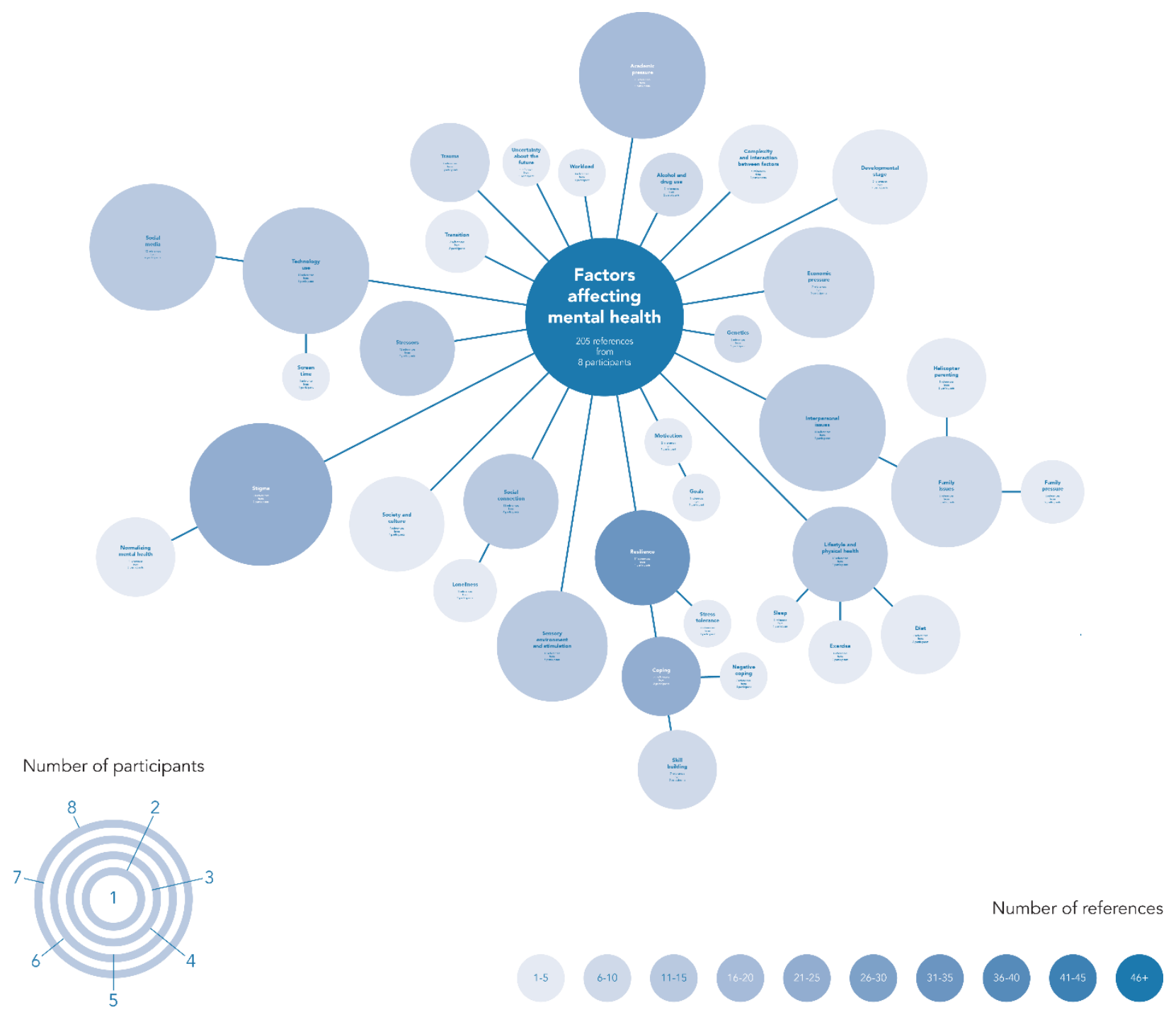

Illustration 28: Factors affecting mental health coding diagram.

The top three most identified factors were academic pressure (18 references from six participants), resilience (34 references from four participants), and stigma (21 references from seven participants).

The "academic pressure" code includes content discussing the pressure that students will put on themselves or that other people (or circumstances) will put onto the student to achieve high grades, perhaps to achieve further goals. This pressure could be intrinsic (self-applied) or stem from family pressure, from the university, from competition with peers, or circumstances like 
needing high grades to maintain a scholarship. For example, participant six said this about the pressure to succeed academically:

So there is, I think, a tremendous pressure that a lot of students would put on themselves to achieve the high marks, to make the right decisions when they hit university, to be in the right program, to get the right marks so that they could get into the next step. So, I think that there is a tremendous amount of pressure there for success.

Participant eight had a similar sentiment, saying:

So, this is the problem too, right. We've also taught students that it's not okay to fail. It's not okay to not do well. Bs don't cut it. You want to have a position in a lab in the summer? You need an A. So, we are continually fostering this notion that success is As. And so, it teaches the students that to fear anything but that, and anything but that is not acceptable.

Additionally, resilience was the factor affecting mental health that had the largest number of references; it was identified as a particularly important factor mediating the connection between external pressures and stress. Resilience is defined as the ability to cope with a challenge or difficulty and to easily adjust to a new set of circumstances. Multiple participants discussed how current students arrive at university lacking the resilience necessary to deal with an unfamiliar and often stressful new environment. According to the participants, this was due to several factors, including helicopter or snowplow parenting (parenting styles where the caregiver(s) hover over their children and swoop in at the first sign of trouble or work to remove all obstacles out of the child's way), a lack of exposure to lower amounts of stress earlier in life, and/or a lack of a diverse set of coping skills. How resilience can be cultured within students in a variety of ways was discussed, by methods such as increasing the range of coping skills one uses or changing the appraisal of external difficulties from "threat" to "challenge".

Although fewer participants talked about student resilience, the subject was discussed extensively by some participants as a key factor that has a buffering effect against mental 
distress. Two participants discussed how the current generation of students may be lower in resilience due to coddling, with participant three saying:

There's the argument that there's less resilience as a function of maybe more helicopter parenting or snowplow parenting, the sheltering that's going on.

Participant eight referred to a lack of exposure to stress early in life as a determinant of lower resilience, saying:

So, we're preventing, and this is kind of what was the argument of one of the talks that I gave on resilience, is that we're preventing our kids from experiencing stress early in life. And then what that does is it doesn't set up the brain well enough to handle stress in the future. So, what we're seeing with our students is this very low threshold for distress tolerance, right? They're not able to tolerate a high amount of stress.

The "stigma" code involves discussions on the existence of a mental health stigma as well as how that stigma may affect the person with a mental health issue and/or their desire to seek help. The majority sentiment about stigma around mental health was that it still exists but that it has been and continues to be reduced. For example, participant seven said the following:

We also have a heightened awareness of mental health. You know, people have been doing a really good job on reducing stigma. When you reduce stigma the need for services increases. So, there's that as well, like talking about it more people are more aware, people are noticing it and other people, the conversation has grown.

\subsubsection{Theme 2: Institutional context}

This theme included 331 references from seven participants. This theme contains 20 different codes. A notable aspect of these interviews was how much the expert interviewees discussed the different services and programs Carleton offers to help students improve their mental health, their academic performance, etc.; this topic had the highest number of references ( 91 references from seven participants). 


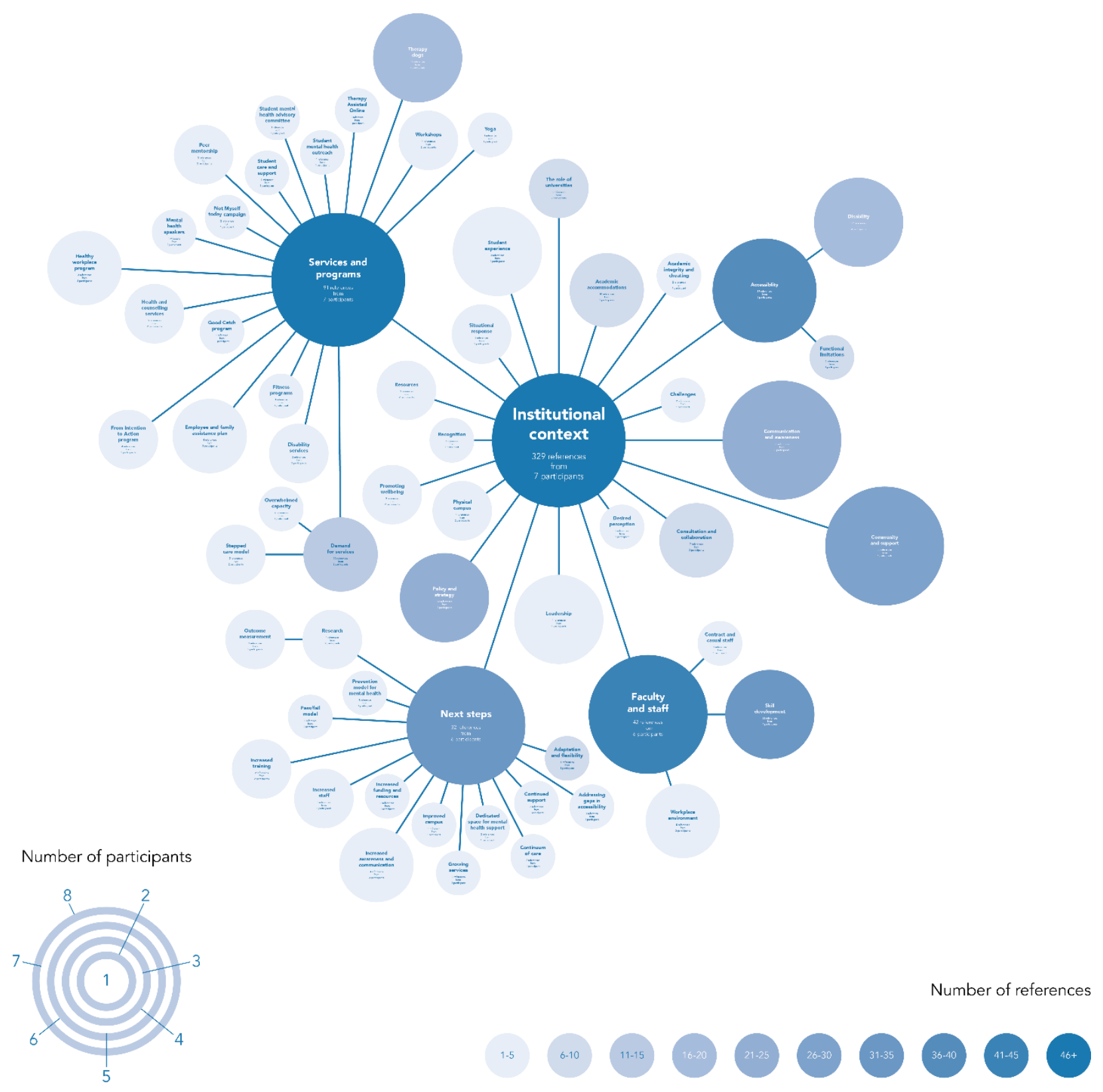

Illustration 29: Institutional issues coding diagram.

The "services and programs" code includes discussions of Carleton University's programs and services that promote mental well-being for students and staff. This topic includes 20 codes, with 17 of those codes naming actual services and programs that Carleton offers. Participants had a positive view of the amount of good Carleton is doing regarding offering all these services and programs. Participant two stated: 
I mean, I'm a bit biased, but I think we're doing a lot. Even just through the healthy workplace program. We do things like I mentioned, training workshops, information sessions. We do different health challenges on a monthly basis.

However, many participants also mentioned that the demand for student mental health services was higher than the ability to deliver those services. Participant three said:

I think Carleton is better than most universities at addressing the mental health crisis and so to speak, on a lot of campuses. I still think that the demand for students for mental health services outweighs our capacity to serve them.

Additionally, participant four stated:

But in terms of the increasing need for almost like a medium level of care, people that need urgent counselling for issues that it's just like, it's increasing. So, it's hard to meet that demand.

\subsubsection{Theme 3: Mental health}

This theme included 87 references from all eight participants. This theme is divided into two large topics: improving mental health and mental illness. 

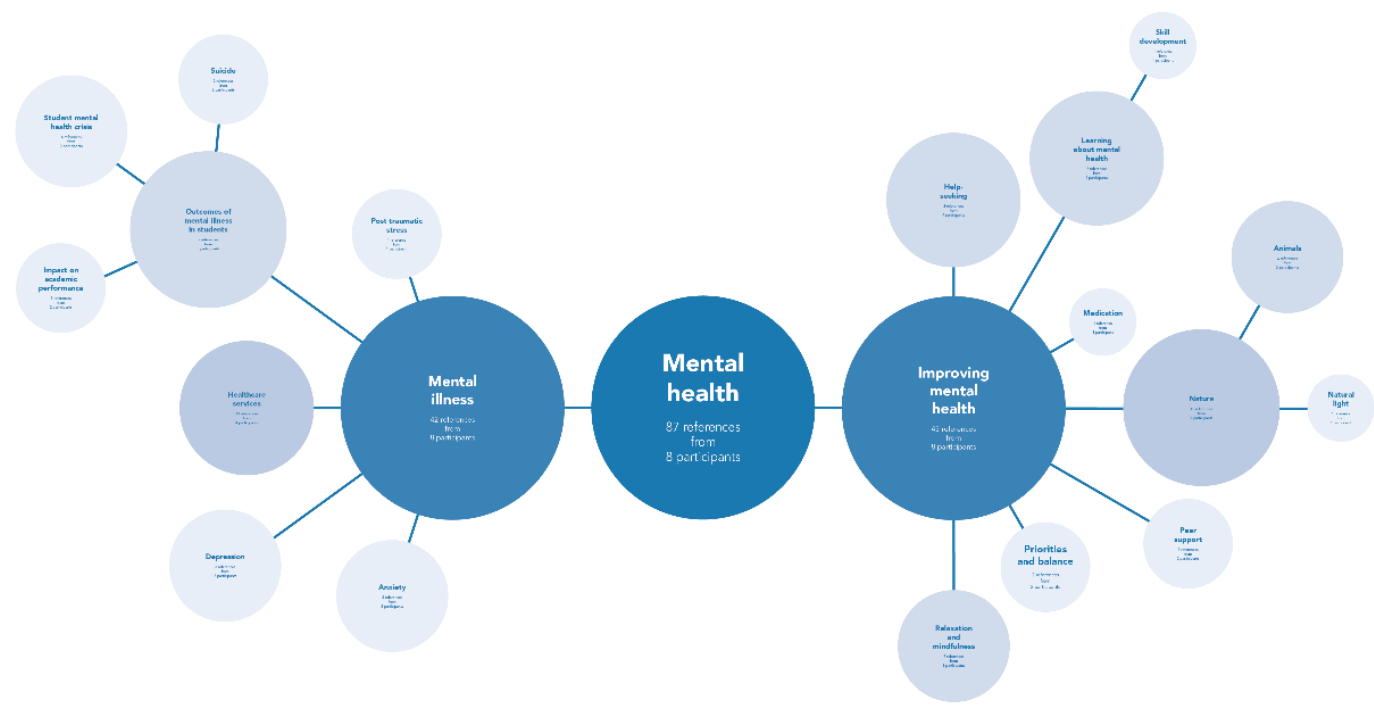

Number of participants

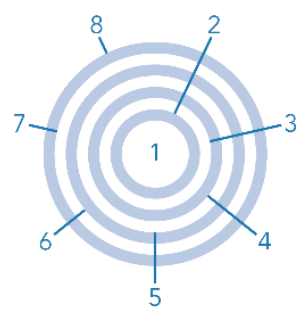

Number of references

Illustration 30: Mental health coding diagram.

The top three most referenced codes within the improving mental health topic were nature (15 references from five participants), help-seeking (eight references from four participants), learning about mental health (nine references from four participants).

The "help-seeking" code refers to discussions about students with mental health issues seeking help, and the conditions that encourage or deter students from seeking help. Some participants discussed that current students are more comfortable asking for help than in the past. Participant three stated,

I do think that students are more self-advocating than ever before. I mean, a lot of the students I see, it's their first or second year and they're already 
seeking out our service and other services that would have probably taken me years to figure out existed when I was an undergrad.

The "learning about mental health" code refers to those with mental health issues learning about mental health to increase self-understanding or to learn what factors may be affecting their mental health, and others learning about mental health issues to create a more understanding and supportive environment. This code is also connected to the issue of resilience; an aspect of resilience is coping, and a way to increase the diversity of coping strategies is to build skills. Participant two said this about how increased mental health literacy can lead to an environment that supports mental well-being:

Where we are trying to work is in the area of prevention, so by building that mental health literacy and the awareness and the education, ideally we're going to create a space where there is a bit more understanding, a bit more empathy, a bit more support.

The top two most referenced codes within the mental illness topic were healthcare services (13 references from four participants) and outcomes of student ill mental health (nine references from five participants).

The "healthcare services" code refers to discussions about the public healthcare system as well as private mental healthcare services outside of Carleton. Multiple participants spoke about the barriers to care outside of Carleton. Participant four said:

But certainly, there is a system here that is not always accessible, not always fully accessible to everyone and that you're really lucky if you have a job that has insurance. But if you don't have insurance and you need mental health counselling it costs $\$ 150$ an hour.

Additionally, participant seven stated:

If a student is diagnosed with cancer at any stage, we can effectively move them into the community for the right kind of support, understanding that if a student has stage four cancer, chances are that they will not be in university. 
They will be receiving extensive treatment and support. And so, we haven't yet figured out a way to manage students with significant mental health issues because the community resources are there but not in abundance. [...] It's sort of the next place, you know, to make sure that that support is seamless into the community.

The "outcomes of ill student mental health" code includes discussions of how ill mental health can impact a student, academically or otherwise. This code also includes discussions about the growing student mental health crisis and suicide. Multiple participants talked about how mental illness can negatively impact academic outcomes; for example, participant seven stated:

It is actually very hard for students to study when they're struggling with significant mental health issues.

Participant three said this about the impact of an increased number of student suicides:

I mean, worst case scenario you've heard of everything that's been happening at University of Ottawa. They've had a record-breaking number of suicides this year. And they worry about things like the contagion effect. So, the idea that the more students act on their suicidal ideation the more other students are going to say, 'Hmm, maybe that's what I should do too'.

\subsection{Research Sub-Question 2}

The information gained from the expert interviewees led to research sub-question 2: what factors affecting mental health can be targeted through an intervention to create the greatest positive impact on student mental health? This research sub-question was further broken down into three questions to elucidate information that was collected during the expert interviews and the literature review:

1. What will post-secondary students report as factors that affected their mental health during their time in post-secondary institutions? Will these factors be the same as those discussed by the expert interviewees? 
2. Considering that the expert interviewees brought up numerous services and programs that are in place to improve student mental wellness, will post-secondary students report use of these services? How effective will students rate these programs and services?

3. Do students currently use any coping skills to improve their mental health? Are those coping methods effective?

In parallel, the researcher was attempting to find a possible intervention, asking the following questions:

4. How can students be prompted to increase their repertoire of coping skills to improve their resilience?

5. How can students experiencing mental distress be reached if they do not seek out help?

The student survey was created to directly answer research sub-question 2 . The answers that the students provided in the survey provided another perspective on the issues discussed by the expert interviewees. Questions four and five were more difficult to answer directly through a method of study as they required a creative "leap". However, the survey information combined with the information gleaned from the expert interviews painted a fuller picture of the issues, and this helped to address questions four and five.

\subsubsection{Phase 2: Student Survey}

The online survey garnered 62 responses over a period of 16 days. As expected by the researcher, most respondents indicated their stress level as being increased during their postsecondary experience (77.4\%), with 19.4\% reporting their stress level as neutral and two respondents reporting their stress level as decreased (3.2\%). 


\section{Level of stress/mental distress \\ during the post-secondary experience}

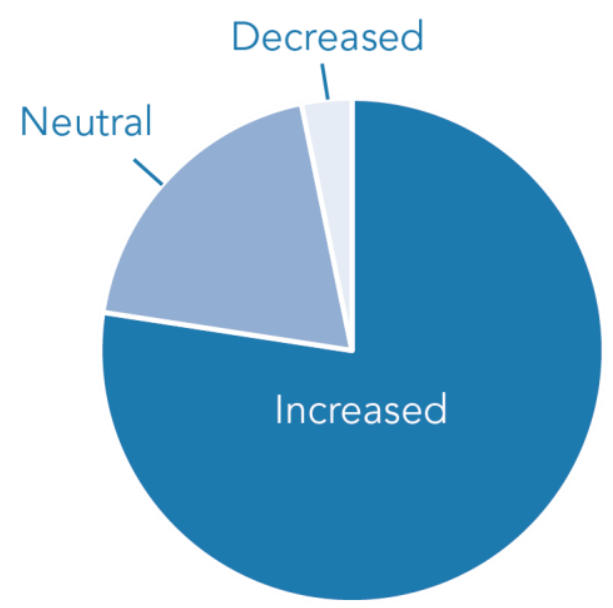

Illustration 31: Pie chart showing levels of stress/mental distress during the post-secondary experience.

The factors cited as having the highest negative impact on mental health during the postsecondary experience were academic pressure with an average score of $2.87 / 4$, disrupted sleeping patterns (2.08/4), spending too much time indoors/lack of contact with nature (2.07/4), and finances (1.96/4). Other factors listed by the respondents were personal health and personal issues such as chronic pain, burn out, and self-doubt; six responses were reported and all that included a rating rated these issues as a $4 / 4$ impact level. The second largest category of listed responses (with five responses) was external events, such as the death of a parent or a student suicide, with an average impact rating of $3 / 4$.

\subsubsection{Improving Mental Health}

Most of the respondents (78.7\%) reported that they took steps to improve their mental health during their post-secondary experience. Of the steps they took to improve their mental health, factors related to physical health all rated highly, as did factors related to friends and socialization. Exercise was rated as the most impactful, with an average score of $2.35 / 4$, followed by confiding in a friend/friends (2.28/4), healthy eating habits (2.27/4), better sleeping habits (2.24/4), and increasing socialization (2.00/4). Of the multiple-choice answers, using an online therapy program was rated as the least impactful with an average score of $0.31 / 4$. Following that was using a post-secondary institution service (0.61/4) and reducing technology use (1.05/4). 
Other factor categories listed by the respondents were relaxation and hobbies (three responses) and physical and mental health treatments (also three responses).

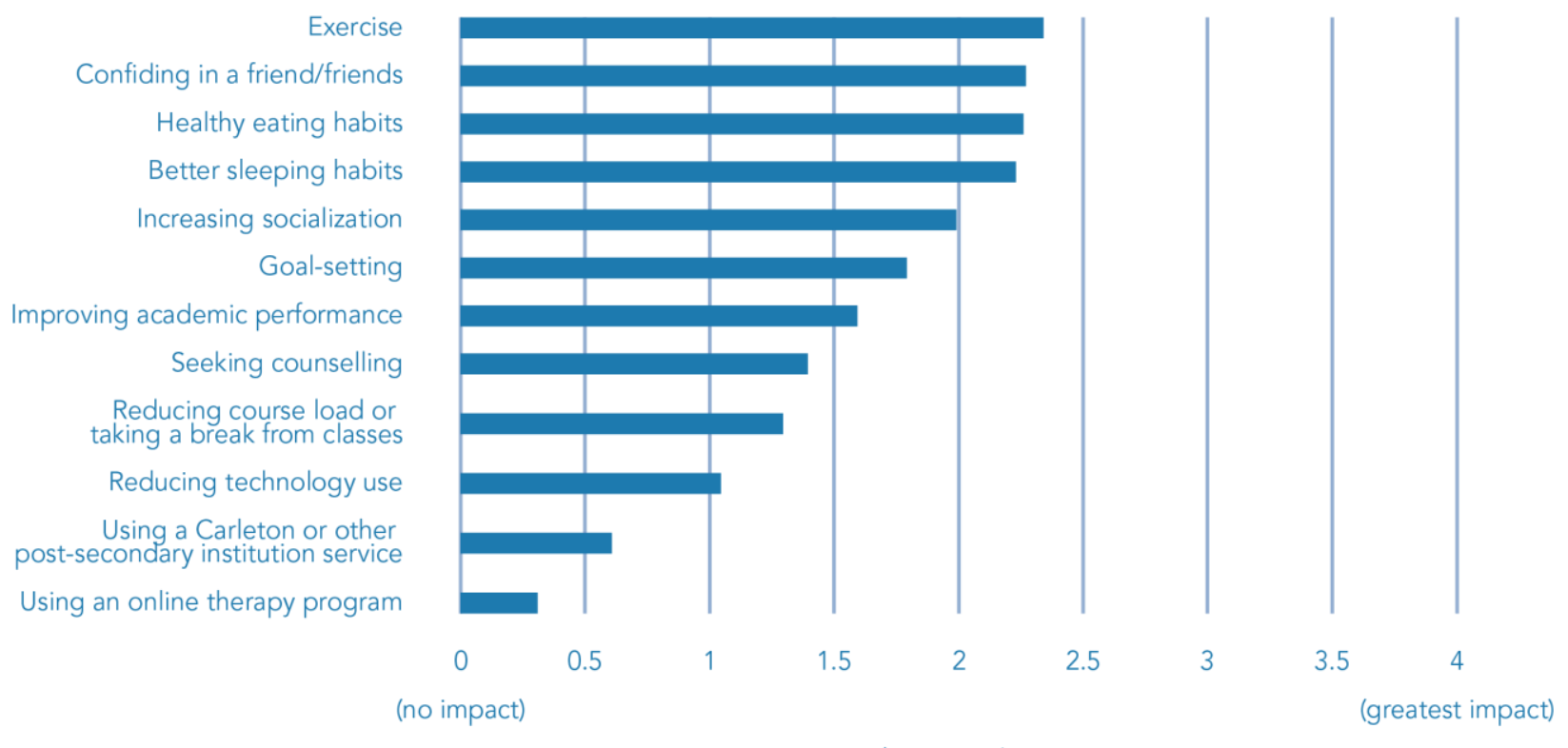

Illustration 32: Steps taken to improve mental health during the post-secondary experience and their impact rating.

The factors respondents selected as having contributed to their neutral or improved levels of mental health during their post-secondary experience were scored somewhat differently to the scores of factors that positively impacted their negative mental health during their postsecondary experience; however, the top five average scores included the same factors (those related to physical health and socializing/confiding in friends).

The factor cited as having the greatest impeding impact on the desire or ability to take steps to improve mental health was feeling overwhelmed with other priorities $(67.6 \%)$, followed by lack of knowledge about how to improve mental health (41.2\%), feeling unable/helpless to improve your mental health (29.4\%), and belief that your mental health is static and would not be improved by your actions $(11.8 \%)$. Listed responses stated that the respondents' mental health was not an issue, that they were unaware of their own issues, or that they expressed intimidation and overwhelm as limiting factors. 


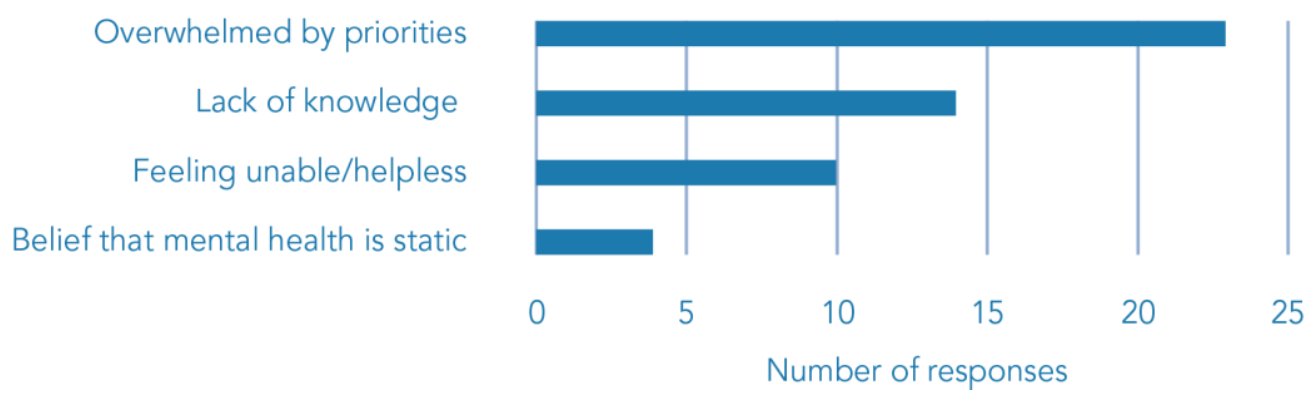

Illustration 33: Factors cited as having the greatest impeding impact on the desire or ability to take steps to improve mental health.

\subsubsection{Mental Health Services}

Most (38.7\%) respondents indicated that they were somewhat aware of their institution's mental health services, $32.3 \%$ were reportedly unaware, and 29\% were aware. Of the multiple-choice responses, $47.1 \%$ reported they learned about the services on the institution website, $23.5 \%$ said through faculty and staff, and 8.8\% said in class. Of the listed responses, $11.8 \%$ had responses related to learning about services through their friends or peers and $8.8 \%$ listed some form of print media.

Only $30.6 \%$ of respondents reported that they used their institution's mental health services. Of the 18 responses detailing which service they used, $13(68.4 \%)$ reported using counselling or therapy and three $(15.8 \%)$ reported using health or medical services.

The largest percentage (47.8\%) of respondents reported that they did not use their institute's mental health services because they did not feel the need to use them. Following that, 37.0\% indicated that they were not sure which service was appropriate for them. The least indicated response $(23.9 \%)$ was not knowing how to find information about the services. Listed responses to this question included lack of time or energy and feeling like their issue was not serious enough to warrant using an institution's services. 


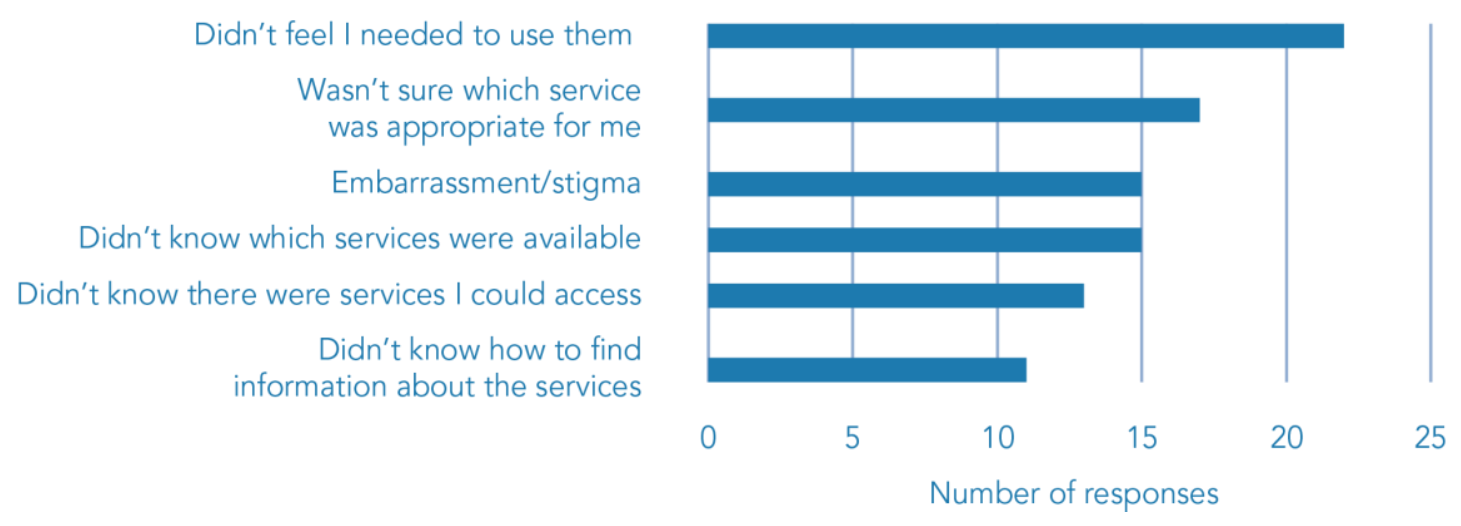

Illustration 34: Reasons cited for not using a post-secondary institution's mental health services.

\subsubsection{Results led to Intervention Opportunity}

In Phase 1, the expert interviewees talked extensively about Carleton's many services, yet "using a Carleton/other post-secondary service" received a low rating in terms of improving mental health (an average impact rating of $0.61 / 4$ ). This information presented a potential intervention opportunity: could it be valuable to communicate information with students about how to improve their mental health without using a mental health service? This is especially relevant since services such as health and counselling are overwhelmed with demand; as participant three stated "At health and counselling they're drowning a little bit." This communication could also potentially reach students who feel too overwhelmed to reach out to health and counselling. The insight into this opportunity led to the third research sub-question: how will experts and the target audience perceive the effectiveness of the proposed design intervention in informing students about their mental health and changing their mental health behaviours?

\subsection{Research Sub-Question 3}

The choice to use a persuasive health campaign using graphic messages is discussed in section 3.4. This decision led to a return to the literature. The topics of health behaviours, health promoting messages, and visual communication were reviewed in preparation for creating a graphic health promotion campaign.

These graphic messages were created in response to questions four and five that arose from Phase 1: 
4. Can students be prompted to increase their repertoire of coping skills to improve their resilience?

5. How can students experiencing mental distress be reached if they do not seek out help?

\subsection{Main Research Question}

To address the main research question, the following questions were posed about the mental health promoting graphics:

1. Are these graphic messages understandable? Purposeful?

2. Will these graphic messages:

a. Cause post-secondary students to examine their own habits and behaviour?

b. Encourage post-secondary students to take steps to improve their mental health?

c. Cause post-secondary students to want to learn more about the topics presented?

d. Teach post-secondary students about how to improve their mental health?

e. Contribute to the de-stigmatization of mental health improvement?

f. Appeal to post-secondary students and catch their interest?

3. Is the layout and graphic design of these graphic messages effective?

a. Are the graphic messages legible?

b. Is the font/typeface appropriate?

c. Are the graphic messages distracting or inconsistent?

d. Is space used effectively? Are the graphic messages cluttered?

e. Are colour and contrast used appropriately?

f. Are the hierarchy and organization of data appropriate?

4. Is the design of these graphic messages appropriate for their audience?

a. Does the design facilitate understanding?

5. Will post-secondary students find the graphic messages aesthetically pleasing?

\subsubsection{Phase 3 and 4: Graphic Message Feedback Form}

This feedback form was created to answer the evaluative questions about the graphics. The feedback form was filled out by both the expert interviewees as well as current and former postsecondary students. 


\subsubsection{Evaluating Message Contents}

The individual graphic messages were rated with four statements:

1. The information conveyed in this image is important for post-secondary students to know

2. Post-secondary students will likely examine their own behaviour and habits after viewing this graphic.

3. The information conveyed in this graphic will help encourage post-secondary students to take steps to improve their mental health.

4. Post-secondary students are likely to want to learn more after seeing this graphic.

Respondents scored each statement with a score from 0 (strongly disagree) to 4 (strongly agree).

Table 7: Scores for the four statements related to the individual graphic messages.

\begin{tabular}{|c|c|c|c|c|c|c|}
\hline \multirow[t]{2}{*}{ Statements } & \multicolumn{2}{|c|}{ Expert Interviewees } & \multicolumn{2}{|c|}{$\begin{array}{l}\text { Post-secondary } \\
\text { students }\end{array}$} & \multicolumn{2}{|l|}{ Overall } \\
\hline & Median & Average & Median & Average & Median & Average \\
\hline \multicolumn{7}{|c|}{ Graphic message 1: Healthy Eating } \\
\hline Statement 1 & 4 & 3.38 & 3 & 3.31 & 3 & 3.32 \\
\hline Statement 2 & 2.5 & 2.13 & 2 & 2.25 & 2 & 2.24 \\
\hline Statement 3 & 2 & 1.88 & 2 & 2.18 & 2 & 2.14 \\
\hline Statement 4 & 2 & 1.75 & 2 & 2.06 & 2 & 2.02 \\
\hline Graphic 1 Overall & 2 & 2.28 & 3 & 2.45 & 3 & 2.43 \\
\hline \multicolumn{7}{|c|}{ Graphic message 2: Confiding } \\
\hline Statement 1 & 4 & 3.75 & 4 & 3.50 & 4 & 3.53 \\
\hline Statement 2 & 2.5 & 2.50 & 3 & 2.73 & 3 & 2.69 \\
\hline Statement 3 & 2.5 & 2.38 & 3 & 2.53 & 3 & 2.51 \\
\hline Statement 4 & 3 & 2.63 & 2 & 2.22 & 2 & 2.27 \\
\hline Graphic 2 Overall & 3 & 2.81 & 3 & 2.74 & 3 & 2.75 \\
\hline \multicolumn{7}{|c|}{ Graphic message 3: Exercise } \\
\hline Statement 1 & 4 & 3.63 & 4 & 3.53 & 4 & 3.54 \\
\hline Statement 2 & 2 & 2.13 & 3 & 2.82 & 3 & 2.73 \\
\hline Statement 3 & 2.5 & 2.25 & 3 & 2.67 & 3 & 2.61 \\
\hline Statement 4 & 2 & 1.88 & 3 & 2.41 & 2 & 2.34 \\
\hline Graphic 3 Overall & 2.5 & 2.47 & 3 & 2.86 & 3 & 2.81 \\
\hline
\end{tabular}




\begin{tabular}{|c|c|c|c|c|c|c|}
\hline \multicolumn{7}{|c|}{ Graphic message 4: Scrolling } \\
\hline Statement 1 & 4 & 3.63 & 4 & 3.68 & 4 & 3.67 \\
\hline Statement 2 & 3 & 2.75 & 3 & 2.96 & 3 & 2.93 \\
\hline Statement 3 & 3 & 2.88 & 3 & 2.76 & 3 & 2.78 \\
\hline Statement 4 & 3 & 2.63 & 2 & 2.45 & 3 & 2.47 \\
\hline Graphic 4 Overall & 3 & 2.97 & 3 & 2.96 & 3 & 2.96 \\
\hline \multicolumn{7}{|c|}{ Graphic message 5: Socializing } \\
\hline Statement 1 & 4 & 3.63 & 4 & 3.41 & 4 & 3.44 \\
\hline Statement 2 & 2.5 & 2.13 & 3 & 2.66 & 3 & 2.59 \\
\hline Statement 3 & 2 & 2.13 & 3 & 2.64 & 3 & 2.57 \\
\hline Statement 4 & 2 & 1.75 & 3 & 2.33 & 2 & 2.25 \\
\hline Graphic 5 Overall & 2 & 2.41 & 3 & 2.76 & 3 & 2.71 \\
\hline \multicolumn{7}{|c|}{ Graphic message 6: Sleep } \\
\hline Statement 1 & 4 & 3.75 & 4 & 3.61 & 4 & 3.63 \\
\hline Statement 2 & 3 & 3.00 & 3 & 2.84 & 3 & 2.86 \\
\hline Statement 3 & 3 & 2.88 & 3 & 2.59 & 3 & 2.63 \\
\hline Statement 4 & 3 & 2.75 & 3 & 2.54 & 3 & 2.57 \\
\hline Graphic 6 Overall & 3 & 3.09 & 3 & 2.89 & 3 & 2.92 \\
\hline \multicolumn{7}{|l|}{ Statements Overall } \\
\hline Statement 1 Overall & 4 & 3.63 & 4 & 3.51 & 4 & 3.52 \\
\hline Statement 2 Overall & 3 & 2.44 & 3 & 2.71 & 3 & 2.67 \\
\hline Statement 3 Overall & 2.5 & 2.40 & 3 & 2.56 & 3 & 2.54 \\
\hline Statement 4 Overall & 2 & 2.23 & 3 & 2.34 & 2 & 2.32 \\
\hline
\end{tabular}

The content of these messages was generally rated as important for post-secondary students to know; all six graphic messages scored higher than 3.00/4 for this statement, with an average across all six graphic messages of 3.52/4 and a median score across all six graphic messages of 4. The next two statements (about the graphics causing one to examine one's own behaviour, take steps to improve mental health) had a median score of 3, indicating general agreement, and the fourth statement (about the graphics causing one to want to learn more) had a median score of 2 , indicating and ambiguous or neutral opinion.

The six graphic messages had messages about healthy eating, confiding, exercise, endless scrolling, socializing, and sleep. The messages that were rated most highly as potentially causing post-secondary students to examine their own behaviours were the message on scrolling (an 
average score of 2.93/4 over both populations) and sleep (an average score of 2.86/4 over both populations). These messages were also rated the most highly in terms of encouraging students to take steps to improve their mental health (2.78/4 for scrolling and 2.63/4 for sleep) and causing post-secondary students to want to learn more (2.47/4 for scrolling and 2.57/4 for sleep). Additionally, several respondents commented that the graphic on scrolling was their favourite or the best. The graphic message that rated lowest in terms of all four statements was the one on healthy eating.

\subsubsection{Evaluating Design Effectiveness}

All aspects evaluated by the expert interviewees scored on average at least a 2 and had at least a median score of 2 (neither agree nor disagree). However, only three aspects scored on average a 3 (agree) or above. The student population generally rated the graphics more favorably in all categories than the expert interviewees, with only two aspects rating on average below a 3/4 and all aspects having a median of at least 3 . When the responses from both populations were added together, all statements had a median score of at least 3 (somewhat agree), indicating at least moderate agreement.

Table 8: Scores for the statements evaluating the usefulness, legibility, design, and aesthetics of the graphic messages

\begin{tabular}{|c|c|c|c|c|c|c|}
\hline \multirow[t]{2}{*}{ Statements } & \multicolumn{2}{|c|}{$\begin{array}{l}\text { Expert } \\
\text { Interviewees }\end{array}$} & \multicolumn{2}{|c|}{$\begin{array}{l}\text { Post-secondary } \\
\text { Students }\end{array}$} & Overall & \multirow[b]{2}{*}{ Average } \\
\hline & Median & Average & Median & Average & Median & \\
\hline Usefulness & & & & & & \\
\hline $\begin{array}{l}\text { I can understand the message of these } \\
\text { graphics. }\end{array}$ & 3.5 & 3.38 & 4 & 3.76 & 4 & 3.71 \\
\hline These graphics have a clear purpose. & 3 & 3.13 & 4 & 3.75 & 4 & 3.66 \\
\hline $\begin{array}{l}\text { Post-secondary students will learn } \\
\text { something about how to improve their } \\
\text { mental health from these graphics. }\end{array}$ & 3 & 3.00 & 3 & 3.10 & 3 & 3.08 \\
\hline $\begin{array}{l}\text { These graphics will encourage post- } \\
\text { secondary students to take steps to } \\
\text { improve their mental health. }\end{array}$ & 2 & 2.00 & 3 & 2.61 & 3 & 2.53 \\
\hline
\end{tabular}




\begin{tabular}{|c|c|c|c|c|c|c|}
\hline $\begin{array}{l}\text { These graphics will contribute to the de- } \\
\text { stigmatization of mental health } \\
\text { improvement. }\end{array}$ & 2.5 & 2.25 & 3 & 3.04 & 3 & 2.93 \\
\hline Overall & 3 & 2.75 & 3 & 3.25 & 3 & 3.18 \\
\hline \multicolumn{7}{|l|}{ Legibility } \\
\hline These graphics are easy to read. & 2.5 & 2.38 & 4 & 3.43 & 3 & 3.29 \\
\hline $\begin{array}{l}\text { The font typeface, size, and colour are } \\
\text { appropriate. }\end{array}$ & 3 & 2.88 & 3 & 3.02 & 3 & 3.00 \\
\hline Overall & 3 & 2.63 & 3 & 3.23 & 3 & 3.14 \\
\hline \multicolumn{7}{|l|}{ Design } \\
\hline $\begin{array}{l}\text { The graphic style is appropriate for its } \\
\text { audience (post-secondary students). }\end{array}$ & 2 & 2.13 & 3 & 3.16 & 3 & 2.98 \\
\hline $\begin{array}{l}\text { The graphics were not distracting or } \\
\text { inconsistent }\end{array}$ & 2.5 & 2.13 & 3 & 3.22 & 3 & 3.07 \\
\hline Space was used effectively. & 2 & 2.88 & 3 & 3.25 & 3 & 3.20 \\
\hline $\begin{array}{l}\text { The graphics were not excessively } \\
\text { cluttered. }\end{array}$ & 3 & 2.75 & 3 & 3.27 & 3 & 3.20 \\
\hline Colour and contrast were used effectively. & 2 & 2.88 & 3 & 3.20 & 3 & 3.15 \\
\hline $\begin{array}{l}\text { The overall design of these graphics } \\
\text { facilitates understanding. }\end{array}$ & 3 & 2.50 & 3 & 3.22 & 3 & 3.12 \\
\hline $\begin{array}{l}\text { The hierarchy and organization of data } \\
\text { were appropriate. }\end{array}$ & 3 & 2.75 & 3 & 3.22 & 3 & 3.16 \\
\hline Overall & 3 & 2.57 & 3 & 3.21 & 3 & 3.13 \\
\hline \multicolumn{7}{|l|}{ Aesthetics } \\
\hline $\begin{array}{l}\text { These graphics will reach post-secondary } \\
\text { students in a way that will appeal to them } \\
\text { and catch their interest. }\end{array}$ & 2 & 2.13 & 3 & 2.73 & 3 & 2.64 \\
\hline $\begin{array}{l}\text { These graphics were aesthetically } \\
\text { pleasing. }\end{array}$ & 3 & 2.38 & 3 & 3.08 & 3 & 2.98 \\
\hline Overall & 2.5 & 2.25 & 3 & 2.90 & 3 & 2.81 \\
\hline
\end{tabular}

Most highly rated were the statements "I can understand the message of these graphics" and "These graphics have a clear purpose", with average scores of 3.71/4 and 3.66/4 respectively and median scores of 4 each over both populations. Lowest rated were the statements "These graphics will reach post-secondary students in a way that will appeal to them and catch their interest" and "These graphics will encourage post-secondary students to take steps to improve their mental health", with ratings $2.64 / 4$ and 2.52/4. 
Table 9: Comments of both respondent populations from questions 8 and 12.

\begin{tabular}{|c|c|c|}
\hline Comment subject & Description & $\begin{array}{l}\text { \# of } \\
\text { comments }\end{array}$ \\
\hline \multicolumn{3}{|l|}{ Visuals } \\
\hline \multirow{6}{*}{$\begin{array}{l}\text { Illustrated } \\
\text { characters }\end{array}$} & Liked the characters/character style & 5 \\
\hline & Disliked the characters/character style & 4 \\
\hline & Felt the characters were too immature or silly & 8 \\
\hline & Liked the mix of characters and photo backgrounds & 1 \\
\hline & Disliked the mix of characters and photo backgrounds & 1 \\
\hline & Suggested increased diversity of representation & 3 \\
\hline Background & Felt the background was distracting & 2 \\
\hline Contrast & Felt that there was not enough contrast & 6 \\
\hline Colour & Disliked the colour choice & 3 \\
\hline \multicolumn{3}{|l|}{ Messages } \\
\hline Brevity & Suggested shortening the text & 4 \\
\hline \multirow[t]{2}{*}{ Message content } & $\begin{array}{l}\text { Suggested pointing out benefits of changed behaviour to the } \\
\text { audience }\end{array}$ & 1 \\
\hline & Suggested including statistics & 1 \\
\hline \multicolumn{3}{|l|}{ Text } \\
\hline \multirow[t]{2}{*}{ Font } & Not enough contrast between font and background & 1 \\
\hline & Felt font size was not large enough & 5 \\
\hline Text backgrounds & Suggested consistency in text backgrounds & 2 \\
\hline \multirow[t]{2}{*}{ Emphasizing text } & Suggested emphasizing steps to take & 1 \\
\hline & Suggested emphasizing campus resources & 1 \\
\hline \multicolumn{3}{|l|}{ Design } \\
\hline Buttons & Suggested two buttons is confusing & 1 \\
\hline \multicolumn{3}{|l|}{ Individual graphics } \\
\hline Scrolling graphic & Especially liked the scrolling graphic & 5 \\
\hline \multicolumn{3}{|l|}{ Overall } \\
\hline \multirow[t]{3}{*}{ Positive } & No changes needed & 2 \\
\hline & Liked the messages & 4 \\
\hline & Liked the graphics in general & 5 \\
\hline Impressions & Suggested making the mental health angle more obvious & 1 \\
\hline Simplicity & Liked the simpler graphics & 1 \\
\hline Bold visuals & Suggested that bolder visuals would attract increased attention & 1 \\
\hline Response & Suggested response to graphics is individual & 2 \\
\hline
\end{tabular}


The main issue that was mentioned by respondents when asked about changes to increase the effectiveness of the graphics was the illustrated characters. Eight respondents had unfavorable attitudes towards the illustrated characters, calling them too goofy, childish, silly, or cartoony. Another issue that was mentioned repeatedly was the use of contrast. Six respondents mentioned issues with the contrast between the illustrated characters and the background images, stating that the background was overpopulated, and suggesting blurring, darkening, or desaturating the background to make the characters "pop" against it.

Five respondents suggested to either enlarge the font in the message box or increase its legibility in some way. Two respondents mentioned the colour use, suggesting use of calmer colours and non-primary colours. Another two respondents stated that the use of text box backgrounds should be consistent. One respondent suggested emphasizing the steps to take, and another respondent suggested emphasizing the campus resources. Finally, ten respondents had positive feedback, stating that the graphics attracted them to the poster' information.

\subsubsection{Evaluating Format Effectiveness}

Respondents were asked to rate the potential effectiveness of a series of possible formats on a scale from 0 (least effective) to 4 (most effective). By expert interviewee respondents, most highly rated was including the graphics as a slide in a class lecture, with an average score of 3.29/4 and a median score of 3.5. Including the graphics in a mass email was ranked as least effective, with an average score of $1.14 / 4$ and a median score of 1 . When asked if the graphics should be displayed in a different format, three respondents suggested social media channels (with two ratings of 3/4), one suggested the institution's app, and one suggested the institution's health and well-being website.

Between the deployment of the feedback form for expert interviewees and for post-secondary students, "social media" was added as an option. Most highly rated by post-secondary students was displaying the graphics on a digital signage system with a score of 3.04/4. Posting the graphics on social media ranked second most effective, with a score of 3.02/4. Including the 
graphics in a mass email was again ranked as least effective, with an average score of 1.90/4 and a median score of 2 .

Table 10: Scores for the different potential formats for transmitting the graphic messages

\begin{tabular}{|c|c|c|c|c|c|c|}
\hline \multirow[t]{2}{*}{ Format } & \multicolumn{2}{|c|}{$\begin{array}{l}\text { Expert } \\
\text { Interviewees }\end{array}$} & \multicolumn{2}{|c|}{$\begin{array}{l}\text { Post-secondary } \\
\text { Students }\end{array}$} & \multicolumn{2}{|l|}{ Overall } \\
\hline & Median & Average & Median & Average & Median & Average \\
\hline $\begin{array}{l}\text { As a pop-up ad on the main page } \\
\text { of Carleton's Mental Health and } \\
\text { Well-Being website. }\end{array}$ & 2.5 & 2.61 & 3 & 2.50 & 3 & 2.59 \\
\hline $\begin{array}{l}\text { As a pop-up ad that appears when } \\
\text { you search for a related topic on } \\
\text { Carleton's Mental Health and } \\
\text { Well-Being website. }\end{array}$ & 3 & 2.65 & 3 & 2.38 & 3 & 2.61 \\
\hline As a mass email to students. & 1 & 1.90 & 2 & 1.13 & 2 & 1.80 \\
\hline As a series of posters on campus. & 3 & 2.92 & 3 & 2.25 & 3 & 2.83 \\
\hline $\begin{array}{l}\text { As an ad on Carleton's digital } \\
\text { signage system. }\end{array}$ & 3 & 3.04 & 3 & 2.88 & 3 & 3.02 \\
\hline $\begin{array}{l}\text { As a slide in the lecture slides of a } \\
\text { course. }\end{array}$ & 3.5 & 2.78 & 3 & 3.38 & 3 & 2.86 \\
\hline On Carleton's social media pages. & 3 & 3.00 & 3 & 3.02 & 3 & 3.02 \\
\hline
\end{tabular}

The post-secondary students had several suggestions for displaying the graphics in physical spaces on campus, including as a mural (two suggestions), in the cafeteria (two suggestions), in washrooms (two suggestions), and on office doors (one suggestion). There were three suggestions for sending the graphics as a text message. Two respondents suggested printing the graphics in postcard form, and there were another two suggestions of including the graphics on clothing. Two respondents suggested featuring the graphics on the university's website's main page, and finally one respondent suggested turning the graphics into short video clips or animations. 


\section{Chapter 5: Discussion}

Post-secondary students are experiencing elevated levels of mental ill health and distress (Lipson \& Eisenberg 2018; Pedrelli et al., 2015; Brown, 2020; Robinson et al., 2016). Additionally, students may be more emotionally fragile and less resilient than in the past (Gray, 2020; CIGNA, 2020; Davydov et al., 2010). However, post-secondary institutions are having difficulty keeping up with the demand for health and counselling services (Brown, 2020; Coordinating Committee of Vice Presidents Students, 2015). Therefore, there is a need for an intervention that does not increase the burden on health and counselling services.

The purpose of this study is to explore the factors that are contributing to student mental ill health and develop a possible intervention that can help increase student resilience. The intervention that was determined to be the most viable was that of a persuasive health campaign that uses graphic messages to communicate information on how students can modify their behaviour to positively influence their own mental health and give resources to help them with those behaviour changes. The investigation also aims to determine the elements that contribute to a graphic message's effectiveness in increasing attention and engagement, communicating information, influencing attitudes and intentions, and subsequently changing behaviour.

\subsection{Research Sub-Questions 1 and 2}

Research sub-question 1 (how can the student mental health crisis be addressed through design in a way that strengthens student mental health self-efficacy and resilience?) and research subquestion 2 (what factors affecting mental health can be targeted through a design intervention to create the greatest positive impact on student mental health?) were addressed with the creation of the graphic message prototypes. How and why these messages were created is discussed in section 3.4.

\subsection{Research Sub-Question 3}

This section deals with the third research sub-question: how will experts and the target audience perceive the effectiveness of the proposed design intervention in informing students about their mental health and changing their mental health behaviours? 


\subsubsection{Effectiveness of the Graphic Messages in Informing Post-Secondary Students}

In the graphic message feedback form, the statement "Post-secondary students will learn something about how to improve their mental health from these graphics" was rated favorably by both populations. However, to definitively answer this question would require further study; with a study structure like that employed by Borg et al. (2019), in which the campaign was developed and launched, and the audience's awareness of the campaign and knowledge about the campaign subject matter was evaluated using pre- and post-intervention surveys (see section 2.4.6 for more detail).

\subsubsection{Effectiveness of the Graphic Messages in Changing Behaviour}

In terms of encouraging students to improve their mental health, it is hard to determine why this aspect was not rated highly, especially by the expert interviewee population (an overall average rating of 2.54/4 and an expert interviewee median score of 2.5 for the statement "The information conveyed in this graphic will help encourage post-secondary students to take steps to improve their mental health" across all six graphics and an average rating of 2.53/4 for the statement "These graphics will encourage post-secondary students to improve their mental health" and an expert interviewee median score of 2). It may be that the effectiveness of these graphics in changing behaviour is low, or that the perceived effectiveness of health messages in general is low. The graphics were designed to be effective in changing behaviour based on some of the behavioural models discussed in the literature review. The graphics were created to inform the audience about the behaviours, give the audience concrete steps on how to perform the behaviours, and to prompt the audience to perform the behaviours. This addresses all three aspects of the IMB model (Fisher et al., 2003; Klonoff, 2019) at least somewhat (being well informed about the behaviour, highly motivated to perform the behaviour, and sufficiently skilled to perform the behaviour). Additionally, in terms of the TTM (Luca \& Suggs, 2012; De Gruchy \& Coppel, 2008; Prochaska \& Velicer, 1997; op den Akker et al., 2016), informing the audience about the behaviours can help shift them from the precontemplation stage to the contemplation stage; giving the audience concrete steps to change their behaviour can help shift them between the contemplation and the preparation/determination stage; and prompting the audience to perform the behaviours can help them shift between the preparation/determination 
and the action stage. Because respondents generally agreed that post-secondary students will learn something about how to improve their mental health from these graphics, in theory this should have some effect on their actual behaviours. However, to determine whether these graphics are effective at changing behaviour is beyond the scope of this study. The purpose of this study is to give recommendations to help future researchers in creating a more effective mental health promotion campaign for post-secondary students. Hopefully, using the guidelines laid out below, future researchers can create more effective graphics, and test whether these graphics have an actual impact on changing behaviour.

\subsection{Main Research Question}

This section of the discussion will discuss the results from the study related to the main research question: how can graphic messages promoting positive mental health behaviours be designed to maximize their effectiveness?

\subsubsection{Evaluation of Message Success}

As stated, median scores indicated that respondents strongly agreed that the information in the graphic messages is important for post-secondary students to know; respondents moderately agreed that the graphic messages would cause students to examine their own behaviour and would help encourage post-secondary students to take steps to improve their mental health, and respondents neither agreed nor disagreed that the graphic messages would cause post-secondary students to want to learn more. However, some of the graphic messages were rated more highly than others. This subsection of the discussion will examine the differences between the most highly rated graphic messages and the least highly rated graphic message to find possible conclusions on what makes a graphic message successful.

The graphics on scrolling and sleep were rated most highly in terms of the four evaluative statements (see Appendix G). The message contents for these two graphics are:

Scrolling: Did you know? Endless scrolling is detrimental to your mental health. A study found that college and university students spend on average 9 hours on their smartphones daily. Smartphone overuse is linked to increased mental illness and loneliness. Taking a step like 
turning off push notifications can begin to change your phone use if you find it's becoming problematic.

Sleep: Did you know? Sleep deprivation increases the risk for poor mental health. In a survey of current and former university students, disrupted sleeping patterns were ranked as the second most detrimental factor to their mental health (behind academic pressure). Some ways to increase sleep quality are to limit caffeine consumption, reduce technology use before bedtime, and get a good amount of physical activity.

The message content for the least highly rated graphic, healthy eating, is:

Healthy eating: Did you know? Diet is as important to mental health as it is to physical health. A recent study found that a diet high in vegetables, fruits, legumes, nuts, beans, cereals, grains, fish, and olive oil led to a reduction in depression among participants. Visit Carleton's nutrition webpage to learn tips on healthy eating at the cafeteria or send a question to Carleton's dietitian!

One notable difference between these messages is the inclusion in the first two messages of concrete steps that the student could take on their own (without seeking an outside resource). Although the message on healthy eating includes information that could potentially persuade a student to change their behaviour (by eating more of the foods listed), the steps are not as concrete. Also, one respondent stated:

\section{I often wonder if messaging that points to benefits for the reader would be} more engaging, as in what is in it for them to consider this behaviour change, rather than our typical public health messaging. Or messaging that suggests one quick change or life hack that would contribute to more overall gain.

This could indicate that giving concrete behavioural change tips or "hacks" affect the graphic's effectiveness. This may increase the viewer's perceived behavioural control, which can enhance the likelihood that behavioural intentions are more likely to be carried out according to the theory of reasoned action/planned behaviour (Ajzen, 2002).

Additionally, as a participant stated: 
The phone overuse [graphic] struck me because it said, 'if you realize it's becoming a problem'. This is a key phrase which sets it apart from the other ads that are for people in general.

The phrasing of the message to include an assessment of one's own habits may have also contributed to its higher effectiveness ratings by making the message seem more personally relevant, which according to the ELM and the SREM should make the audience pay closer attention to the message and make the message more persuasive (Burnkrant \& Unnava, 1995; Chang, 2011; Jensen et al., 2012; Petty \& Cacioppo, 1986).

Another difference between these messages is that the first two messages discuss the negative effects of the discussed behaviours (linking smartphone overuse to increased mental illness and loneliness and linking disrupted sleep to detrimental mental health effects), whereas the message about healthy eating only discusses the protective effects of positive behaviours (a healthy diet). This may indicate that discussing the negative effects of behaviours that may harm mental health is more effective than discussing the positive or protective effects of wanted behaviours. If it is assumed that the messages have a low perceived efficacy, this is in line with Block and Keller's findings that negative framing is more effective for messages that use a high-involvement processing style (1995).

\subsubsection{Evaluation of Character Design}

As stated, many respondents commented that the character style used was too childish or silly for the audience or subject matter. This is an important issue as relatability to the characters may be critical to the effectiveness of the graphic messages. According to the ELM and the SREM, the messages are more likely to be attention-getting and persuasive if they are tailored to the audience (Jensen et al., 2012; Chang, 2011). Because the illustrations were highly stylized and playful, many respondents characterized the characters as more appropriate for a younger audience; respondents stated that they were "far too childish for a post-secondary audience", and "a bit immature". For this reason, the illustrations may be detrimental to the effectiveness of the graphics. Additionally, the statement "The graphic style is appropriate for its audience" and "These graphics will reach post-secondary students in a way that will appeal to them and catch 
their interest" both had a median score of 2 from the expert interviewees. This indicates that a more mature style of illustration may be more appropriate for this application.

The graphic characters may also have been unrelatable to some respondents for reasons other than style. As three commenters stated, the characters should represent a diverse range of people. This makes sense as being able to see oneself represented as the characters can help make the messages more personal, and post-secondary students are a very heterogeneous group in terms of ethnicity, gender, age, ability, and personality. As one respondent commented:

For the exercise one, there was a student who looked very athletic running and I was thinking that's not me [...] Perhaps more representation of women would be good. I see young guys and I'm like, they experience the world differently than I do.

Therefore, ensuring representation of a diverse group of people within the graphic messages is important.

\subsubsection{Evaluation of Backgrounds and Contrast}

Three expert interviewee respondents and three student respondents stated that the graphic on scrolling was the best or their favourite; this was the only graphic that was singled out in this way. This graphic was particular because it was the only one without an everyday context; the character was floating in outer space as opposed to being situated in a café, lecture hall, or campus, etc. 


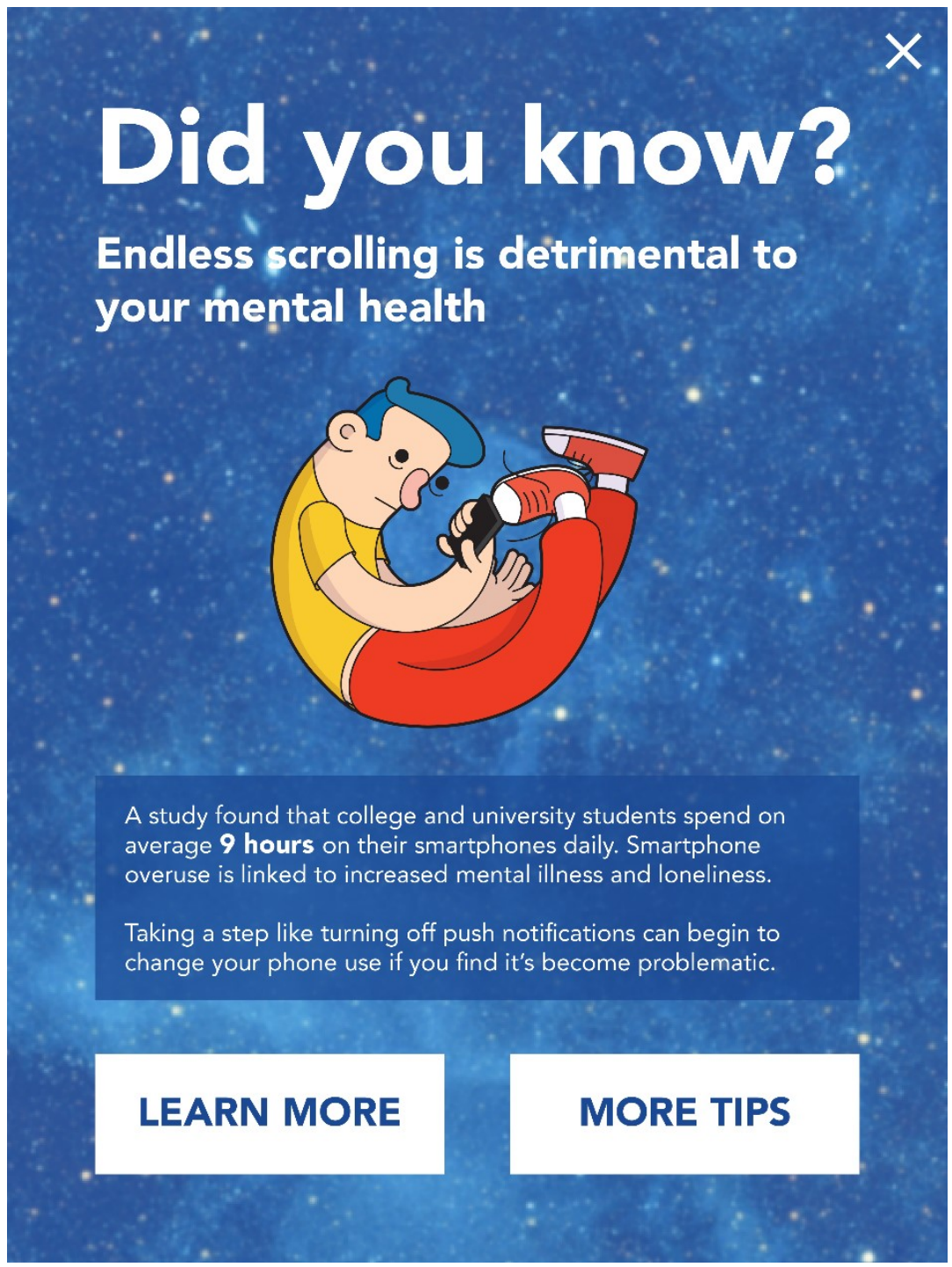

Illustration 35: Graphic message on scrolling.

Another reason the scrolling graphic may have been singled out as the best may be the visual simplicity; because the graphic is not in a realistic context, the background is visually uniform. As one respondent stated, "[I] liked some graphics more than others. The simpler the better". There were two other commenters that suggested that the background was too populated. This relates to the concepts of visual clutter and simplicity discussed in the literature review; visual complexity adds value to a composition up to a point, at which it begins to diminish the value of the composition (Davidson, 2017; Kocaoğlu \& Olguntürk, 2018). Because the graphic messages already have a variety of text and illustration elements, a busy background may be pushing the 
composition past the tipping point into visual disorder. Additionally, the respondent preference for the scrolling graphic may indicate that it is not critical to show the characters in a realistic context to create an attractive graphic.

Additionally, although the contrast and colour use had an overall average score of 3.15/4 and a median score of 3 , there were six comments that either indicated that there was not enough contrast between the background and characters/text or suggested increasing the contrast between background and characters/text.

\subsubsection{Evaluation of Text Use}

Although the overall scores for ease of reading and font use were somewhat favorable, the expert interviewees rated the ease of reading much lower (average score of 2.38/4, median score of 2.5) than the student population (average score of 3.43/4, median score of 4). Additionally, five commenters felt that the font size was not large enough, and four commenters suggested shortening the written messages. This may indicate that the message text should be shortened and displayed in a larger font size.

\subsubsection{Evaluation of User Interaction}

One commenter mentioned that having more than one button could cause confusion in terms of not knowing which button to click. This comment is in accordance with the persuasive design principle of simplification; the user is more likely to click through to the website if they are provided with fewer options (Nodder, 2013).

\subsubsection{Design Recommendations}

The design recommendations that arose from the issues discussed in section 5.3.1 to 5.3.5 are summarized in table 11 below. The three final design recommendation categories are based on respondent comments expressing a preference for design simplicity, survey results indicating the preference for the graphic to be displayed on social media or a digital signage system, and respondent suggestions that the graphic should meet accessibility standards. 
Table 11: Summary of design recommendations for graphic messages with reasoning.

\begin{tabular}{|c|c|}
\hline Recommendation & Reasoning \\
\hline $\begin{array}{l}\text { Give recommendations for } \\
\text { actions that are concrete and } \\
\text { can be performed by oneself. }\end{array}$ & $\begin{array}{l}\text { - Respondent preference for scrolling and sleep graphics } \\
\text { (which provide concrete steps) over health eating } \\
\text { graphic (which does not provide concrete steps). } \\
\text { - May increase perceived behavioural control and } \\
\text { therefore increase the likelihood that behavioural } \\
\text { intentions be carried out according to the theory of } \\
\text { reasoned action/planned behaviour (Ajzen, 2002). }\end{array}$ \\
\hline $\begin{array}{l}\text { Use wording that refers to an } \\
\text { assessment of one's own } \\
\text { behaviours. }\end{array}$ & $\begin{array}{l}\text { - Respondent preference for the scrolling graphic } \\
\text { (which mentions assessing one's own behaviour). } \\
\text { May make the message seem more personally } \\
\text { relevant, which according to the elaboration likelihood } \\
\text { model and the self-encoding referencing model should } \\
\text { make the audience pay closer attention to the message } \\
\text { and make the message more persuasive (Burnkrant \& } \\
\text { Unnava, 1995; Chang, 2011; Jensen et al., 2012; Petty } \\
\text { \& Cacioppo, 1986). }\end{array}$ \\
\hline $\begin{array}{l}\text { Discuss the negative effects } \\
\text { of unwanted behaviours. }\end{array}$ & $\begin{array}{l}\text { - Respondent preference for scrolling and sleep graphics } \\
\text { (which discuss the negative effects of unwanted } \\
\text { behaviour) over health eating graphic (which does } \\
\text { not). } \\
\text { - If the messages have a low perceived efficacy and a } \\
\text { high-involvement processing style is used, negative } \\
\text { framing may be more effective (Block \& Keller, } \\
\text { 1995). }\end{array}$ \\
\hline \multicolumn{2}{|c|}{ Character Design Recommendations } \\
\hline Recommendation & Reasoning \\
\hline $\begin{array}{l}\text { Balance the "fun" aspect of } \\
\text { character illustration with age } \\
\text { and maturity appropriateness. }\end{array}$ & $\begin{array}{l}\text { Respondent comments that they did not like the } \\
\text { character design and/or the character design was too } \\
\text { immature/childish for the audience. }\end{array}$ \\
\hline $\begin{array}{l}\text { Ensure the characters have } \\
\text { diverse appearances, genders, } \\
\text { ages, and abilities. }\end{array}$ & $\begin{array}{l}\text { - Respondents commented to ensure diversity of } \\
\text { representation. } \\
\text { - Seeing oneself represented in a message may make } \\
\text { that message seem more personally relevant, leading }\end{array}$ \\
\hline
\end{tabular}




\begin{tabular}{|c|c|}
\hline & $\begin{array}{l}\text { to an increased likelihood of behaviour change (Jensen } \\
\text { et al., 2012; Petty \& Cacioppo, 1986). } \\
\text { - Inclusive marketing (marketing that considers the } \\
\text { importance of consumers seeing themselves reflected } \\
\text { in advertising) has a positive influence on behaviour } \\
\text { (Zalis, 2020). }\end{array}$ \\
\hline \multicolumn{2}{|c|}{ Background Use Recommendations } \\
\hline Recommendation & Reasoning \\
\hline $\begin{array}{l}\text { Favour background images } \\
\text { that are visually uniform or } \\
\text { sparse over cluttered images } \\
\text { of realistic contexts. }\end{array}$ & $\begin{array}{l}\text { - Respondent preference for the scrolling graphic } \\
\text { (which has a visually sparse background). } \\
\text { - Respondent comments that the background images } \\
\text { were too busy or visually distracting. }\end{array}$ \\
\hline $\begin{array}{l}\text { Ensure backgrounds have } \\
\text { high contrast with foreground } \\
\text { elements. }\end{array}$ & $\begin{array}{l}\text { - Respondent comments that there was not enough } \\
\text { contrast between foreground and background } \\
\text { elements. }\end{array}$ \\
\hline \multicolumn{2}{|l|}{ Text Recommendations } \\
\hline Recommendation & Reasoning \\
\hline $\begin{array}{l}\text { Convey message in the most } \\
\text { succinct way possible }\end{array}$ & - Respondent comments that text should be shortened \\
\hline $\begin{array}{l}\text { Ensure font is } \\
\text { large/contrasted enough for } \\
\text { easy reading }\end{array}$ & $\begin{array}{l}\text { - Respondent comments that there was not enough } \\
\text { contrast between text and background elements } \\
\text { - Respondent comments suggesting increased font size }\end{array}$ \\
\hline \multicolumn{2}{|l|}{ Interaction Recommendations } \\
\hline Recommendation & Reasoning \\
\hline $\begin{array}{l}\text { Reduce the number of options } \\
\text { for the user to choose for } \\
\text { simplification. }\end{array}$ & \multirow[t]{2}{*}{$\begin{array}{l}\text { People are more likely to enact a behaviour if it is } \\
\text { simpler to perform (Fogg, 2009) or if they have fewer } \\
\text { options (Nodder, 2013). }\end{array}$} \\
\hline $\begin{array}{l}\text { Ensure that the audience has } \\
\text { a simple way to access } \\
\text { further information (i.e., by } \\
\text { clicking the ad or scanning a } \\
\text { QR code). }\end{array}$ & \\
\hline \multicolumn{2}{|c|}{ Graphic Design Recommendations } \\
\hline Recommendation & Reasoning \\
\hline $\begin{array}{l}\text { Use simplicity as much as } \\
\text { possible in the visuals, layout, } \\
\text { and text. }\end{array}$ & $\begin{array}{l}\text { - Respondent comment that simpler graphics are } \\
\text { preferred. }\end{array}$ \\
\hline
\end{tabular}




\begin{tabular}{|l|c|}
\hline & $\begin{array}{l}\text { Reducing visual clutter can reduce the cognitive load } \\
\text { needed to process a message's content (Davidson, } \\
2017 \text {; Kocaoğlu \& Olguntürk, 2018). }\end{array}$ \\
\hline $\begin{array}{l}\text { Format Recommendations } \\
\text { Recommendation }\end{array}$ & Reasoning \\
\hline $\begin{array}{l}\text { Display the graphics on social } \\
\text { media or on a digital signage } \\
\text { system. }\end{array}$ & $\bullet$ Respondent preference for these formats. \\
\hline $\begin{array}{l}\text { Accessibility Recommendations } \\
\text { Recommendation }\end{array}$ & Reasoning \\
\hline $\begin{array}{l}\text { Ensure graphics meet web } \\
\text { accessibility standard (i.e., } \\
\text { providing alt-text for screen } \\
\text { readers) }\end{array}$ & $\begin{array}{l}\text { Respondent comment to meet accessibility standards. } \\
\text { Meeting Ontario web accessibility standards } \\
\text { (Government of Ontario, 2020). }\end{array}$ \\
\hline
\end{tabular}

\subsection{A Human-Centered Design Process}

This study used elements of Wallen \& Daut's HCD framework for behaviour change strategy (2018), adapted from IDEO’s HCD framework (2015), although not in order:

Diagnose: The literature explored the subject of post-secondary mental health and why behaviours that contribute to mental ill health occur. Through interviews with experts and a survey with target audience, the context of how post-secondary students may be experiencing mental ill-health, and the factors reported to be affecting their mental health the most, both positively and negatively, were explored. The interviews and survey added a "critical dimension to the academic literature review" (Borg et al., 2019, p. 2) to address issues in practice and implementation. Most of the literature on mental health involves studies performed in clinical settings (Bishop \& Dzidic, 2014). Therefore, gaining an understanding of the issues from the perspective of people working at and attending post-secondary institutions is critical, as according to Bishop and Dzidic, psychology can only make an impact on large social processes if it steps outside of a strictly clinical setting (2014). Additionally, including the target audience input in the development and evaluation can help avoid designing something that does not appeal to the target audience, as with the Rethink Vape study (England et al., 2020). 
Because both experts working at a university in positions related to student mental health as well as the target audience of post-secondary students were consulted, the gap between how the different populations talked about the services offered by the post-secondary institutions was revealed. Consulting with the target audience also gave insight on the specific behaviour strategies they had successfully used to improve their mental health.

Define: From there, the behaviours for change were targeted: adopting a healthier diet, increasing exercise, reducing behaviours associated with poorer sleep quality, reducing screen time, increasing socializing, and encouraging confiding.

Design: The prototype graphic messages were designed following principles from the fields of visual communication, graphic design, and behaviour.

Test: The prototypes were evaluated by both the expert interviewees and the target audience. The statements rating the graphic messages were generally higher with the target audience than with the people working in the field, again suggesting that evaluation with the target audience is important, as they may not have the same tastes and opinions as the consulted professionals.

\subsection{Limitations}

There were several limitations to this study. The first limitation is related to sample size. In the expert interview phase, only eight participants were interviewed. Additionally, both the student survey and the evaluation feedback form had fewer than 100 respondents.

The second major limitation of this study is related to sample bias. All eight of the experts interviewed in the first phase worked at Carleton university. Therefore, it is hard to say whether their responses are representative of the attitudes and opinions of professionals working at other Canadian colleges and universities. However, due to the range of the expert interviewees' positions and departments, there seemed to at least be a diversity of perspectives in terms of how the participants conceptualized and described the issues surrounding student mental health. For example, the participant from the disability center talked about mental illness in terms of functional limitations (how much the mental illness interfered with the student's daily function), the participant from environmental health and safety talked about mental illness in terms of 
psychological health and safety strategy and preventing injury and incidents on campus, and the participant from the neuroscience department talked about mental illness in terms of how the environmental and internal factors that can contribute to mental ill-health.

Sample bias also occurred because a convenience sampling method was used for the student survey and graphic message feedback form. Therefore, many of the participants were likely from Carleton University, which may have limited the range of academic experiences reported by the respondents in the student survey.

There was also sample bias in the student survey as most of the respondents were alumni (75.8\%) and not current students. The survey was advertised to both current and former postsecondary students to broaden the number of potential respondents. However, because so many of the respondents were former students, this may have affected how the respondents answered some of the questions. For example, the question on how technology overuse may have negatively impacted their mental health may have been less applicable to respondents who attended college or university before the widespread adoption of personal electronic devices. And because demographic information was not collected with the graphic message feedback forms, this data may be subject to the same type of sample bias.

Because the evaluation feedback form was not anonymous, it may have been subject to response bias, as participants may have felt pressure to give the graphic messages a higher rating than they felt they deserved.

Another limitation was the scope of the study, as discussed in section 1.6. Due to time and resource constraints, the actual effectiveness of the prototype graphic messages was not able to be evaluated, as this would require deploying the graphic messages and using pre- and postintervention survey to evaluate any changes in attitudes, resilience, behavioural intentions, and actual changed behaviours.

\subsection{Recommendations for Future Research}

Future research could extend the scope of this research or apply this type of study design to different contexts. To address the sample bias present in this study, future researchers could 
conduct exploratory interviews with professionals from other post-secondary institutions to uncover new issues and gain a better understanding about how generalizable the findings from this study are. Additionally, it would be valuable to conduct a student survey on a much wider range, targeting a large population of current students from Canadian colleges and universities.

Additionally, this study focused mainly on using behavioural models and visual communication principles from the literature to craft persuasive graphic messages, and subsequently evaluating messages with the target audience. Future researchers could include the target audience in the development process of graphic messages, using stakeholder dialogue focus groups and/or advisory councils to include the opinions of the target demographic earlier in the process, as were used in some of the persuasive media campaigns discussed in the literature review. Future researchers could also conduct participatory design sessions to further involve the target demographic in the design of a persuasive health campaign.

As stated, this study was limited in its scope, as time and resource restrictions did not allow for deployment and measurement of the efficacy of the design intervention. Using the study design and the recommendations listed above, future researchers could design graphic messages promoting behaviours that could improve mental health, deploy the intervention, and evaluate the efficacy of the messages in changing the behaviour of post-secondary students.

Alternatively, future researchers could use the study design to create a persuasive health campaign aimed to increase resilience and mental wellness in a different target audience, such as primary/secondary students or professionals working in an industry that experiences a high rate of mental illness. Another direction that future researchers could take is using the study design to develop a persuasive health campaign that targets a wider variety of healthcare issues experienced by post-secondary students. 


\section{Chapter 6: Conclusion}

Post-secondary student mental health is a critical issue; mental illness rates in post-secondary students are prevalent and increasing. This study explored a possible intervention that could help improve student mental health. Eight exploratory interviews with professionals working in positions related to student mental health, as well as a survey asking post-secondary students about the factors that impair or improve their mental health, were used to help determine the format of this intervention; a persuasive health campaign that uses several graphic messages targeted at improving student mental health by giving suggestions of behaviours to enact that support mental wellness. The graphic messages were developed using insights from several behavioural models and theories, as well as visual communication and graphic design principles. The graphic messages were then evaluated by both the expert interviewees as well as the target audience (post-secondary students).

This study contributes to the literature in four major ways.

\section{1) Student Mental Health Overview}

The first major research contribution of this thesis is an overview of post-secondary student mental health. This research contribution is most closely related to sub-question 2 (what factors affecting mental health can be targeted through a design intervention to create the greatest positive impact on student mental health?) as this overview focuses on the factors and issues that professionals and the target audience consider to be negatively impacting student mental health (such as academic pressure, physical health behaviours such as diet, exercise, and sleep, issues with loneliness and socialization, overuse of technology, adolescence, etc.). Also discussed are factors and particularly behaviours that can prevent mental ill health or promote mental wellness (such as adopting better health behaviours, increasing socialization, reducing technology use, increasing resilience by increasing one's repertoire of coping skills, etc.).

This overview of student mental health came from three sources: the literature review, expert interviews, and the student survey. The research studies and behavioural theory from the literature review provided an academic understanding of the issues facing post-secondary students and how behaviour can be changed. The expert interviewees provided an understanding 101 
of the contextual issues surrounding post-secondary institutions as well as issues surrounding the practice and implementation of student mental health initiatives. The student survey provided the perspective of students on which factors were most detrimental to their academic experience as well as strategies they successfully used to improve their mental health. Because this overview of post-secondary student mental health includes perspectives from both professionals and postsecondary students, the information presented can be used to provide grounded contextual and practical information to supplement the clinical evidence-based findings on student mental health in the literature.

\section{2) Graphic Messages Approach}

The next and perhaps most important contribution of this thesis is the proposal of an alternative approach for post-secondary institutions to take to help address the student mental health crisis. This contribution relates to the first research sub-question: how can the student mental health crisis be addressed through design in a way that strengthens student mental health self-efficacy and resilience?

This alternative approach is separate from what the institutions are already doing to improve student mental wellness and can help promote some of the underutilized services offered by the institution. This approach could impact students without the chance of unintentionally weakening self-efficacy by suggesting that students need outside help with their mental health; in fact, this approach should help to increase self-efficacy by implying that students have some control over their own mental health. Additionally, this approach aims to strengthen resilience by offering concrete steps that students can use to start changing behaviours that are weakening their mental wellness.

This has potential practical applications for post-secondary institutions. With further development and testing, a college or university could deploy a series of graphic messages and could run their own pilot project to see if being exposed to these messages could help change students' attitudes about how much control they have over their own mental health through their behaviours using survey questionnaires. 
Beyond the intervention itself, the insights from this study suggest that colleges and universities should perhaps augment how they are approaching student mental health. It seems evident that it requires many highly skilled professionals and resources to offer student mental health services. However, these services are reportedly having little impact on students' mental health. Perhaps a small sliver of the resources that go into running these services could have a greater impact by going into initiatives that may encourage students to learn about what impacts their mental health and cultivate their own positive coping methods.

\section{3) Importance of Interdisciplinary Collaboration}

Another way that this study contributed to the literature was by highlighting the importance of collaboration between the designer, experts, and the target audience to create an effective persuasive health campaign. Consulting both the literature as well as people working in the field and the target audience was key to developing a potential solution that was alternative to what universities are already doing to combat the student mental health crisis. The graphic message approach was only chosen due to the differences in how the professionals and students talked about student services.

Another benefit of collaborating with the target audience is being able to consult them on their

lived experience. Through the survey students were asked about their experience with issues that negatively impacted their mental health as well as strategies they had successfully used to improve their mental health during their time at college or university. Because the coping strategies conveyed in the graphic messages have been effective for students in the past, they could be more likely to work for current students within their contexts, as opposed to strategies that have been successful in clinical trials.

Follow up evaluation of the graphic message prototypes was important in identifying which elements of the prototypes were successful and which could be improved. Additionally, evaluating the intervention with the target audience is important in ensuring that the audience 
will ultimately be receptive to the messages. Using a modified human-centered design framework to develop a potential intervention seems to produce promising results as the graphic message prototypes were generally rated favorably in all categories, and further rounds of prototyping and testing can be used to refine a prototype into a product that is ready for deployment.

\section{4) Guidelines for Graphic Messages for a Persuasive Health Campaign}

The last contribution that this study has made to the literature is a list of concrete guidelines on how to design this type of graphic message for a persuasive health campaign. The guidelines (detailed in table 11) relate to the main research question of this thesis: how can graphic messages promoting positive mental health behaviours be designed to maximize their effectiveness? The main research question was answered in this study, as analysis of the data from the feedback forms led to very granular data on the design decisions that should be made in the development of the type of persuasive graphic message proposed as this study's intervention. 


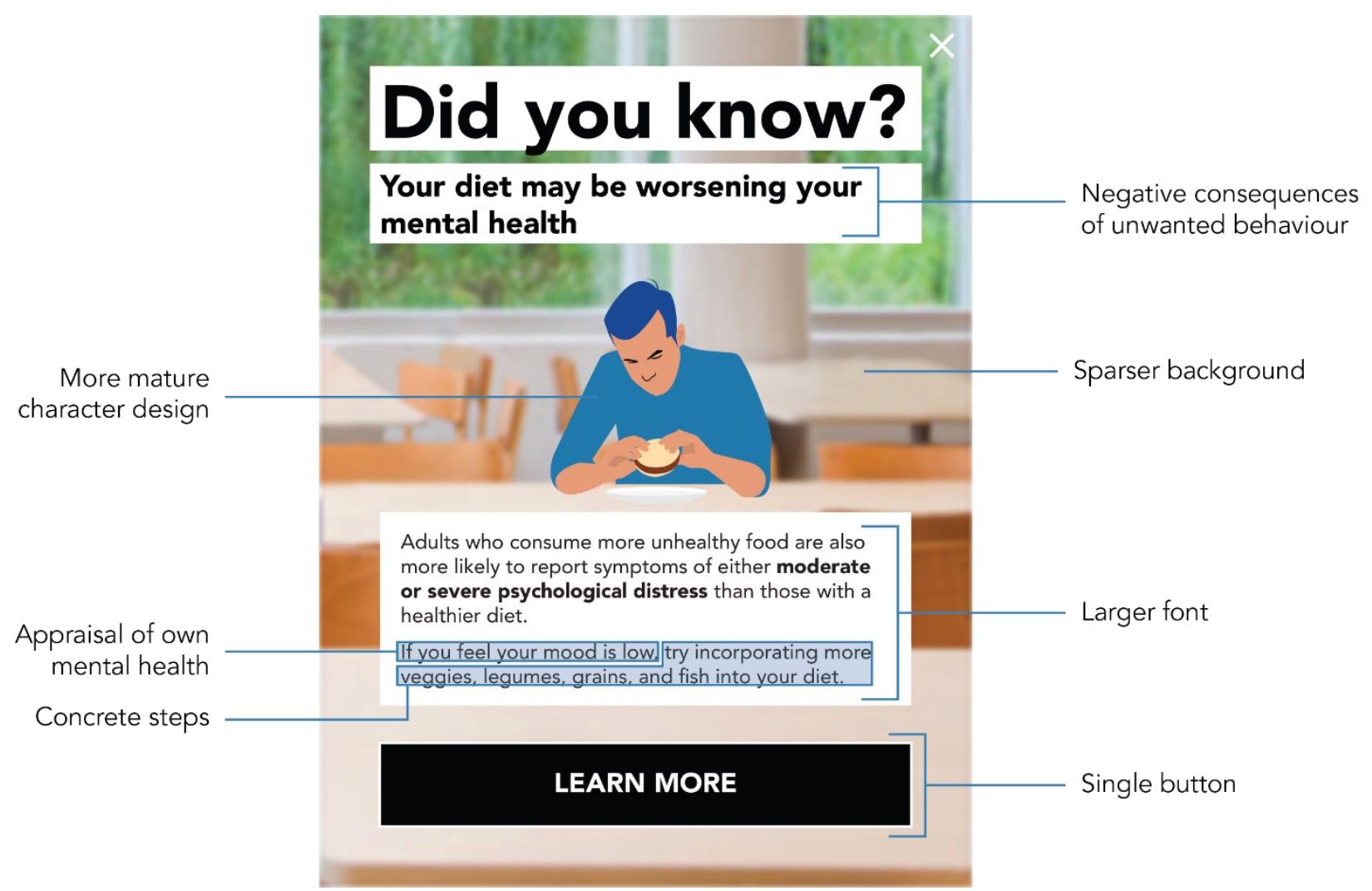

Illustration 36: The health eating graphic message altered based on the design recommendations generated from the feedback form data.

Although it is unclear whether this type of message will be effective in changing students' behaviour as the scope of this thesis did not extend to deploying the graphic messages and evaluating their efficacy, hopefully future researchers can use these recommendations to increase the potential efficacy of persuasive graphic messages.

In closing, student mental health is a critical and worsening issue. There is an increasing number of severely distressed students attending Canadian colleges and universities who experience mental ill health due to issues like technology overuse, increasing economic uncertainty, and reduced resilience. Post-secondary education is a time to grow and learn: a time of challenge and stress. Because many people attending post-secondary education are transitioning from late adolescence to adulthood, they are learning many new life skills along with their academic pursuits. It is arguable that learning how to maintain positive mental health is an important part 
of growing up, like learning to pay bills and do laundry. The aim of the proposed intervention is to do just that: to help students learn coping skills to manage their mental health.

Part of the reason it is important to encourage students to manage their own mental health through their behaviours is because they may not be willing to accept professional counselling. It's easy to tell someone who is struggling to "get help", but when someone is overwhelmed by other priorities and experiencing emotional lows, they are less likely to be motivated to seek help, especially if they may have to wait weeks to see a counsellor. It is also important to convey that mental health, like physical health, is affected by one's behaviour and therefore can be negatively or positively impacted by one's actions. This fact may not be obvious to someone who has just left the family home and must for the first time regulate their own sleep schedule with no established routine, make all their own food choices, and deal with the intense pressure of an academic program. A dysregulated sleep schedule, a steady diet of pizza, and two midterm exams coming up is a perfect recipe for increased anxiety, but it is not always apparent to someone experiencing mental illness for the first time why they are suddenly feeling so awful.

Because higher education requires juggling many responsibilities, priorities like deadlines and exams can easily take priority over taking care of one's mental health. It is therefore important to stress the importance of enacting behaviours that maintain mental health, because mental ill health can negatively affect all aspects of life including daily function and academic performance. Encouraging students to start regulating their own mental health behaviours may be a helpful first step to ensure that more students can achieve their academic goals without sacrificing their mental health. 


\section{References}

Adlaf, Edward M., Demers, Andrée, and Gliksman, Louis (Eds.) Canadian Campus Survey 2004. Toronto, Centre for Addiction and Mental Health. 2005

Ajzen, I. (2002). Perceived behavioral control, self-efficacy, locus of control, and the theory of planned behavior. Journal of Applied Social Psychology, 32(4), 665-683.

Al Rawahi, S. H., Asimakopoulou, K., Masood, M., Al Bulushi, N. M., Al Yaqoobi, K. H., \& Newton, J. T. (2020). The Psychological Models of Health-related Behavior in Understanding Sugars Intake in Adults: A Review. Oman Medical Journal, 35(2), e114.

Allen, I. E., \& Seaman, C. A. (2007). Likert scales and data analyses. Quality progress, 40(7), 64-65.

American Psychiatric Association. (n.d.). Mental Health Disparities: Diverse Populations. Retrieved March 18, 2020 from https:/www.psychiatry.org/psychiatrists/culturalcompetency/education/mental-health-facts

Arnstein R. L. (1995). Mental health on the campus revisited. Journal of American college health : J of ACH, 43(6), 248-251. https://doi.org/10.1080/07448481.1995.9940898

Balcaitis, R. (2019). Design Thinking models. IDEO - Empathize IT. Retrieved 28 January 2021, from https:/empathizeit.com/design-thinking-models-ideo/

Bandura, A., Freeman, W. H., \& Lightsey, R. (1999). Self-efficacy: The exercise of control. Worth Publishers.

Barnard, M. (2013). Graphic design as communication. Routledge.

Becker, M., Martin, L., Wajeeh, E., Ward, J., \& Shern, D. (2002). Students with mental illnesses in a university setting: Faculty and student attitudes, beliefs, knowledge, and experiences. Psychiatric Rehabilitation Journal, 25(4), 359. 
Becker, S., Miron-Shatz, T., Schumacher, N., Krocza, J., Diamantidis, C., \& Albrecht, U. V. (2014). mHealth 2.0: experiences, possibilities, and perspectives. JMIR mHealth and uHealth, 2(2), e24.

Belk, R. W. (1988). Possessions and the extended self. Journal of Consumer Research, 15(2), 139-168.

Binkley, C., \& Fenn, L. (2020). Colleges struggle with soaring student demand for counselling. Retrieved March 18, 2020 from https://toronto.citynews.ca/2019/11/25/colleges-strugglewith-soaring-student-demand-for-counselling/

Biroscak, B. J., Schneider, T., Martinez Tyson, D., Aguado Loi, C. X., \& Bryant, C. A. (2018). Applying tools from human-centered design to social marketing planning. Social Marketing Quarterly, 24(2), 63-73.

Bishop, B. J., \& Dzidic, P. L. (2014). Dealing with wicked problems: Conducting a causal layered analysis of complex social psychological issues. American Journal of Community Psychology, 53(1-2), 13-24.

Block, L. G., \& Keller, P. A. (1995). When to accentuate the negative: The effects of perceived efficacy and message framing on intentions to perform a health-related behavior. Journal of Marketing Research, 32(2), 192-203.

Boradkar, P. (2017). Taming wickedness by interdisciplinary design. The Oxford handbook of interdisciplinarity. Oxford University Press, Oxford, 456-467.

Borg, K., Wright, B., Sannen, L., Dumas, D., Walker, T., \& Bragge, P. (2019). Ambulances are for emergencies: shifting attitudes through a research-informed behaviour change campaign. Health Research Policy and Systems, 17(1), 1-9.

Brown, S. (2020). Overwhelmed: The real campus mental-health crisis and new models for wellbeing. The Chronicle of Higher Education.

Burnkrant, R. E., \& Unnava, H. R. (1995). Effects of self-referencing on persuasion. Journal of Consumer Research, 22(1), 17-26. 
Bustamante, J. (2019, June 7). College Enrollment Statistics: Total by Demographic. Retrieved June 20, 2020 from https://educationdata.org/college-enrollment-statistics

Carr, S. (2020, September 24). How Many Ads Do We See A Day? Retrieved October 13, 2020 from https://ppcprotect.com/how-many-ads-do-we-see-a-day/

CBC. (2019, December 13). The mental health crisis among young Canadians | CBC Radio. Retrieved April 12, 2020 from https:/www.cbc.ca/radio/thesundayedition/the-sundayedition-for-december-15-2019-1.5393079/the-mental-health-crisis-among-youngcanadians-1.5393085

Chang, C. (2011). Enhancing self-referencing to health messages. Journal of Consumer Affairs, 45(1), 147-164.

Chu, Y. (2018, October). Analysis of the Application of Illustration Art in Graphic Design. In 2018 3rd International Conference on Politics, Economics and Law (ICPEL 2018). Atlantis Press.

CIGNA. (2020). New Landmark Study From Cigna Shows American Resilience Is At Risk. Retrieved December 3, 2020 from https://www.biospace.com/article/releases/newlandmark-study-from-cigna-shows-american-resilience-is-at-risk/

Clark, N. (2020, July 23). How to Stop Information Overload in its Tracks. Retrieved August 3, 2020 from https://www.forbes.com/sites/womensmedia/2020/07/23/how-to-stopinformation-overload-in-its-tracks/

Clarke, J., Proudfoot, J., Birch, M. R., Whitton, A. E., Parker, G., Manicavasagar, V., ... \& Hadzi-Pavlovic, D. (2014). Effects of mental health self-efficacy on outcomes of a mobile phone and web intervention for mild-to-moderate depression, anxiety, and stress: secondary analysis of a randomized controlled trial. BMC Psychiatry, 14(1), 272.

Collins, R. L., Wong, E. C., Roth, E., Cerully, J. L., \& Marks, J. (2015). Changes in mental illness stigma in California during the statewide Stigma and Discrimination Reduction Initiative. Rand Health Quarterly, 5(2). 
Cook, M. P. (2006). Visual representations in science education: The influence of prior knowledge and cognitive load theory on instructional design principles. Science Education, 90(6), 1073-1091.

Cooper, E. (2009). Overloading on slides: Cognitive load theory and Microsoft's slide program PowerPoint. AACE Journal, 17(2), 127-135.

Coordinating Committee of Vice Presidents Students. (2015). White Paper on Postsecondary Student Mental Health [White paper]. https://occccco.files.wordpress.com/2015/05/ccvps-white-paper-on-postsecondarystudent-mental-health-april-2015.pdf

Corman, S. R., Trethewey, A., \& Goodall, B. (2007). A 21 st century model for communication in the global war of ideas. Consortium for Strategic Communication, Report, 701.

Creswell, J. W., \& Clark, V. L. P. (2017). Designing and conducting mixed methods research. Sage Publications.

Cyr, D., Head, M., Lim, E., \& Stibe, A. (2018). Using the elaboration likelihood model to examine online persuasion through website design. Information \& Management, 55(7), 807-821.

Davidson, J. (2017). The Most Important Rule in UX Design that Everyone Breaks. Retrieved March 18, 2020 from https://blog.prototypr.io/the-most-important-rule-in-ux-design-thateveryone-breaks-1c1cb188931

Davydov, D. M., Stewart, R., Ritchie, K., \& Chaudieu, I. (2010). Resilience and mental health. Clinical Psychology Review, 30(5), 479-495.

De Gruchy, J., \& Coppel, D. (2008). “Listening to reason”: A social marketing stop-smoking campaign in Nottingham. Social Marketing Quarterly, 14(1), 5-17.

Demirci, K., Akgönül, M., \& Akpinar, A. (2015). Relationship of smartphone use severity with sleep quality, depression, and anxiety in university students. Journal of Behavioral Addictions, 4(2), 85-92. 
Dunlap, J. C., \& Lowenthal, P. R. (2016). Getting Graphic About Infographics: Design lessons learned from popular infographics. Journal of Visual Literacy, 35(1), 42-59.

Ecclestone, K., \& Hayes, D. (2019). The dangerous rise of therapeutic education. Routledge.

Elhai, J. D., Dvorak, R. D., Levine, J. C., \& Hall, B. J. (2017). Problematic smartphone use: A conceptual overview and systematic review of relations with anxiety and depression psychopathology. Journal of Affective Disorders, 207, 251-259.

England, K. J., Edwards, A. L., Paulson, A. C., Libby, E. P., Harrell, P. T., \& Mondejar, K. A. (2020). Rethink Vape: Development and evaluation of a risk communication campaign to prevent youth E-cigarette use. Addictive Behaviors, 113, 106664.

Fagan, R. W. (1994). Social well-being in university students. Journal of Youth and Adolescence, 23(2), 237-249.

Fisher, W. A., Fisher, J. D., \& Harman, J. (2003). The information-motivation-behavioral skills model: A general social psychological approach to understanding and promoting health behavior. Social Psychological Foundations of Health and Illness, 22, 82-106.

Fitch, C., Hamilton, S., Bassett, P., \& Davey, R. (2011). The relationship between personal debt and mental health: a systematic review. Mental Health Review Journal.

Fogg, B. J. (2002). Persuasive technology: Using computers to change what we think and do. Ubiquity, 2002 (December), 5.

Fogg, B. J. (2009, April). A behavior model for persuasive design. In Proceedings of the 4th international Conference on Persuasive Technology (p. 40). ACM.

French, J., Blair-Stevens, C., McVey, D., \& Merritt, R. (Eds.). (2010). Social marketing and public health: Theory and practice. Oxford University Press.

Garcia, D. L. (1996). Global Communications: Opportunities for Trade and Aid. SAIS Review, $16(1), 35-66$. 
Glassman, T., Paprzycki, P., Castor, T., Wotring, A., Wagner-Greene, V., Ritzman, M., ... \& Kruger, J. (2018). Using the Elaboration Likelihood Model to Address Drunkorexia among College Students. Substance Use \& Misuse, 53(9), 1411-1418.

Government of Ontario. (2020). How to make websites accessible. Retrieved December 1, 2020 from https://www.ontario.ca/page/how-make-websites-accessible

Gray, P. (2020). Declining Student Resilience: A Serious Problem for Colleges. Retrieved December 23, 2020, from https://www.psychologytoday.com/ca/blog/freedomlearn/201509/declining-student-resilience-serious-problem-colleges

Gulliver, A., Griffiths, K. M., \& Christensen, H. (2010). Perceived barriers and facilitators to mental health help-seeking in young people: a systematic review. BMC psychiatry, 10(1), 113.

Hensley, L. (2020). 'One size doesn't fit all': Canadian campuses desperately need better mental health services. Retrieved December 15, 2020 from https://globalnews.ca/news/5969461/mental-health-canadian-campus/

Hollnagel, E., \& Woods, D. D. (2005). Joint cognitive systems: Foundations of cognitive systems engineering. CRC press.

Holmes, R., \& Follow. (2019, February 19). We Now See 5,000 Ads A Day ... And It's Getting Worse. Retrieved April 16, 2020 from https://www.linkedin.com/pulse/have-we-reachedpeak-ad-social-media-ryan-holmes

Hunt, M. G., Marx, R., Lipson, C., \& Young, J. (2018). No more FOMO: Limiting social media decreases loneliness and depression. Journal of Social and Clinical Psychology, 37(10), 751-768.

IDEO (Firm). (2015). The field guide to human-centered design. IDEO.

Jansen, C. (2017). Developing persuasive health campaign messages. In A., Black, P., Luna, O., Lund, \& , S. Walker (Eds.), Information Design : Research and Practice. Routledge. 
Jensen, J. D., King, A. J., Carcioppolo, N., \& Davis, L. (2012). Why are tailored messages more effective? A multiple mediation analysis of a breast cancer screening intervention. Journal of Communication, 62(5), 851-868.

Johnson, H. H., \& Hartwein, G. (1980). Psychosocial stress, performance, and affective and somatic responses in college students. Research in Higher Education, 12(2), 139-153.

Klonoff, D. C. (2019). Behavioral Theory: The Missing Ingredient for Digital Health Tools to Change Behavior and Increase Adherence. Journal of Diabetes Science and Technology, 13(2), 276-281.

Kocaoğlu, R., \& Olguntürk, N. (2018). Color and visual complexity in abstract images. Color Research \& Application, 43(6), 952-957.

Kraft, D. (2011). One hundred years of college mental health. Journal of American College Health, 59(6), 477-481.

Laing, B. Y., Mangione, C. M., Tseng, C. H., Leng, M., Vaisberg, E., Mahida, M., ... \& Bell, D. S. (2014). Effectiveness of a smartphone application for weight loss compared with usual care in overweight primary care patients: a randomized, controlled trial. Annals of Internal Medicine, 161(10_Supplement), S5-S12.

Lankow, J., Ritchie, J., \& Crooks, R. (2012). Infographics: The power of visual storytelling. John Wiley \& Sons.

Lefebvre, R. C. (2013). Social marketing and social change: Strategies and tools for improving health, well-being, and the environment. John Wiley \& Sons.

Legault L. (2017) Self-Determination Theory. In: Zeigler-Hill V., Shackelford T. (Eds) Encyclopedia of Personality and Individual Differences. Springer, Cham. https://doi.org/10.1007/978-3-319-28099-8_1162-1

Lidwell, W., Holden, K., \& Butler, J. (2010). Universal principles of design, revised and updated: 125 ways to enhance usability, influence perception, increase appeal, make better design decisions, and teach through design. Rockport Pub. 
Link, B. G. (1982). Mental patient status, work, and income: An examination of the effects of a psychiatric label. American Sociological Review, 47, 202-215.

Lipson, S. K., \& Eisenberg, D. (2018). Mental health and academic attitudes and expectations in university populations: results from the healthy minds study. Journal of Mental Health, 27(3), 205-213.

Luca, N. R., \& Suggs, L. S. (2013). Theory and model use in social marketing health interventions. Journal of Health Communication, 18(1), 20-40.

Madan, C. R., Bayer, J., Gamer, M., Lonsdorf, T. B., \& Sommer, T. (2018). Visual complexity and affect: ratings reflect more than meets the eye. Frontiers in Psychology, 8, 2368.

Maldonado, C. (2018, July 24). Price of College Increasing Almost 8 Times Faster Than Wages. Forbes. Retrieved April 12, 2020 from https://www.forbes.com/sites/camilomaldonado/2018/07/24/price-of-college-increasingalmost-8-times-faster-than-wages/\#4134cdb566c1

Male, A. (2019). The Power and Influence of Illustration: Achieving Impact and Lasting Significance through Visual Communication. London: Bloomsbury Visual Arts.

Markowitz, F. E. (2005). Sociological models of mental illness stigma: Progress and prospects. On the stigma of mental illness: Practical strategies for research and social change, 129144.

McCoy, K. (2000). Information and Persuasion: Rivals or Partners?. Design Issues, 16(3), 80-83.

McMichael, A. J. (1974). The relationship between social stress, adolescence, and mental health among university students. Australian \& New Zealand Journal of Psychiatry, 8(4), 251260.

McMichael, A. J., \& Hetzel, B. S. (1974). An epidemiological study of the mental health of Australian university students. International Journal of Epidemiology, 3(2), 125-134. 
Moller, A. C., Ryan, R. M., \& Deci, E. L. (2006). Self-determination theory and public policy: Improving the quality of consumer decisions without using coercion. Journal of Public Policy \& Marketing, 25(1), 104-116.

Morley, B., Niven, P., Dixon, H., Swanson, M., Szybiak, M., Shilton, T., ... \& Wakefield, M. (2016). Population-based evaluation of the 'LiveLighter' healthy weight and lifestyle mass media campaign. Health Education Research, 31(2), 121-135.

Morrison, L. G. (2015). Theory-based strategies for enhancing the impact and usage of digital health behaviour change interventions: a review. Digital Health, 1, 2055207615595335.

Mortier, P., Cuijpers, P., Kiekens, G., Auerbach, R. P., Demyttenaere, K., Green, J. G., ... \& Bruffaerts, R. (2018). The prevalence of suicidal thoughts and behaviours among college students: a meta-analysis. Psychological Medicine, 48(4), 554-565.

Murchie, K. J., \& Diomede, D. (2020). Fundamentals of graphic design-essential tools for effective visual science communication. FACETS. 5(1): 409-422. https://doi.org/10.1139/facets-2018-0049

Nodder, C. (2013). Evil by design: Interaction design to lead us into temptation. John Wiley \& Sons.

Nodder, C. (2014, April 9). Persuasive UX [Video file]. Retrieved January 3, 2020 from https://www.linkedin.com/learning/persuasive-ux-influencing-behaviorpatterns/welcome? $\mathrm{u}=48561921$

Oinas-Kukkonen, H., \& Harjumaa, M. (2008, June). A systematic framework for designing and evaluating persuasive systems. In International conference on persuasive technology ( $\mathrm{p}$. 164-176). Springer, Berlin, Heidelberg.

Okanagan College Library. (2020, September 11). Evaluating Infographics. Retrieved October 3, 2020 from https://libguides.okanagan.bc.ca/c.php?g=400553 
op den Akker, H. J., Klaassen, R., \& Nijholt, A. (2016). Virtual coaches for healthy lifestyle. In Toward Robotic Socially Believable Behaving Systems-Volume II (pp. 121-149). Springer, Cham.

Pedrelli, P., Nyer, M., Yeung, A., Zulauf, C., \& Wilens, T. (2015). College students: mental health problems and treatment considerations. Academic Psychiatry, 39(5), 503-511.

Petty, R. E. (2018). Attitudes and persuasion: Classic and contemporary approaches. Routledge.

Petty, R. E., \& Cacioppo, J. T. (1986). The elaboration likelihood model of persuasion. In Communication and persuasion (pp. 1-24). Springer, New York, NY.

Pew Research Centre (2019, June 12). Demographics of Mobile Device Ownership and Adoption in the United States. Retrieved April 23, 2020 from https://www.pewresearch.org/internet/fact-sheet/mobile/

Pittman, M., \& Reich, B. (2016). Social media and loneliness: Why an Instagram picture may be worth more than a thousand Twitter words. Computers in Human Behavior, 62, 155-167.

Prochaska, J. O., \& Velicer, W. F. (1997). The transtheoretical model of health behavior change. American Journal of Health Promotion, 12(1), 38-48.

Reifler, C. B., Liptzin, M. B., \& Fox, J. T. (1967). College psychiatry as public health psychiatry. American Journal of Psychiatry, 124(5), 662-671.

Roberts, J. A., Yaya, L. H. P. \& Manolis, C. (2014). The invisible addiction: Cell-phone activities and addiction among male and female college students. Journal of Behavioral Addictions, 3(4), 254-265.

Robinson, A. M., Jubenville, T. M., Renny, K., \& Cairns, S. L. (2016). Academic and mental health needs of students on a Canadian campus. Canadian Journal of Counselling and Psychotherapy, 50(2).

Roloff, M. E., \& Miller, G. R. (1980). Persuasion: New directions in theory and research (Vol. 8). SAGE Publications, Incorporated. 
Rosen, L. D., Whaling, K., Rab, S., Carrier, L. M., \& Cheever, N. A. (2013). Is Facebook creating "iDisorders"? The link between clinical symptoms of psychiatric disorders and technology use, attitudes, and anxiety. Computers in Human Behavior, 29(3), 1243-1254.

Rueve, M. E., \& Welton, R. S. (2008). Violence and mental illness. Psychiatry (Edgmont), 5(5), 34.

Rust, R. M. (1960). Epidemiology of mental health in college. The Journal of Psychology, 49(2), 235-248.

Ryan, R. M., \& Deci, E. L. (2000). Self-determination theory and the facilitation of intrinsic motivation, social development, and well-being. American Psychologist, 55(1), 68.

Saldaña, J. (2009). The coding manual for qualitative researchers. Sage.

SanJosé-Cabezudo, R., Gutiérrez-Arranz, A. M., \& Gutiérrez-Cillán, J. (2009). The combined influence of central and peripheral routes in the online persuasion process. CyberPsychology \& Behavior, 12(3), 299-308.

Schwartz, A. J. (2006). Are college students more disturbed today? Stability in the acuity and qualitative character of psychopathology of college counseling center clients: 1992-1993 through 2001-2002. Journal of American College Health, 54(6), 327-337.

Scull, A. (2011). Madness: A very short introduction (Vol. 279). Oxford University Press.

Seo, B. K. (2020). Meta-Analysis on Visual Persuasion-Does Adding Images to Texts Influence Persuasion?. Athens Journal of Mass Media and Communications.

Serrano, K. J., Coa, K. I., Yu, M., Wolff-Hughes, D. L., \& Atienza, A. A. (2017). Characterizing user engagement with health app data: a data mining approach. Translational Behavioral Medicine, 7(2), 277-285.

Siricharoen, W. V., \& Siricharoen, N. (2015). How infographic should be evaluated. In Proceedings of the 7th International Conference on Information Technology (ICIT 2015) (p. 558-564). 
Sivertsen, B., Hysing, M., Knapstad, M., Harvey, A. G., Reneflot, A., Lønning, K. J., \& O'Connor, R. C. (2019). Suicide attempts and non-suicidal self-harm among university students: Prevalence study. BJPsych Open, 5(2).

Smiciklas, M. (2012). The power of infographics: Using pictures to communicate and connect with your audiences. Que Publishing.

Spring, B., Moller, A. C., \& Coons, M. J. (2012). Multiple health behaviours: overview and implications. Journal of Public Health, 34(suppl_1), i3-i10.

Stallman, H. M. (2010). Psychological distress in university students: A comparison with general population data. Australian Psychologist, 45(4), 249-257.

Sweet, S. N., Fortier, M. S., Strachan, S. M., \& Blanchard, C. M. (2012). Testing and integrating self-determination theory and self-efficacy theory in a physical activity context. Canadian Psychology/Psychologie Canadienne, 53(4), 319.

Sykes, M., Malik, A. N., \& West, M. D. (2012). Stories that move mountains: Storytelling and visual design for persuasive presentations. John Wiley \& Sons.

Szasz, T. S. (1960). The myth of mental illness. American Psychologist, 15(2), 113.

Velasco, A. A., Santa Cruz, I. S., Billings, J., Jimenez, M., \& Rowe, S. (2020). What are the barriers, facilitators and interventions targeting help-seeking behaviours for common mental health problems in adolescents? A systematic review. BMC Psychiatry, 20(1), 122.

Wackett, J. (1998). A theory-based initiative to reduce the rates of Chlamydia Trachomatis infection among young adults in the Yukon. The Canadian Journal of Human Sexuality, 7(4), 347-347.

Wakefield, M. A., Loken, B., \& Hornik, R. C. (2010). Use of mass media campaigns to change health behaviour. The Lancet, 376(9748), 1261-1271.

Wallen, K. E., \& Daut, E. (2018). The challenge and opportunity of behaviour change methods and frameworks to reduce demand for illegal wildlife. Nature Conservation, 26, 55. 
Zalis, S. (2020). The Inclusion Imperative: Why Media Matters. Retrieved from December 18, 2020 from https://www.forbes.com/sites/shelleyzalis/2020/01/14/the-inclusionimperative-why-media-matters/?sh=4681410e2943 


\section{Appendices}

\section{Appendix A Expert Interview Protocol}

(The interview will only take place if the participate has already read, signed, and sent back the consent form).

\section{A.1 Introduction}

"Hello, my name is Alanna Bamber, and I am a graduate student in the School of Industrial Design at Carleton University. I am working under the supervision of Dr. Lois Frankel. I would like to invite you to participate in a study titled Well-being, Stress, and the Post-Secondary Student Experience. This study aims to determine how the post-secondary student experience affects the mental health of the students."

\section{A.2 Questions}

1) How would you describe your role at Carleton University?

2) Can you describe Carleton's campus environment in terms of how it supports or doesn't support student mental health?

3) In your opinion, what are the major issues causing a lack of student mental wellness?

4) Do you think Carleton has any issues that contribute to the negative mental health of the students?

5) What are they?

6) What is Carleton currently doing to promote the mental well-being of students on campus?

7) What (if anything) would you like to see Carleton implement to increase the mental wellbeing of students?

8) Can you recommend anyone else I can speak to learn more about these issues? 


\section{Appendix B Online Student Survey}

\section{B.1 Introduction}

Please note that the following survey asks questions about your personal mental health during your time in college or university. Because these topics are of a sensitive nature, please do not feel obligated to fill out this survey. Feel free to skip any question that you find distressing; you do not need to answer every question to complete the survey. This survey is completely anonymous.

\section{B.2 Questions}

1) You are a:
a) Current student
b) Former student

2) You are:
a) Male
b) Female
c) Other

3) You are:
a) 18 to 22
b) 23 to 30
c) 31 to 40
d) 41 to 50
e) 51 to 60
f) $60+$

4) During your university experience, did you experience:
a) Increased levels of stress or mental distress
b) Neutral levels of stress or mental distress
c) Decreased levels of stress or mental distress

5) Which of these factors would you say were detrimental to your mental health? Please rate the impact of each factor on a scale from 0 (no impact) to 4 (greatest impact). 


\begin{tabular}{|c|c|c|c|c|c|}
\hline & 0 & 1 & 2 & 3 & 4 \\
\hline a) Academic pressure & & & & & \\
\hline b) Interpersonal/family conflict & & & & & \\
\hline c) Loneliness/isolation & & & & & \\
\hline d) Alcohol use & & & & & \\
\hline e) Other drug use & & & & & \\
\hline f) Smartphone/technology overuse & & & & & \\
\hline g) Social comparison on social media & & & & & \\
\hline h) Disrupted sleeping patterns & & & & & \\
\hline i) Unhealthy food consumption & & & & & \\
\hline j) Lack of exercise & & & & & \\
\hline k) Spending too much time indoors/lack of contact with nature & & & & & \\
\hline 1) Finances & & & & & \\
\hline
\end{tabular}

6) If you were negatively impacted by factors other than those listed above, please list them here with an impact rating from 0 (no impact) to 4 (greatest impact):

7) Did your mental health ever affect your ability to thrive in terms of the following factors? Please rate the impact of each factor on a scale from 0 (no impact) to 4 (greatest impact).

\begin{tabular}{|l|l|l|l|l|l|}
\hline & 0 & 1 & 2 & 3 & 4 \\
\hline a) On your ability to thrive academically & & & & \\
\hline b) On your ability to thrive socially & & & \\
\hline c) On your ability to pursue your personal goals (non-academic) & & & & \\
\hline $\begin{array}{l}\text { d) On your ability to thrive functionally (in terms of daily activities } \\
\text { like eating, showering, etc.) }\end{array}$ & & & & \\
\hline
\end{tabular}


8) During your time as a university student, did you take any steps to improve your mental health?
a) Yes
b) No

9) If you did take steps the improve your mental health, did they involve any of the following factors? Please rate the impact of each factor on a scale from 0 (no impact) to 4 (greatest impact).

\begin{tabular}{|l|l|l|l|l|}
\hline & 0 & 1 & 2 & 3 \\
\hline a) Exercise & & & & \\
\hline b) Healthy eating habits & & & & \\
\hline c) Better sleeping habits & & & \\
\hline d) Reducing technology use & & & \\
\hline e) Increasing socialization & & & & \\
\hline f) Confiding in a friend/friends & & & & \\
\hline g) Goal setting & & & & \\
\hline h) Seeking counselling & & & & \\
\hline i) Using and online therapy program & & & & \\
\hline j) Using a Carleton/other post-secondary institute service & & & & \\
\hline k) Reducing course load or taking a break from classes & & & & \\
\hline 1) Improving your academic performance & & & \\
\hline
\end{tabular}

10) If you took steps other than those listed above, please list them here with an impact rating from 0 (no impact) to 4 (greatest impact):

11) If you did not take any steps to improve your mental health, would you attribute that to any of the following factors? (please select all that apply)
a) Feeling unable/helpless to improve your mental health
b) Belief that your mental health is static and would not be improved by your actions 

c) Feeling overwhelmed by other priorities
d) Lack of knowledge about how to improve your mental health
e) Other:

12) During your time as a student, were you aware of your institution's mental health services?
a) Yes
b) Somewhat
c) No

13) If you selected yes in the previous question, how did you hear about your institution's mental health services? (please select all that apply)
a) In class
b) On Carleton's/your institute's website
c) Through faculty or staff
d) Other:

14) During your time as a student, did you use your institution's mental health services?
a) Yes
b) $\mathrm{No}$

15) If you selected yes in the previous question, please list the service(s) here:

16) If you selected no (you didn't use any mental health services), why do you think that is? (please select all that apply)
a) Didn't feel I needed to use them
b) Not knowing there were services I could access
c) Not knowing which services were available
d) Didn't know how to find information about the services
e) Wasn't sure which service was appropriate for me
f) Embarrassment/stigma
g) Other:

17) If you experienced neutral or increased mental health during your college/university experience, what would you attribute that to? Please rate the impact of each factor on a scale from 0 (no impact) to 4 (greatest impact). 


\begin{tabular}{|c|c|c|c|c|c|}
\hline & 0 & 1 & 2 & 3 & 4 \\
\hline a) Exercise & & & & & \\
\hline b) Healthy eating habits & & & & & \\
\hline c) Better sleeping habits & & & & & \\
\hline d) Reducing technology use & & & & & \\
\hline e) Increasing socialization & & & & & \\
\hline f) Confiding in a friend/friends & & & & & \\
\hline g) Goal setting & & & & & \\
\hline h) Seeking counselling & & & & & \\
\hline i) Using and online therapy program & & & & & \\
\hline j) Using a Carleton/other post-secondary institute service & & & & & \\
\hline k) Reducing course load or taking a break from classes & & & & & \\
\hline 1) Improving your academic performance & & & & & \\
\hline
\end{tabular}

18) If you were positively impacted by factors other than those listed above, please list them here with an impact rating from 0 (no impact) to 4 (greatest impact): 


\section{Appendix C Online Student Survey Results}

\section{C.1 Question 1-3: Demographics}

\begin{tabular}{|l|c|c|}
\hline Demographics & $\#$ & $\%$ \\
\hline Student Status (62 responses) & 15 & 24.2 \\
\hline Current & 47 & 75.8 \\
\hline Former & $\#$ & $\%$ \\
\hline Gender (60 responses) & 19 & 31.7 \\
\hline Male & 40 & 66.7 \\
\hline Female & 1 & 1.7 \\
\hline Non-binary & $\#$ & $\%$ \\
\hline Age (62 responses) & 7 & 11.3 \\
\hline $18-22$ & 25 & 40.3 \\
\hline $23-30$ & 7 & 11.3 \\
\hline $31-40$ & 6 & 9.7 \\
\hline $41-50$ & 13 & 21.0 \\
\hline $51-60$ & 4 & 6.5 \\
\hline $61+$ & & \\
\hline
\end{tabular}

\section{C.2 Question 4: Level of stress or mental distress during the post-secondary experience}

\begin{tabular}{|l|c|c|}
\hline Stress Level (62 responses) & $\#$ & $\%$ \\
\hline Increased & 48 & 77.4 \\
\hline Neutral & 12 & 19.4 \\
\hline Decreased & 2 & 3.2 \\
\hline
\end{tabular}

\section{C.3 Questions 5-6: Factors detrimental to mental health during the post-secondary}

experience

\begin{tabular}{|l|c|c|c|c|c|c|}
\hline \multirow{2}{*}{ Factor } & \multicolumn{7}{c|}{ Number of responses per } \\
impact rating & \multicolumn{5}{c|}{ Average score } \\
\hline & 0 & 1 & 2 & 3 & 4 & \\
\hline Academic pressure & 0 & 9 & 10 & 21 & 20 & 2.87 \\
\hline Interpersonal/family conflict & 27 & 8 & 10 & 6 & 8 & 1.32 \\
\hline Loneliness/isolation & 19 & 15 & 10 & 9 & 8 & 1.54 \\
\hline Alcohol use & 40 & 8 & 7 & 0 & 2 & 0.53 \\
\hline Other drug use & 46 & 4 & 4 & 1 & 2 & 0.40 \\
\hline Smartphone/technology overuse & 30 & 11 & 7 & 7 & 3 & 1.00 \\
\hline
\end{tabular}




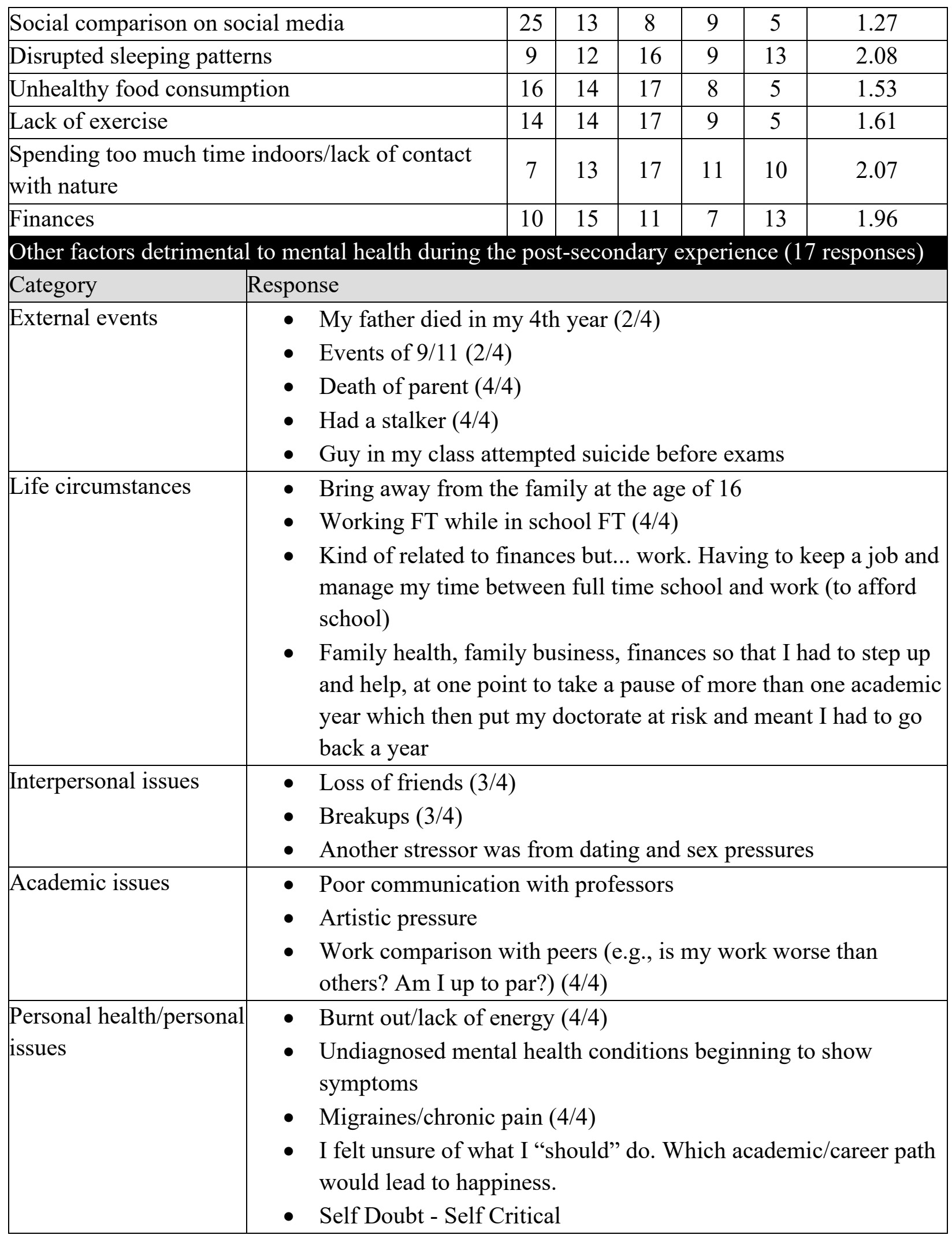


- $\quad$ Lack of purpose and direction (4/4)

\section{C.4 Question 7: Factors affected by mental health during the post-secondary experience}

\begin{tabular}{|l|c|c|c|c|c|c|}
\hline Factor & \multicolumn{7}{c|}{$\begin{array}{c}\text { Number of responses per } \\
\text { impact rating }\end{array}$} \\
\hline & 0 & 1 & 2 & 3 & 4 & \\
\hline Ability to thrive academically & 9 & 16 & 15 & 11 & 9 & 1.92 \\
\hline Ability to thrive socially & 15 & 11 & 10 & 13 & 13 & 1.97 \\
\hline $\begin{array}{l}\text { Ability to pursue your personal goals (non- } \\
\text { academic) }\end{array}$ & 12 & 11 & 11 & 11 & 15 & 2.10 \\
\hline $\begin{array}{l}\text { Ability to thrive functionally (in terms of daily } \\
\text { activities like eating, showering, etc.) }\end{array}$ & 20 & 16 & 6 & 10 & 8 & 1.50 \\
\hline
\end{tabular}

\section{C.5 Questions 8-10: Steps taken to improve mental health during the post-secondary} experience

\begin{tabular}{|c|c|c|c|c|c|c|}
\hline $\begin{array}{l}\text { During your time as a university student, did you } \\
\text { take any steps to improve your mental health? (61 } \\
\text { responses) }\end{array}$ & \multicolumn{5}{|c|}{ \# } & $\%$ \\
\hline Yes & \multicolumn{5}{|c|}{48} & 78.7 \\
\hline No & \multicolumn{5}{|c|}{13} & 21.3 \\
\hline Step taken & \multicolumn{5}{|c|}{$\begin{array}{l}\text { Number of responses per } \\
\text { impact rating }\end{array}$} & Average score \\
\hline & 0 & 1 & 2 & 3 & 4 & \\
\hline Exercise & 3 & 9 & 14 & 12 & 10 & 2.35 \\
\hline Healthy eating habits & 2 & 9 & 17 & 14 & 6 & 2.27 \\
\hline Better sleeping habits & 3 & 9 & 16 & 10 & 8 & 2.24 \\
\hline Reducing technology use & 14 & 15 & 12 & 2 & 0 & 1.05 \\
\hline Increasing socialization & 2 & 14 & 13 & 14 & 2 & 2.00 \\
\hline Confiding in a friend/friends & 2 & 10 & 12 & 17 & 5 & 2.28 \\
\hline Goal setting & 9 & 9 & 12 & 10 & 4 & 1.80 \\
\hline Seeking counselling & 19 & 7 & 8 & 4 & 7 & 1.40 \\
\hline Using an online therapy program & 33 & 2 & 3 & 0 & 1 & 0.31 \\
\hline $\begin{array}{l}\text { Using a Carleton/other post-secondary institution } \\
\text { service }\end{array}$ & 31 & 5 & 4 & 2 & 2 & 0.61 \\
\hline $\begin{array}{l}\text { Reducing course load or taking a break from } \\
\text { classes }\end{array}$ & 22 & 4 & 4 & 11 & 3 & 1.30 \\
\hline Improving your academic performance & 11 & 10 & 9 & 9 & 3 & 1.60 \\
\hline
\end{tabular}




\begin{tabular}{|c|c|}
\hline Category & Response \\
\hline $\begin{array}{l}\text { Relaxation and } \\
\text { hobbies }\end{array}$ & $\begin{array}{l}\text { - Meditation }(3 / 4) \\
\text { - Holidays, cultural experiences, interesting travels, walks around } \\
\text { and outside the city } \\
\text { - Taking up a hobby (pottery) }\end{array}$ \\
\hline Confiding & $\begin{array}{l}\text { - Confiding in family and admitting I wasn't at the level I needed } \\
\text { to be to TAs and professors }\end{array}$ \\
\hline $\begin{array}{l}\text { Learning about mental } \\
\text { health }\end{array}$ & - Read a book about Depression (4/4) \\
\hline $\begin{array}{l}\text { Physical and mental } \\
\text { health treatments }\end{array}$ & $\begin{array}{l}\text { - Medication }(0 / 4) \\
\text { - Message therapy/physiotherapy (for pain) }(2 / 4) \\
\text { - Seeing an outside therapist after multiple bad experiences with } \\
\text { Carleton's mental health services (that are overworked and } \\
\text { stretched thin) }\end{array}$ \\
\hline Changing habits & - Decreased drug use \\
\hline Other & $\begin{array}{l}\text { - Mental health did not have a big emphasis when I was in } \\
\text { university (1997-2004) } \\
\text { Because your questions relate to a time when technology was } \\
\text { just becoming more common for my age range, I found } \\
\text { technology a huge help, and likely would have availed myself } \\
\text { of more online services if they had been available. Reducing } \\
\text { course load was not an option for the path I took, I wish it had } \\
\text { been as I was working and raising a family while going to } \\
\text { school }\end{array}$ \\
\hline
\end{tabular}

\section{C.6 Question 11: Factors that impeded taking steps to improve mental health}

\begin{tabular}{|l|c|c|}
\hline Impeding factor (34 responses) & $\#$ \\
\hline Feeling unable/helpless to improve your mental health & 10 & 29.4 \\
\hline Belief that your mental health is static and would not be improved by your actions & 4 & 11.8 \\
\hline Feeling overwhelmed by other priorities & 23 & 67.6 \\
\hline Lack of knowledge about how to improve your mental health & 14 & 41.2 \\
\hline Other impeding factors & \\
\hline Category & Response & \\
\hline
\end{tabular}




\begin{tabular}{|l|l|}
\hline $\begin{array}{l}\text { Mental health not an } \\
\text { issue }\end{array}$ & $\begin{array}{l}\text { - } \\
\text { - }\end{array}$ \\
\hline Lack of awareness & $\begin{array}{l}\text { Never felt my mental health was an issue } \\
\text { putting on myself (Stress) was causing Physical symptoms. }\end{array}$ \\
\hline $\begin{array}{l}\text { Intimidation/overwhel } \\
\mathrm{m}\end{array}$ & $\begin{array}{l}\text { - } \begin{array}{l}\text { Anaware of any problems } \\
\text { daunting }\end{array} \\
\text { Even knowing there were options it was time and energy that } \\
\text { were limiting factors }\end{array}$ \\
\hline
\end{tabular}

\section{C.7 Question 12-13: Awareness of institutional mental health services}

\begin{tabular}{|c|c|c|c|}
\hline \multicolumn{2}{|c|}{$\begin{array}{l}\text { During your time as a student, were you aware of your institution's mental health } \\
\text { services? ( } 62 \text { responses) }\end{array}$} & $\#$ & $\%$ \\
\hline \multicolumn{2}{|l|}{ Yes } & 19 & 29.0 \\
\hline \multicolumn{2}{|l|}{ Somewhat } & 24 & 38.7 \\
\hline \multicolumn{2}{|l|}{ No } & 20 & 32.3 \\
\hline \multicolumn{2}{|c|}{ How did you hear about your institution's mental health services? (34 responses) } & $\#$ & $\%$ \\
\hline \multicolumn{2}{|l|}{ In class } & 3 & 8.8 \\
\hline \multicolumn{2}{|c|}{ On Carleton's/your institute's website } & 16 & 47.1 \\
\hline \multicolumn{2}{|c|}{ Through faculty or staff } & 8 & 23.5 \\
\hline \multicolumn{4}{|l|}{ Other channels } \\
\hline Category & Response & $\#$ & $\%$ \\
\hline Print media & $\begin{array}{l}\text { - Posters in University Centre } \\
\text { - Posters } \\
\text { - Paper booklet/brochure }\end{array}$ & 3 & 8.8 \\
\hline Frosh/Orientation & $\begin{array}{ll}\text { - } & \text { Orientation week } \\
\text { - } & \text { During frosh week/ orientation }\end{array}$ & 2 & 5.9 \\
\hline $\begin{array}{l}\text { Through friends or } \\
\text { peers }\end{array}$ & $\begin{array}{ll}\text { - } & \text { Friends } \\
\text { - } & \text { Through peers } \\
\text { - } & \text { Friends } \\
\text { - } & \text { Friends/peers }\end{array}$ & 4 & 11.8 \\
\hline $\begin{array}{l}\text { Through other institute } \\
\text { services }\end{array}$ & $\begin{array}{l}\text { - Through residence services } \\
\text { - Through on campus clubs }\end{array}$ & 2 & 5.9 \\
\hline
\end{tabular}




\begin{tabular}{|l|c|c|c|}
\hline Sought out & $\bullet \quad \begin{array}{l}\text { I sought out a tutorial service in areas where I } \\
\text { struggled to keep A average }\end{array}$ & 1 & 2.9 \\
\hline Other & $\bullet \quad$ Don't remember & 1 & 2.9 \\
\hline
\end{tabular}

\section{C.8 Questions 14-15: Use of institute's mental health services}

\section{During your time as a student, did you use your institution's mental health} services? (62 responses)

Yes

No

\begin{tabular}{|l|l|}
\hline 19 & 30.6 \\
\hline 43 & 69.4 \\
\hline
\end{tabular}

Services used (18 responses)

\section{Category}

Counselling/therapy
Response

- The clinic has a therapist I once went.

- Therapists on site

- Counselling

- Mental Health Counselling

- Counselling/Psychotherapy/Prescription

- Psychology \& Psychiatry

- Saw a counsellor (but she was kinda crap)

- Counselling

- Counselling

- Counselling services a few times

- I tried to see a psychiatrist; I had an intake, but they told me because I wasn't actively suicidal that I wasn't a priority for them. Years later I found out there was counselling and was able to see a counsellor. I wish the psychiatry department had referred me to counselling but they basically just told me my mental problems weren't severe enough for treatment

- Therapy/counselling

- Short-term counselling through the health promotion department

- Through University Medical centre services

- Doctors, OBGYN

- Carleton University Health Services 


\begin{tabular}{|l|c|c|c|}
\hline In class services & $\bullet \begin{array}{l}\text { Psychologists came visited our class as a group } \\
\text { after the suicide attempt. }\end{array}$ & 1 & 5.3 \\
\hline Religious services & $\bullet$ Bible Study & 1 & 5.3 \\
\hline Academic services & $\bullet$ Learning assessment & 1 & 5.3 \\
\hline
\end{tabular}

\section{C.9 Question 16: Reasons for a lack of use of institute's mental health services}

\begin{tabular}{|c|c|c|c|}
\hline \multicolumn{2}{|c|}{$\begin{array}{l}\text { If you selected no (you didn't use any mental health services), why do you think } \\
\text { that is? ( } 46 \text { responses) }\end{array}$} & $\#$ & $\%$ \\
\hline \multicolumn{2}{|c|}{ Didn't feel I needed to use them } & 22 & 47.8 \\
\hline \multicolumn{2}{|c|}{ Not knowing there were services I could access } & 13 & 28.3 \\
\hline \multicolumn{2}{|c|}{ Not knowing which services were available } & 15 & 32.6 \\
\hline \multicolumn{2}{|c|}{ Didn't know how to find information about the services } & 11 & 23.9 \\
\hline \multicolumn{2}{|c|}{ Wasn't sure which service was appropriate for me } & 17 & 37.0 \\
\hline \multicolumn{2}{|l|}{ Embarrassment/stigma } & 15 & 32.6 \\
\hline \multicolumn{4}{|c|}{ Other reasons for lack of use of services } \\
\hline Category & Response & $\#$ & $\%$ \\
\hline Lack of time or energy & $\begin{array}{l}\text { - No time for counselling } \\
\text { - Adding another thing to my to do list seemed } \\
\text { too much }\end{array}$ & 2 & 4.3 \\
\hline $\begin{array}{l}\text { Feeling that their } \\
\text { issues were not serious } \\
\text { enough }\end{array}$ & $\begin{array}{l}\text { - felt that I might take up room for someone who } \\
\text { needs it more than me } \\
\text { - I thought it was only for people in serious } \\
\text { trouble }\end{array}$ & 2 & 4.3 \\
\hline $\begin{array}{l}\text { Lack of cultural/racial } \\
\text { sensitivity }\end{array}$ & $\begin{array}{l}\text { - Heard from other students that they weren't } \\
\text { helpful and that the staff was majority white } \\
\text { and did not understand/take into account (or } \\
\text { understand) cultural and racial experiences }\end{array}$ & 1 & 2.2 \\
\hline Waiting list & - Long waiting list & 1 & 2.2 \\
\hline Other & $\begin{array}{l}\text { - I chose to connect with a counsellor not } \\
\text { associated with my school in all my academic } \\
\text { history because of a pre-existing relationship } \\
\text { - General inaction }\end{array}$ & 2 & 4.3 \\
\hline
\end{tabular}




\section{C.10 Question 17-18: Reasons for neutral or improved levels of stress or mental distress during the post-secondary experience}

\begin{tabular}{|c|c|c|c|c|c|c|c|}
\hline \multicolumn{2}{|l|}{ Step taken } & \multicolumn{5}{|c|}{$\begin{array}{l}\text { Number of responses per } \\
\text { impact rating }\end{array}$} & \multirow[t]{2}{*}{ Average score } \\
\hline & & 0 & 1 & 2 & 3 & 4 & \\
\hline \multicolumn{2}{|l|}{ Exercise } & 6 & 4 & 10 & 7 & 9 & 2.25 \\
\hline \multicolumn{2}{|c|}{ Healthy eating habits } & 6 & 5 & 12 & 8 & 5 & 2.03 \\
\hline \multicolumn{2}{|c|}{ Better sleeping habits } & 4 & 7 & 9 & 10 & 4 & 2.09 \\
\hline \multicolumn{2}{|c|}{ Reducing technology use } & 15 & 10 & 5 & 2 & 1 & 0.91 \\
\hline \multicolumn{2}{|c|}{ Increasing socialization } & 3 & 6 & 15 & 11 & 2 & 2.08 \\
\hline \multicolumn{2}{|c|}{ Confiding in a friend/friends } & 3 & 4 & 14 & 10 & 3 & 2.18 \\
\hline \multicolumn{2}{|l|}{ Goal setting } & 8 & 6 & 10 & 9 & 0 & 1.61 \\
\hline \multicolumn{2}{|c|}{ Seeking counselling } & 19 & 6 & 2 & 3 & 3 & 0.94 \\
\hline \multicolumn{2}{|c|}{ Using an online therapy program } & 26 & 3 & 2 & 0 & 1 & 0.34 \\
\hline \multicolumn{2}{|c|}{$\begin{array}{l}\text { Using a Carleton/other post-secondary institution } \\
\text { service }\end{array}$} & 24 & 3 & 1 & 4 & 1 & 0.64 \\
\hline \multicolumn{2}{|c|}{$\begin{array}{l}\text { Reducing course load or taking a break from } \\
\text { classes }\end{array}$} & 20 & 2 & 7 & 4 & 2 & 1.03 \\
\hline \multicolumn{2}{|c|}{ Improving your academic performance } & 11 & 5 & 6 & 12 & 0 & 1.56 \\
\hline \multicolumn{8}{|c|}{ Other steps taken to improve mental health during the post-secondary experience (4 responses) } \\
\hline Category & \multicolumn{7}{|l|}{ Response } \\
\hline $\begin{array}{l}\text { Relaxation and } \\
\text { hobbies }\end{array}$ & \multicolumn{7}{|c|}{$\begin{array}{l}\text { - } \text { Taking up a hobby (pottery) } \\
\text { - } \quad \text { Volunteer work }(3 / 4)\end{array}$} \\
\hline Changing habits & \multicolumn{7}{|c|}{$\begin{array}{l}\text { - I got a dog in } 4 \text { th year which forced me to have a routine, go } \\
\text { outside, and prioritize something other than school - that helped }\end{array}$} \\
\hline Support & \multicolumn{7}{|l|}{ - Family support } \\
\hline
\end{tabular}




\section{Appendix D Graphic message feedback form}

\section{D.1 Introduction}

The purpose of this survey is to evaluate the effectiveness of proposed graphic messages targeted towards post-secondary students. These ads aim to inform post-secondary students about the factors that influence mental health as well as give tips on how to improve mental health and suggested resources to find further information.

\section{D.2 Questions}

1) Please take time to review this image, and then rate the following statements on a scale from 0 (strongly disagree) to 4 (strongly agree).

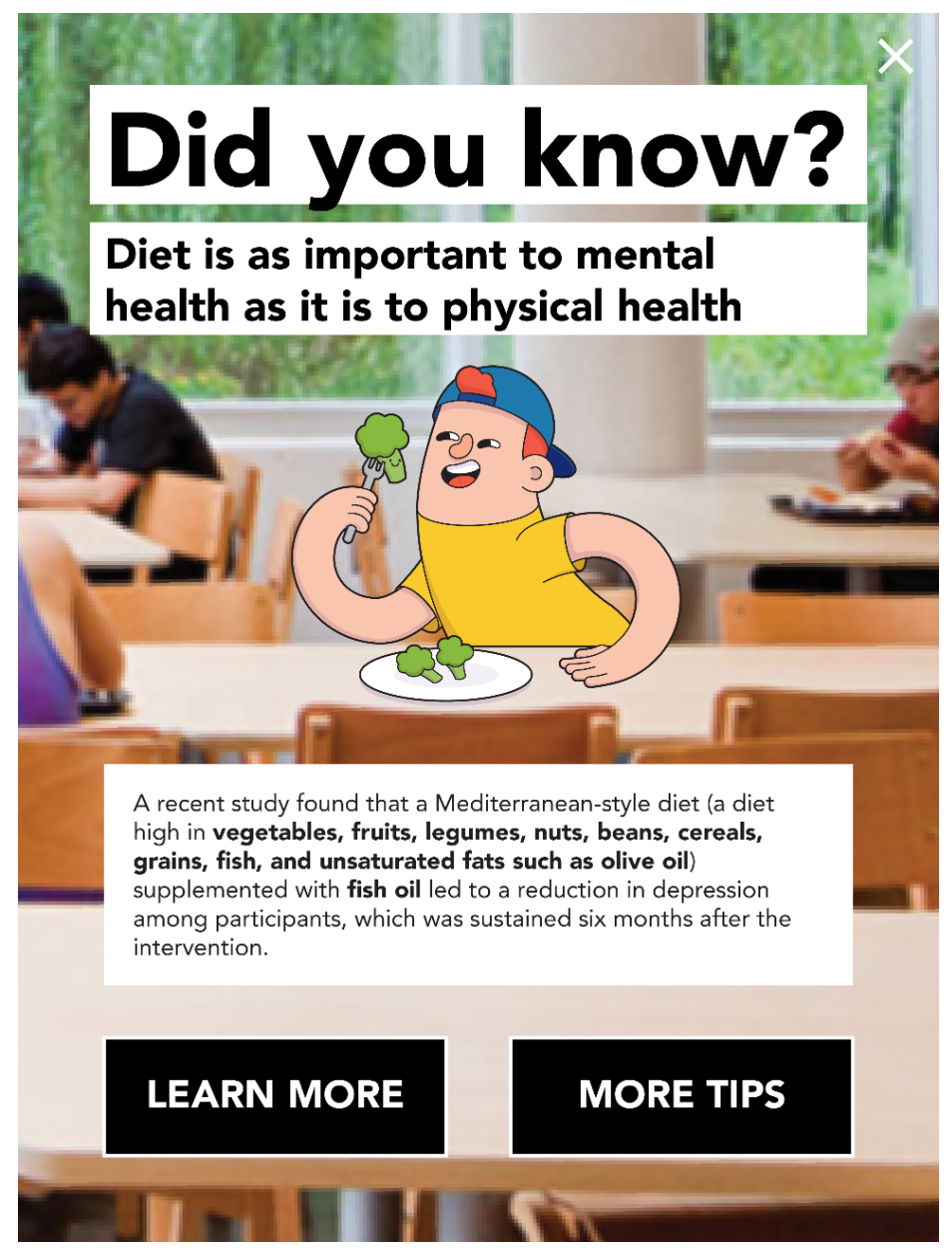




\begin{tabular}{|c|c|c|c|c|c|}
\hline & 0 & 1 & 2 & 3 & 4 \\
\hline $\begin{array}{l}\text { a) The information conveyed in this image is important for post- } \\
\text { secondary students to know. }\end{array}$ & & & & & \\
\hline $\begin{array}{l}\text { b) Post-secondary students will likely examine their own behaviour } \\
\text { and habits after viewing this graphic. }\end{array}$ & & & & & \\
\hline $\begin{array}{l}\text { c) The information conveyed in this graphic will help empower post- } \\
\text { secondary students to take steps to improve their mental health. }\end{array}$ & & & & & \\
\hline $\begin{array}{l}\text { d) Post-secondary students are likely to want to learn more after } \\
\text { seeing this graphic. }\end{array}$ & & & & & \\
\hline
\end{tabular}

2) Please take time to review this image, and then rate the following statements on a scale from 0 (strongly disagree) to 4 (strongly agree).

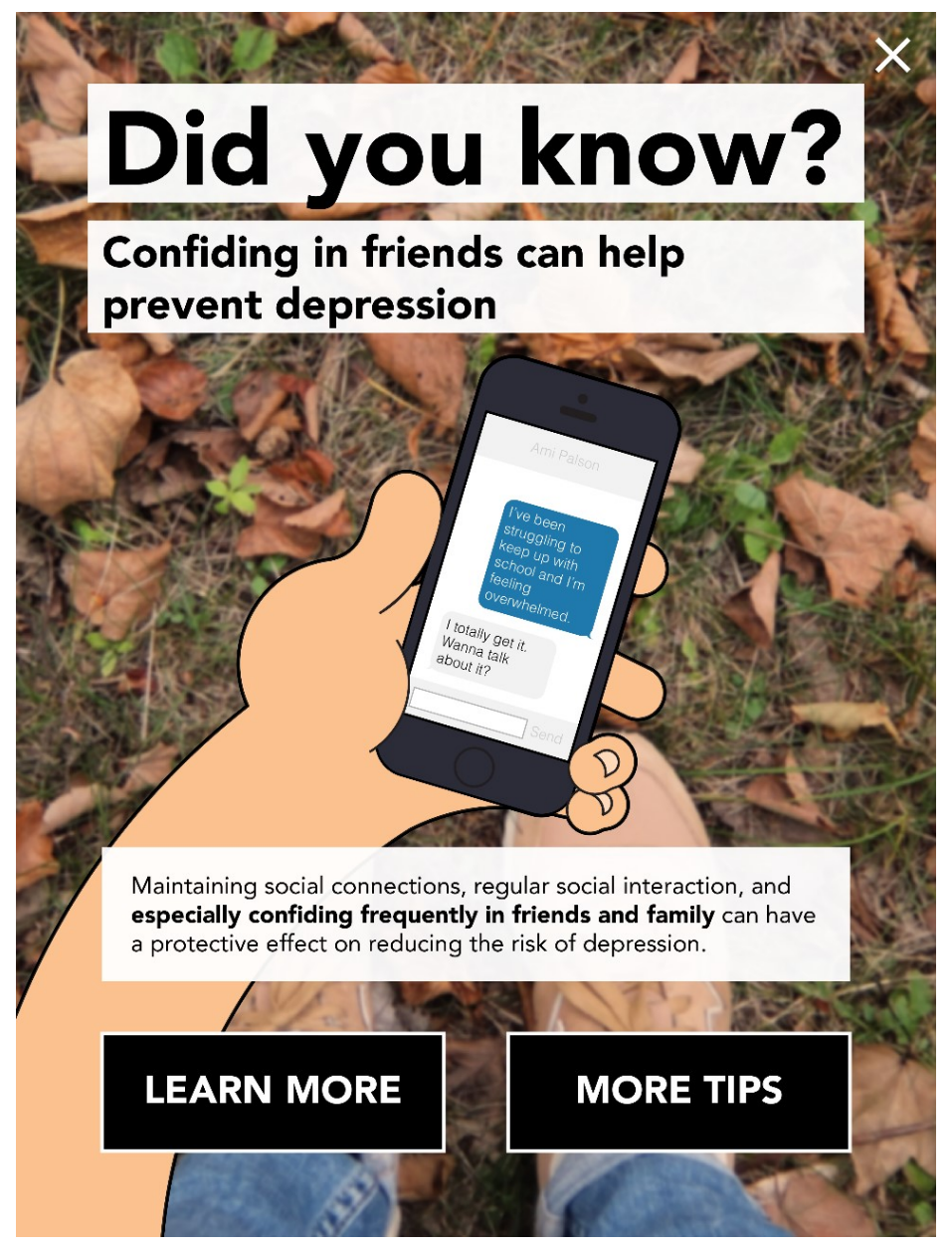




\begin{tabular}{|c|c|c|c|c|c|}
\hline & 0 & 1 & 2 & 3 & 4 \\
\hline $\begin{array}{l}\text { a) The information conveyed in this image is important for post- } \\
\text { secondary students to know. }\end{array}$ & & & & & \\
\hline $\begin{array}{l}\text { b) Post-secondary students will likely examine their own behaviour } \\
\text { and habits after viewing this graphic. }\end{array}$ & & & & & \\
\hline $\begin{array}{l}\text { c) The information conveyed in this graphic will help empower post- } \\
\text { secondary students to take steps to improve their mental health. }\end{array}$ & & & & & \\
\hline $\begin{array}{l}\text { d) Post-secondary students are likely to want to learn more after } \\
\text { seeing this graphic. }\end{array}$ & & & & & \\
\hline
\end{tabular}

3) Please take time to review this image, and then rate the following statements on a scale from 0 (strongly disagree) to 4 (strongly agree). 


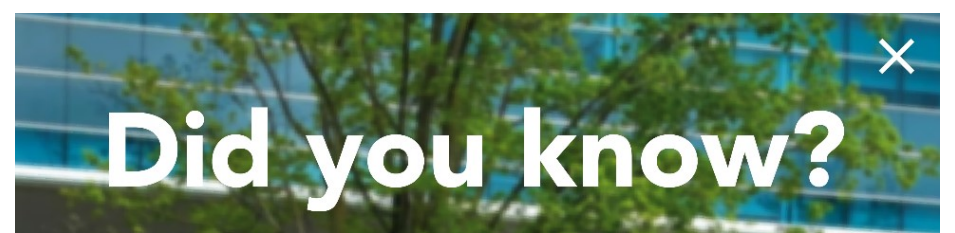

Exercise can reduce stress and

protect against mental illness

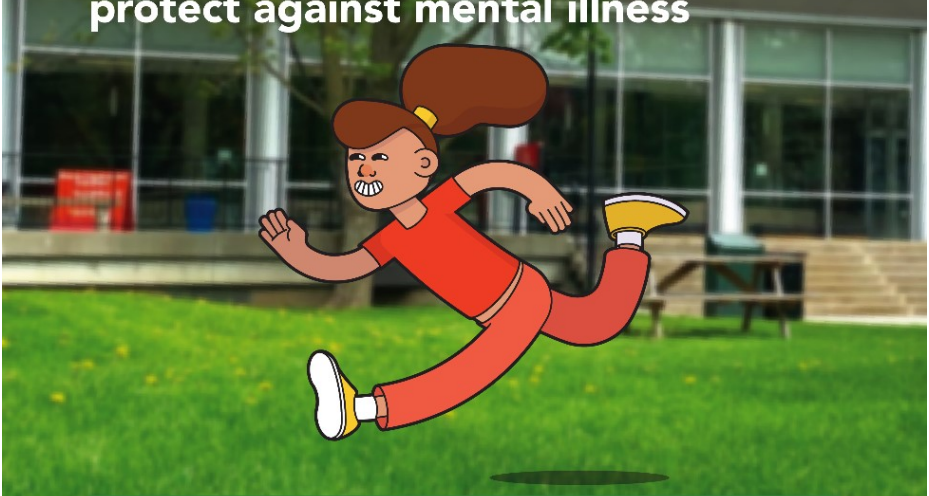

In a survey of 62 current and former university students,

exercise was ranked as the most effective method of reducing stress during their time in school. Try joining a team sport,

visiting Carleton's Fitness Center, or simply by walking or biking

to class instead of taking the bus.

\section{LEARN MORE}

\section{MORE TIPS}

a) The information conveyed in this image is important for postsecondary students to know.

b) Post-secondary students will likely examine their own behaviour and habits after viewing this graphic.

c) The information conveyed in this graphic will help empower postsecondary students to take steps to improve their mental health.

d) Post-secondary students are likely to want to learn more after seeing this graphic. 
4) Please take time to review this image, and then rate the following statements on a scale from 0 (strongly disagree) to 4 (strongly agree).

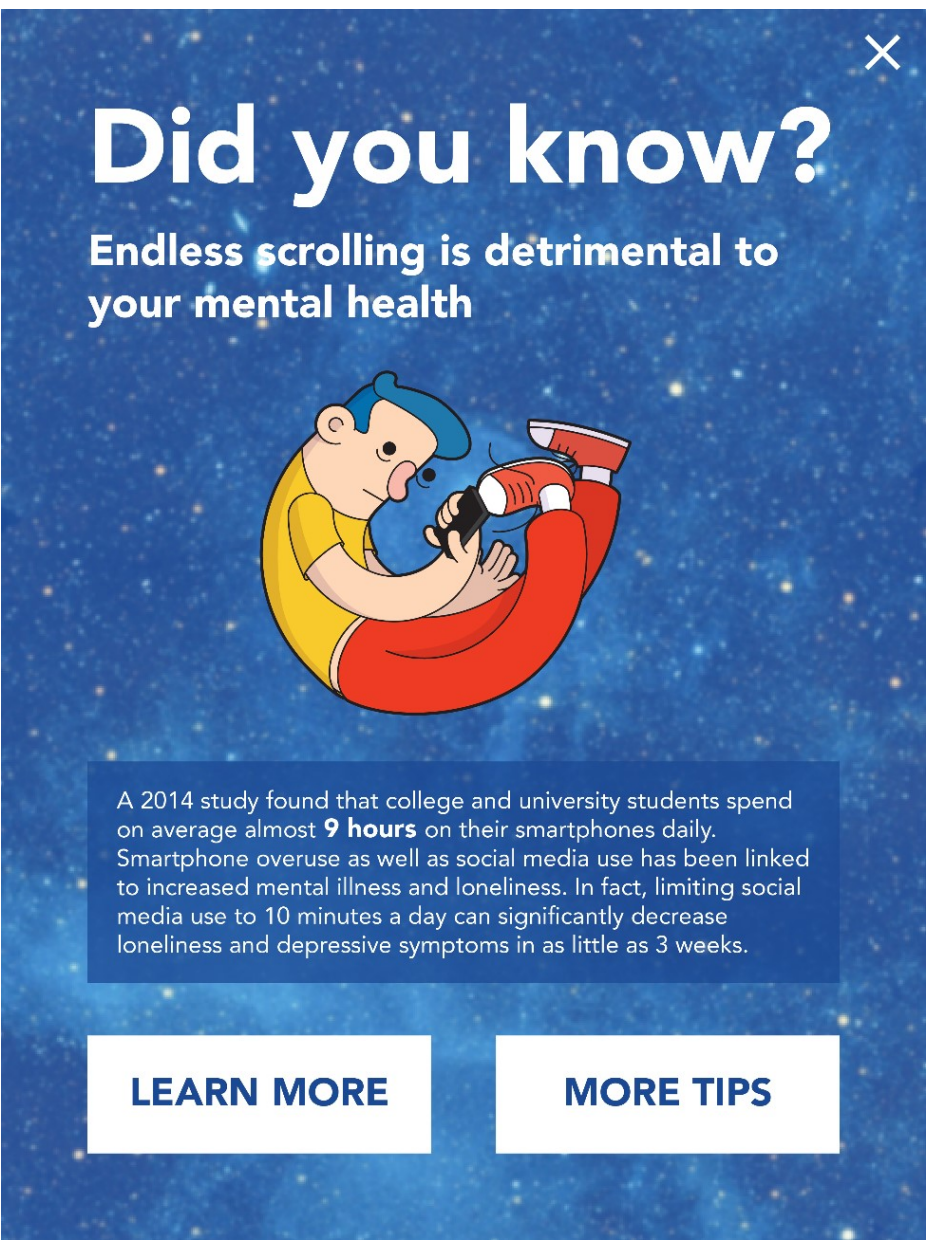

\begin{tabular}{|c|c|c|c|c|c|}
\hline & 0 & 1 & 2 & 3 & 4 \\
\hline $\begin{array}{l}\text { a) The information conveyed in this image is important for post- } \\
\text { secondary students to know. }\end{array}$ & & & & & \\
\hline $\begin{array}{l}\text { b) Post-secondary students will likely examine their own behaviour } \\
\text { and habits after viewing this graphic. }\end{array}$ & & & & & \\
\hline $\begin{array}{l}\text { c) The information conveyed in this graphic will help empower post- } \\
\text { secondary students to take steps to improve their mental health. }\end{array}$ & & & & & \\
\hline $\begin{array}{l}\text { d) Post-secondary students are likely to want to learn more after } \\
\text { seeing this graphic. }\end{array}$ & & & & & \\
\hline
\end{tabular}


5) Please take time to review this image, and then rate the following statements on a scale from 0 (strongly disagree) to 4 (strongly agree).

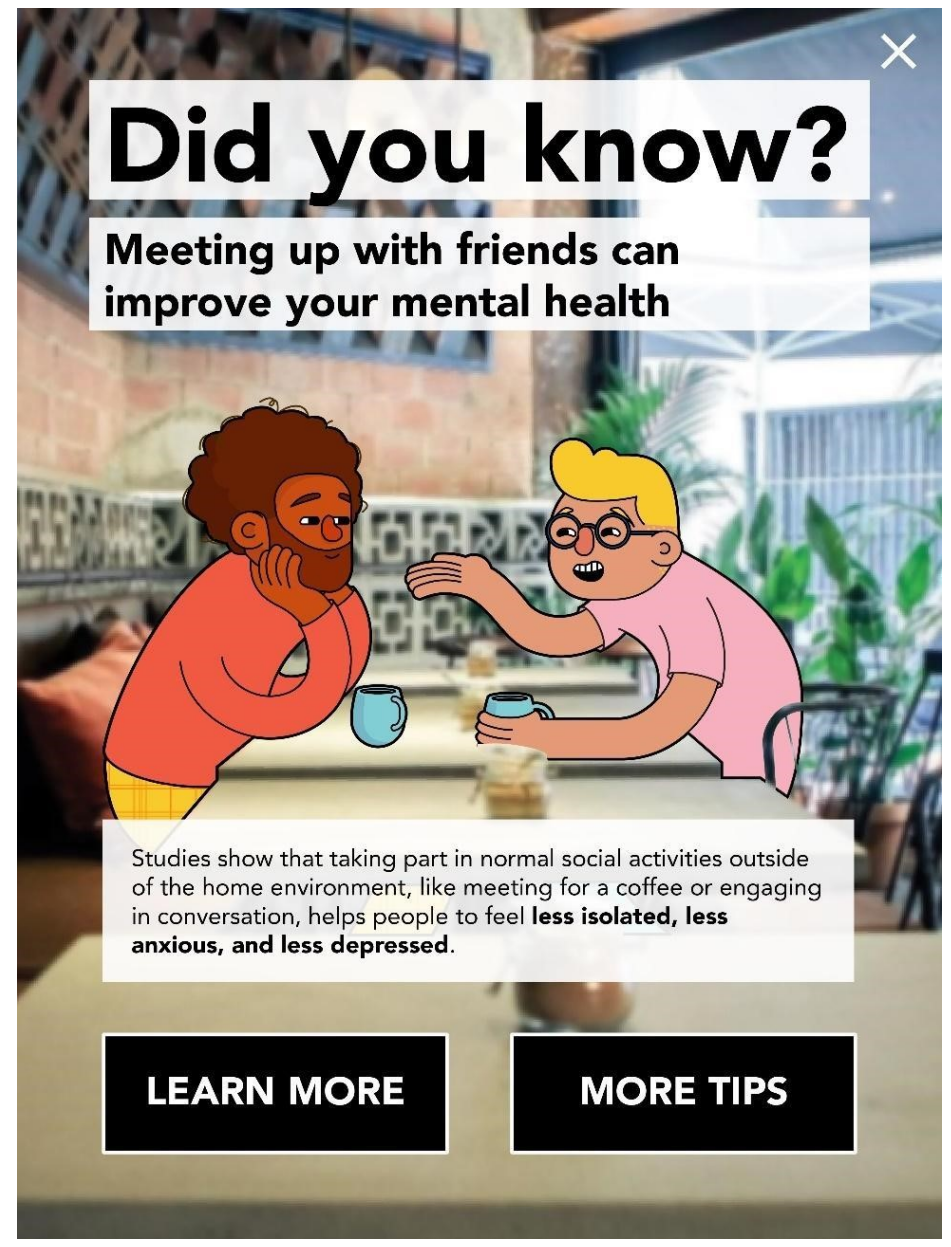

\begin{tabular}{|c|c|c|c|c|c|}
\hline & 0 & 1 & 2 & 3 & 4 \\
\hline $\begin{array}{l}\text { a) The information conveyed in this image is important for post- } \\
\text { secondary students to know. }\end{array}$ & & & & & \\
\hline $\begin{array}{l}\text { b) Post-secondary students will likely examine their own behaviour } \\
\text { and habits after viewing this graphic. }\end{array}$ & & & & & \\
\hline $\begin{array}{l}\text { c) The information conveyed in this graphic will help empower post- } \\
\text { secondary students to take steps to improve their mental health. }\end{array}$ & & & & & \\
\hline
\end{tabular}


d) Post-secondary students are likely to want to learn more after seeing this graphic.

6) Please take time to review this image, and then rate the following statements on a scale from 0 (strongly disagree) to 4 (strongly agree).

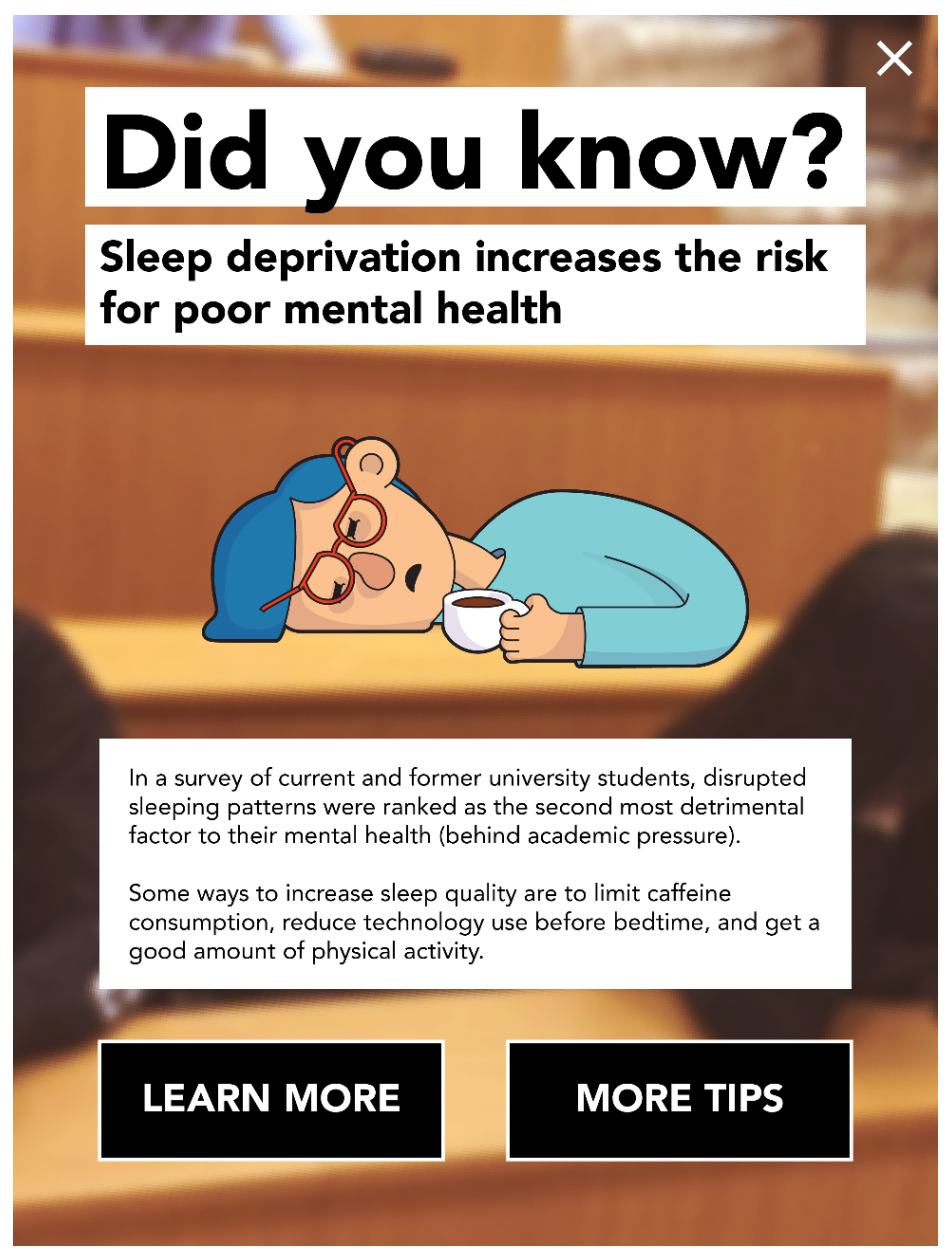

\begin{tabular}{|c|c|c|c|c|}
\hline & 0 & 1 & 2 & 3 \\
\hline $\begin{array}{l}\text { a) The information conveyed in this image is important for post- } \\
\text { secondary students to know. }\end{array}$ & & & & \\
\hline $\begin{array}{l}\text { b) Post-secondary students will likely examine their own behaviour } \\
\text { and habits after viewing this graphic. }\end{array}$ & & & & \\
\hline
\end{tabular}


c) The information conveyed in this graphic will help empower postsecondary students to take steps to improve their mental health.

d) Post-secondary students are likely to want to learn more after seeing this graphic.

7) The following questions are related to the graphic messages as a whole. Please rate the following statements on a scale from 0 (strongly disagree) to 4 (strongly agree).

\begin{tabular}{|c|c|c|c|c|c|}
\hline & 0 & 1 & 2 & 3 & 4 \\
\hline a) I can understand the message of these graphics. & & & & & \\
\hline b) These graphics have a clear purpose. & & & & & \\
\hline $\begin{array}{l}\text { c) Post-secondary students will learn something about how to } \\
\text { improve their mental health from these graphics. }\end{array}$ & & & & & \\
\hline $\begin{array}{l}\text { d) These graphics will empower post-secondary students to take } \\
\text { steps to improve their mental health. }\end{array}$ & & & & & \\
\hline $\begin{array}{l}\text { e) These graphics will contribute to the de-stigmatization of mental } \\
\text { health improvement. }\end{array}$ & & & & & \\
\hline f) These graphics are easy to read. & & & & & \\
\hline g) The font typeface, size, and colour are appropriate. & & & & & \\
\hline $\begin{array}{l}\text { h) The graphic style is appropriate for its audience (post-secondary } \\
\text { students). }\end{array}$ & & & & & \\
\hline i) The graphics were not distracting or inconsistent. & & & & & \\
\hline j) Space was used effectively. & & & & & \\
\hline k) The graphics were not excessively cluttered. & & & & & \\
\hline 1) Colour and contrast were used effectively. & & & & & \\
\hline $\begin{array}{l}\text { m) These graphics will reach post-secondary students in a way that } \\
\text { will appeal to them and catch their interest. }\end{array}$ & & & & & \\
\hline n) The overall design of these graphics facilitates understanding. & & & & & \\
\hline o) The hierarchy and organization of data were appropriate. & & & & & \\
\hline
\end{tabular}


p) These graphics were aesthetically pleasing.

8) Is there anything you would change about the graphics to enhance their usefulness, legibility, design, or aesthetics?

9) In what format do you think these graphics would be most effective? Please rate the formats on a scale from 0 (least effective) to 4 (most effective).

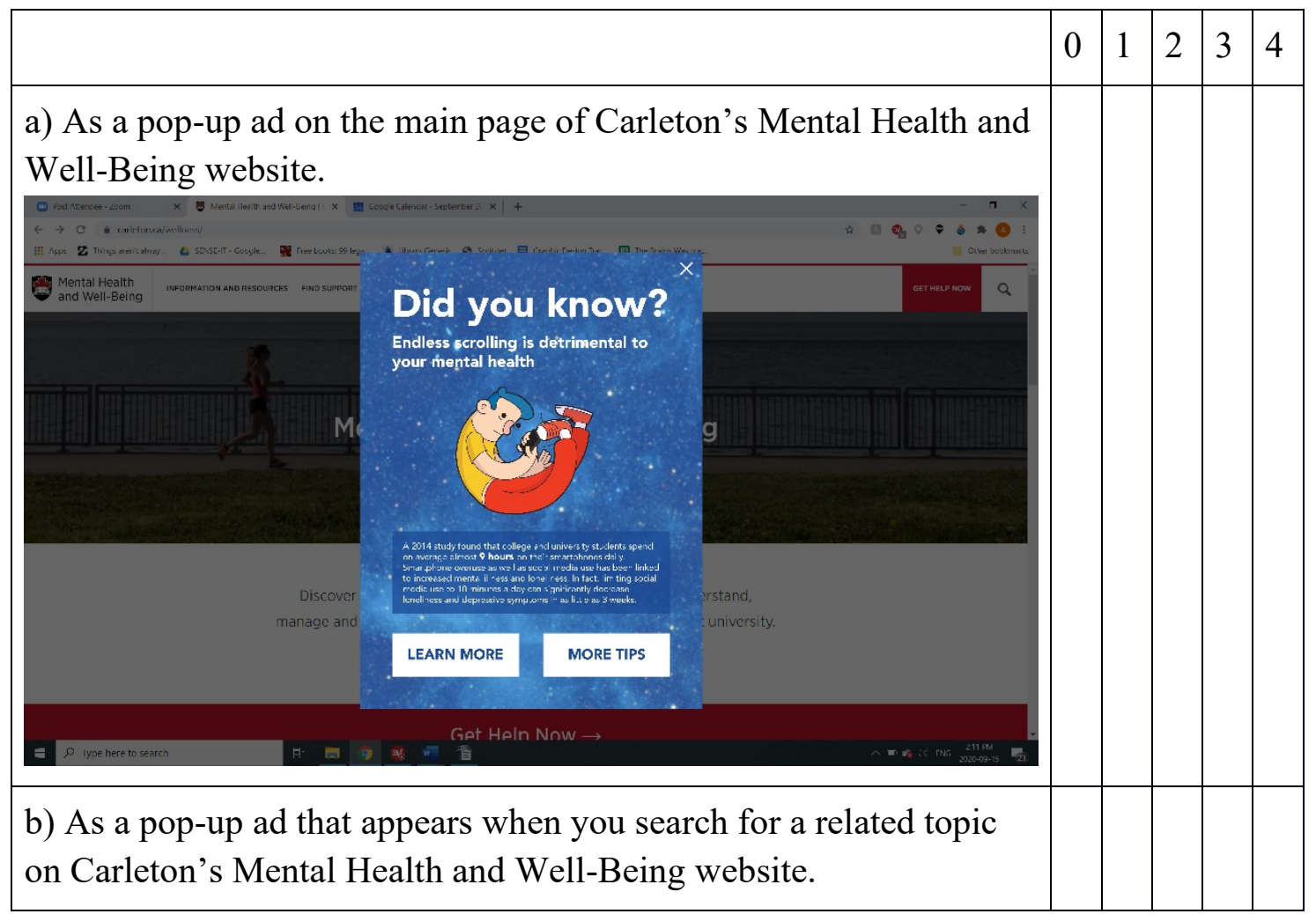




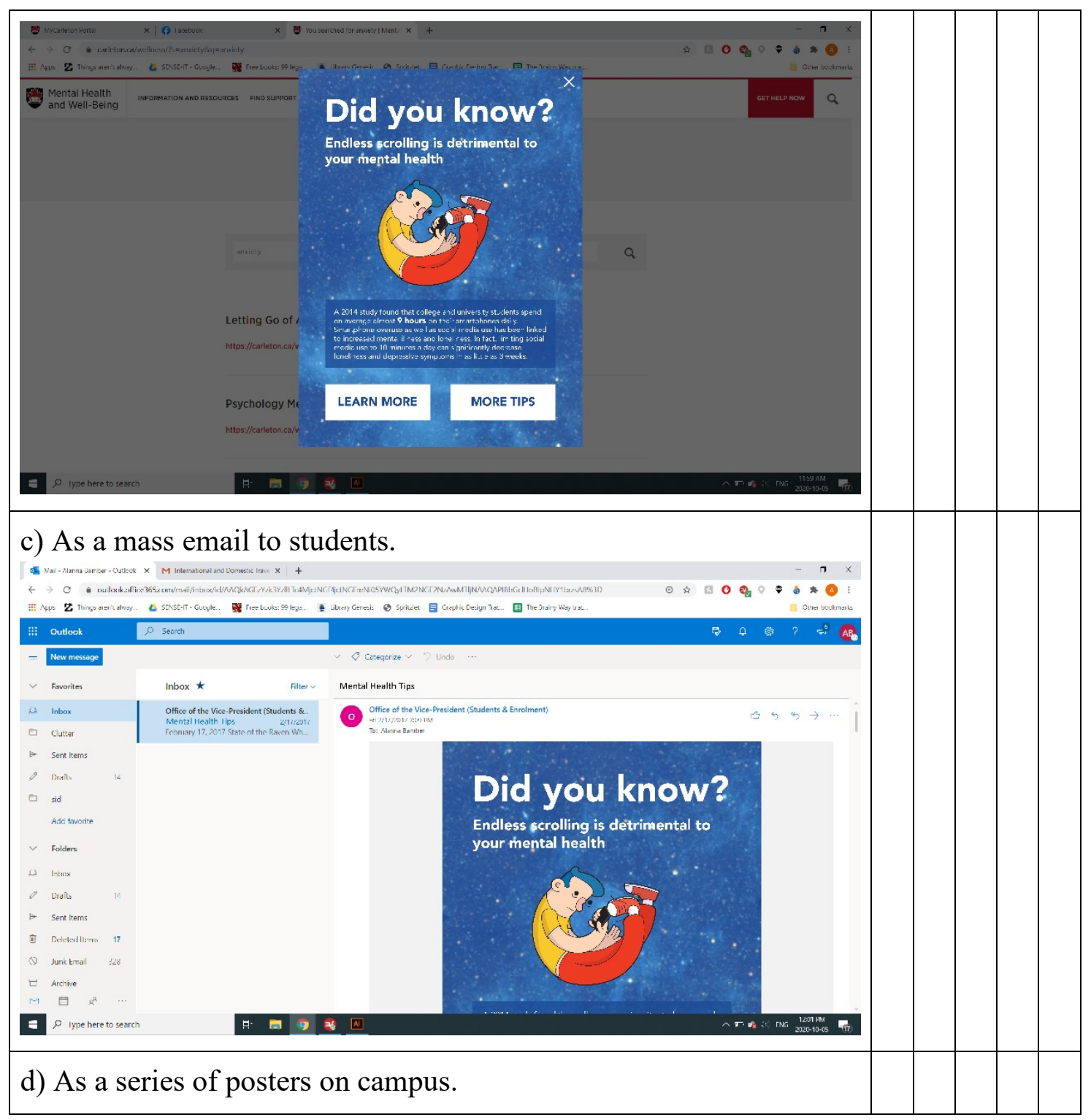




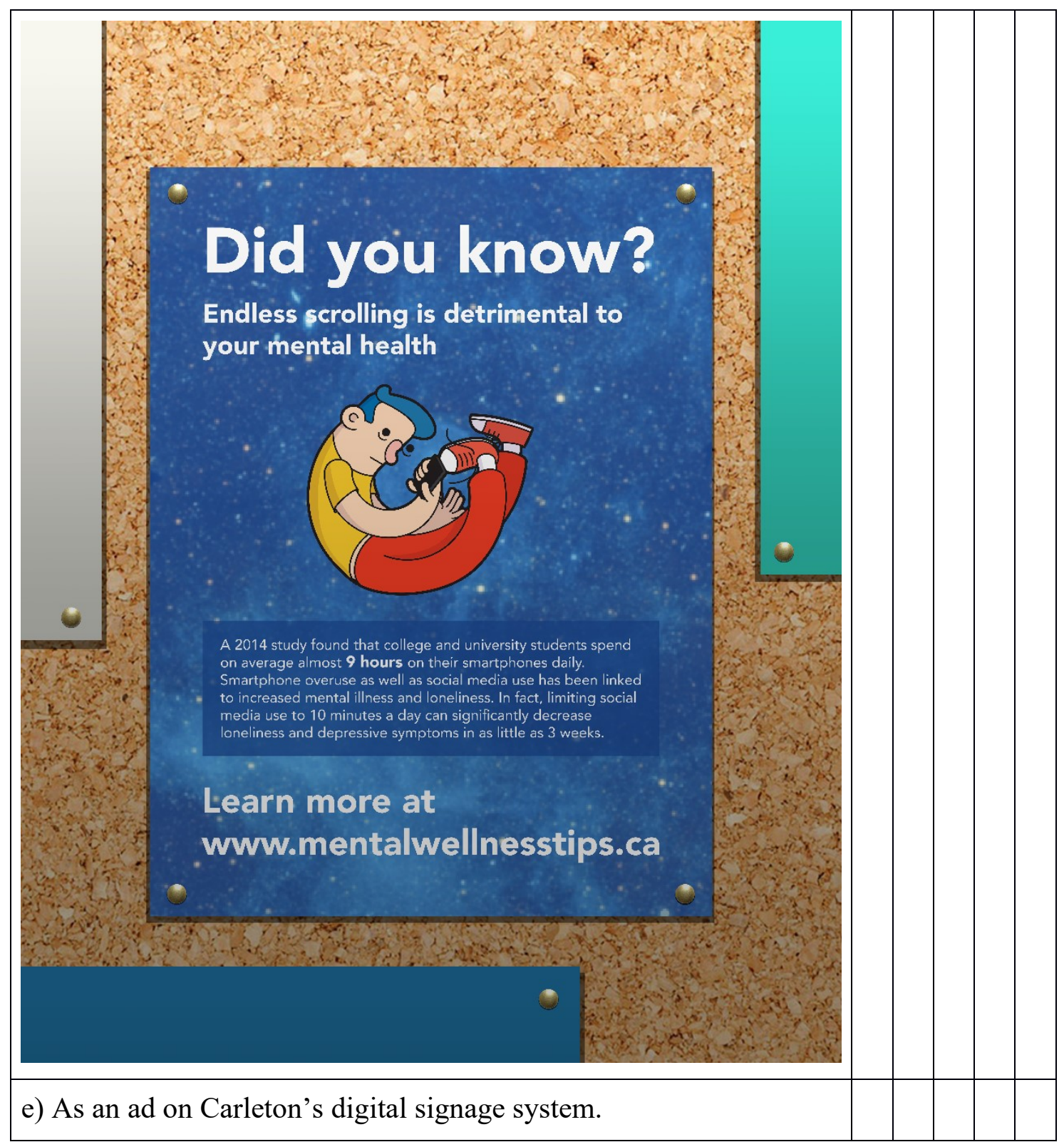




\section{Did you know?}

Endless scrolling is detrimental to your mental health

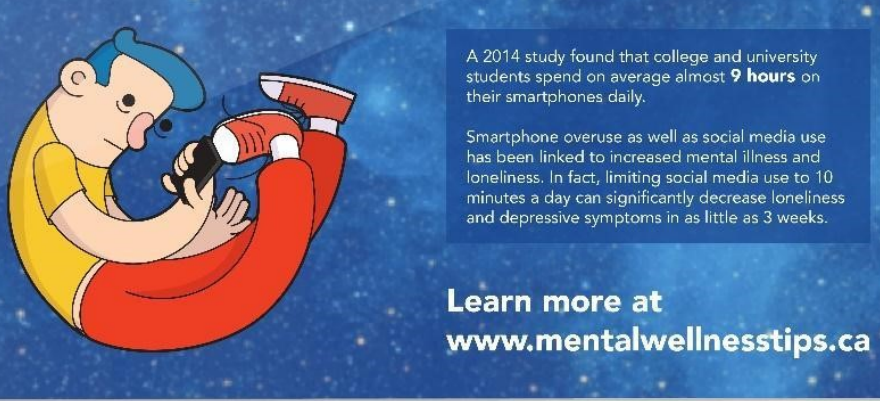

f) As a slide in the lecture slides of a course.

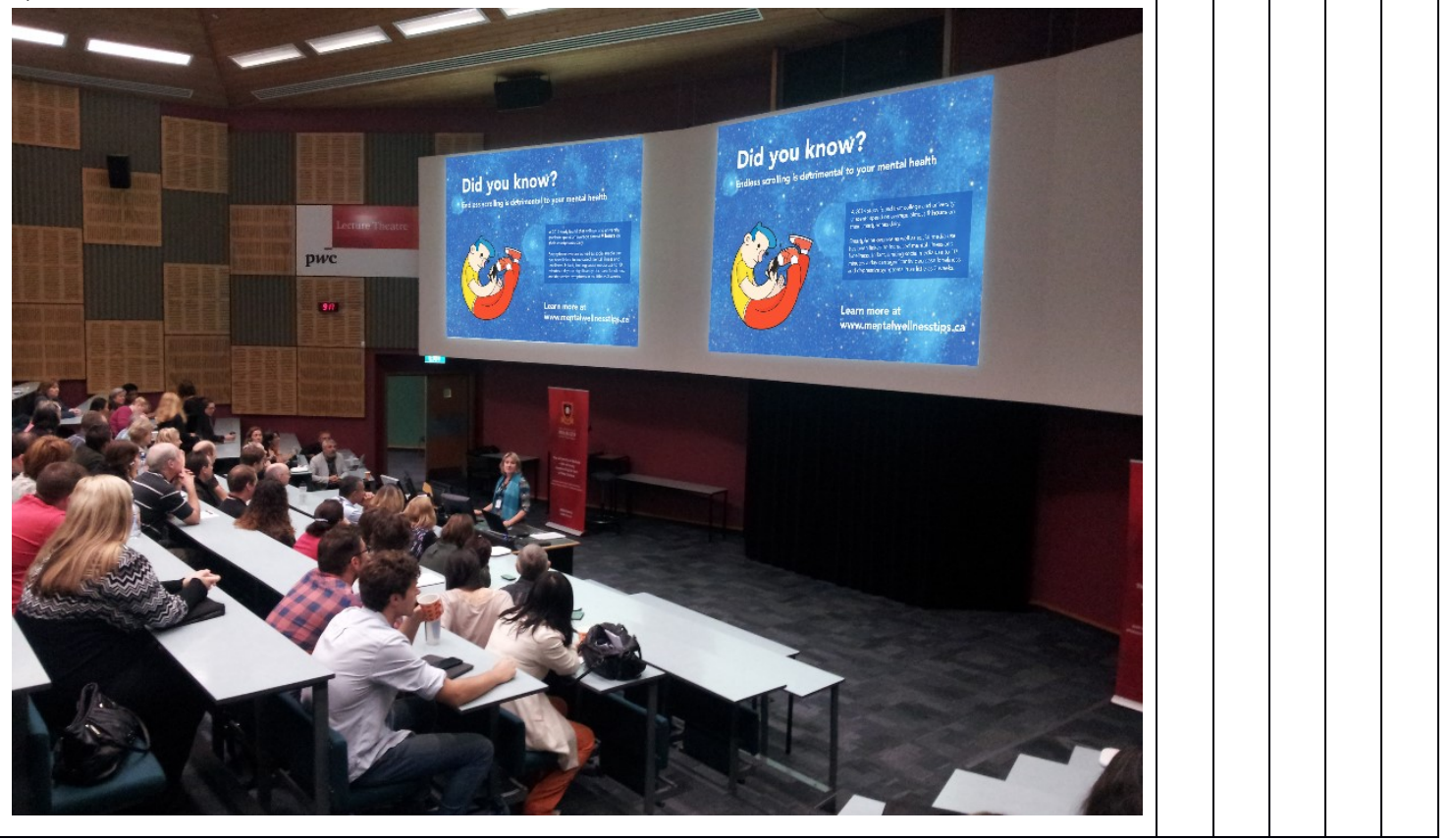

10) If there are other formats that you think would be effective other than those listed above, please list them here with an effectiveness rating from 0 (least effective) to 4 (most effective). 
11) Is there a different way you would like to see this information conveyed? Please explain.

12) Do you have any additional comments about the graphic? 


\section{Appendix E Graphic message feedback form Results from Expert Interviewees}

\section{E.1 Question 1-6: Evaluation of individual graphic messages}

\begin{tabular}{|c|c|c|c|c|c|c|c|}
\hline Statements & $\begin{array}{l}\mathrm{Nu} \\
\text { res } \\
\text { agr }\end{array}$ & on & es & $\begin{array}{l}\text { er } \\
\text { rati }\end{array}$ & & $\begin{array}{l}\text { Median } \\
\text { score }\end{array}$ & $\begin{array}{l}\text { Average } \\
\text { score }\end{array}$ \\
\hline Graphic message 1: Healthy Eating & 0 & 1 & 2 & 3 & 4 & & \\
\hline $\begin{array}{l}\text { The information conveyed in this image is } \\
\text { important for post-secondary students to know. }\end{array}$ & 0 & 1 & 0 & 2 & 5 & 4 & 3.38 \\
\hline $\begin{array}{l}\text { Post-secondary students will likely examine their } \\
\text { own behaviour and habits after viewing this } \\
\text { graphic. }\end{array}$ & 1 & 1 & 2 & 4 & 0 & 2.5 & 2.13 \\
\hline $\begin{array}{l}\text { The information conveyed in this graphic will help } \\
\text { empower post-secondary students to take steps to } \\
\text { improve their mental health. }\end{array}$ & 1 & 0 & 6 & 1 & 0 & 2 & 1.88 \\
\hline $\begin{array}{l}\text { Post-secondary students are likely to want to learn } \\
\text { more after seeing this graphic. }\end{array}$ & 1 & 2 & 3 & 2 & 0 & 2 & 1.75 \\
\hline Overall & & & & & & 2 & 2.28 \\
\hline Graphic message 2: Confiding & 0 & 1 & 2 & 3 & 4 & & \\
\hline $\begin{array}{l}\text { The information conveyed in this image is } \\
\text { important for post-secondary students to know. }\end{array}$ & 0 & 0 & 0 & 2 & 6 & 4 & 3.75 \\
\hline $\begin{array}{l}\text { Post-secondary students will likely examine their } \\
\text { own behaviour and habits after viewing this } \\
\text { graphic. }\end{array}$ & 0 & 0 & 4 & 4 & 0 & 2.5 & 2.50 \\
\hline $\begin{array}{l}\text { The information conveyed in this graphic will help } \\
\text { empower post-secondary students to take steps to } \\
\text { improve their mental health. }\end{array}$ & 0 & 1 & 3 & 4 & 0 & 2.5 & 2.38 \\
\hline $\begin{array}{l}\text { Post-secondary students are likely to want to learn } \\
\text { more after seeing this graphic. }\end{array}$ & 0 & 1 & 1 & 6 & 0 & 3 & 2.63 \\
\hline Overall & & & & & & 3 & 2.81 \\
\hline Graphic message 3: Exercise & 0 & 1 & 2 & 3 & 4 & & \\
\hline $\begin{array}{l}\text { The information conveyed in this image is } \\
\text { important for post-secondary students to know. }\end{array}$ & 0 & 0 & 1 & 1 & 6 & 4 & 3.63 \\
\hline $\begin{array}{l}\text { Post-secondary students will likely examine their } \\
\text { own behaviour and habits after viewing this } \\
\text { graphic. }\end{array}$ & 1 & 0 & 4 & 3 & 0 & 2 & 2.13 \\
\hline
\end{tabular}




\begin{tabular}{|c|c|c|c|c|c|c|c|}
\hline $\begin{array}{l}\text { The information conveyed in this graphic will help } \\
\text { empower post-secondary students to take steps to } \\
\text { improve their mental health. }\end{array}$ & 1 & 0 & 3 & 4 & 0 & 2.5 & 2.25 \\
\hline $\begin{array}{l}\text { Post-secondary students are likely to want to learn } \\
\text { more after seeing this graphic. }\end{array}$ & 1 & 1 & 4 & 2 & 0 & 2 & 1.88 \\
\hline \multicolumn{6}{|l|}{ Overall } & 2.5 & 2.47 \\
\hline Graphic message 4: Scrolling & 0 & 1 & 2 & 3 & 4 & & \\
\hline $\begin{array}{l}\text { The information conveyed in this image is } \\
\text { important for post-secondary students to know. }\end{array}$ & 0 & 0 & 0 & 3 & 5 & 4 & 3.63 \\
\hline $\begin{array}{l}\text { Post-secondary students will likely examine their } \\
\text { own behaviour and habits after viewing this } \\
\text { graphic. }\end{array}$ & 0 & 2 & 0 & 4 & 2 & 3 & 2.75 \\
\hline $\begin{array}{l}\text { The information conveyed in this graphic will help } \\
\text { empower post-secondary students to take steps to } \\
\text { improve their mental health. }\end{array}$ & 0 & 1 & 1 & 4 & 2 & 3 & 2.88 \\
\hline $\begin{array}{l}\text { Post-secondary students are likely to want to learn } \\
\text { more after seeing this graphic. }\end{array}$ & 1 & 1 & 1 & 2 & 3 & 3 & 2.63 \\
\hline \multicolumn{6}{|l|}{ Overall } & 3 & 2.97 \\
\hline Graphic message 5: Socializing & 0 & 1 & 2 & 3 & 4 & & \\
\hline $\begin{array}{l}\text { The information conveyed in this image is } \\
\text { important for post-secondary students to know. }\end{array}$ & 0 & 0 & 1 & 1 & 6 & 4 & 3.63 \\
\hline $\begin{array}{l}\text { Post-secondary students will likely examine their } \\
\text { own behaviour and habits after viewing this } \\
\text { graphic. }\end{array}$ & 1 & 2 & 1 & 3 & 1 & 2.5 & 2.13 \\
\hline $\begin{array}{l}\text { The information conveyed in this graphic will help } \\
\text { empower post-secondary students to take steps to } \\
\text { improve their mental health. }\end{array}$ & 1 & 1 & 3 & 2 & 1 & 2 & 2.13 \\
\hline $\begin{array}{l}\text { Post-secondary students are likely to want to learn } \\
\text { more after seeing this graphic. }\end{array}$ & 1 & 2 & 4 & 0 & 1 & 2 & 1.75 \\
\hline \multicolumn{6}{|l|}{ Overall } & 2 & 2.41 \\
\hline Graphic message 6: Sleep & 0 & 1 & 2 & 3 & 4 & & \\
\hline $\begin{array}{l}\text { The information conveyed in this image is } \\
\text { important for post-secondary students to know. }\end{array}$ & 0 & 0 & 0 & 2 & 6 & 4 & 3.75 \\
\hline $\begin{array}{l}\text { Post-secondary students will likely examine their } \\
\text { own behaviour and habits after viewing this } \\
\text { graphic. }\end{array}$ & 0 & 0 & 2 & 4 & 2 & 3 & 3.00 \\
\hline
\end{tabular}




\begin{tabular}{|l|l|l|l|l|l|l|l|}
\hline $\begin{array}{l}\text { The information conveyed in this graphic will help } \\
\text { empower post-secondary students to take steps to } \\
\text { improve their mental health. }\end{array}$ & 0 & 0 & 2 & 5 & 1 & 3 & 2.88 \\
\hline $\begin{array}{l}\text { Post-secondary students are likely to want to learn } \\
\text { more after seeing this graphic. }\end{array}$ & 0 & 1 & 2 & 3 & 2 & 3 & 2.75 \\
\hline Overall
\end{tabular}

E.2 Question 7: Evaluation of the graphic messages as a whole

\begin{tabular}{|c|c|c|c|c|c|c|c|}
\hline \multirow{2}{*}{$\begin{array}{l}\text { Statements } \\
\text { Usefulness }\end{array}$} & \multicolumn{5}{|c|}{$\begin{array}{l}\text { Number of } \\
\text { responses per } \\
\text { agreement rating }\end{array}$} & \multirow[t]{2}{*}{$\begin{array}{l}\text { Median } \\
\text { Score }\end{array}$} & \multirow[t]{2}{*}{$\begin{array}{l}\text { Average } \\
\text { score }\end{array}$} \\
\hline & 0 & 1 & 2 & 3 & 4 & & \\
\hline I can understand the message of these graphics. & 0 & 0 & 1 & 3 & 4 & 3.5 & 3.38 \\
\hline These graphics have a clear purpose. & 0 & 1 & 0 & 4 & 3 & 3 & 3.13 \\
\hline $\begin{array}{l}\text { Post-secondary students will learn something about } \\
\text { how to improve their mental health from these } \\
\text { graphics. }\end{array}$ & 0 & 0 & 0 & 6 & 1 & 3 & 3.00 \\
\hline $\begin{array}{l}\text { These graphics will empower post-secondary } \\
\text { students to take steps to improve their mental } \\
\text { health. }\end{array}$ & 1 & 1 & 3 & 3 & 0 & 2 & 2.00 \\
\hline $\begin{array}{l}\text { These graphics will contribute to the de- } \\
\text { stigmatization of mental health improvement. }\end{array}$ & 1 & 1 & 2 & 3 & 1 & 2.5 & 2.25 \\
\hline \multicolumn{6}{|l|}{ Overall } & 3 & 2.75 \\
\hline Legibility & 0 & 1 & 2 & 3 & 4 & & \\
\hline These graphics are easy to read. & 1 & 0 & 3 & 3 & 1 & 2.5 & 2.38 \\
\hline The font typeface, size, and colour are appropriate. & 0 & 1 & 1 & 4 & 2 & 3 & 2.88 \\
\hline \multicolumn{6}{|l|}{ Overall } & 3 & 2.63 \\
\hline Design & 0 & 1 & 2 & 3 & 4 & & \\
\hline $\begin{array}{l}\text { The graphic style is appropriate for its audience } \\
\text { (post-secondary students). }\end{array}$ & 0 & 2 & 4 & 1 & 1 & 2 & 2.13 \\
\hline The graphics were not distracting or inconsistent & 1 & 2 & 1 & 3 & 1 & 2.5 & 2.13 \\
\hline Space was used effectively. & 0 & 1 & 5 & 2 & 0 & 2 & 2.88 \\
\hline The graphics were not excessively cluttered. & 0 & 1 & 1 & 5 & 1 & 3 & 2.75 \\
\hline Colour and contrast were used effectively. & 1 & 0 & 4 & 3 & 0 & 2 & 2.88 \\
\hline $\begin{array}{l}\text { The overall design of these graphics facilitates } \\
\text { understanding. }\end{array}$ & 1 & 0 & 2 & 4 & 1 & 3 & 2.50 \\
\hline
\end{tabular}




\begin{tabular}{|l|c|c|c|c|c|c|c|c|}
\hline $\begin{array}{l}\text { The hierarchy and organization of data were } \\
\text { appropriate. }\end{array}$ & 0 & 1 & 0 & 7 & 0 & 3 & 2.75 \\
\hline \begin{tabular}{l} 
Overall \\
\hline Aesthetics
\end{tabular} & 0 & 1 & 2 & 3 & 4 & & \\
\hline $\begin{array}{l}\text { These graphics will reach post-secondary students } \\
\text { in a way that will appeal to them and catch their } \\
\text { interest. }\end{array}$ & 1 & 1 & 3 & 2 & 1 & 2 & 2.13 \\
\hline $\begin{array}{l}\text { These graphics were aesthetically pleasing. } \\
\text { Overall }\end{array}$ & 1 & 1 & 1 & 4 & 1 & 3 & 2.38 \\
\hline
\end{tabular}

\section{E.3 Questions 8: Changes to the graphics to enhance their usefulness, legibility, design,} and/or aesthetics

\begin{tabular}{|c|c|}
\hline Category & Response \\
\hline Brevity & $\begin{array}{l}\text { - Less text in the tip section - something shorter and catchier that } \\
\text { will encourage them to go to a website or somewhere else for } \\
\text { more detailed info. }\end{array}$ \\
\hline Message content & $\begin{array}{l}\text { I often wonder if messaging that points to benefits for the reader } \\
\text { would be more engaging, as in what is in it for them to consider } \\
\text { this behaviour change, rather than our typical public health } \\
\text { messaging. Or messaging that suggests one quick change or life } \\
\text { hack that would contribute to more overall gain. }\end{array}$ \\
\hline Illustrated characters & $\begin{array}{l}\text { Not to mix real life images (and low-quality images) with } \\
\text { graphic cartoons } \\
\text { - Sadly, I am not a fan or "cartoon" characters in reinforcing a } \\
\text { message, and therefore would have connected more effectively, } \\
\text { had real people been used. } \\
\text { - I must say the drawing style doesn't do it for me (mind you, I } \\
\text { am in my 40s so students may see it differently). }\end{array}$ \\
\hline Background images & $\begin{array}{l}\text { I really liked the messages in each of the graphics. I did find, } \\
\text { however, that some of them had a lot going on and the } \\
\text { background images could possibly distract the reader from } \\
\text { reading the message or contribute to the reader glancing quickly } \\
\text { over it without engaging. }\end{array}$ \\
\hline
\end{tabular}




\begin{tabular}{|l|l|}
\hline Contrast & - $\begin{array}{l}\text { The third image [on exercise] contrast is not very high in terms } \\
\text { of text vs background. }\end{array}$ \\
\hline Positive & - $\begin{array}{l}\text { The Screen time one was the best one } \\
\text { - }\end{array}$ \\
\hline - & I thought the strongest graphic was about the endless scrolling. \\
- & The scrolling one was most engaging
\end{tabular}

\section{E.4 Question 9: Effectiveness of formats}

\begin{tabular}{|c|c|c|c|c|c|c|c|}
\hline \multirow[t]{2}{*}{ Format } & \multicolumn{4}{|c|}{$\begin{array}{l}\text { Number of } \\
\text { responses per } \\
\text { effectiveness } \\
\text { rating }\end{array}$} & & \multirow[t]{2}{*}{$\begin{array}{l}\text { Median } \\
\text { score }\end{array}$} & \multirow[t]{2}{*}{$\begin{array}{l}\text { Average } \\
\text { score }\end{array}$} \\
\hline & 0 & 1 & 2 & 3 & 4 & & \\
\hline $\begin{array}{l}\text { As a pop-up ad on the main page of Carleton's } \\
\text { Mental Health and Well-Being website. }\end{array}$ & 0 & 2 & 2 & 2 & 2 & 2.5 & 2.50 \\
\hline
\end{tabular}




\begin{tabular}{|l|l|l|l|l|l|l|l|}
\hline $\begin{array}{l}\text { As a pop-up ad that appears when you search for a } \\
\text { related topic on Carleton's Mental Health and } \\
\text { Well-Being website. }\end{array}$ & 0 & 2 & 1 & 5 & 0 & 3 & 2.38 \\
\hline As a mass email to students. & 2 & 4 & 1 & 1 & 0 & 1 & 1.13 \\
\hline As a series of posters on campus. & 1 & 0 & 2 & 3 & 1 & 3 & 2.43 \\
\hline As an ad on Carleton's digital signage system. & 0 & 2 & 1 & 2 & 3 & 3 & 2.88 \\
\hline As a slide in the lecture slides of a course. & 0 & 0 & 1 & 3 & 4 & 3.5 & 3.38 \\
\hline
\end{tabular}

\section{E.5 Questions 10-11: Alternative formats and ways the information can be conveyed}

\begin{tabular}{|c|c|}
\hline \multicolumn{2}{|c|}{ Alternative formats } \\
\hline Category & Response \\
\hline Social media & $\begin{array}{l}\text { - } \text { Social media campaigns } \\
\text { - } \quad \text { Social media channels }(3 / 4) \\
\text { - } \text { On Carleton's social media channels } \\
\text { - } \quad \text { On Carleton's social media pages }(3 / 4)\end{array}$ \\
\hline $\begin{array}{l}\text { Institution's } \\
\text { app/website }\end{array}$ & $\begin{array}{l}\text { - Carleton app (4/4) } \\
\text { - The website should be directly the CU mental health and well- } \\
\text { being website for more information }\end{array}$ \\
\hline \multicolumn{2}{|c|}{ Alternative methods of conveyance } \\
\hline Category & Response \\
\hline Social media & - Social media \\
\hline
\end{tabular}

\section{E.6 Questions 12: Additional comments}

\section{Additional comments}

\begin{tabular}{|l|r|}
\hline Category & Response \\
\hline Diversity & $\bullet \quad$ Ensure diversity of representation \\
\hline
\end{tabular}




\section{Appendix F Graphic message feedback form Results from Post-Secondary Students}

\section{F.1 Question 1-6: Evaluation of individual graphic messages}

\begin{tabular}{|c|c|c|c|c|c|c|c|}
\hline Statements & $\begin{array}{l}\text { Nui } \\
\text { res! } \\
\text { agr }\end{array}$ & nbe & $\begin{array}{l}\text { r of } \\
\text { es } p \\
\text { ent } r\end{array}$ & ratin & & $\begin{array}{l}\text { Median } \\
\text { score }\end{array}$ & $\begin{array}{l}\text { Average } \\
\text { score }\end{array}$ \\
\hline Graphic message 1: Healthy Eating & 0 & 1 & 2 & 3 & 4 & & \\
\hline $\begin{array}{l}\text { The information conveyed in this image is } \\
\text { important for post-secondary students to know. }\end{array}$ & 0 & 4 & 0 & 23 & 24 & 3 & 3.31 \\
\hline $\begin{array}{l}\text { Post-secondary students will likely examine their } \\
\text { own behaviour and habits after viewing this } \\
\text { graphic. }\end{array}$ & 1 & 11 & 14 & 24 & 1 & 2 & 2.25 \\
\hline $\begin{array}{l}\text { The information conveyed in this graphic will help } \\
\text { empower post-secondary students to take steps to } \\
\text { improve their mental health. }\end{array}$ & 1 & 13 & 16 & 18 & 3 & 2 & 2.18 \\
\hline $\begin{array}{l}\text { Post-secondary students are likely to want to learn } \\
\text { more after seeing this graphic. }\end{array}$ & 3 & 13 & 12 & 22 & 0 & 2 & 2.06 \\
\hline Overall & & & & & & 3 & 2.45 \\
\hline Graphic message 2: Confiding & 0 & 1 & 2 & 3 & 4 & & \\
\hline $\begin{array}{l}\text { The information conveyed in this image is } \\
\text { important for post-secondary students to know. }\end{array}$ & 0 & 1 & 1 & 21 & 28 & 4 & 3.50 \\
\hline $\begin{array}{l}\text { Post-secondary students will likely examine their } \\
\text { own behaviour and habits after viewing this } \\
\text { graphic. }\end{array}$ & 0 & 5 & 9 & 32 & 5 & 3 & 2.73 \\
\hline $\begin{array}{l}\text { The information conveyed in this graphic will help } \\
\text { empower post-secondary students to take steps to } \\
\text { improve their mental health. }\end{array}$ & 0 & 8 & 10 & 26 & 4 & 3 & 2.53 \\
\hline $\begin{array}{l}\text { Post-secondary students are likely to want to learn } \\
\text { more after seeing this graphic. }\end{array}$ & 2 & 9 & 20 & 16 & 4 & 2 & 2.22 \\
\hline Overall average & & & & & & 3 & 2.74 \\
\hline Graphic message 3: Exercise & 0 & 1 & 2 & 3 & 4 & & \\
\hline $\begin{array}{l}\text { The information conveyed in this image is } \\
\text { important for post-secondary students to know. }\end{array}$ & 0 & 1 & 1 & 19 & 30 & 4 & 3.53 \\
\hline $\begin{array}{l}\text { Post-secondary students will likely examine their } \\
\text { own behaviour and habits after viewing this } \\
\text { graphic. }\end{array}$ & 0 & 3 & 7 & 37 & 4 & 3 & 2.82 \\
\hline
\end{tabular}




\begin{tabular}{|c|c|c|c|c|c|c|c|}
\hline $\begin{array}{l}\text { The information conveyed in this graphic will help } \\
\text { empower post-secondary students to take steps to } \\
\text { improve their mental health. }\end{array}$ & 0 & 5 & 12 & 29 & 5 & 3 & 2.67 \\
\hline $\begin{array}{l}\text { Post-secondary students are likely to want to learn } \\
\text { more after seeing this graphic. }\end{array}$ & 0 & 8 & 16 & 25 & 2 & 3 & 2.41 \\
\hline \multicolumn{6}{|l|}{ Overall average } & 3 & 2.86 \\
\hline Graphic message 4: Scrolling & 0 & 1 & 2 & 3 & 4 & & \\
\hline $\begin{array}{l}\text { The information conveyed in this image is } \\
\text { important for post-secondary students to know. }\end{array}$ & 0 & 0 & 1 & 14 & 35 & 4 & 3.68 \\
\hline $\begin{array}{l}\text { Post-secondary students will likely examine their } \\
\text { own behaviour and habits after viewing this } \\
\text { graphic. }\end{array}$ & 0 & 6 & 5 & 25 & 15 & 3 & 2.96 \\
\hline $\begin{array}{l}\text { The information conveyed in this graphic will help } \\
\text { empower post-secondary students to take steps to } \\
\text { improve their mental health. }\end{array}$ & 2 & 4 & 9 & 25 & 10 & 3 & 2.76 \\
\hline $\begin{array}{l}\text { Post-secondary students are likely to want to learn } \\
\text { more after seeing this graphic. }\end{array}$ & 1 & 12 & 6 & 27 & 5 & 2 & 2.45 \\
\hline \multicolumn{6}{|l|}{ Overall average } & 3 & 2.96 \\
\hline Graphic message 5: Socializing & 0 & 1 & 2 & 3 & 4 & & \\
\hline $\begin{array}{l}\text { The information conveyed in this image is } \\
\text { important for post-secondary students to know. }\end{array}$ & 0 & 1 & 3 & 21 & 31 & 4 & 3.41 \\
\hline $\begin{array}{l}\text { Post-secondary students will likely examine their } \\
\text { own behaviour and habits after viewing this } \\
\text { graphic. }\end{array}$ & 0 & 8 & 6 & 31 & 5 & 3 & 2.66 \\
\hline $\begin{array}{l}\text { The information conveyed in this graphic will help } \\
\text { empower post-secondary students to take steps to } \\
\text { improve their mental health. }\end{array}$ & 0 & 3 & 15 & 33 & 3 & 3 & 2.64 \\
\hline $\begin{array}{l}\text { Post-secondary students are likely to want to learn } \\
\text { more after seeing this graphic. }\end{array}$ & 2 & 10 & 12 & 23 & 4 & 3 & 2.33 \\
\hline \multicolumn{6}{|l|}{ Overall average } & 3 & 2.76 \\
\hline Graphic message 6: Sleep & 0 & 1 & 2 & 3 & 4 & & \\
\hline $\begin{array}{l}\text { The information conveyed in this image is } \\
\text { important for post-secondary students to know. }\end{array}$ & 0 & 0 & 1 & 18 & 32 & 4 & 3.61 \\
\hline $\begin{array}{l}\text { Post-secondary students will likely examine their } \\
\text { own behaviour and habits after viewing this } \\
\text { graphic. }\end{array}$ & 0 & 3 & 9 & 31 & 7 & 3 & 2.84 \\
\hline
\end{tabular}




\begin{tabular}{|l|l|l|l|l|l|l|l|}
\hline $\begin{array}{l}\text { The information conveyed in this graphic will help } \\
\text { empower post-secondary students to take steps to } \\
\text { improve their mental health. }\end{array}$ & 0 & 3 & 20 & 23 & 5 & 3 & 2.59 \\
\hline $\begin{array}{l}\text { Post-secondary students are likely to want to learn } \\
\text { more after seeing this graphic. }\end{array}$ & 0 & 5 & 19 & 20 & 6 & 3 & 2.54 \\
\hline Overall average
\end{tabular}

F.2 Question 7: Evaluation of the graphic messages as a whole

\begin{tabular}{|c|c|c|c|c|c|c|c|}
\hline \multirow{2}{*}{$\begin{array}{l}\text { Statements } \\
\text { Usefulness }\end{array}$} & \multicolumn{5}{|c|}{$\begin{array}{l}\text { Number of } \\
\text { responses per } \\
\text { agreement rating }\end{array}$} & \multirow[t]{2}{*}{$\begin{array}{l}\text { Median } \\
\text { score }\end{array}$} & \multirow[t]{2}{*}{$\begin{array}{l}\text { Average } \\
\text { score }\end{array}$} \\
\hline & 0 & 1 & 2 & 3 & 4 & & \\
\hline I can understand the message of these graphics. & 0 & 1 & 0 & 9 & 42 & 4 & 3.76 \\
\hline These graphics have a clear purpose. & 0 & 0 & 0 & 13 & 38 & 4 & 3.75 \\
\hline $\begin{array}{l}\text { Post-secondary students will learn something about } \\
\text { how to improve their mental health from these } \\
\text { graphics. }\end{array}$ & 0 & 1 & 7 & 29 & 14 & 3 & 3.10 \\
\hline $\begin{array}{l}\text { These graphics will empower post-secondary } \\
\text { students to take steps to improve their mental } \\
\text { health. }\end{array}$ & 1 & 2 & 21 & 19 & 8 & 3 & 2.61 \\
\hline $\begin{array}{l}\text { These graphics will contribute to the de- } \\
\text { stigmatization of mental health improvement. }\end{array}$ & 0 & 3 & 9 & 21 & 17 & 3 & 3.04 \\
\hline \multicolumn{6}{|l|}{ Overall } & 3 & 3.25 \\
\hline Legibility & 0 & 1 & 2 & 3 & 4 & & \\
\hline These graphics are easy to read. & 0 & 2 & 1 & 21 & 27 & 4 & 3.43 \\
\hline The font typeface, size, and colour are appropriate. & 0 & 4 & 5 & 27 & 14 & 3 & 3.02 \\
\hline \multicolumn{6}{|l|}{ Overall } & 3 & 3.23 \\
\hline Design & 0 & 1 & 2 & 3 & 4 & & \\
\hline $\begin{array}{l}\text { The graphic style is appropriate for its audience } \\
\text { (post-secondary students). }\end{array}$ & 2 & 2 & 5 & 21 & 21 & 3 & 3.16 \\
\hline The graphics were not distracting or inconsistent & 0 & 3 & 4 & 23 & 21 & 3 & 3.22 \\
\hline Space was used effectively. & 0 & 2 & 1 & 30 & 18 & 3 & 3.25 \\
\hline The graphics were not excessively cluttered. & 0 & 1 & 6 & 22 & 22 & 3 & 3.27 \\
\hline Colour and contrast were used effectively. & 0 & 2 & 5 & 25 & 19 & 3 & 3.20 \\
\hline $\begin{array}{l}\text { The overall design of these graphics facilitates } \\
\text { understanding. }\end{array}$ & 0 & 1 & 4 & 29 & 17 & 3 & 3.22 \\
\hline
\end{tabular}




\begin{tabular}{|c|c|c|c|c|c|c|c|}
\hline $\begin{array}{l}\text { The hierarchy and organization of data were } \\
\text { appropriate. }\end{array}$ & 0 & 0 & 4 & 31 & 15 & 3 & 3.22 \\
\hline Overall & & & & & & 3 & 3.21 \\
\hline Aesthetics & 0 & 1 & 2 & 3 & 4 & & \\
\hline $\begin{array}{l}\text { These graphics will reach post-secondary students } \\
\text { in a way that will appeal to them and catch their } \\
\text { interest. }\end{array}$ & 1 & 5 & 9 & 28 & 8 & 3 & 2.73 \\
\hline These graphics were aesthetically pleasing. & 0 & 3 & 9 & 19 & 19 & 3 & 3.08 \\
\hline Overall & & & & & & 3 & 2.90 \\
\hline
\end{tabular}

F.3 Questions 8: Changes to the graphics to enhance their usefulness, legibility, design, and/or aesthetics

\begin{tabular}{|l|l|}
\hline Changes to enhance the graphic messages \\
\hline Category & Response \\
\hline Overall impressions & $\begin{array}{l}\text { Make it more obvious they are about mental health from a quick } \\
\text { glance }\end{array}$ \\
\hline & $\begin{array}{l}\text { Liked some graphics more than others. The simpler the better } \\
\text { - It's hard to generalize ALL post-secondary students. I think } \\
\text { some students would LOVE the style and others wouldn't feel } \\
\text { as drawn. }\end{array}$ \\
\hline Message content & $\begin{array}{l}\text { Would more bold or eye catching visuals attract increased } \\
\text { attention to the graphics and information contained within? }\end{array}$ \\
\hline $\begin{array}{l}\text { - I would suggest including statistics. It makes a greater impact } \\
\text { on the reader if they can visualize the numbers then just reading } \\
\text { "studies have shown". }\end{array}$ \\
$\begin{array}{l}\text { Well, I think that the challenge is getting people to change their } \\
\text { behaviour. I was thinking for the info that it's a good idea, but } \\
\text { it's not realistic for the sleep one that I'd not look at a screen } \\
\text { before bed and their other suggestions. I would reduce caffeine } \\
\text { though. }\end{array}$ \\
$\begin{array}{l}\text { I think that connecting with family and friends is important. I'd } \\
\text { be interested to. know what you can tell them and what to tell a } \\
\text { counsellor who is accredited and accountable to what they do. } \\
\text { In university, I had a very controlling person in my life who } \\
\text { isolated me from everyone else. }\end{array}$ \\
\hline
\end{tabular}




\begin{tabular}{|c|c|}
\hline & $\begin{array}{l}\text { - The phone overuse struck me because it said "if you realize it's } \\
\text { becoming a problem". This is a key phrase which sets it apart } \\
\text { from the other ads that are for people in general. } \\
\text { - I think that money to get good food as a student might interfere } \\
\text { with action on examining diet. } \\
\text { - I would do a graphic about the crisis line. } \\
\text { - Yeah, I guess I'd have ads like it's ok to go for coffee because } \\
\text { the pressures of university or college can be so much that a } \\
\text { person can feel guilty doing other things. On the other } \\
\text { hand...there can be too much socialization in first year, so } \\
\text { grades can suffer. } \\
\text { I'd want to learn more about clubs and what you can do to } \\
\text { change your behaviour with too much technology use, without } \\
\text { feeling that it's a part of school and you have to have it around } \\
\text { all the time. I'd say that technology can cause procrastination. }\end{array}$ \\
\hline Colour & $\begin{array}{l}\text { - So for me, the colours were too bold: orange-black-bright. I } \\
\text { would use more calming colours, but I get that you have to } \\
\text { catch people's attention. } \\
\text { - Overall style and typography were great but I think posters need } \\
\text { to improve in colour. Use of primary colours does not go well } \\
\text { with background image. } \\
\text { - I didn't like the black box with the white writing on it...the } \\
\text { combo was eerie for some reason. }\end{array}$ \\
\hline Illustrated characters & $\begin{array}{l}\text { - The ad at the bench about joining clubs, one of the friends } \\
\text { looked lonely and that he wasn't paying attention even with a } \\
\text { person, so I didn't find that helpful. } \\
\text { - For the exercise one, There was a student who looked very } \\
\text { athletic running and I was thinking that's not me. I might add } \\
\text { something like, "it's ok to take time to exercise". I know that } \\
\text { getting your heart rate up is the best exercise for mental health. } \\
\text { I would would turn to swimming or Zumba that you can get } \\
\text { your heart rate up, but you have a choice about how hard you } \\
\text { push yourself. I'm a woman. But I'm not sure that the add would } \\
\text { even encourage me to do that. The colours were too bright in } \\
\text { that ad too. }\end{array}$ \\
\hline
\end{tabular}




\begin{tabular}{|c|c|}
\hline & $\begin{array}{l}\text { - Perhaps, more representation of women would be good. I see } \\
\text { young guys and I'm like, they experience the world differently } \\
\text { than I do. } \\
\text { - The cartoon characters could be nicer - especially the teeth on } \\
\text { the guy running. } \\
\text { - The people were too goofy looking for such a serious topic. } \\
\text { - Not sure that the cartoons are likely to catch the attention of } \\
\text { post-secondary students... May come off as being too childish. } \\
\text { - The cartoon characters seemed a bit silly, but I think that the } \\
\text { other parts worked well. } \\
\text { - The cartoons are a bit immature. } \\
\text { - If it looks like it's for kids, they won't look as much } \\
\text { The graphics seem far too childish for a post-secondary } \\
\text { audience and feels like they are being talked down too. I } \\
\text { imagine most post-secondary students are already aware of } \\
\text { most of these things and will implement them if they can, but } \\
\text { these graphics come across as assuming that students are doing } \\
\text { these detrimental things to themselves for fun. They are much } \\
\text { too cartoon-y for a post-secondary audience. } \\
\text { - They may be a bit too cartoon-y for post-secondary students. }\end{array}$ \\
\hline $\begin{array}{l}\text { Background images } \\
\text { and contrast }\end{array}$ & $\begin{array}{l}\text { - I feel like the overall background was a little overpopulated. It } \\
\text { took away from the main text and characters, I feel like if it was } \\
\text { slightly more transparent or blurred, it might highlight the } \\
\text { individuals depicted stronger. But not blurred enough that you } \\
\text { can't tell the situation or environment they are in } \\
\text { - Lower the opacity/darken the background picture for some of } \\
\text { the posters for the characters to "pop" more. } \\
\text { - 2nd poster had poor contrast of the person's hand band } \\
\text { background } \\
\text { - Maybe revise the background in some of them so there is a } \\
\text { higher contrast (e.g. the space background had white stars and } \\
\text { some of the type got lost). Very good otherwise! } \\
\text { - Maybe decrease the colour saturation of the background to } \\
\text { focus more on the cartoon character or a vignette } \\
\text { - There were a few posters where the white font blended in a bit. }\end{array}$ \\
\hline Brevity & - I think the posters had too much text (maybe use bullets) \\
\hline
\end{tabular}




\begin{tabular}{|c|c|}
\hline Positive & $\begin{array}{l}\text { - No [changes needed] } \\
\text { - I really liked the graphics } \\
\text { - Overall love the idea of the character and the graphics are } \\
\text { simple and easy to read, size of the title is eyegrabbing and } \\
\text { appropriate } \\
\text { - I think that this is a fantastic study! } \\
\text { - No, graphics look great! } \\
\text { - I like the graphics as they attracted me to focus more on the } \\
\text { - I thought it was great. And overall super good reminders :). } \\
\text { - Great job!! } \\
\text { - Tasy to read with clear purpose and objectives } \\
\text { - I really hope that these ads keep circulating because I think that } \\
\text { the mental health initiative is so important. }\end{array}$ \\
\hline Alternative strategies & $\begin{array}{l}\text { - One thing that could be tried out is maybe emphasizing the } \\
\text { steps to take/highlighted words even more or in a different way } \\
\text { (for example the foods that could improve mental health could } \\
\text { be put in their own box somehow - not to put in too much more } \\
\text { detail since they should be looked up later but just to emphasize } \\
\text { them a bit more - maybe a checklist style thing) but this is just a } \\
\text { minor thing, } \\
\text { - This might be irrelevant but, maybe having a QR code to link } \\
\text { them to the Carleton site would be more effective since telling } \\
\text { someone to head to a website is often times cumbersome for the } \\
\text { "viewer". if say Carleton gym has a discount going on or the } \\
\text { cafeteria has a meal plan deal going on, that would further } \\
\text { encourage students to take action. often times, going to the gym } \\
\text { and preparing a healthy meal is not first priority for some } \\
\text { students. }\end{array}$ \\
\hline Font and legibility & $\begin{array}{l}\text { - Font size larger, but I am viewing them on a phone which might } \\
\text { not be the intended medium for the graphics. } \\
\text { - Legibility of the short explanation at the bottom could be } \\
\text { improved } \\
\text { - The writing could be enlarged. }\end{array}$ \\
\hline
\end{tabular}




\begin{tabular}{|c|c|}
\hline & $\begin{array}{l}\text { - Make the bottom font a little bigger, good use of bolding to } \\
\text { highlight important words } \\
\text { - It might be appropriate to put the campus resources in bold or } \\
\text { highlighted. }\end{array}$ \\
\hline Consistency & $\begin{array}{l}\text { - Perhaps consistency between text backgrounds. Otherwise if I } \\
\text { saw these across campus I would definitely recognize them as } \\
\text { part of a series } \\
\text { - Consistency (some had boxes on Did you know, some didn't) }\end{array}$ \\
\hline Buttons & $\begin{array}{l}\text { - "More tips" and "learn more" can be redundant or cause } \\
\text { confusion of which one they should click on }\end{array}$ \\
\hline
\end{tabular}

\section{F.4 Question 9: Effectiveness of formats}

\begin{tabular}{|l|c|c|c|c|c|c|c|}
\hline Format & $\begin{array}{l}\text { Number of } \\
\text { responses per } \\
\text { effectiveness } \\
\text { rating }\end{array}$ & $\begin{array}{l}\text { Median } \\
\text { score }\end{array}$ & $\begin{array}{l}\text { Average } \\
\text { score }\end{array}$ \\
\hline & 0 & 1 & 2 & 3 & 4 & & 2.61 \\
\hline $\begin{array}{l}\text { As a pop-up ad on the main page of Carleton's } \\
\text { Mental Health and Well-Being website. }\end{array}$ & 4 & 6 & 8 & 21 & 12 & 3 & \\
\hline $\begin{array}{l}\text { As a pop-up ad that appears when you search for a } \\
\text { related topic on Carleton's Mental Health and }\end{array}$ & 4 & 6 & 7 & 21 & 13 & 3 & 2.65 \\
\hline Well-Being website. & & & & & & & \\
\hline As a mass email to students. & 1 & 5 & 15 & 12 & 5 & 2 & 1.90 \\
\hline As a series of posters on campus. & 0 & 5 & 5 & 24 & 17 & 3 & 3.04 \\
\hline As an ad on Carleton's digital signage system. & 3 & 2 & 13 & 18 & 15 & 3 & 2.78 \\
\hline As a slide in the lecture slides of a course. & 3 & 3 & 5 & 17 & 21 & 3 & 3.02 \\
\hline On Carleton's social media pages & & & & & \\
\hline
\end{tabular}

\section{F.5 Questions 10-11: Alternative formats and ways the information can be conveyed}

\section{Alternative formats}

\begin{tabular}{|c|c|}
\hline Category & Response \\
\hline Postcard & $\begin{array}{l}\text { - Mailed to the students? As a postcard. } \\
\text { - Not sure if CUSA still does those "exam care packages" but } \\
\text { having them in a postcard size inside the care packages }(3 / 4)\end{array}$ \\
\hline
\end{tabular}




\begin{tabular}{|c|c|}
\hline $\begin{array}{l}\text { Physical spaces on } \\
\text { campus }\end{array}$ & $\begin{array}{l}\text { - Paint on side of buildings } \\
\text { - On the screen in the cafeteria }(4 / 4) \\
\text { - Perhaps near line up queues in the cafeteria where kids idle. I } \\
\text { think that would at least be a } 3 / 4 \text { for effectiveness. } \\
\text { - Washroom doors }(4 / 4) \\
\text { - Large floor posters /mural thing in the tunnels, could the } \\
\text { temporary or in smaller time versions } \\
\text { - In boys washrooms, in front of the urinals. ( } 3 / 4) \\
\text { - Maybe professors can have stickers of these graphics and can } \\
\text { choose to put them on their office or department doors. }\end{array}$ \\
\hline $\begin{array}{l}\text { Institution's } \\
\text { app/website }\end{array}$ & $\begin{array}{l}\text { - Carleton's main page } \\
\text { - Perhaps as a feature graphic directly upon the Carleton main } \\
\text { page, I think that may be a } 3 / 4 \text {. }\end{array}$ \\
\hline $\begin{array}{l}\text { CULearn (Carleton's } \\
\text { website for sharing } \\
\text { course material, } \\
\text { submitting } \\
\text { assignments, forum } \\
\text { discussions, etc.) }\end{array}$ & $\begin{array}{l}\text { Incorporated into CU learn (4/4). Especially on the TA support } \\
\text { page. } \\
\text { I am not sure if it would be an appropriate place, but Culearn } \\
\text { would be most effective (4/4). Especially with online learning, I } \\
\text { am on Culearn every single day }\end{array}$ \\
\hline Other & $\begin{array}{l}\text { - I really think the slide one will help stigma } \\
\text { - Automated text message system } \\
\text { - On merchandises such as pens and tshirts } \\
\text { - School paper }(3 / 4)\end{array}$ \\
\hline \multicolumn{2}{|c|}{ Alternative methods of conveyance (9 respondents) } \\
\hline Category & Response \\
\hline Accessibility & $\begin{array}{l}\text { - Would suggest that they follow accessibility guidelines, } \\
\text { especially in electronic format. }\end{array}$ \\
\hline Text messages & $\begin{array}{l}\text { - Text message } \\
\text { - Text messages. Many students wear fitness watches. They track } \\
\text { heart rate etc. that may be related to times of anxiety. If they } \\
\text { can sync with a text during the time of stress it might be the } \\
\text { most effective and useful time for the student to view it. (4/4) }\end{array}$ \\
\hline Pamphlets & $\begin{array}{l}\text { - Pamphlet available in campus offices (CUSA, registrar's office, } \\
\text { etc.) }\end{array}$ \\
\hline
\end{tabular}




\begin{tabular}{|c|c|}
\hline $\begin{array}{l}\text { Carleton merchandise } \\
\text { and stickers }\end{array}$ & $\begin{array}{l}\text { - Minimize words as much as possible to get message across } \\
\text { - on Carleton mittens, stickers on the doors of the library or office } \\
\text { doors }\end{array}$ \\
\hline Video & $\begin{array}{l}\text { - If this information could be turned into short little clips or } \\
\text { videos, it would be useful to play on screens or have on social } \\
\text { media. It may be more engaging for people who scroll past still } \\
\text { images. }\end{array}$ \\
\hline Other & $\begin{array}{l}\text { - Memes? } \\
\text { - I think graphics are the easiest and quickest way to transmit } \\
\text { information. } \\
\text { - I think through email would be the best. }\end{array}$ \\
\hline
\end{tabular}

\section{F.6 Questions 12: Additional comments}

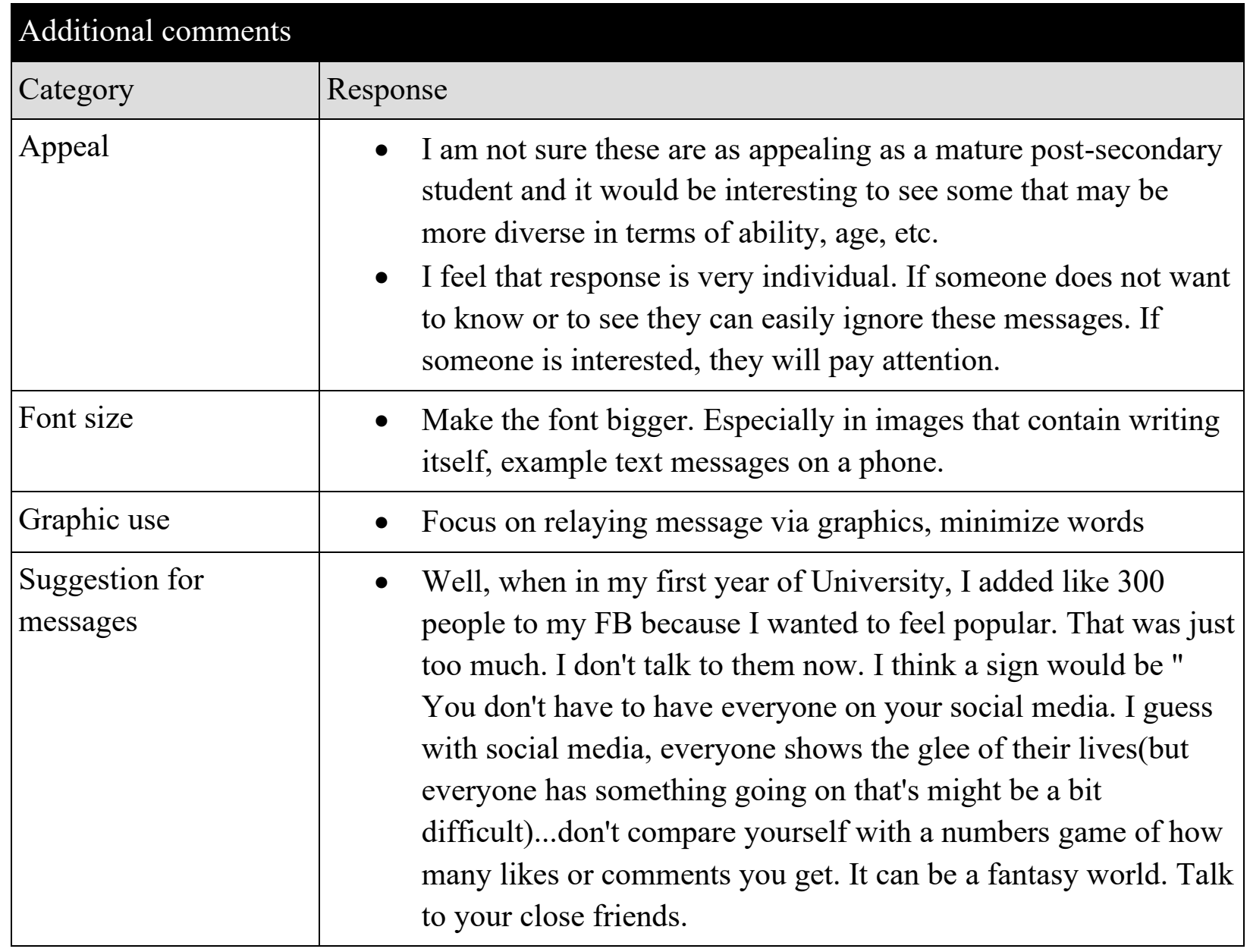




\begin{tabular}{|c|c|}
\hline Positive & $\begin{array}{l}\text { - I really enjoy the contrast of the blurred, realistic background } \\
\text { image to the graphic of the person } \\
\text { - I think the graphic people are fun and engaging! It also doesn't } \\
\text { look like a traditional poster for mental health which } \\
\text { destigmatizes it a bit. } \\
\text { - Simple but important messages...I find the posters around } \\
\text { campus are easy to miss, pop-ups are a great idea and would be } \\
\text { harder to ignore! I think they would be most effective on social } \\
\text { media because the platforms are so widely used, I think seeing a } \\
\text { reminder about the detrimental effects of screen time, while on } \\
\text { their phone is great...because often content for social media is } \\
\text { designed to KEEP you scrolling, but this might be the reminder } \\
\text { someone needs to put their phone down! } \\
\text { - Love them! } \\
\text { very nice! } \\
\text { They're fun, clear, and ambiguous enough to be universal in my } \\
\text { opinion. I can appreciate their message and the concrete action } \\
\text { items are definitely a key touch that much of this } \\
\text { communication is missing. Mental health is tricky in the way } \\
\text { that it's relatively easy to know what one should do, but another } \\
\text { question entirely to actually enact that change. At the end of the } \\
\text { day I think these graphics are useful, and at the very least not } \\
\text { detrimental to the mental health of their audience. } \\
\text { I like the graphic on this page very much! [The scrolling } \\
\text { graphic] }\end{array}$ \\
\hline
\end{tabular}


Appendix G Graphic Message Prototypes

\section{G.1 Healthy Eating}

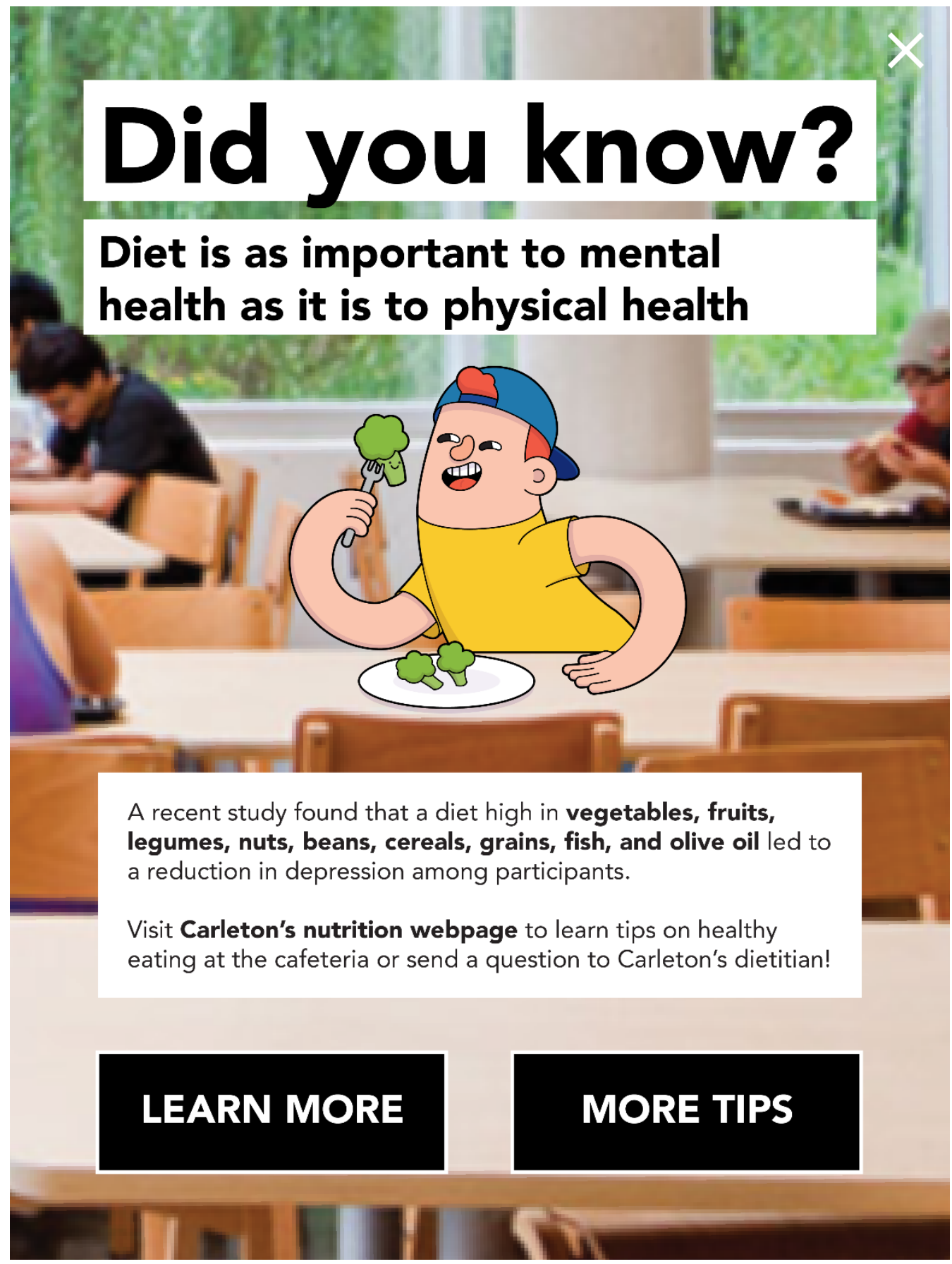




\section{G.2 Confiding}

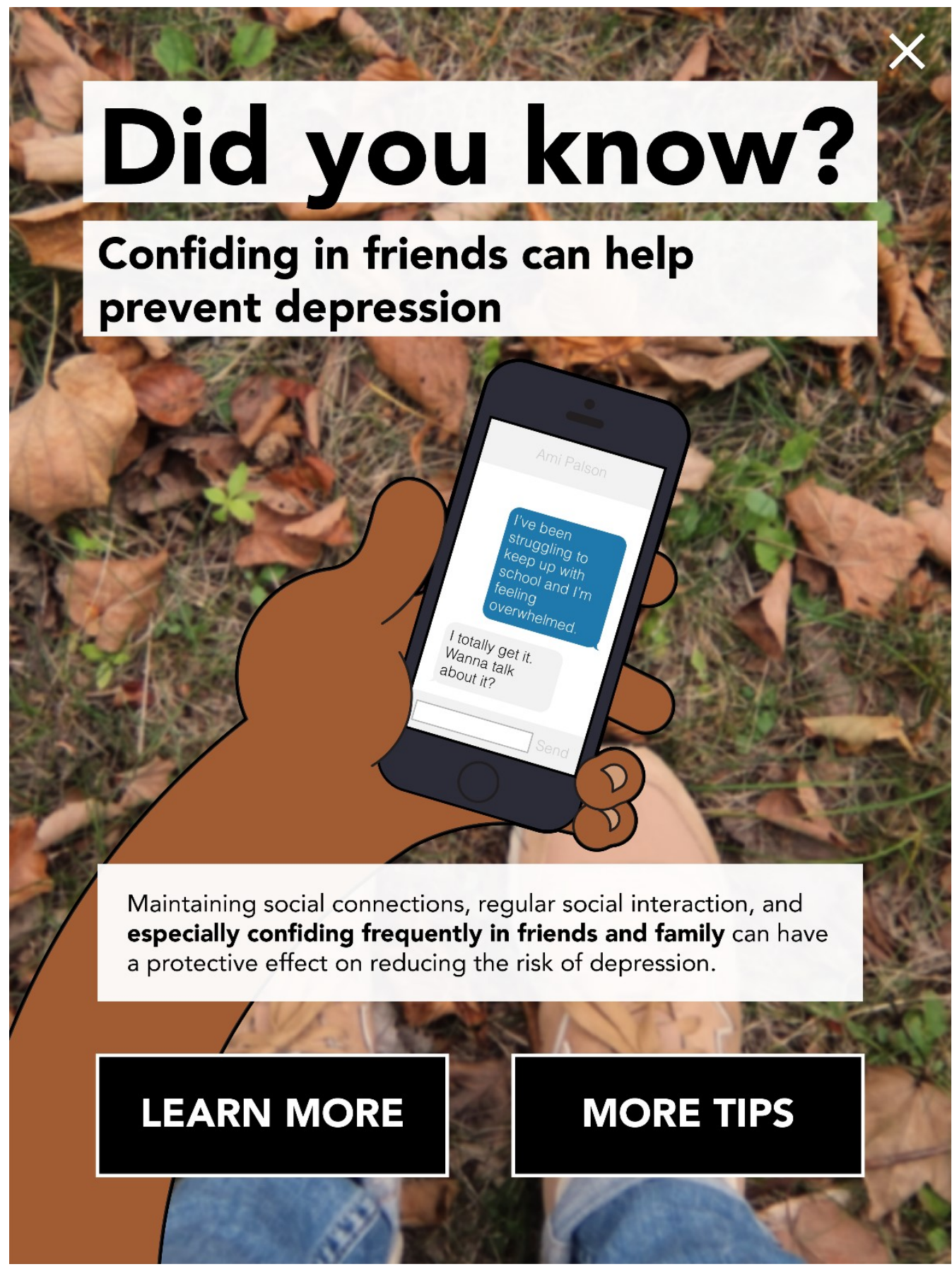




\section{G.3 Exercising}

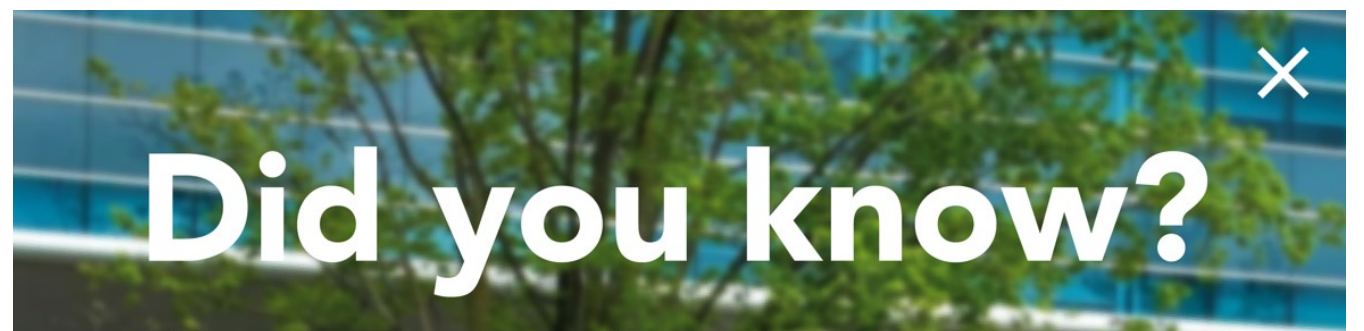

\section{Exercise can reduce stress and}

protect against mental illness

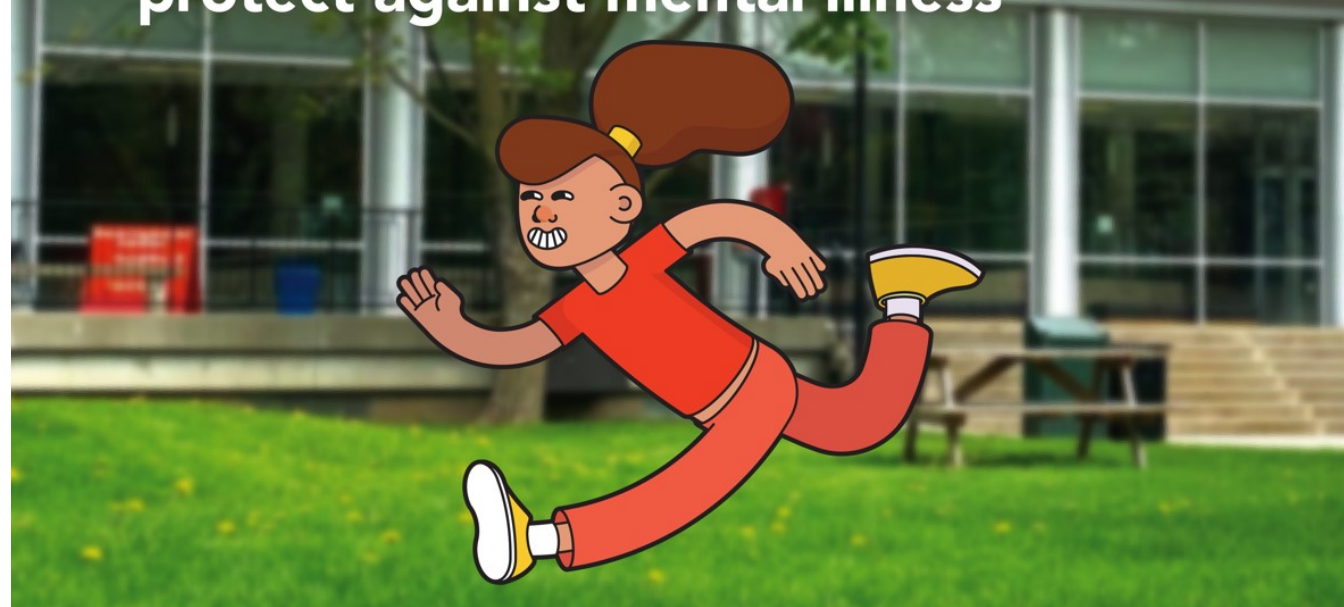

In a survey of current and former university students, exercise was ranked as the most effective method of reducing stress during their time in school.

Try joining a team sport, visiting Carleton's Fitness Center, or simply by walking or biking to class.

\section{LEARN MORE}

\section{MORE TIPS}




\section{G.4 Scrolling}

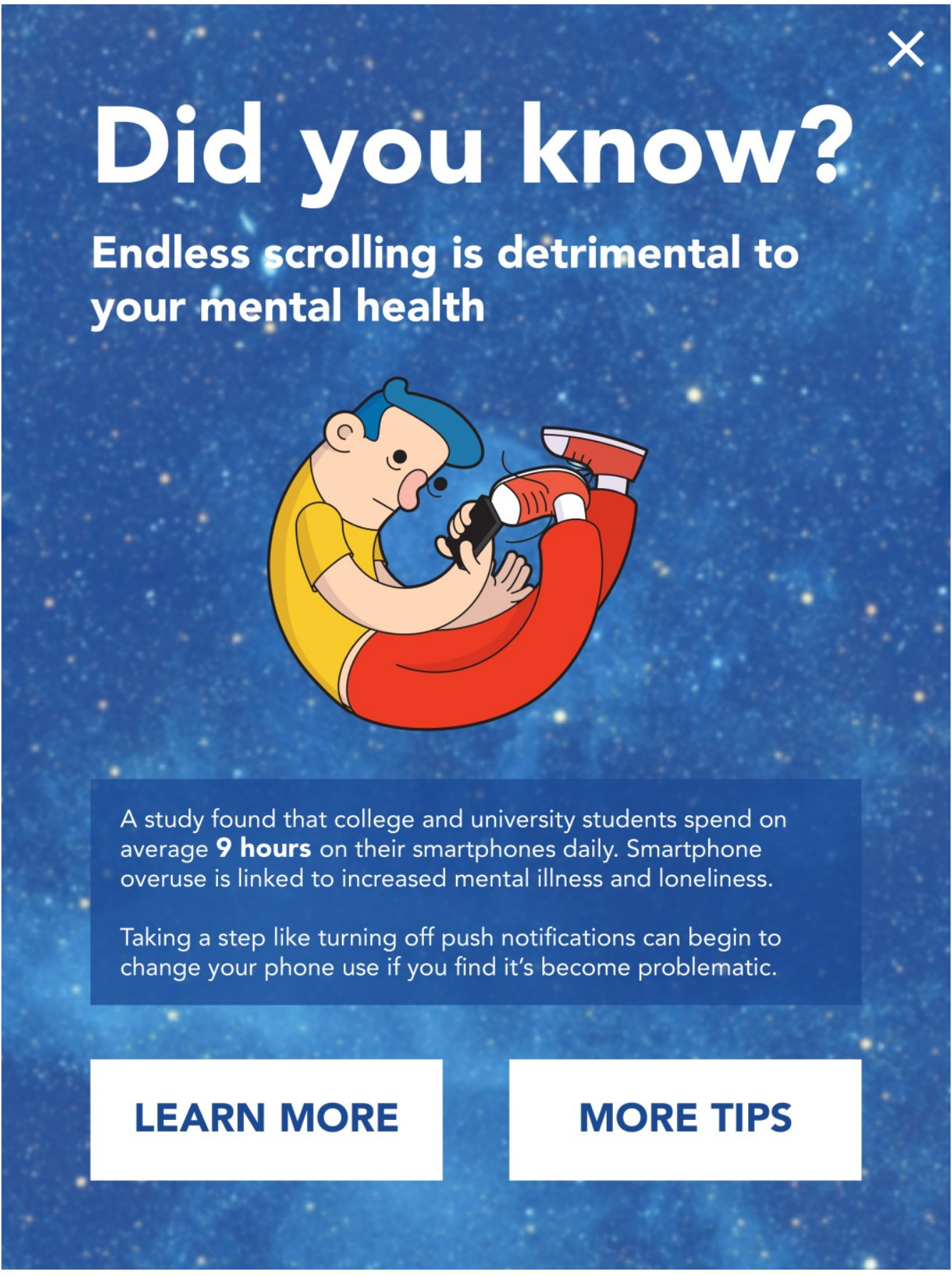




\section{G.5 Socializing}

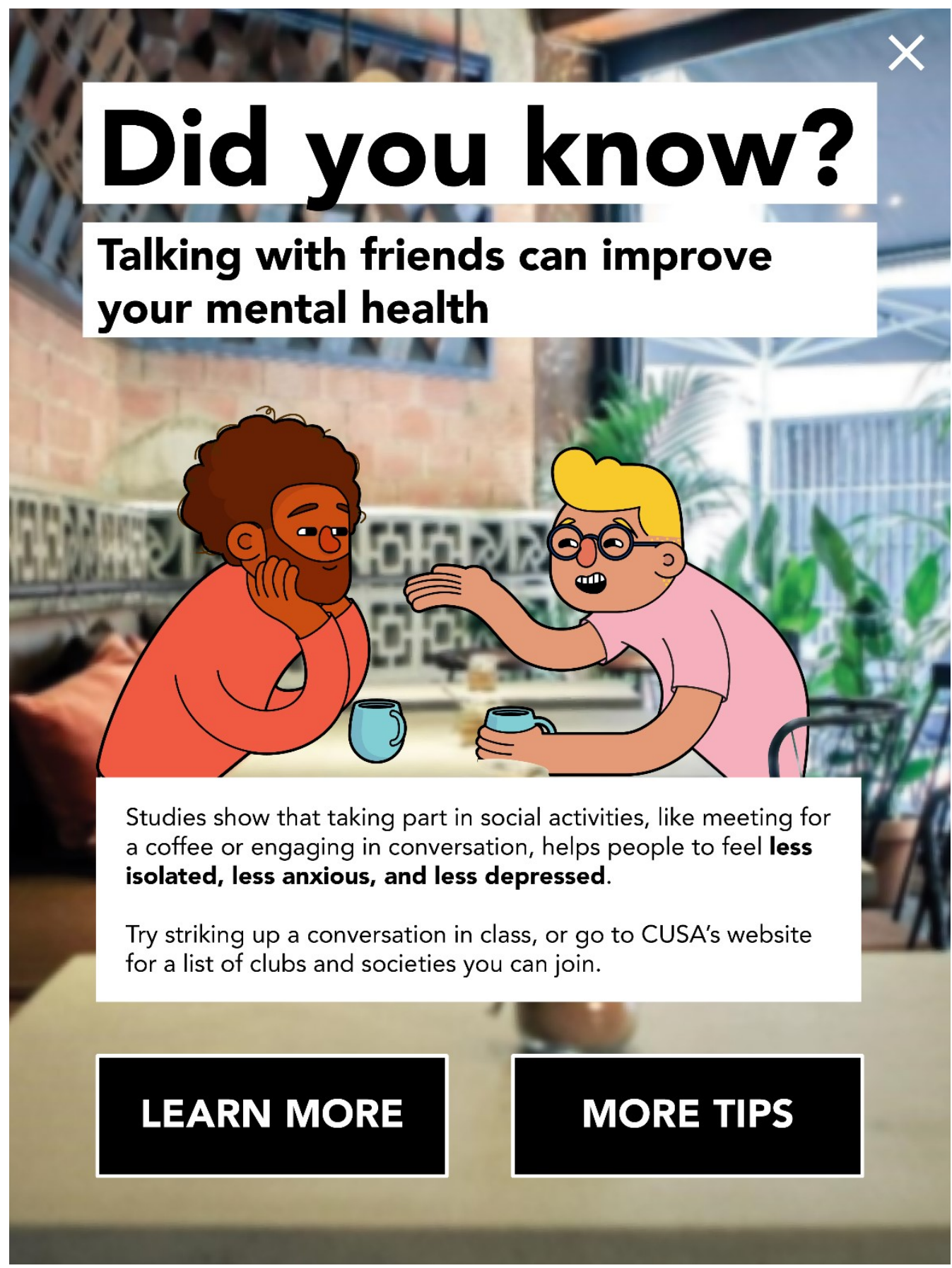




\section{G.6 Sleep}

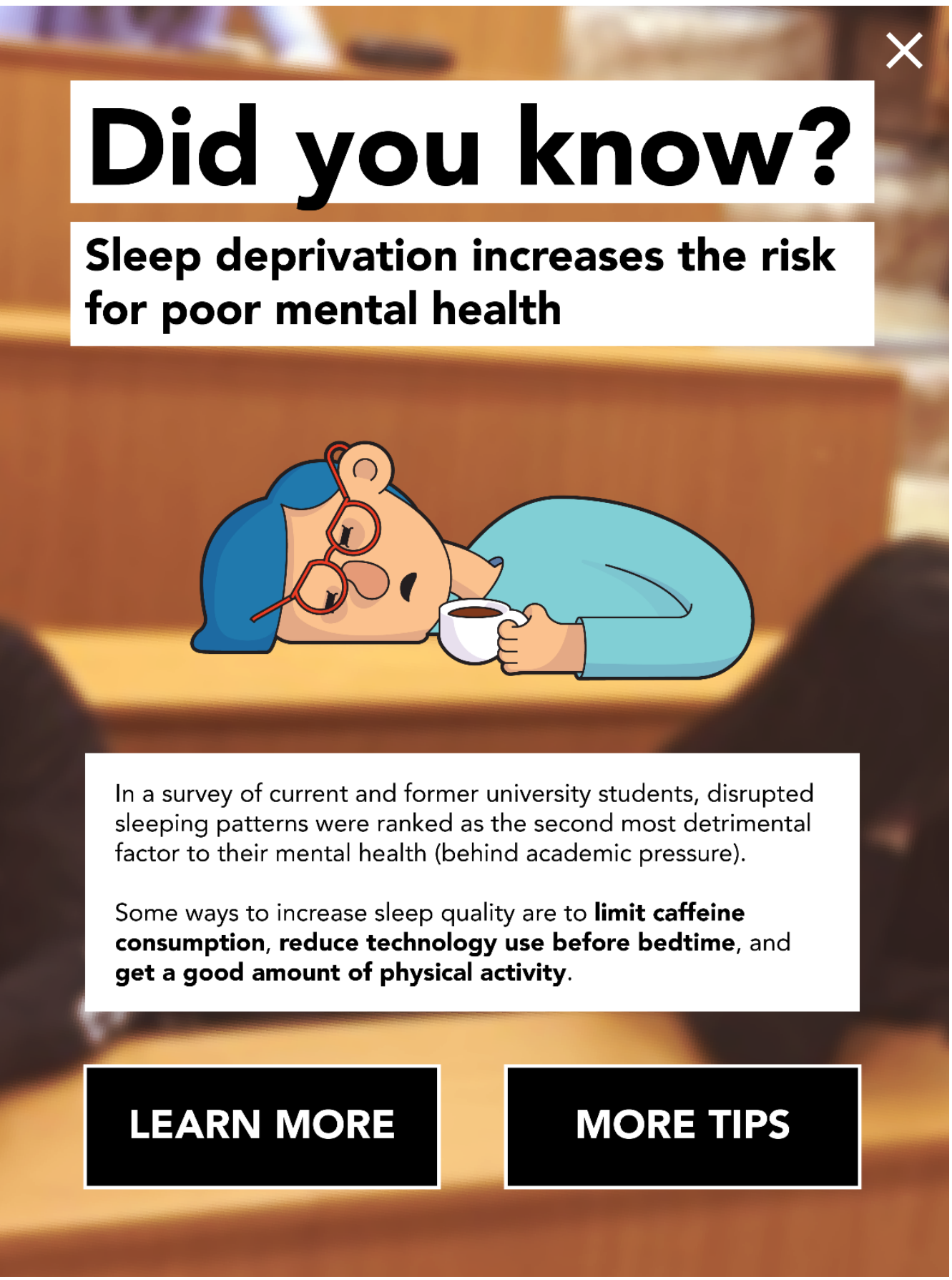

